\title{
DETECÇÃO DE “FLUTTER” POR IMAGEAMENTO INFRAVERMELHO
}

Tese apresentada à Escola de Engenharia de São Carlos da Universidade de São Paulo para obtenção do título de Doutor em Engenharia Mecânica.

Área de Concentração: Aeronaves

Orientador: Prof. Titular Eduardo Morgado Belo

ESTE EXEMPLAR TRATA-SE DA VERSÃO CORRIGIDA.

A VERSÃO ORIGINAL ENCONTRA-SE DISPONÍVEL JUNTO AO DEPARTAMENTO DE ENGENHARIA MECÂNICA DA EESC-USP

São Carlos

- 2014 - 
AUTORIZO A REPRODUÇÃO TOTAL OU PARCIAL DESTE TRABALHO, POR QUALQUER MEIO C'ONVENCIONAL OU ELETRÔNICO, PARA FINS DE ESTUDO E PESQUISA, DESDE QUE CITADA A FONTE.

\section{Bidinotto, Jorge Henrique}

Detecção de "flutter" por imageamento infravermelho / Jorge Henrique Bidinotto; orientador Eduardo Morgado Belo. São Carlos, 2014.

Tese (Doutorado) - Programa de Pós-Graduação em Engenharia Mecânica e Área de Concentração em Aeronaves -- Escola de Engenharia de São Carlos da Universidade de São Paulo, 2014.

1. Flutter. 2. Infravermelho. 3. Ensaios. 4. Termomecânica. I. Título. 


\section{FOLHA DE JULGAMENTO}

Candidato: Engenheiro JORGE HENRIQUE BIDINOTTO

Título da tese: "Detecção de "flutter" por imageamento infravermelho",

Data da defesa: $29 / 10 / 2014$

\section{Comissão Julgadora:}

Resultado:

Prof. Titular Eduardo Margado Belo(Orientador)

(Escola de Engenharia de São Carlos/EESC)

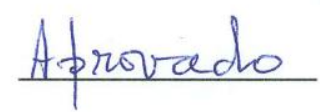

Prof. Associado Luiz Gonçalves Neto

(Escola de Engenharia de São Carlos/EESC)

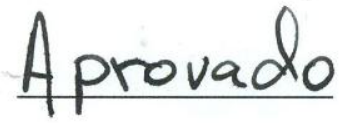

Prof. Dr. Flávio Yukio Watanabe

(Universidade Federal de São Carlos/UFSCar)

Prof. Dr. Roberto Gil Annes da Silva

(Instituto Tecnológico de Aeronáutica/ITA)

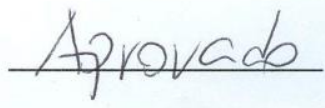

Dr. Alexandre Hyodo

(EMBRAER)

Aprovado

Coordenador do Programa de Pós-Graduação em Engenheira Mecânica: Prof. Associado Marcelo Areias Trindade

Presidente da Comissão de Pós-Graduação:

Prof. Associado Paulo César Lima Segantine 

Intencionalmente em branco 


\section{AGRADECIMENTOS}

Agradeço primeiramente a Deus, por me permitir investigar um pouquinho mais os muitos mistérios que Ele colocou na Terra, para que nós, com o auxílio da ciência, possamos desvendar.

No plano terreno, as ajudas foram muitas:

Aos meus pais, Paulo e Josefina, pelo exemplo e zelo, sem os quais eu jamais teria chegado até aqui. Aos meus irmãos Mauricio e Lucas, pelo exemplo e amizade ao longo de todos esses anos.

À Dani, que esteve ao meu lado durante toda essa jornada. À Maria Júlia, que nos últimos cinco anos me apoiou com todos os argumentos que ela tinha: um olhar apaixonado e um sorriso apaixonante.

Ao meu orientador e amigo, Prof. Eduardo Belo, que me encaminhou desde os primeiros passos na vida acadêmica, e sem saber estava trilhando para mim uma nova carreira.

Aos professores dos departamentos de Engenharia Mecânica e Engenharia Aeronáutica da EESC, que de várias formas me ajudaram ao longo do trabalho. Em especial os professores Varoto, De Marqui, Greco, Catalano e Leopoldo.

Agradeço à Roberta, a Engenheira-de-equinos-veterinária-civil-de-ensaios, pelo empréstimo da câmera infravermelho durante os ensaios modais.

Aos alunos de graduação (hoje já formados) que me auxiliaram nas simulações: Wander e o casal Anselmo e Maíra.

Aos funcionários do departamento de Engenharia Aeronáutica, em especial o Cláudio, Gallo, Gisele, MaZé, Osnan e Carlinhos. 
Aos companheiros da pós da engenharia aeronáutica, que mesmo eu não estando muito presente, sempre me acolheram e ajudaram com muito boa vontade.

Aos saudosos amigos da área de Ensaios em Voo da EMBRAER, em especial o engenheiro Roberto Becker, que sempre confiou e apoiou meu trabalho na área acadêmica.

Ao Maximilian, que me apresentou o fabuloso e colorido (\#sqn) mundo do infravermelho, me levando a alterar totalmente os rumos do meu trabalho... para melhor!

Aos colegas do departamento de Engenharia Mecânica da UFSCar, pelo apoio e confiança para que eu terminasse esse trabalho.

Aos membros da banca de defesa: Professores Flávio (UFSCar), Gil Annes (ITA), Luiz (EESC), Belo (EESC) e Engenheiro Hyodo (EMBRAER), pelas valorosas dicas para engrandecimento do texto final.

Este trabalho tem um pedacinho de cada um de vocês, e por isso me orgulho de poder contar com pessoas tão especiais! 
scientia sine art nihil est 
Intencionalmente em branco 


\section{RESUMO}

BIDINOTTO, J. H. Detecção de "flutter" por imageamento infravermelho. Tese apresentada à Escola de Engenharia de São Carlos da Universidade de São Paulo para obtenção do título de Doutor em Engenharia Mecânica. São Carlos, 2014.

O crescente desempenho das aeronaves aliado ao desenvolvimento de materiais cada vez mais leves e flexíveis tem levado os projetistas a utilizar coeficientes de segurança estruturais cada vez menores, o que pode tornar as superfícies aerodinâmicas mais susceptíveis a fenômenos aeroelásticos, entre eles o flutter, que deve ser cuidadosamente investigado com ensaios em solo e em voo durante o desenvolvimento e certificação de aeronaves. Para tais ensaios, é importante uma instrumentação adequada, que possa prever o aparecimento de vibrações indesejadas e possa agir de forma menos intrusiva possível, de forma a não modificar o comportamento dinâmico do sistema. Esse trabalho propõe o uso do imageamento infravermelho como instrumento para detecção de flutter, analisando se essa técnica é adequada para tal aplicação e quais as vantagens e desvantagens de seu uso. Para isso é feita uma revisão da literatura pertinente, apresentando conceitos de flutter, mecânica estrutural e tecnologia infravermelho, e em seguida é apresentada uma estrutura conhecida para se testar a técnica referida. São realizados simulações e testes na estrutura para levantamento das suas características e finalmente testes em túnel de vento, onde se verifica o funcionamento desta técnica, seus pontos positivos e pontos que requerem melhorias.

Palavras-chave: Flutter, Infravermelho, Ensaios, Termomecânica 
Intencionalmente em branco 


\begin{abstract}
BIDINOTTO, J. H. Flutter detection by infrared imaging. Tese apresentada à Escola de Engenharia de São Carlos da Universidade de São Paulo para obtenção do título de Doutor em Engenharia Mecânica. São Carlos, 2014.

The increasing performance of aircraft together with the development of increasingly lightweight and flexible materials has led designers to use smaller structural safety factors, which can make the aerodynamic surfaces more susceptible to aeroelastic phenomena, including flutter, which should be carefully investigated with ground and flight tests during the aircraft development and certification. For such assays, it is important to use proper instrumentation, which can predict the occurrence of unwanted vibrations to act in less intrusive way possible, in order to not modify the system dynamic behavior. This work proposes the use of infrared imaging as a tool for detection of flutter, analyzing whether this technique is suitable for such application, the advantages and disadvantages of their use. For this, a review of the relevant literature is made, presenting flutter concepts, structural mechanics and infrared technology, and then a known structure used to test the technique is presented. Simulations and tests to survey the structure characteristics are presented as well as tests in the wind tunnel, performing the operation of this technique in order to address its positive points and areas that needs improvement.
\end{abstract}

Keywords: Flutter, Infrared, Tests, Thermomechanics 
Intencionalmente em branco 


\section{LISTA DE ILUSTRAÇÕES}

Figura 1.1 - Tentativa de Langley sobre o rio Potomac........................................................25

Figura 1.2 - O biplano Flyer 1, dos irmãos Wright..........................................................26

Figura 1.3 - Santos Dumont e sua aeronave biplano 14-bis ...............................................2 27

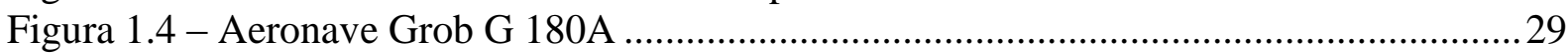

Figura 1.5 - Gráfico dos resultados de ensaio utilizado por Von Schlippe..............................29

Figura 1.6 - Fluxograma do desenvolvimento do modelo aeroelástico de uma estrutura ........30

Figura 1.7 - Posição dos acelerômetros utilizados em ensaios de flutter ............................... 31

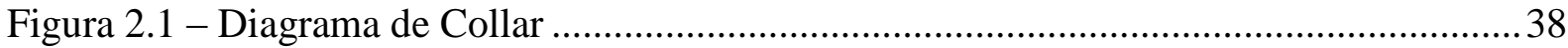

Figura 2.2 - Situações de aplicação da carga aerodinâmica sobre uma superfície aeronáutica

Figura 2.3 - Modelo de Dowel para o cálculo da velocidade de divergência ..............................42

Figura 2.4 - Modelo simplificado para estudo do fenômeno flutter ........................................ 44

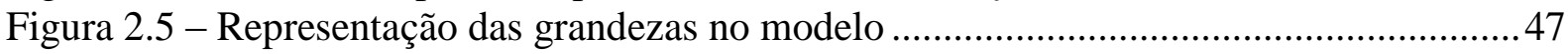

Figura 2.6 - Aplicações distintas para imageamento infravermelho........................................54

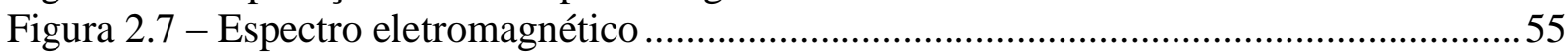

Figura 2.8 - Potência de radiação em função do comprimento de onda .................................57

Figura 2.9 - Comparação entre a teoria clássica de radiação e a catástrofe do ultravioleta.....57

Figura 2.10 - Diagrama simplificado de uma câmera infravermelho ...................................59

Figura 2.11 - Curvas de detectividade para diferentes tipos de detectores .............................60

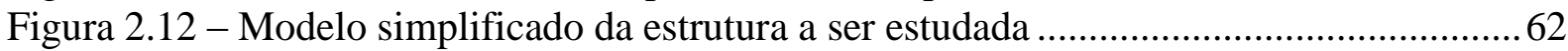

Figura 2.13 - Modelo de viga em flexão sob influência da força cortante ............................. 63

Figura 2.14 - Diagramas de força cortante e momento fletor aplicados na estrutura ..............63

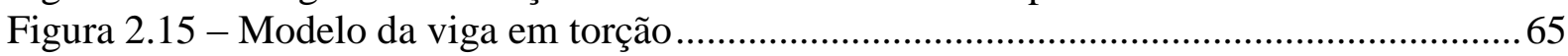

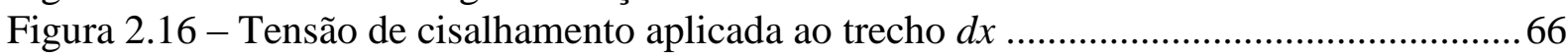

Figura 3.1 - Fluxograma de atividades para dimensionamento e validação dos modelos utilizados

Figura 4.1 - Desenho em CAD da estrutura acoplada à asa, esquema de sua montagem no

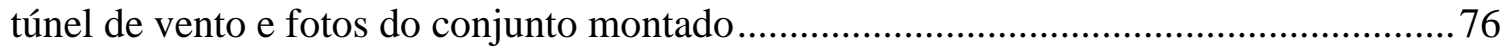

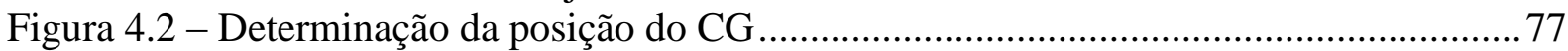

Figura 4.3 - Ilustração das definições de centro aerodinâmico e centro de pressão .................78

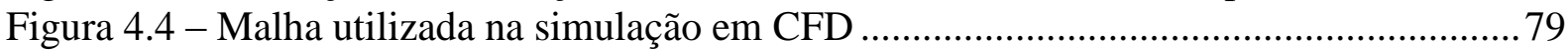

Figura 4.5 - Resultado da simulação em CFD da asa ......................................................... 79

Figura 4.6 - Posições do centro aerodinâmico e centro de pressão ......................................... 80

Figura 4.7 - Resultado da simulação em CFD com vários ângulos de ataque......................... 81

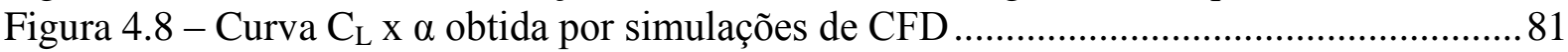

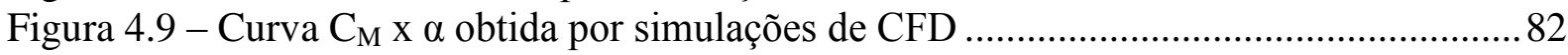

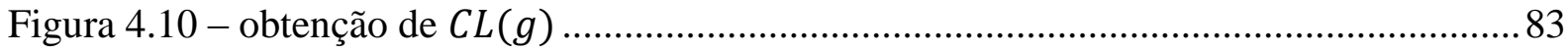

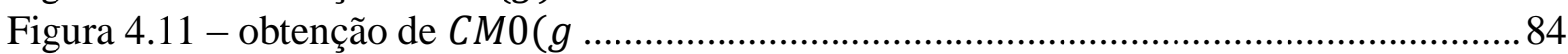

Figura 4.12 - Modelo estrutural simulado pelo método dos elementos finitos........................87

Figura 4.13 - Primeiro modo de vibrar a $1,56 \mathrm{~Hz}$............................................................ 88

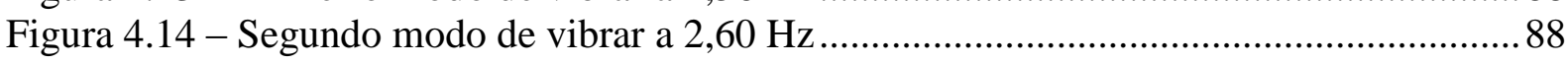

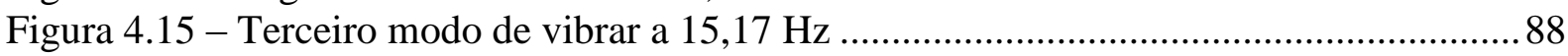

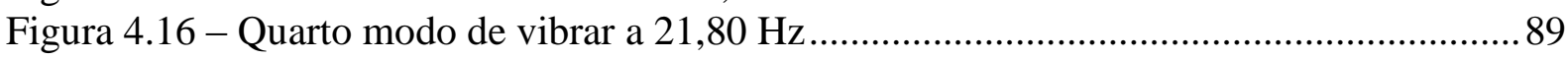

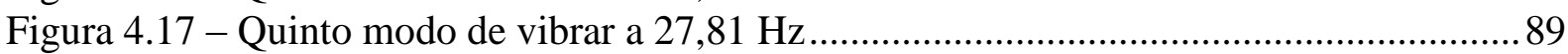

Figura 4.18 - Resultado da simulação estática flexional.....................................................90

Figura 4.19 - Resultado da simulação estática torsional .....................................................90

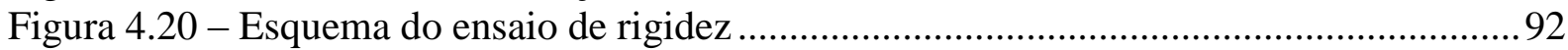

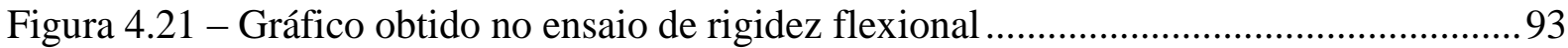

Figura 4.22 - Gráfico obtido no ensaio de rigidez torsional .................................................94 


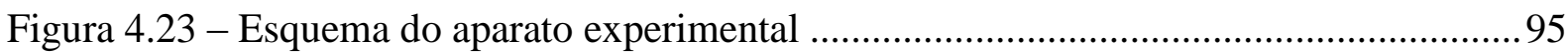

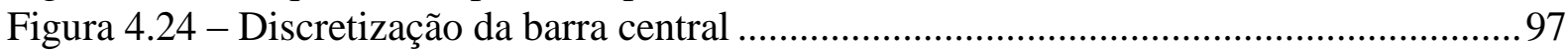

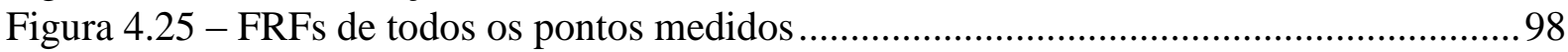

Figura 4.26 - primeiro modo de vibrar determinado experimentalmente ............................... 99

Figura 4.27 - segundo modo de vibrar determinado experimentalmente ...............................99

Figura 4.28 - terceiro modo de vibrar determinado experimentalmente ................................99

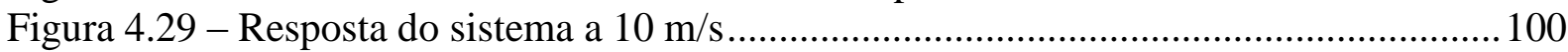

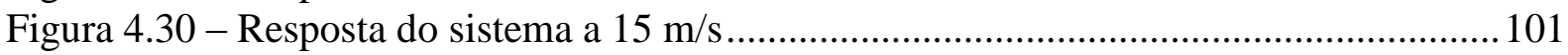

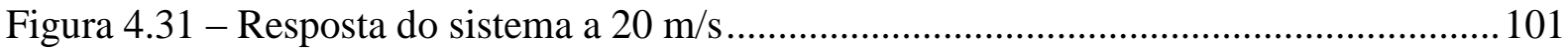

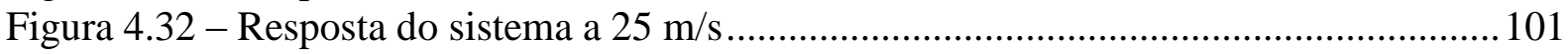

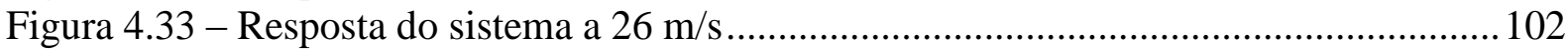

Figura 4.34 - Função resposta em frequência do sistema em várias velocidades, de 5 a $27 \mathrm{~m} / \mathrm{s}$

Figura 4.35 - Diagramas V-g para determinação das condições de flutter

Figura 4.36 - Esquema do experimento para obtenção das características de flutter ............. 104

Figura 4.37 - Experimento para cálculo das características de flutter .................................. 106

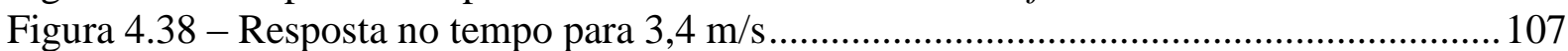

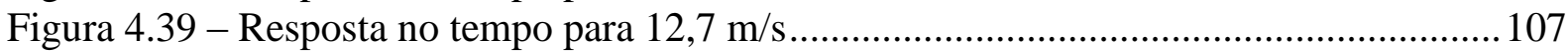

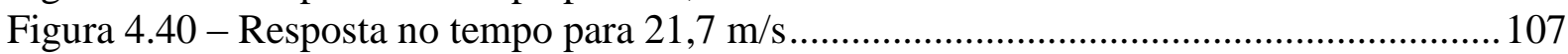

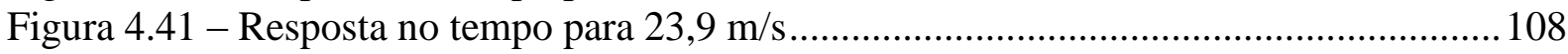

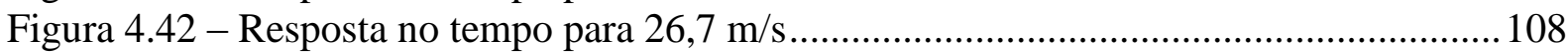

Figura 4.43 - Gráfico de amortecimento em função da velocidade ........................................ 109

Figura 5.1 - Modelo utilizado para deformação da estrutura em flexão e torção ...................115

Figura 5.2 - Estado de tensões na estrutura sujeita à flexão ........................................... 115

Figura 5.3 - Espectro de variação de temperatura na estrutura sujeita à flexão......................116

Figura 5.4 - Estado de tensões na estrutura sujeita à torção ............................................... 116

Figura 5.5 - Espectro de variação de temperatura na estrutura sujeita à torção.....................117

Figura 5.6 - Aparato experimental utilizado na validação do modelo termomecânico ..........118

Figura 5.7 - Fotos do experimento realizado para validação do modelo termomecânico ..... 120

Figura 5.8 - Imagens infravermelho da estrutura excitada em flexão, em seu ponto neutro e no

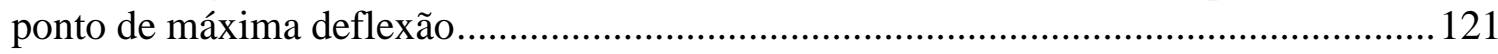

Figura 5.9 - Temperatura de cada pixel da barra central plotado pelo Matlab ...................... 122

Figura 5.10 - Comparativo entre os resultados obtidos pelo modelo termomecânico, dados experimentais e dados experimentais com tratamento .................................................122

Figura 5.11 - Imagens infravermelho da estrutura excitada em torção, em seu ponto neutro e

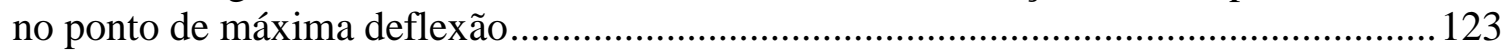

Figura 5.12 - Temperatura de cada pixel da barra central plotado pelo Matlab ....................124

Figura 5.13 - Comparativo entre os resultados obtidos pelo modelo termomecânico, dados experimentais e dados experimentais com tratamento ................................................. 124

Figura 5.14 - Aparato experimental para detecção de flutter com imageamento infravermelho

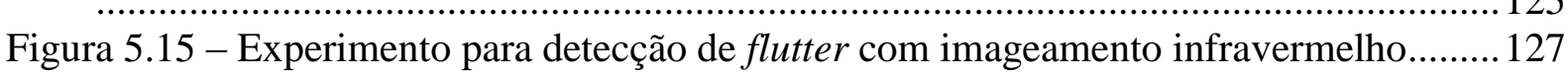

Figura 5.16 - Imagens infravermelho da estrutura a velocidades inferiores à de flutter ....... 128

Figura 5.17 - Imagens infravermelho da estrutura em condição de flutter............................. 130 


\section{LISTA DE TABELAS}

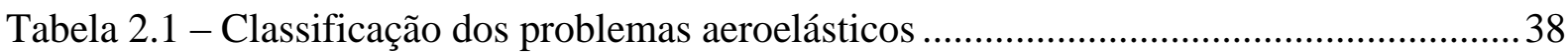

Tabela 2.2 - Tipos de detectores tipicamente usados em câmeras infravermelho ....................61

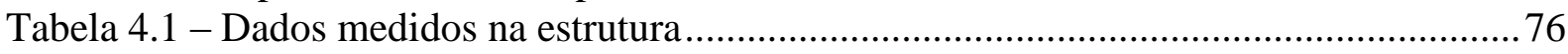

Tabela 4.2 - Valores obtidos para as derivadas de estabilidade ............................................ 86

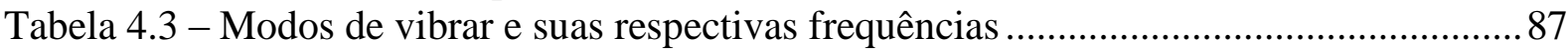

Tabela 4.4 - Resultados obtidos no ensaio de rigidez flexional..............................................92

Tabela 4.5 - Resultados obtidos no ensaio de rigidez torsional ............................................93

Tabela 4.6 - Valores de rigidez obtidos experimentalmente..............................................94

Tabela 4.7 - Frequências naturais obtidas experimentalmente ............................................98

Tabela 4.8 - Amortecimento calculado para cada velocidade obtida no ensaio .................... 109

Tabela 4.9 - Propriedades obtidas para a estrutura .............................................................. 110

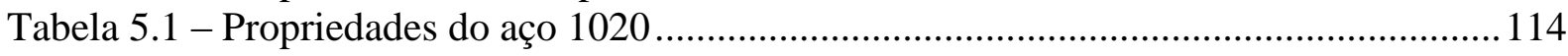


Intencionalmente em branco 


\title{
LISTA DE ABREVIATURAS E SÍMBOLOS
}

\author{
Abreviaturas: \\ APU Auxiliary Power Unit (Unidade Auxiliar de Potência) \\ CA Centro Aerodinâmico \\ CAD Computer Aided Design (Projeto Assistido por Computador) \\ CFD Computational Fluid Dynamics (Dinâmica dos Fluidos Computacional) \\ CG Centro de Gravidade \\ CMA Corda Média Aerodinâmica \\ CP Centro de Pressão
}

EESC Escola de Engenharia de São Carlos

FPA Focal Plan Array (Matriz de Plano Focal)

FRF Função Resposta em Frequência

GVT Ground Vibration Tests (Ensaios de Vibração em Solo)

LADinC Laboratório de Aeroelasticidade, Dinâmica de Voo e Controle

QWIP Quantum Well Infrared Photon (Detector Quântico de Fótons em Fonte Infravermelha)

UFSCar Universidade Federal de São Carlos

USP Universidade de São Paulo

VANT Veículo Aéreo Não-Tripulado

\section{Símbolos:}


A Operador aerodinâmico, área

$b \quad$ Semi corda do aerofólio, largura

c Velocidade da luz, coordenada vertical ao longo da espessura, calor específico, amortecimento estrutural, corda

C Função de Theodorsen

$c_{1}, c_{2} \quad$ Coeficientes estruturais

$C_{L} \quad$ Coeficiente de sustentação

$c_{\ell} \quad$ Coeficiente de sustentação para o caso bidimensional

$C_{M} \quad$ Coeficiente de momento de arfagem

D Força de arrasto

$e \quad$ Número de Euler, distância, energia fundamental

E Energia, módulo de elasticidade, operador estrutural

$g$ Aceleração da gravidade, amortecimento aerodinâmico

G Módulo de elasticidade transversal

$h \quad$ Constante de Planck, espessura, deslocamento

I Momento de inércia, radiância espectral, operador inercial

$k \quad$ Constante de Boltzmann, constante de rigidez, frequência reduzida

L Força de sustentação para o caso tridimensional, comprimento da viga

$\ell \quad$ Distância

$m \quad$ Massa 
M Momento em torno de um ponto, número de Mach

$N \quad$ Força normal

$P \quad$ Carga aplicada na estrutura

$p \quad$ Pressão

$q \quad$ Pressão dinâmica

$r_{\theta} \quad$ Raio de giro

$Q \quad$ Quantidade de calor

$S \quad$ Área da asa, momento estático

$T \quad$ Temperatura, energia cinética

$u \quad$ Energia interna

$U \quad$ Velocidade do ar, energia de deformação

$v \quad$ Frequência de radiação

W Radiação, módulo de resistência à flexão, trabalho

$W_{g} \quad$ Perturbações no escoamento aerodinâmico (turbulência)

$x$ Deformação da estrutura por flexão, coordenada

y Coordenada

$z \quad$ Coordenada

\section{Símbolos gregos:}

$\alpha \quad$ Ângulo de ataque, Coeficiente de absorção

$\beta \quad$ Constante dependente de Mach 
$\varepsilon \quad$ Emissividade

$\zeta \quad$ Fator de amortecimento

$\mu \quad$ Razão de massa

$\rho \quad$ Densidade, Coeficiente de reflexão

$\sigma \quad$ Constante de Stefan-Boltzmann, Tensão normal

$\lambda$ Comprimento de onda, autovalor

$\theta \quad$ Incidência

$\phi \quad$ Deslocamento torsional

$\tau \quad$ Coeficiente de transmissão, Tensão de cisalhamento

$\omega \quad$ Frequência natural

$v \quad$ Frequência de radiação

$\Lambda \quad$ Enflechamento

Matrizes e vetores:

A Matriz aerodinâmica

C Vetor de amortecimento

$Q^{n \boldsymbol{n}} \quad$ Vetor de cargas não-conservativas

$\boldsymbol{\Psi} \quad$ Vetor de coordenadas generalizadas

K Matriz de rigidez

M Matriz de massa 
$\boldsymbol{M}_{\boldsymbol{s}} \quad$ Matriz de massa estrutural

$\boldsymbol{M}_{\boldsymbol{a}} \quad$ Matriz de massa aerodinâmica

$\boldsymbol{M}_{\boldsymbol{g}} \quad$ Vetor de acoplamento de massa

$\boldsymbol{D}_{\boldsymbol{s}} \quad$ Matriz de amortecimento estrutural

$\boldsymbol{D}_{\boldsymbol{a}} \quad$ Matriz de amortecimento aerodinâmico

$\boldsymbol{K}_{\boldsymbol{s}} \quad$ Matriz de rigidez estrutural

$\boldsymbol{K}_{\boldsymbol{a}} \quad$ Matriz de rigidez aerodinâmica

$\boldsymbol{Q}_{\mathbf{0}}^{\boldsymbol{e}} \quad$ Vetor de forças generalizadas aerodinâmicas estáticas

$\{x\} \quad$ Vetor de variáveis

Índices:

(.) $)_{h} \quad$ Referente à flexão

(.) $\theta \quad$ Referente à torção

$\widetilde{(.)}$ Referente à perturbação

(.) $)_{0} \quad$ Estático

(.) $)_{\sigma} \quad$ Referente à tensão normal

$(.)_{\tau} \quad$ Referente à tensão de cisalhamento

$\operatorname{Im}($.) Parte imaginária de um número complexo

$\operatorname{Re}($.$) \quad Parte real de um número complexo$

$\Delta \quad$ Variação

$\delta, \partial \quad$ Variação infinitesimal 
Intencionalmente em branco 


\section{SUMÁRIO}

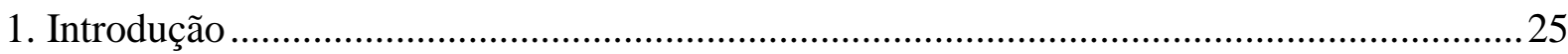

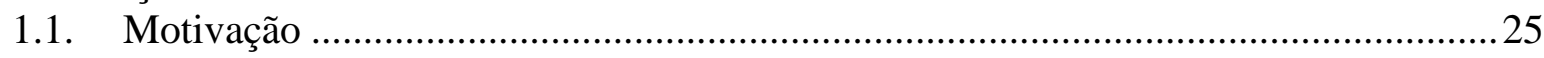

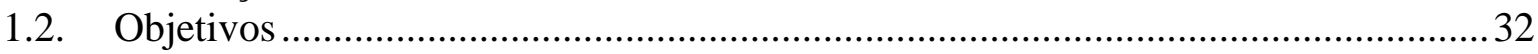

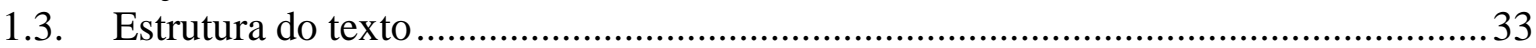

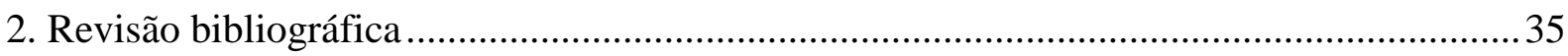

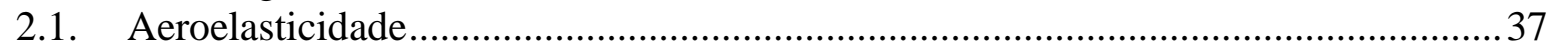

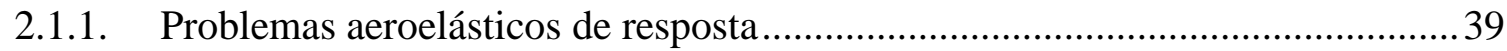

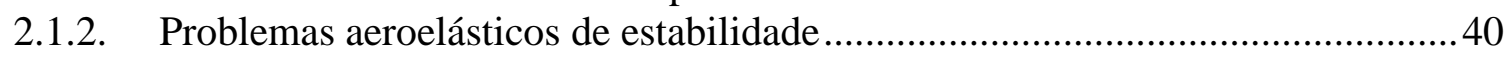

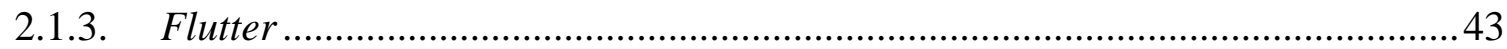

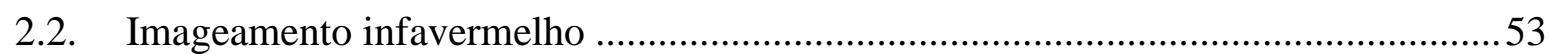

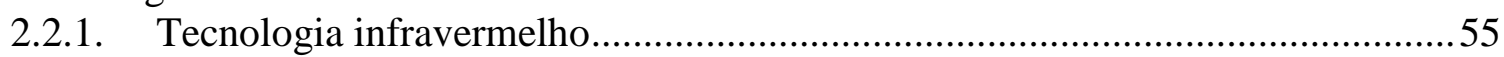

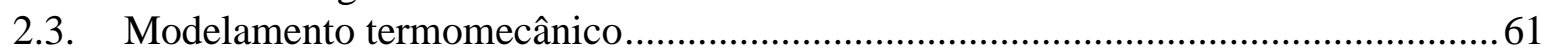

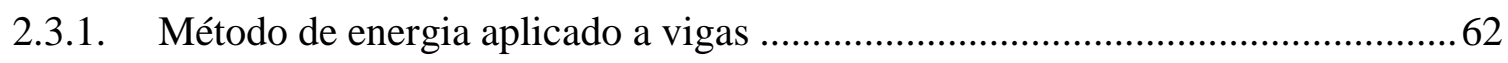

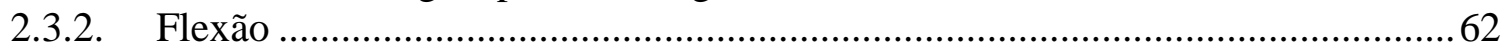

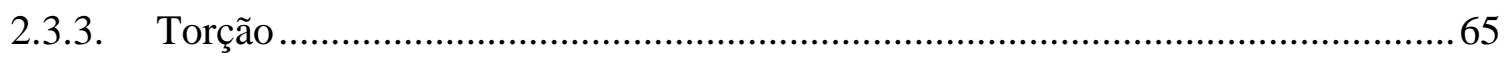

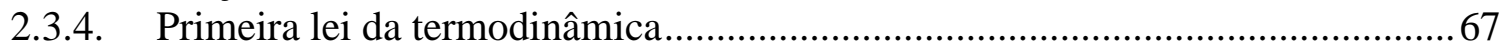

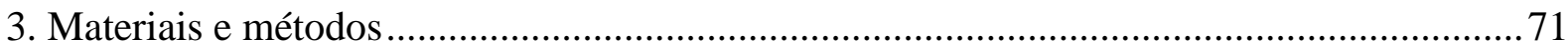

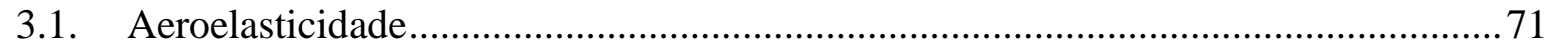

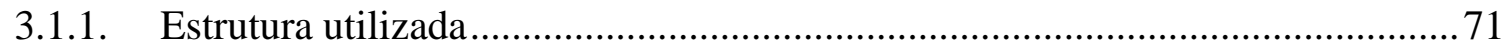

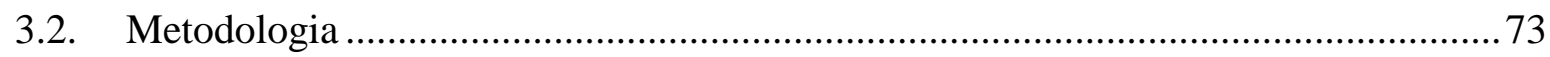

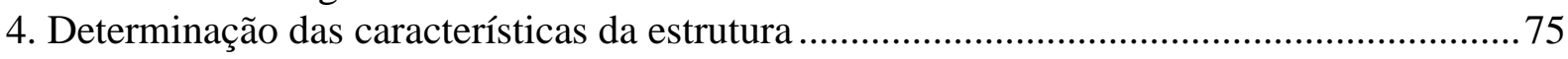

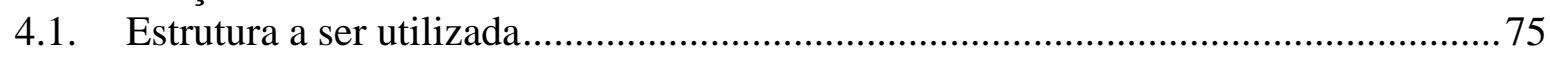

4.2. Características geométricas da estrutura .............................................................. 76

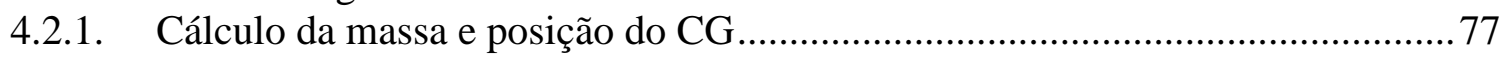

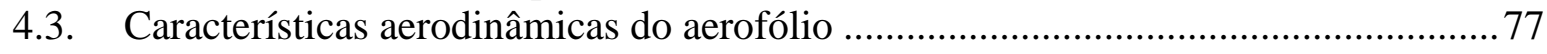

4.3.1. Centro aerodinâmico e centro de pressão ........................................................ 78

4.3.2. Coeficientes de sustentação e momento de arfagem ......................................... 80

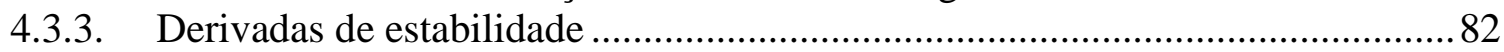

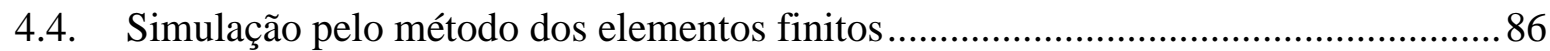

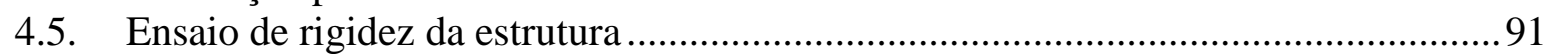

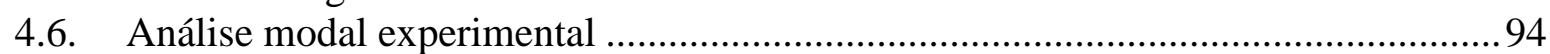

4.7. Cálculo da velocidade e frequência de flutter ........................................................ 100

4.8. Determinação experimental das características de flutter ....................................... 104

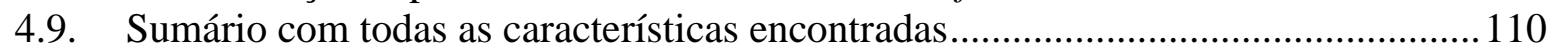

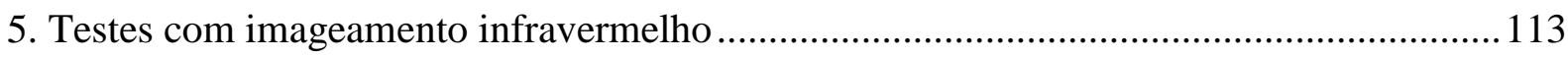

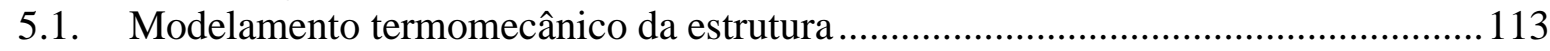

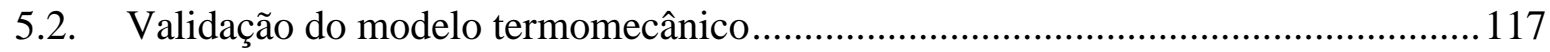

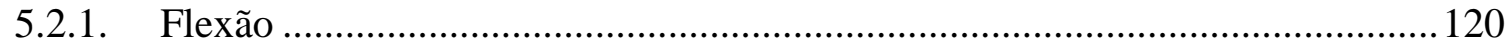

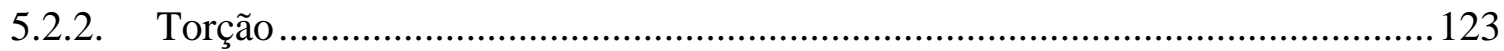

5.3. Detecção de flutter com imageamento infravermelho ......................................... 125

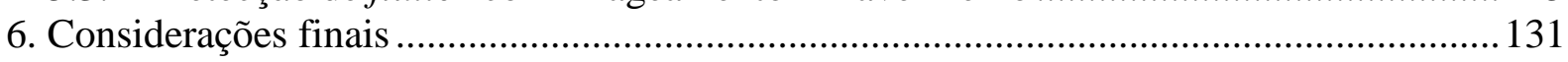

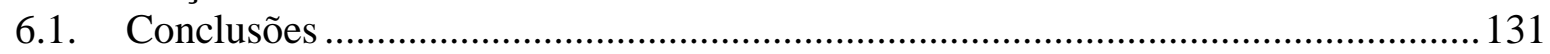

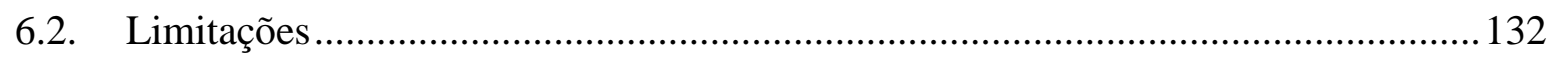

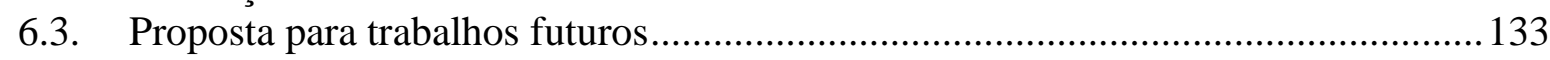

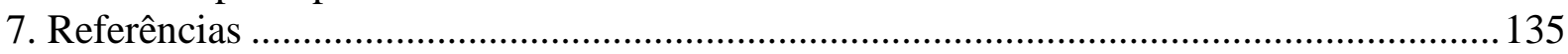

Anexo A: Catálogos de câmeras infravermelho .............................................................. 141 
Intencionalmente em branco 


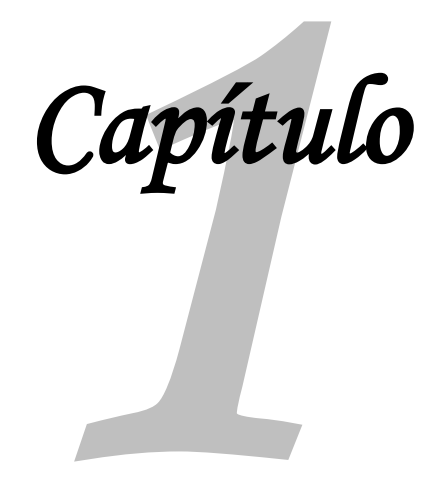

\section{Introdução}

\subsection{Motivação}

A história da aviação possui diversos exemplos de avanço tecnológico e superação, que influenciaram positiva ou negativamente diversas áreas da engenharia, como materiais, mecânica, automobilística, além da própria aeronáutica.

Exemplos de fenômenos que ocorrem desde os primórdios da aviação são os aeroelásticos, que tiveram papel fundamental na escolha da forma das aeronaves nos primeiros anos de seu desenvolvimento.

Em 1903, o professor Samuel Pierpont Langley tentou por duas vezes cruzar o rio Potomac utilizando um monoplano em tandem, que era catapultado por um sistema sobre uma barcaça, conforme mostrado na Figura 1.1.

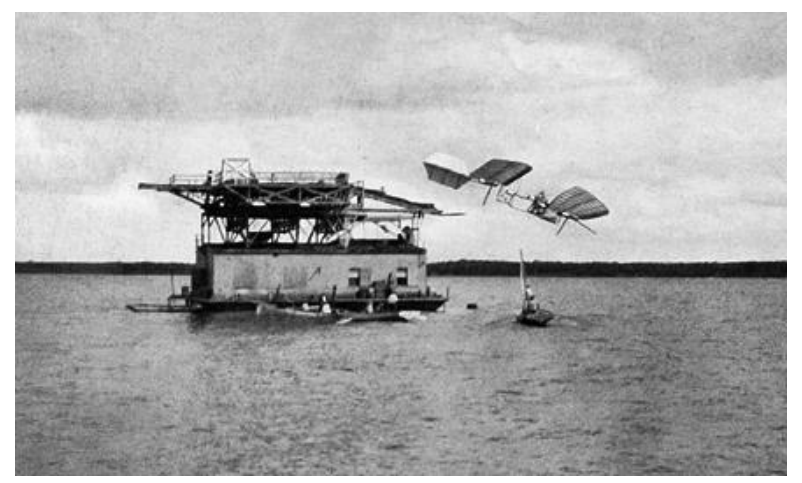

Figura 1.1 - Tentativa de Langley sobre o rio Potomac. Fonte: Bowers (1984) 
Segundo Bisplinghoff et al. (1955), ambas as tentativas terminaram em fracasso, e os relatos à época indicavam uma torção na ponta das asas levando ao seu colapso, o que poderia ser um indicativo de ocorrência do fenômeno posteriormente denominado "divergência". Collar (1959) cita que anos depois, a aeronave de Langley foi reestruturada e voou com sucesso, mas infelizmente seu criador já havia falecido e não pôde ver o êxito de sua invenção.

No mesmo ano desta tentativa frustrada, os irmãos Orville e Willbur Wright fizeram com sucesso aquele que é considerado por alguns o primeiro voo da história, catapultando sua aeronave Flyer 1 (Figura 1.2), que era um biplano e, consequentemente, tinha a estrutura das asas mais rígida e menor envergadura, diminuindo a possibilidade de fenômenos aeroelásticos.

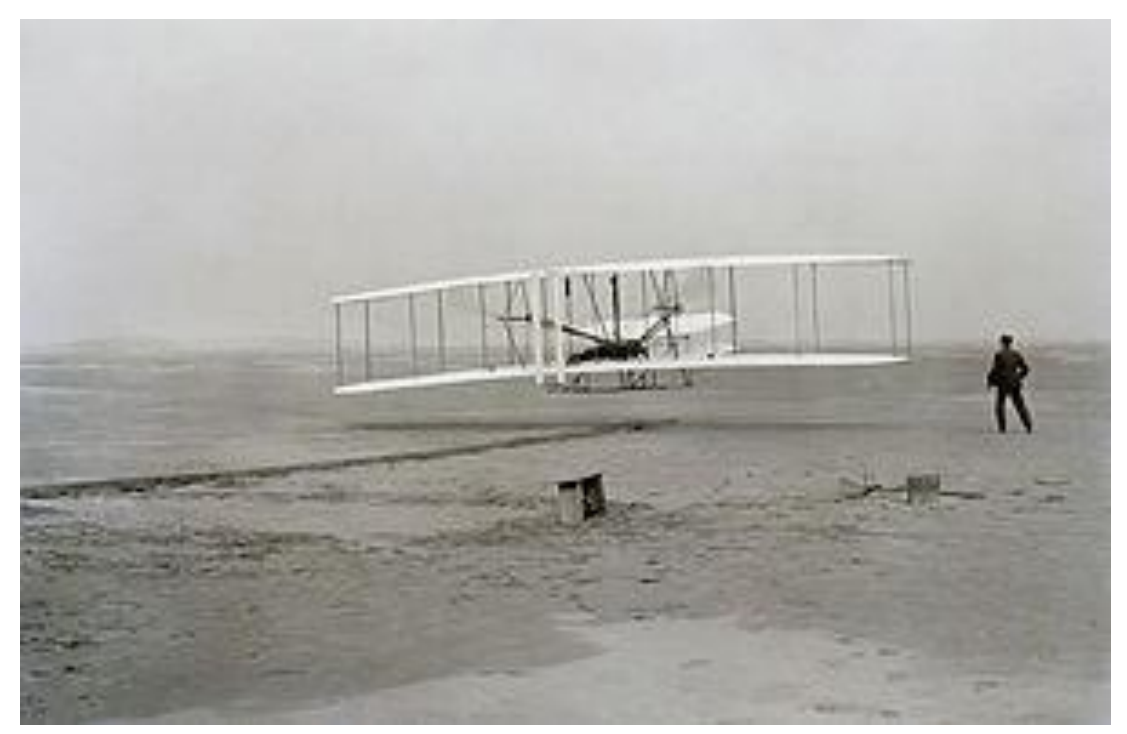

Figura 1.2 - O biplano Flyer 1, dos irmãos Wright. Fonte: Bowers (1984)

Collar (1959), Garrick (1976) e Garrick \& Reed (1981) relatam que os irmãos Wright já utilizavam efeitos aeroelásticos para controle de sua aeronave e tinham conhecimento da perda de tração causada por efeitos aeroelásticos nas hélices, medidos através de experimentos com as mesmas antes de seu voo.

Três anos depois, o brasileiro Alberto Santos Dumont fez o lendário voo do 14-bis (Figura 1.3) que, apesar das controvérsias envolvendo a autoria do primeiro voo da história, não há dúvidas de que esse é o primeiro voo com sucesso de uma aeronave autopropelida, e cabe ressaltar que esta também era um biplano. 


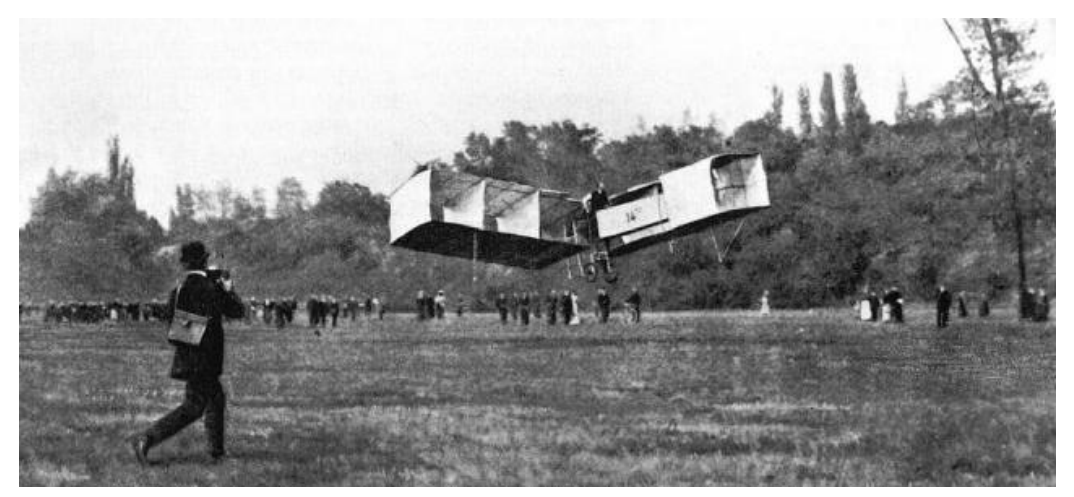

Figura 1.3 - Santos Dumont e sua aeronave biplano 14-bis. Fonte: Bowers (1984)

Os sucessos dos irmãos Wright e de Santos Dumont, aliado ao fracasso de Langley, foram determinantes para que os projetistas da recém instituída engenharia aeronáutica optassem fortemente pelos biplanos em detrimento dos monoplanos. Uma prova disso é o artigo de Brewer (1913) que mostra sua preocupação com o uso de monoplanos, citando os exemplos anteriores e indicando que até então os acidentes com aeronaves deste tipo não haviam sido satisfatoriamente explicados.

Pode-se afirmar que o não conhecimento satisfatório de fenômenos aeroelásticos atrasou em muitos anos o desenvolvimento de aeronaves de alta performance, já que os biplanos, apesar de serem mais rígidos, geram maior arrasto aerodinâmico e possuem estrutura mais pesada, o que piora sensivelmente seu desempenho.

Com o desenvolvimento de estruturas mais leves e flexíveis, o surgimento de fenômenos aeroelásticos começou a ocorrer também em biplanos, como o Handley Page 0/400, que durante a Primeira Guerra Mundial apresentou flutter em sua empenagem. Com essa aeronave foi possível, pela primeira vez, se fazer um estudo desse tipo de fenômeno, atribuído a Lanchester, a partir do qual se concluiu que uma solução simples, como a interligação dos profundores da aeronave (que eram independentes), poderia sanar o problema. Porém não foi tão simples a solução de problemas aeroelásticos nas aeronaves Albatros D-III e Fokker DVIII, que apresentavam séria tendência à divergência (Collar, 1959).

Segundo Kehoe (1995), a partir de pesquisas como a de Lanchester, o estudo da aeroelasticidade se tornou possível, fazendo com que os profissionais da aviação pudessem conhecer melhor esse tipo de fenômeno, e graças a isso o desenvolvimento de monoplanos se tornou possível a partir da década de 1930. 
Com a Segunda Guerra Mundial as aeronaves passaram a alcançar velocidades próximas às do som e transportar cargas externas como armamentos, tanques de ponta de asa, etc. O que modificou a condição de carregamento e facilitou a ocorrência de fenômenos aeroelásticos. Estes problemas levaram à necessidade de estudos mais aprofundados e modelos teóricos mais refinados.

No final da década de 40 as primeiras aeronaves passaram a romper a barreira do som, gerando problemas até então desconhecidos, como o flutter de painel, que depende de efeitos térmicos e de compressibilidade. Tais problemas estimularam muitas pesquisas nas décadas de 50 e 60, principalmente no tocante a fenômenos supersônicos, fadiga e tensões devidas a efeitos térmicos.

Segundo De Marqui Jr. et al. (2001), a partir da década de 70, iniciou-se o desenvolvimento de sistemas de controle para o aumento de estabilidade e melhoria na resposta dinâmica das aeronaves. Paralelamente a isso, foram desenvolvidos computadores mais potentes que permitiram o uso de técnicas de simulação como o CFD (Computational Fluid Dynamics). Ambos os fatores associados levaram a uma maior confiabilidade do projeto, permitindo que as aeronaves ficassem cada vez mais leves e atingissem condições de voo cada vez mais críticas.

Atualmente são realizadas pesquisas no campo da aeroservoelasticidade, que envolvem a interação entre dinâmica estrutural, cargas aerodinâmicas e sistemas de controle. Esse campo, atualmente muito promissor, pode levar a um grande desenvolvimento das aeronaves no sentido de se evitar fenômenos aeroelásticos.

Muitos avanços ao longo dos anos foram obtidos no sentido de se conhecer e evitar problemas aeroelásticos, porém a aviação mundial ainda está longe de dizer que já domina plenamente estes fenômenos. Uma prova disso foi um acidente ocorrido no recente ano de 2006, com uma aeronave protótipo Grob G 180A, mostrada na Figura 1.4, que caiu durante um simples voo de demonstração a clientes, matando o piloto, seu único tripulante. O relatório da BFU (2010) concluiu que, apesar de a aeronave estar fazendo um voo com a instrumentação desligada, foi possível atribuir a causa do acidente a uma ocorrência de flutter no estabilizador horizontal, o que tornou a aeronave incontrolável, levando à queda. Acidentes como esse mostram que, apesar da grande capacidade de prevenção de acidentes e dos projetos cada vez mais bem estruturados, a aviação não está livre de problemas sérios como esse. 


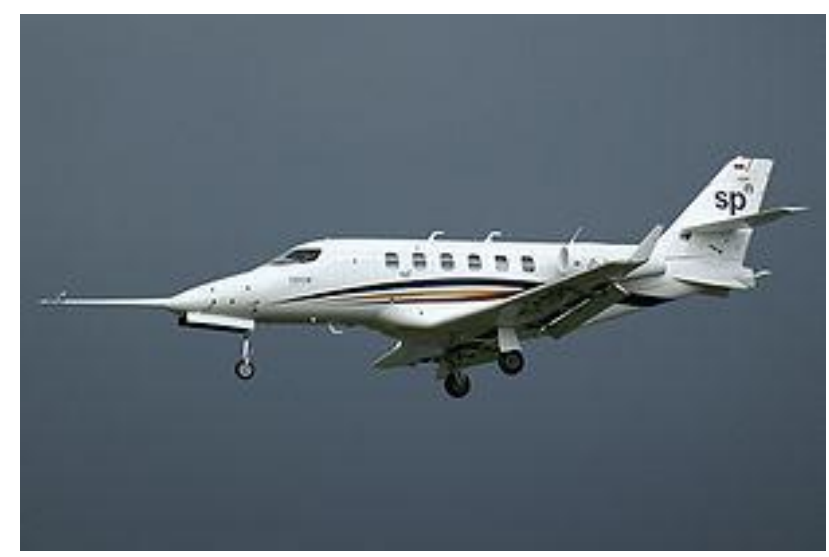

Figura 1.4 - Aeronave Grob G 180A. Fonte: BFU (2010)

Para a verificação e validação dos modelos aeroelásticos produzidos e para realimentação dos mesmos, tornando-os mais robustos, ensaios normalmente são realizados, sejam eles em túnel de vento ou em voo. Para que eles aconteçam, a estrutura em questão é instrumentada com acelerômetros e excitada. A resposta obtida nos sensores é comparada com a prevista nos modelos numéricos.

Kehoe (1995) afirma que os primeiros ensaios em voo para estudo de flutter foram realizados em 1935 por von Schlippe e sua técnica consistia em excitar a aeronave em frequências ressonantes a velocidades cada vez mais altas, plotando a amplitude da resposta em função da velocidade. Isso significa que o aumento da amplitude correspondia à diminuição no amortecimento. Com essa técnica, a velocidade de flutter era determinada pela assíntota da curva quando a amplitude tendesse ao infinito. A Figura 1.5 mostra um gráfico semelhante ao obtido no ensaio de von Schlippe.

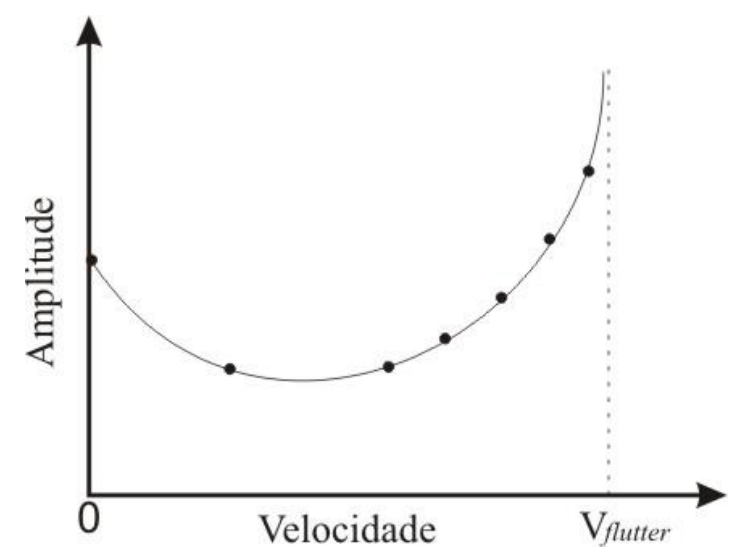

Figura 1.5 - Gráfico dos resultados de ensaio utilizado por Von Schlippe. Fonte: Adaptado de Kehoe (1995) 
Com o desenvolvimento dos instrumentos de medição, da computação e de novas técnicas, os ensaios de flutter tornaram-se mais acurados e seguros, porém ainda assim são considerados de alto risco e devem ser planejados e executados de forma cuidadosa.

As empresas utilizam, hoje em dia, um método interativo para os testes de flutter, envolvendo modelos matemáticos, ensaios em solo e ensaios em voo.

A National Test Pilots School (1995) relata que inicialmente são levantadas características importantes referentes ao comportamento da aeronave através de modelos teóricos que são validados com modelos em escala, como modos de vibrar e frequências naturais. Em seguida são realizados testes chamados GVT (Ground Vibration Tests) e medidas de rigidez. Estes testes consistem em excitar a aeronave em determinadas frequências, utilizando shakers ou martelos de impacto, e medir as respostas por meio de acelerômetros ou de strain-gages. Todos estes dados são utilizados para validação e refinamento do modelo matemático, para em seguida se realizarem os ensaios em voo.

Van Nunen \& Piazzoli (1979) apresentam um fluxograma de desenvolvimento do comportamento aeroelástico de uma estrutura, que é mostrado na Figura 1.6.

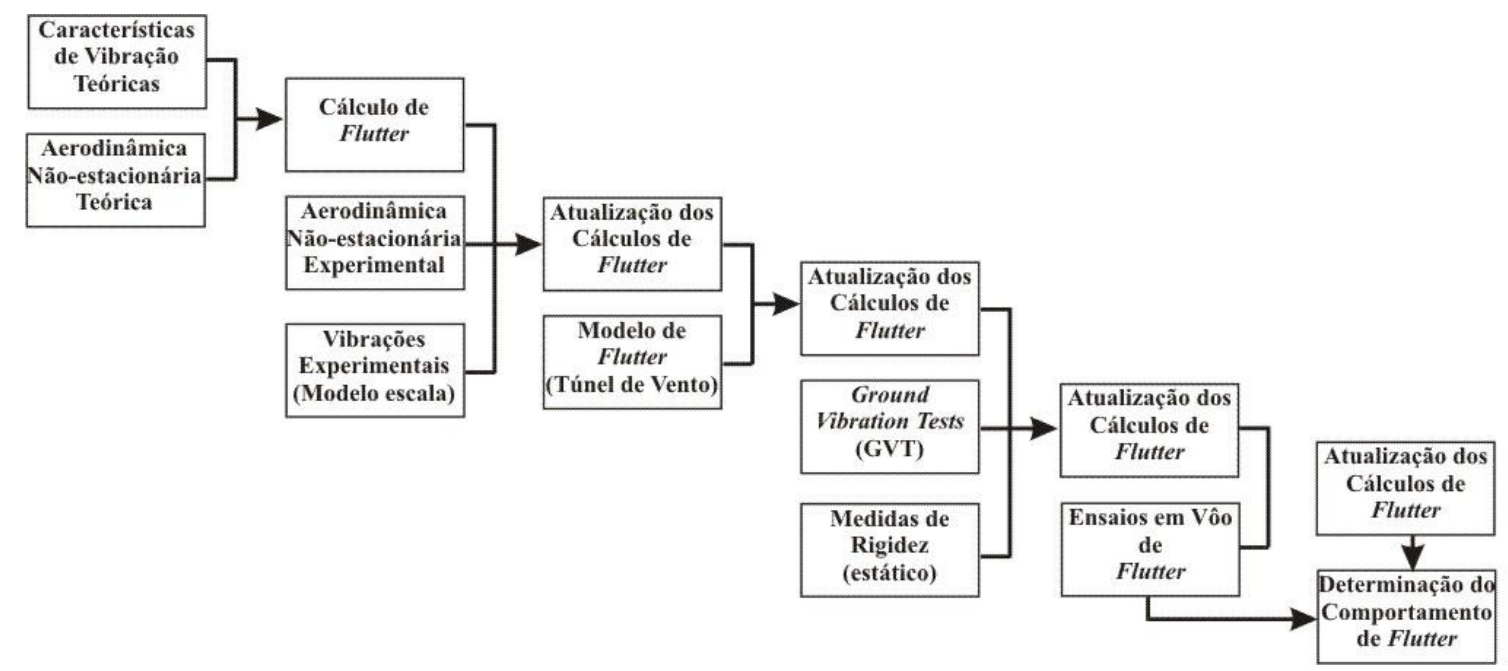

Figura 1.6 - Fluxograma do desenvolvimento do modelo aeroelástico de uma estrutura. Fonte: Adaptado de Van Nunen \& Piazzoli (1979)

São utilizados ainda ensaios em túnel de vento, com modelos em escala dinâmica, para levantamento das cargas aerodinâmicas e da mesma forma melhorar o modelo matemático. Ward et al (2006) afirmam ainda que mesmo durante a campanha de ensaios em voo, ajustes importantes podem ser feitos no modelo matemático. Por esse motivo, ensaios em voo de 
flutter são caros, consomem tempo e, mesmo com instrumentação adequada, possuem alto risco envolvido.

Ward et al. (2006) afirmam que a instrumentação necessária para ensaios deste tipo consiste apenas em acelerômetros colocados nas superfícies aerodinâmicas, tais como asas e empenagens, e regiões sujeitas a vibrações, tais como naceles e motores.

A National Test Pilots School (1995) reforça que a coleta de dados deve ser feita com alta taxa de amostragem, pois as características de estabilidade podem variar abruptamente com uma pequena variação na velocidade. A Figura 1.7 mostra as posições dos acelerômetros utilizados nos ensaios típicos de flutter de uma aeronave durante sua campanha de ensaios de certificação. Nota-se que os acelerômetros são concentrados nas superfícies aerodinâmicas e em algumas regiões de interesse, como pilones e escapamento do APU (Auxiliary Power Unit). Alguns acelerômetros são colocados na fuselagem de modo a se determinar o comportamento vibratório da aeronave.

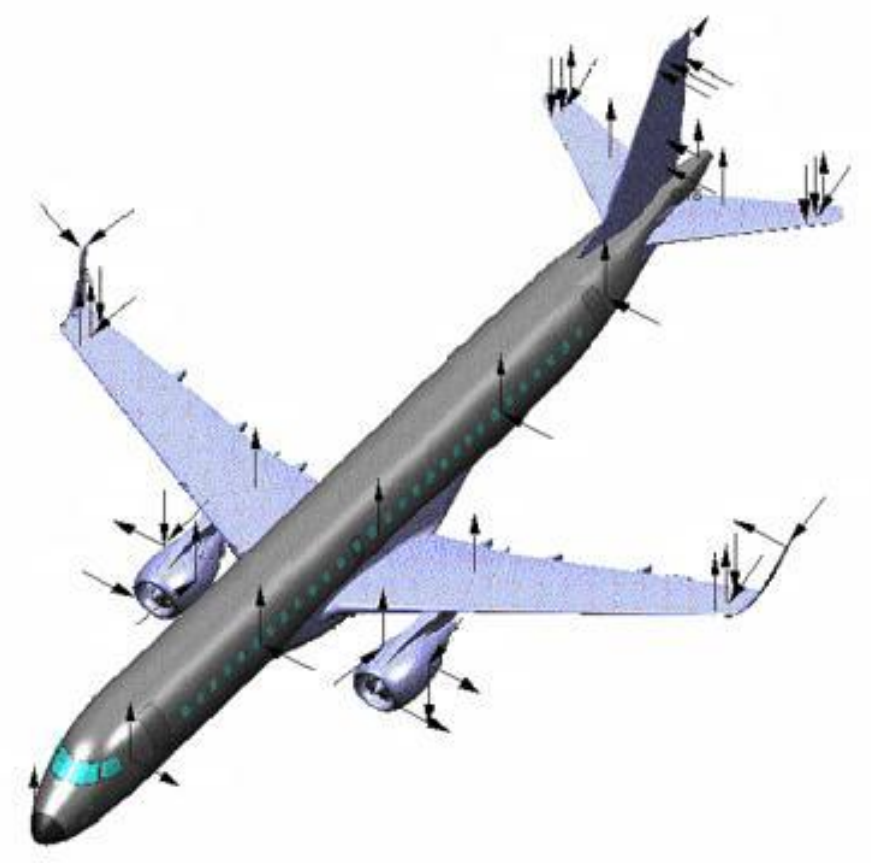

Figura 1.7 - Posição dos acelerômetros utilizados em ensaios de flutter

Hoje em dia, com o uso de estruturas cada vez mais leves e utilizações mais diversificadas, como VANTs (Veículos Aéreos Não-Tripulados) ou aeromodelos fotográficos, a presença dos acelerômetros em sua superfície pode afetar consideravelmente a resposta dada pelos sensores, levando a dados inconsistentes e modelos pouco confiáveis. 
Um grande desafio é o uso de sensores cada vez menos intrusivos e leves, de modo a deixar a estrutura com as mesmas propriedades que ela teria em sua utilização real.

\subsection{Objetivos}

O objetivo deste trabalho é a proposição de um método para detecção da ocorrência de flutter em ensaios, baseada na geração de calor instantânea em regiões da estrutura que estão sujeitas a maior concentração de tensões. Esse calor pode ser detectado com termossensores, tais como uma câmera de imageamento infravermelho, e por isso a técnica é totalmente não invasiva e possui boa precisão de detecção.

Diferentemente dos métodos atualmente utilizados, o aqui proposto não possui qualquer influência da presença de sensores na estrutura, o que poderia prejudicar os resultados medidos, e por esse motivo pode ser aplicado a estruturas extremamente leves, como asas de pequenos aeromodelos, VANTs, asas rotativas de drones ou estruturas de materiais inovadores e extremamente leves, como o Aerogel.

Com esse trabalho, espera-se contribuir com o estudo em areas relacionadas a imageamento, que possui inúmeras possibilidades de aplicação e mesmo assim é pouco estudado no Brasil atualmente. Além disso, propõe-se um método inovador para detecção de flutter e medição de forma de modos de vibrar em uma estrutura. O uso de imageamento com essa aplicação não foi encontrado na bibliografia consultada.

Para detecção de flutter espera-se ainda que o método aqui proposto contribua futuramente para a redução do tempo em ensaios em voo desse tipo e diminuição das horas de voo, implicando em grande economia e ganhos em segurança, além de confiabilidade e facilidade na calibração dos instrumentos utilizados.

Para tal proposição, serão apresentados os fundamentos teóricos necessários e em seguida a metodologia será testada em uma estrutura já existente no laboratório, onde serão realizadas pesquisas para levantamento das suas características. Será realizado então o levantamento experimental dos modos de vibrar da estrutura baseado em imageamento infravermelho e finalmente o método será testado em túnel de vento onde sua funcionalidade e precisão serão colocados à prova. 
Como resultado, se espera uma metodologia precisa e que forneça em tempo real a ocorrência do fenômeno flutter e a forma de vibrar da estrutura na iminência do fenômeno, medida através da concentração de tensões ao longo da estrutura. Tais resultados serão comparados com modelos teóricos, sendo possível se avaliar, dessa forma, a viabilidade do método e a validação dos resultados obtidos.

\subsection{Estrutura do texto}

O presente trabalho está organizado em tópicos divididos por assuntos. No Capítulo 2 é apresentada uma cuidadosa revisão bibliográfica abordando os temas que serão utilizados nesse trabalho, como aeroelasticidade, tecnologia infravermelho e modelamento termomecânico em estruturas, bem como o estado da arte desses tópicos na tecnologia atual. No Capítulo 3 serão apresentados os materiais e a metodologia utilizados para a realização do trabalho. O Capítulo 4 apresenta a estrutura utilizada neste trabalho, como foram obtidas as características necessárias para seu estudo e os resultados alcançados. A estrutura utilizada foi construída para pesquisas anteriores no laboratório e foi feito um trabalho de engenharia reversa para que suas características básicas fossem levantadas. De posse dessas características foram feitos os experimentos com imageamento infravermelho. Primeiramente foi realizado o levantamento dos modos de vibrar e em seguida o ensaio em túnel de vento para detecção de flutter, abordados no Capítulo 5, com sua metodologia e resultados. Por fim o Capítulo 6 apresenta algumas considerações finais, com as conclusões obtidas, dificuldades encontradas e propostas para trabalhos futuros. O Capítulo 7 mostra as referências bibliográficas utilizadas ao longo do texto e o Anexo A apresenta especificações técnicas de câmeras de imageamento infravermelho citadas neste texto, cujas informações auxiliam o entendimento das conclusões apresentadas nos capítulos anteriores. 
Intencionalmente em branco 


\section{Capitulo}

\section{Revisão bibliográfica}

Este capítulo tem por objetivo mostrar o estágio atual do conhecimento nos tópicos referentes à teoria que será utilizada neste trabalho. Nesse sentido, foi feita uma pesquisa na bibliografia relacionada e o resultado são os conceitos apresentados adiante, que fornecem a base para a parte prática do trabalho, apresentada a partir do Capítulo 4.

No tocante a aeroelasticidade, Collar (1946) fornece os primeiros estudos e a definição básica deste ramo das ciências aeronáuticas, com seu famoso diagrama relacionando a interação de forças aerodinâmicas, inerciais e elásticas, empregado até hoje para explicar este tipo de fenômeno.

Bisplinghoff et al. (1955), Dowell et al. (2004) e Hodges \& Pierce (2002) fornecem as bases gerais e a teoria clássica da aeroelasticidade, além de conhecimentos utilizados nas simulações computacionais que visam a previsão de velocidade e frequência da ocorrência de flutter.

Benini (2002), De Marqui Jr. (2004) e Costa (2007) descrevem de forma detalhada os modelos aeroelásticos em seus trabalhos e Nitzche (2001) apresenta teorias fundamentais para a confecção de novos modelos desse tipo.

National Test Pilots School (1995) e Naval Test Pilots School (1992) fornecem informações sobre ensaios em voo aplicados a fenômenos aeroelásticos, assim como Ward et al. (2006), Van Nunen \& Piazzoli (1979) e Olson (2000) mostram os conceitos teóricos aplicados nesse tipo de ensaio. 
Brenner et al. (1997), Kehoe (1995), Lind (1997, 2003), Lind et al. (1998) e Wright et al. (2003) descrevem ensaios em voo de flutter, permitindo conhecimentos sobre o estado da arte para ensaios desse tipo, assim como De Marqui Jr. et al. (2007), Sutherland (2008) e Suleman et al. (2002) fornecem estudos práticos e ensaios em laboratório e túnel de vento de fenômenos aeroelásticos.

Federal Aviation Administration (2000) fornece os requisitos de certificação para este tipo de ensaio e Federal Aviation Administration (1998) um guia para a realização de ensaios, demonstrando o cumprimento destes requisitos.

Para informações a respeito de tecnologia infravermelho, Hudson Jr. (1969) fornece a teoria básica de radiação infravermelho e Holst (2003) explica seu uso para imageamento e como termossensor, enquanto Wyatt (1987) dá noções de projeto para dispositivos com essa finalidade.

McShea (2010) mostra aplicações aeronáuticas para o imageamento infravermelho, enquanto Clifton (1996) e Fisher et al. (2003) fornecem aplicações voltadas especificamente a ensaios em voo.

Dehne et al. (2012), Fujino et al. (2003) e FLIR Systems (2011, 2012a) mostram algumas aplicações de imageamento infravermelho na indústria aeronáutica, principalmente voltados a conforto térmico ou transição de escoamento aerodinâmico de laminar para turbulento.

Os mesmos temas são abordados, porém de forma mais acadêmica, nos trabalhos de Malerba et al. (2008), Banks (2000) e Zuccher et al. (2003).

FLIR Systems (2012b) e ITC (2008) fornecem informações sobre o uso e as melhores condições para aplicação de câmeras infravermelho para diversas finalidades.

Para o estudo do comportamento termomecânico do material na estrutura, foi realizado um estudo em três frentes distintas, dada a característica multidisciplinar desse fenômeno. A primeira delas em Ciência dos Materiais, onde as bibliografias de Guy (1976) e Van Vlack (1992) foram de extrema importância.

A segunda frente desse estudo foi em Resistência dos Materiais, obtendo-se todas as informações necessárias em Beer et al. (2010). A terceira linha de pesquisa foi em termodinâmica, onde as referências de Schulz (2003) e Van Wylen \& Sonntag (1970) forneceram as informações necessárias para o estudo. 
Poucos artigos foram encontrados nessa área, sendo que nenhum deles com finalidade semelhante. Razo et al. (1995) faz uma interessante análise termomecânica de um material específico, patenteado por uma empresa privada.

Outros artigos, como Lee et al. (1993) e Wedekind et al. (2010) fazem menção ao estudo de comportamento termomecânico numa abordagem voltada à fabricação mecânica.

Yang \& Wang (2013) e Brinson (1993) abordam a questão sob a ótica de materiais inteligentes, como ligas com memória de forma.

\subsection{Aeroelasticidade}

Collar (1946) define aeroelasticidade como a ciência que estuda as interações mútuas entre forças aerodinâmicas, elásticas e inerciais. Bisplinghoff et al. (1955) explicam que o fenômeno ocorre devido à flexibilidade das estruturas, sejam aeronáuticas ou não. Segundo ele, a carga aerodinâmica provoca uma deformação na estrutura, gerando uma distribuição de carregamento aerodinâmico diferente, que por sua vez provoca outro tipo de deformação. Em um caso estável, essa interação é cada vez menor, até que seja encontrado um ponto de equilíbrio. Em caso de instabilidade, essas interações divergem até causar falha estrutural.

Inicialmente, Collar (1946) propôs uma classificação para os problemas aeroelásticos utilizando um triângulo com a representação das forças inercial (I), aerodinâmica (A) e elástica (E) em seus vértices, distribuindo os fenômenos nos campos correspondentes a vibrações mecânicas, estabilidade dinâmica, aeroelasticidade estática e aeroelasticidade dinâmica, dependendo das cargas envolvidas em cada fenômeno.

A Figura 2.1 representa o diagrama de Collar, que mais tarde foi proposto por Bisplinghoff et al. (1955) com os fenômenos distribuídos em suas áreas correspondentes.

Nitzsche (2001) classifica ainda os problemas aeroelásticos segundo sua solução. Ele afirma que os problemas podem ser divididos em problemas de estabilidade e problemas de resposta, dividindo-os segundo a Tabela 2.1. 


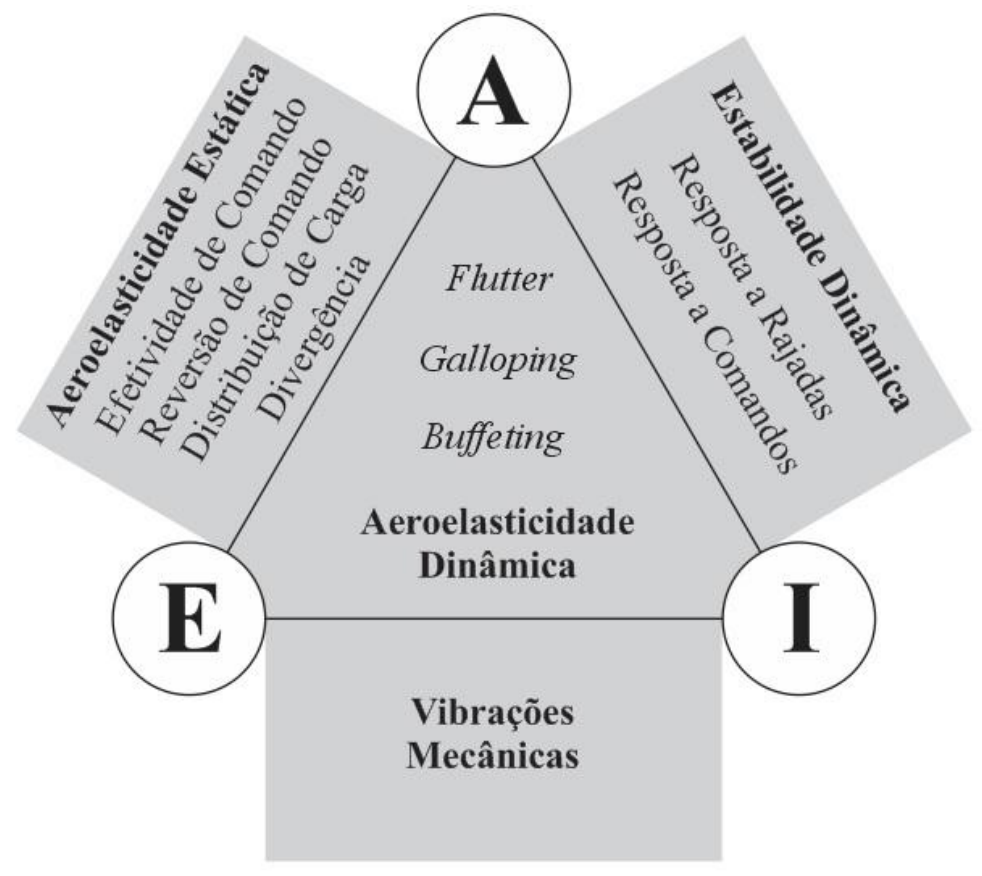

Figura 2.1 - Diagrama de Collar. Fonte: Adaptado de Bisplinghoff et al. (1955)

Tabela 2.1 - Classificação dos problemas aeroelásticos. Fonte: Adaptado de Nitzsche (2001)

\begin{tabular}{ccc}
\hline Tipo de problema & Estática & Dinâmica \\
\hline Estabilidade & Divergência & Flutter \\
\hline & Distribuição de carga & Resposta a rajadas \\
Resposta & Efetividade de comando & Resposta a comandos \\
& Reversão de comando & Buffeting \\
& & Galloping \\
\hline
\end{tabular}

Segundo a mesma fonte, a solução destes problemas se dá pela solução de equações homogêneas (problemas de autovalor) para os casos de estabilidade, e de equações não homogêneas para os casos de resposta. Uma forma de se representar os operadores e sua solução seria a seguinte:

$$
(E+A+I)\{x\}=\left\{\begin{array}{cc}
0 & \text { (estabilidade) } \\
f(t) & \text { (resposta) }
\end{array}\right.
$$

onde:

$E$ é o operador estrutural, que depende do tipo de estrutura utilizada (viga, placa, sólido, etc.) e de seu material; 
$A$ é o operador aerodinâmico, que é função do número de Mach, da geometria da estrutura, da velocidade e do ângulo de ataque;

I é o operador inercial (leis de Newton);

$\{x\}$ vetor de variáveis a ser calculado no problema;

$f(t)$ entrada (carga) aplicada ao sistema.

Da equação (2.1) pode-se concluir que os problemas de estabilidade são autoexcitados, ou seja, se aplicada uma perturbação inicial, o fenômeno se desenvolve independentemente de fatores externos, diferentemente dos problemas de resposta, onde a remoção da carga aplicada (representada como $f(t)$ ) é suficiente para cessar a ocorrência do fenômeno.

Estruturas aeronáuticas, por estarem sujeitas a grandes cargas aerodinâmicas e por serem leves e flexíveis, são muito sujeitas à ocorrência de fenômenos deste tipo, portanto no projeto de qualquer nova estrutura aeronáutica deve-se mostrar que ela é livre desses fenômenos em toda sua faixa de aplicação por cálculos analíticos, simulações computacionais, ensaios em solo (incluindo testes em túnel de vento) e ensaios em voo dentro das condições de operação previstas.

A seguir é apresentada uma definição resumida de cada fenômeno aeroelástico citado anteriormente, conforme a classificação apresentada na Tabela 2.1.

\subsubsection{Problemas aeroelásticos de resposta}

Como visto anteriormente, estes problemas podem ser classificados como estáticos ou dinâmicos e cada um dos fenômenos conhecidos serão brevemente descritos a seguir. Tais fenômenos são caracterizados por ocorrerem em situações de voo extremas e influenciar na vida útil da estrutura, gerando fadiga ou outros efeitos indesejados. Por não serem objeto de estudo deste trabalho, serão apresentadas breves definições sugeridas por Bisplinghoff et al. (1955) e Dowell et al. (2004).

Distribuição de carga: cargas aerodinâmicas distribuídas ao longo da superfície da estrutura devido à influência das deformações elásticas da mesma sob o efeito das pressões aerodinâmicas. 
Efetividade de comando: deformações elásticas da estrutura causadas por altas incidências aerodinâmicas podem resultar em diminuição da eficiência aerodinâmica ou não-linearidade das respostas da aeronave aos comandos, afetando severamente sua controlabilidade.

Reversão de comando: fenômeno que ocorre a uma determinada velocidade, onde os efeitos causados pela deformação da estrutura fazem com que a carga aerodinâmica aplicada por um comando tenham efeito inverso ao esperado na resposta da aeronave.

Resposta a rajadas: resposta dinâmica da aeronave a uma carga aplicada repentinamente resultante de uma rajada, levando em conta os efeitos da deformação da estrutura devido à pressão aerodinâmica.

$\underline{\text { Resposta a comandos: }}$ resposta dos componentes estruturais da aeronave a impulsos aerodinâmicos provocados por movimentos abruptos dos comandos de voo.

Buffeting: vibração dos componentes estruturais da aeronave que ocorre quando alguma seção da estrutura é sujeita à ação de vórtices gerados por outras partes da aeronave, especialmente em manobras de alto ângulo de ataque. Normalmente esse fenômeno ocorre em aeronaves onde sua empenagem está sujeita à esteira aerodinâmica gerada pelas asas, que em condições de alto ângulo de ataque pode gerar o descolamento do fluxo aerodinâmico, deixando a empenagem sujeita a um escoamento perturbado, causando vibrações indesejadas.

Galloping: vibração de grande amplitude que pode ocorrer na direção do eixo vertical de estruturas, inclusive civis, sujeitas a um escoamento aerodinâmico, e que possuam formato e ângulo de incidência apropriados. Normalmente a formação de gelo em superfícies de aeronaves pode facilitar a ocorrência deste fenômeno.

\subsubsection{Problemas aeroelásticos de estabilidade}

Existem dois principais fenômenos de estabilidade aeroelástica, sendo um dinâmico e o outro estático. Tais fenômenos são de maior importância no estudo da aeroelasticidade, pois causam falha imediata da estrutura e podem ocorrer em situações de voo típicas, ou seja, longe dos extremos do envelope operacional da aeronave. Por esse motivo, serão apresentadas definições mais detalhadas desse tipo de fenômeno. 
Flutter: instabilidade dinâmica que ocorre em voo na denominada "velocidade de flutter". Pela Figura 2.1 pode-se observar que a elasticidade, a inércia e a carga aerodinâmica influenciam na sua ocorrência. Este fenômeno, por ser o objeto principal de estudo deste trabalho, será explicado detalhadamente em uma seção à parte.

Divergência: instabilidade estática de uma superfície aerodinâmica que ocorre na denominada "velocidade de divergência", onde a elasticidade da estrutura, aliada à carga aerodinâmica aplicada, tem papel fundamental na sua ocorrência.

A National Test Pilots School (1995) define divergência como a condição em que o momento aerodinâmico excede o momento restaurador elástico.

Se a resultante da carga aerodinâmica é aplicada sobre a linha neutra da asa, ela irá apenas fletir, como demonstrado na Figura 2.2. Mas se esta é aplicada em qualquer outro ponto, a asa sofrerá também uma torção. Se a linha neutra está à frente da resultante da carga, a asa tende a se deformar de modo a diminuir seu ângulo de ataque. Nesse caso, a torção estará agindo em sentido contrário à sustentação da asa, fazendo com que a interação destas duas cargas levem a uma condição estável ou de equilíbrio.

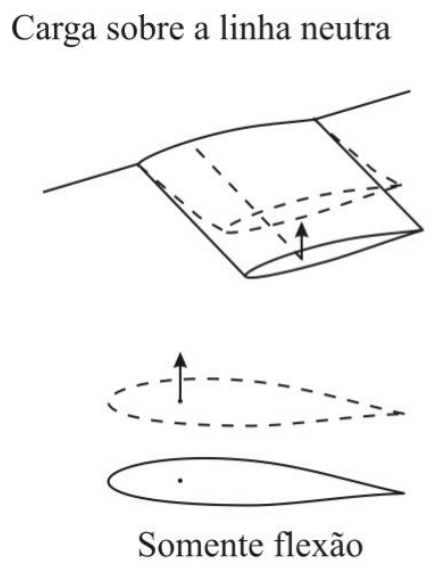

Carga atrás da linha neutra
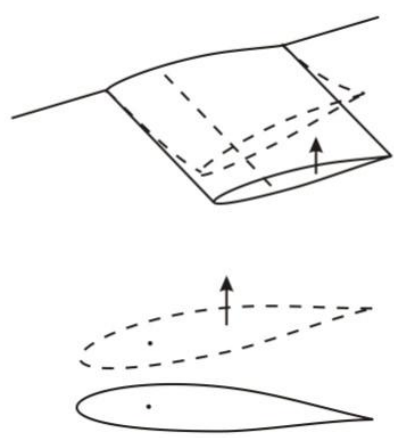

Situação estável
Carga à frente da linha neutra
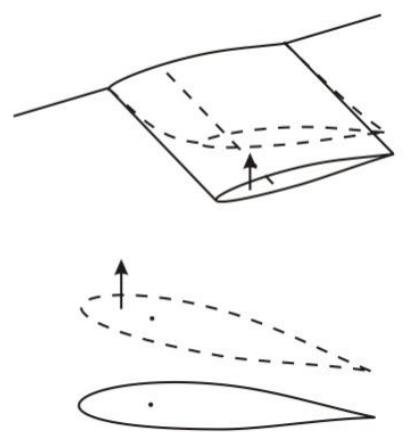

Situação instável

Figura 2.2 - Situações de aplicação da carga aerodinâmica sobre uma superfície aeronáutica

Se a resultante da carga aerodinâmica, por sua vez, for aplicada à frente da linha neutra, o momento torsional agirá de forma a aumentar o ângulo de ataque, o que aumentará a sustentação, aumentando o momento torsional. Dessa forma a deformação aumentará, fazendo com que a situação seja realimentada, agravando o fenômeno e gerando uma situação de instabilidade. Quando esta carga ultrapassar o limite estrutural, ocorrerá o rompimento da estrutura. 
A sustentação e consequentemente o momento aerodinâmico são funções da pressão dinâmica. Sendo assim, existe uma velocidade onde o momento torsional se iguala ao momento restaurador, que é chamada velocidade de divergência $\left(V_{d}\right)$.

Um modelo típico de divergência aplicada em uma seção de aerofólio, retirada de Dowel (1995), é mostrado na Figura 2.3.

Nele apresenta-se um aerofólio com uma força de sustentação $L$ aplicada no centro aerodinâmico, que sofre um momento $M_{a c}$ e é engastado por uma mola torsional na linha elástica, com uma constante $k_{\theta}$. O centro aerodinâmico se distancia da linha elástica por $e$ e o ângulo de ataque do aerofólio se divide em duas partes: o ângulo de ataque rígido $\alpha_{r} \mathrm{e} o$ ângulo causado pela torção no aerofólio $\theta$. No equilíbrio, o momento aerodinâmico com relação à linha elástica deve ser igual ao momento restaurador, $k_{\theta} \theta$.

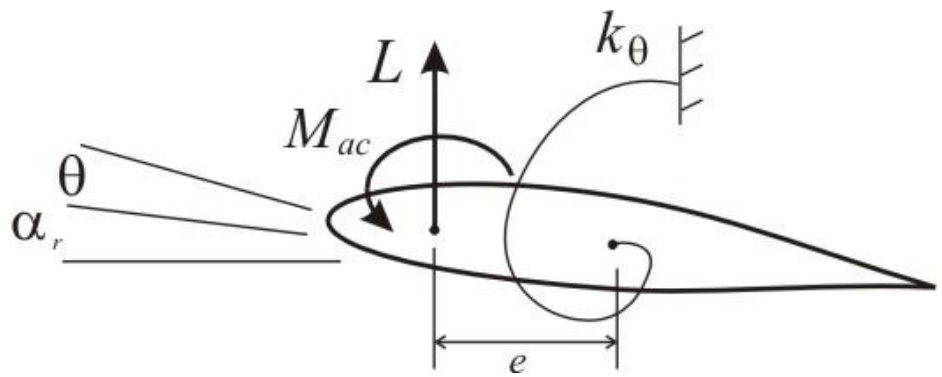

Figura 2.3 - Modelo de Dowel para o cálculo da velocidade de divergência

Somando os momentos aplicados em torno da linha elástica, tem-se:

$$
M=L e-M_{a c}=e q S C_{L \alpha}\left(\alpha_{r}+\theta\right)-q S \bar{c} C_{M a c}=k_{\theta} \theta
$$

Logo,

$$
\theta=\frac{q S\left(e C_{L \alpha} \alpha_{r}-\bar{c} C_{M a c}\right)}{k_{\theta}-q S e C_{L \alpha}}
$$

onde:

$q$ é a pressão dinâmica;

$S$ é a área do aerofólio

$C_{L \alpha}$ é o coeficiente de sustentação do aerofólio em função do seu ângulo de ataque;

$\bar{c}$ é a corda média aerodinâmica; 
$C_{M a c}$ é o coeficiente de momento de arfagem em torno de seu centro aerodinâmico.

Na divergência, o ângulo de torção $\theta$ tende ao infinito, logo o denominador deve ser igual a zero.

$$
k_{\theta}-q S e C_{L \alpha}=0
$$

Para pressão dinâmica:

$$
q_{d}=1 / 2 \rho V_{d}^{2}=\frac{k_{\theta}}{S e C_{L \alpha}} \Rightarrow V_{d}=\sqrt{\frac{k_{\theta}}{1 / 2 \rho S e C_{L \alpha}}}
$$

onde $q_{d}$ e $V_{d}$ são a pressão dinâmica e a velocidade de divergência, respectivamente.

National Test Pilots School (1995) afirma que tal modelo é simplista e possui hipóteses grosseiras, mas do ponto de vista didático dá uma boa ideia dos parâmetros e como eles influenciam no valor da velocidade de divergência.

\subsubsection{Flutter}

Bisplinghoff et al. (1955) e Ward et al. (2006) definem flutter como um fenômeno aeroelástico dinâmico de estabilidade que ocorre quando há o acoplamento de dois ou mais modos de vibrar, tornando a estrutura instável. Para uma viga semi-engastada (como no caso de superfícies aerodinâmicas típicas), normalmente os modos acoplados são os de torção e de flexão.

Serão utilizados nesse trabalho dois métodos diferentes para previsão das características de flutter e seus resultados serão comparados entre si. São eles o método quase-estático e método V-g, que são clássicos na literatura.

Em ambos os métodos sera utilizado o modelo da Figura 2.4, muito comum nesse tipo de equacionamento, conforme usado por Bisplinghoff et al. (1955), Hodges \& Pierce (2002) e Fung (1955), que apresenta uma seção típica com os dois graus de liberdade em questão. Para o modelamento aeroelástico da estrutura, serão utilizadas as equações de Lagrange a fim de se obter as equações de movimento do sistema e o princípio do trabalho virtual para a determinação das forças generalizadas. 
Dessa forma definem-se então as coordenadas generalizadas representadas na Figura 2.4 como sendo $h$ o deslocamento vertical e $\theta$ o ângulo de incidência do aerofólio.

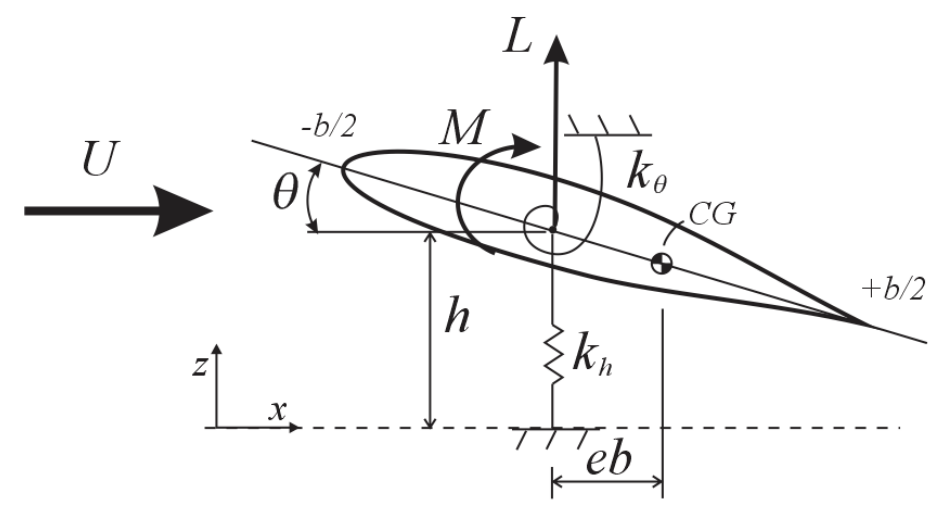

Figura 2.4 - Modelo simplificado para estudo do fenômeno flutter

\section{Método quase-estático}

Para o equacionamento desse método, inicialmente determina-se a energia cinética do sistema, baseado em seu deslocamento total em um ponto genérico $x$. Considerando a hipótese de pequenas perturbações, seu deslocamento $v$ é dado pela equação a seguir.

$$
v=h+\theta x
$$

Sendo $\mu$ a densidade linear da estrutura, a energia cinética é dada então por:

$$
T=\frac{1}{2} \int_{c} \dot{v}^{2} \mu d x
$$

Substituindo (2.6) em (2.7) para o caso do modelo estudado:

$$
T=\frac{1}{2} \int_{-b}^{b}\left(\dot{h}^{2}+2 \dot{h} \dot{\theta}+\dot{\theta}^{2} h^{2}\right) \mu d x
$$

Pode-se definir ainda:

$m=\int \mu d x \quad$ é a massa do corpo

$S_{\theta}=\int x \mu d x \quad$ é o momento estático

$I=\int x^{2} \mu d x \quad$ é o momento de inércia com relação ao C.G. 
Após a energia cinética determinada, calcula-se a energia potencial, que se divide em duas parcelas: a energia potencial gravitacional $\left(U_{g}\right)$ e a energia potencial de deformação $\left(U_{e}\right)$ dadas por

$$
\begin{gathered}
U_{g}=-m g(h+e b \operatorname{sen} \theta) \\
U_{e}=\frac{1}{2} k_{h} h^{2}+\frac{1}{2} k_{\theta} \theta^{2}
\end{gathered}
$$

Logo a energia potencial total é dada por

$$
U_{T}=U_{g}+U_{e}=-m g(h+e b \operatorname{sen} \theta)+\frac{1}{2} k_{h} h^{2}+\frac{1}{2} k_{\theta} \theta^{2}
$$

Com as equações de energia bem definidas, são utilizadas as equações de Lagrange, que consistem em um conjunto de equações diferenciais de segunda ordem usadas para se obter o comportamento do sistema a partir da energia envolvida. Para o caso estudado:

$$
\begin{aligned}
& \frac{d}{d t}\left(\frac{\partial T}{\partial \dot{h}}\right)-\frac{\partial T}{\partial h}+\frac{\partial U_{T}}{\partial h}=Q_{h} \\
& \frac{d}{d t}\left(\frac{\partial T}{\partial \dot{\theta}}\right)-\frac{\partial T}{\partial \theta}+\frac{\partial U_{T}}{\partial \theta}=Q_{\theta}
\end{aligned}
$$

Onde $Q_{h}$ e $Q_{\theta}$ são as cargas associadas às coordenadas generalizadas de flexão e torção, respectivamente.

Substituindo as equações de energia potencial e cinética (2.11) e (2.8) em (2.12) e (2.13), tem-se:

$$
\begin{gathered}
\ddot{h} m+\ddot{\theta}(m e b)+k_{h} h=g \cos \theta(m e b)+Q_{h} \\
\ddot{h}(m e b)+\ddot{\theta}\left(I+m(e b)^{2}\right)+k_{\theta} \theta=g \cos \theta(m e b)+Q_{\theta}
\end{gathered}
$$

Resultando na forma matricial

$$
\left[\begin{array}{cc}
m & m e b \\
m e b & I+m(e b)^{2}
\end{array}\right]\left[\begin{array}{c}
\ddot{h} \\
\ddot{\theta}
\end{array}\right]+\left[\begin{array}{cc}
k_{h} & 0 \\
0 & k_{\theta}
\end{array}\right]\left[\begin{array}{l}
h \\
\theta
\end{array}\right]=\left[\begin{array}{c}
m \\
m e b \cos \theta
\end{array}\right] g+\left[\begin{array}{l}
Q_{h} \\
Q_{\theta}
\end{array}\right]
$$

Pode-se simplificar a equação anterior da seguinte forma:

$S_{\theta}=m e b \quad$ é o momento estático 
$I_{\theta}=I+m(e b)^{2}$ é o momento de inércia com relação ao ponto de aplicação das cargas

Logo:

$$
\left[\begin{array}{ll}
m & S_{\theta} \\
S_{\theta} & I_{\theta}
\end{array}\right]\left[\begin{array}{c}
\ddot{h} \\
\ddot{\theta}
\end{array}\right]+\left[\begin{array}{cc}
k_{h} & 0 \\
0 & k_{\theta}
\end{array}\right]\left[\begin{array}{l}
h \\
\theta
\end{array}\right]=\left[\begin{array}{c}
m \\
m e b \cos \theta
\end{array}\right] g+\left[\begin{array}{l}
Q_{h} \\
Q_{\theta}
\end{array}\right]
$$

Em seguida, deve-se proceder o cálculo das cargas generalizadas, que se dividem em forças não-conservativas, que consistem nas forças estruturais do sistema, e as forças externas, que são as cargas aerodinâmicas. Ambos os tipos atuam no sistema e serão calculadas separadamente.

Para o cálculo das cargas não-conservativas, deve-se inicialmente determinar o amortecimento estrutural, que Fung (1955) sugere que seja utilizado, neste modelo, o do tipo proporcional, ou seja: $c=2 m \zeta v$.

Dessa forma, as cargas de amortecimento serão as únicas não-conservativas. Logo o vetor que as representa será dado por:

$$
Q^{n c}=C\left[\begin{array}{c}
\dot{h} \\
\dot{\theta}
\end{array}\right]
$$

Com o modelo de amortecimento previamente definido:

$$
\left[\begin{array}{l}
Q_{h}^{n c} \\
Q_{\theta}^{n c}
\end{array}\right]=\left[\begin{array}{cc}
m & S_{\theta} \\
S_{\theta} & I_{\theta}
\end{array}\right]\left[\begin{array}{l}
\ddot{h} \\
\ddot{\theta}
\end{array}\right]+\left[\begin{array}{cc}
2 \varsigma_{h} h & 0 \\
0 & 2 \varsigma_{\theta} \theta
\end{array}\right]\left[\begin{array}{l}
\dot{h} \\
\dot{\theta}
\end{array}\right]
$$

Como cargas externas, serão consideradas as cargas aerodinâmicas do modelo em questão, para o cálculo das mesmas, será utilizado o princípio do trabalho virtual, dado por:

$$
\delta W_{e}+\delta W_{\text {in }}=\delta U
$$

$\delta W_{e} \quad$ Trabalho virtual realizado por cargas externas

$\delta W_{\text {in }} \quad$ Trabalho virtual realizado por cargas inerciais

$\delta U \quad$ Variação de energia devido a um deslocamento vertical

Logo, as cargas estáticas em flexão e torção são dadas, respectivamente, por:

$$
Q_{h}^{e}=\frac{\partial \delta W}{\partial \delta h}
$$




$$
Q_{\theta}^{e}=\frac{\partial \delta W}{\partial \delta \theta}
$$

Em termos das coordenadas generalizadas,

$$
\delta W=Q_{\theta}^{e} \delta \theta+Q_{h}^{e} \delta h
$$

Assim sendo, o trabalho virtual é dado por:

$$
\delta W=\int_{0}^{L_{w}} \int_{-b / 2}^{b / 2} p(x, y, t) \delta z(x, y, t) d x d y
$$

$p(x, y, t) \quad$ Distribuição de pressões sobre a superfície

$\delta z(x, y, t) \quad$ Deslocamento virtual da superfície

$L_{w} \quad$ Envergadura da asa
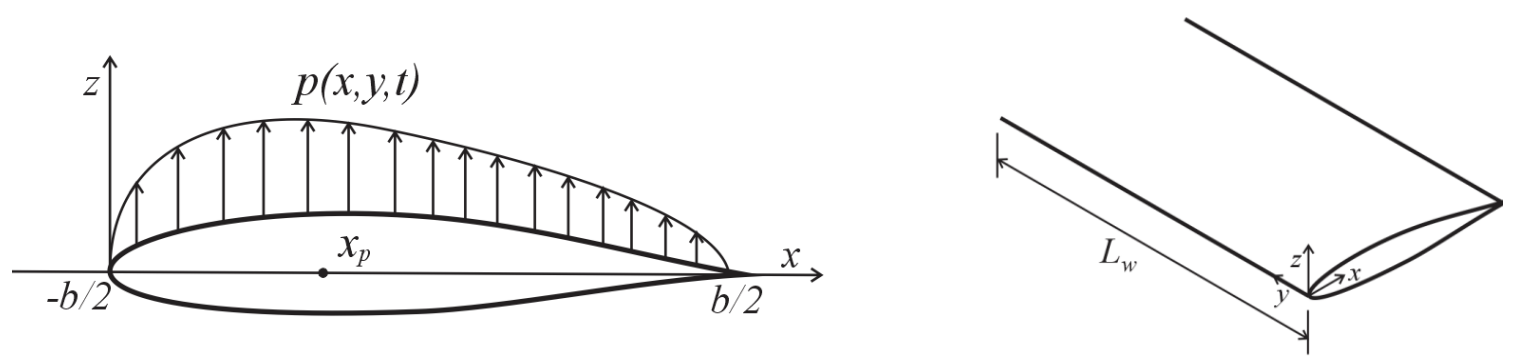

Figura 2.5 - Representação das grandezas no modelo

Escrevendo (2.24) em termos das coordenadas generalizadas,

$$
\delta z(x, y, t)=\delta h(t)+\left(x-x_{p}\right) \delta \theta(t)
$$

Substituindo (2.25) em (2.24),

$$
\delta W=\delta h \int_{0}^{L_{W}} \int_{-b / 2}^{b / 2} p(x, y, t) d x d y+\delta \theta \int_{0}^{L_{w}} \int_{-b / 2}^{b / 2} p(x, y, t)\left(x-x_{p}\right) d x d y
$$

Assim sendo, tem-se a expressão para o trabalho virtual e ela pode ser definida em termos de cargas aerodinâmicas.

$$
\delta W=\delta h(-L)+\delta \theta(M)
$$


Sendo $L$ e $M$ a sustentação e o momento de arfagem, respectivamente, aplicados à estrutura, que podem por sua vez ser escritos através de derivadas de estabilidade e controle. Tais derivadas podem ser obtidas por medição em ensaios ou calculadas empiricamente por métodos propostos na bibliografia. Este trabalho utilizará a metodologia empírica para essa obtenção, que sera descrita no Item 4.3.3 deste texto.

Para esse caso, onde os movimentos devem ocorrer a baixas frequências, pode-se afirmar que:

$$
\begin{gathered}
L=q S C_{L}=q S\left[C_{L 0}+C_{L \alpha} \alpha+\frac{\bar{c}}{2 U_{0}}\left(C_{L \dot{\alpha}} \dot{\alpha}+C_{L q} \dot{\theta}\right)\right] \\
M=q S \bar{c} C_{M}=q S \bar{c}\left[C_{M 0}+C_{M \alpha} \alpha+\frac{\bar{c}}{2 U_{0}}\left(C_{M \dot{\alpha}} \dot{\alpha}+C_{M q} \dot{\theta}\right)\right]
\end{gathered}
$$

Para a modelagem dessas forças, faz-se necessária uma relação entre o ângulo de ataque $\alpha$ e as coordenadas generalizadas utilizadas até aqui.

$$
\alpha(x, t)=\theta(t)+\frac{\dot{h}(t)}{U_{0}}+\frac{\ell(x) \dot{\theta}(t)}{U_{0}}-\frac{w_{g}(x, t)}{U_{0}}
$$

$\ell(x)$ distância entre o ponto de fixação da estrutura e o ponto de medição de $\alpha$

$U_{0} \quad$ Velocidade do escoamento livre aerodinâmico

$w_{g}(x, t) \quad$ Perturbações do escoamento (turbulência), que podem ser desprezadas para o modelo em questão.

Substituindo (2.30) em (2.29) e (2.28), e colocando na forma matricial:

$$
\begin{gathered}
{\left[\begin{array}{c}
Q_{h}^{e} \\
Q_{\theta}^{e}
\end{array}\right]=q S\left[\begin{array}{l}
-C_{L 0} \\
\bar{c} C_{M 0}
\end{array}\right]+\frac{q S \bar{c}}{2 U_{0}^{2}}\left[\begin{array}{cc}
-C_{L \dot{\alpha}} & -\ell(x) C_{L \dot{\alpha}} \\
\bar{c} C_{M \dot{\alpha}} & \bar{c} \ell(x) C_{M \dot{\alpha}}
\end{array}\right]\left[\begin{array}{c}
\ddot{h} \\
\ddot{\theta}
\end{array}\right]+} \\
\frac{q S}{U_{0}}\left[\begin{array}{cc}
-C_{L \alpha} & -\ell(x) C_{L \alpha}-\frac{\bar{c}}{2}\left(C_{L \dot{\alpha}}+C_{L q}\right) \\
\bar{c} C_{M \alpha} & \bar{c} \ell(x) C_{M \alpha}-\frac{\bar{c}^{2}}{2}\left(C_{M \dot{\alpha}}+C_{M q}\right)
\end{array}\right]\left[\begin{array}{c}
\dot{h} \\
\dot{\theta}
\end{array}\right]+q S\left[\begin{array}{ll}
0 & -C_{L \alpha} \\
0 & \bar{c} C_{M \alpha}
\end{array}\right]\left[\begin{array}{c}
h \\
\theta
\end{array}\right]
\end{gathered}
$$

Pode-se obter, dessa forma, a equação completa de movimento substituindo-se (2.19) e (2.31) em (2.17): 


$$
\left(\boldsymbol{M}_{\boldsymbol{s}}-\frac{q S \bar{c}}{2 U_{0}^{2}} \boldsymbol{M}_{\boldsymbol{a}}\right) \ddot{\boldsymbol{\Psi}}+\left(\boldsymbol{D}_{\boldsymbol{s}}-\frac{q S}{2 U_{0}} \boldsymbol{D}_{\boldsymbol{a}}\right) \dot{\boldsymbol{\Psi}}+\left(\boldsymbol{K}_{\boldsymbol{s}}-q S \boldsymbol{K}_{\boldsymbol{a}}\right) \boldsymbol{\Psi}=q S \boldsymbol{Q}_{\mathbf{0}}^{\boldsymbol{e}}+\boldsymbol{M}_{\boldsymbol{g}} g
$$

onde:

$$
\begin{aligned}
& \boldsymbol{\Psi}=\left[\begin{array}{l}
h \\
\theta
\end{array}\right] \quad \text { Vetor de coordenadas generalizadas } \\
& \boldsymbol{M}_{\boldsymbol{s}}=\left[\begin{array}{cc}
m & S_{\theta} \\
S_{\theta} & I_{\theta}
\end{array}\right] \quad \text { Matriz de massa estrutural } \\
& \boldsymbol{M}_{\boldsymbol{a}}=\left[\begin{array}{ll}
-C_{L \dot{\alpha}} & -\ell(x) C_{L \dot{\alpha}} \\
\bar{c} C_{M \dot{\alpha}} & \bar{c} \ell(x) C_{M \dot{\alpha}}
\end{array}\right] \quad \text { Matriz de massa aerodinâmica } \\
& \boldsymbol{M}_{\boldsymbol{g}}=\left[\begin{array}{l}
m \\
S_{\theta}
\end{array}\right] \quad \text { Vetor de acoplamento de massa } \\
& \boldsymbol{D}_{\boldsymbol{s}}=-\boldsymbol{M}_{\boldsymbol{s}}\left[\begin{array}{cc}
2 \varsigma_{h} h & 0 \\
0 & 2 \varsigma_{\theta} \theta
\end{array}\right] \quad \text { Matriz de amortecimento estrutural } \\
& \boldsymbol{D}_{\boldsymbol{a}}=\left[\begin{array}{cc}
-C_{L \alpha} & -\ell(x) C_{L \alpha}-\frac{\bar{c}}{2}\left(C_{L \dot{\alpha}}+C_{L q}\right) \\
\bar{c} C_{M \alpha} & \bar{c} \ell(x) C_{M \alpha}-\frac{\bar{c}^{2}}{2}\left(C_{M \dot{\alpha}}+C_{M q}\right)
\end{array}\right] \quad \text { Matriz de amortecimento aerodinâmico } \\
& \boldsymbol{K}_{\boldsymbol{s}}=\left[\begin{array}{cc}
k_{h} & 0 \\
0 & k_{\theta}
\end{array}\right] \quad \text { Matriz de rigidez estrutural } \\
& \boldsymbol{K}_{\boldsymbol{a}}=\left[\begin{array}{cc}
0 & -C_{L \alpha} \\
0 & \bar{c} C_{M \alpha}
\end{array}\right] \quad \text { Matriz de rigidez aerodinâmica } \\
& \boldsymbol{Q}_{\mathbf{0}}^{\boldsymbol{e}}=\left[\begin{array}{l}
-C_{L 0} \\
\bar{c} C_{M 0}
\end{array}\right] \quad \text { Vetor de forças generalizadas aerodinâmicas estáticas }
\end{aligned}
$$

Pela equação (2.32) observa-se a influência das cargas aerodinâmicas sobre o sistema, pois elas modificam as propriedades de massa, rigidez e amortecimento da estrutura. Esse acoplamento é a fonte de instabilidades aeroelásticas da estrutura.

Pode-se afirmar que o valor de todas as coordenadas generalizadas são a soma de uma parte estática $\left(\Psi_{0}\right)$, obtida no equilíbrio do sistema e uma perturbação $(\widetilde{\Psi})$, conforme a equação (2.33).

$$
\boldsymbol{\Psi}=\boldsymbol{\Psi}_{0}+\widetilde{\boldsymbol{\Psi}}
$$


O que se deseja é realizar o estudo das perturbações e como elas influenciam na estabilidade do sistema. Logo é necessário se calcular as condições de equilíbrio para que sejam subtraídas da equação geral de movimento, permanecendo apenas a parcela de perturbações, objeto de estudo do sistema.

Para isso, considera-se, para a equação (2.32), todas as derivadas como sendo zero. Resolvendo, chega-se a:

$$
\Psi_{0}=\frac{Q_{0}^{e}+M_{g} g}{K_{s}-K_{a}}
$$

Substituindo (2.34) em (2.33), e esta em (2.32), e resolvendo o sistema, chega-se a:

$$
\begin{aligned}
& {\left[\begin{array}{c}
\ddot{\widetilde{\Psi}} \\
\dot{\widetilde{\Psi}}
\end{array}\right]}
\end{aligned}
$$

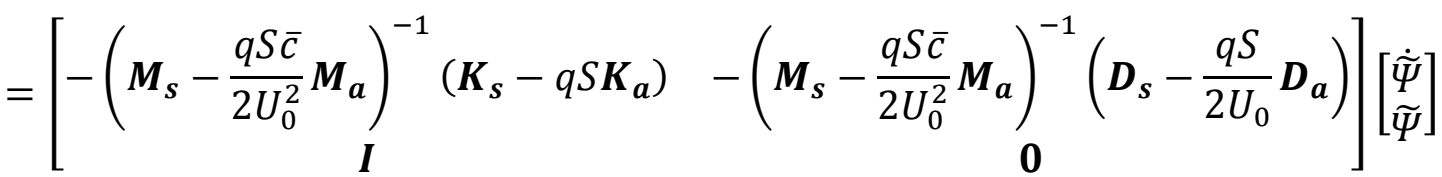

Que fornece a matriz de estados. A equação (2.35) será utilizada adiante para o estudo do comportamento do sistema, onde será aplicada uma entrada e serão analisadas as respostas no tempo e em frequência, para a previsão da velocidade e frequência de flutter.

\section{Método V-g}

Este método consiste no modelamento da estrutura baseado em seus autovalores, de onde se obtém a frequência e o amortecimento calculado. Considera-se a estrutura em flutter quando seu amortecimento atinge o valor zero.

Inicialmente para esse método, desconsidera-se a parcela devido à energia potencial gravitacional podendo, dessa forma, reescrever a equação (2.17) da seguinte forma:

$$
\left[\begin{array}{cc}
m & m e b \\
m e b & m r_{\theta}^{2}
\end{array}\right]\left[\begin{array}{c}
\ddot{h} \\
\ddot{\theta}
\end{array}\right]+\left[\begin{array}{cc}
k_{h} & 0 \\
0 & k_{\theta}
\end{array}\right]\left[\begin{array}{l}
h \\
\theta
\end{array}\right]=\left[\begin{array}{l}
Q_{h} \\
Q_{\theta}
\end{array}\right]=\left[\begin{array}{c}
L \\
M
\end{array}\right]
$$

onde $r_{\theta}^{2}=I_{\theta} / m$ é o raio de giro do momento aplicado.

Em seguida procede-se a adimensionalização dos termos da equação, ficando da seguinte forma: 


$$
\left[\begin{array}{cc}
1 & \frac{e}{r_{\theta}^{2}}
\end{array}\right]\left[\begin{array}{c}
\ddot{h} / b \\
\ddot{\theta}
\end{array}\right]+\left[\begin{array}{cc}
\omega_{h}^{2} & 0 \\
0 & \omega_{\theta}^{2} \overline{r_{\theta}^{2}}
\end{array}\right]\left[\begin{array}{c}
h / b \\
\theta
\end{array}\right]=\left[\begin{array}{c}
L / m b \\
M / m b^{2}
\end{array}\right]
$$

onde

$\overline{r_{\theta}}=r_{\theta} / b$ é o raio de giro adimensionalizado

$\omega_{h}^{2}=k_{h} / m$ é a frequência natural em flexão

$\omega_{\theta}^{2}=k_{\theta} / m$ é a frequência natural em torção

Assumindo movimento harmônico, tem-se

$$
\begin{aligned}
& h=h_{0} e^{i \omega t} \\
& \theta=\theta_{0} e^{i \omega t}
\end{aligned}
$$

Assim, a equação (2.37) pode ser escrita como:

$$
-\omega^{2}\left[\begin{array}{cc}
1 & \frac{e}{r_{\theta}^{2}}
\end{array}\right]\left[\begin{array}{c}
h / b \\
\theta
\end{array}\right]+\left[\begin{array}{cc}
\omega_{h}^{2} & 0 \\
0 & \omega_{\theta}^{2} \overline{r_{\theta}^{2}}
\end{array}\right]\left[\begin{array}{c}
h / b \\
\theta
\end{array}\right]=\left[\begin{array}{c}
L / m b \\
M / m b^{2}
\end{array}\right]
$$

Sabendo que $k=\frac{\omega b}{U}$ é a frequência reduzida e utilizando a função de Theodorsen $(C)$ para aerodinâmica não-estacionária, pode-se afirmar que:

$$
L=\pi \rho b^{3} \omega^{2}\left[\frac{h}{b} L_{h}+\theta\left(L_{\theta}-\frac{1}{2} L_{h}\right)\right]
$$

onde

$$
\begin{aligned}
& L_{h}=1-i 2 C \frac{1}{k} \\
& L_{\theta}=\frac{1}{2}-i \frac{1+2 C}{k}-\frac{2 C}{k^{2}}
\end{aligned}
$$

Da mesma forma:

$$
M=\pi \rho b^{4} \omega^{2}\left\{\left[M_{h}-\frac{1}{2} L_{h}\right] \frac{h}{b}+\left[M_{\theta}-\frac{1}{2}\left(L_{\theta}+M_{h}\right)+\left(\frac{1}{2}\right)^{2} L_{h}\right] \theta\right\}
$$


onde

$M_{h}=\frac{1}{2}$

$M_{\theta}=\frac{3}{8}-i \frac{1}{k}$

Assim, a equação (2.39) pode ser reescrita como:

$$
\begin{aligned}
-\omega^{2}\left[\begin{array}{cc}
1 & e \\
e & r_{\theta}^{2}
\end{array}\right]\left[\begin{array}{c}
h / b \\
\theta
\end{array}\right]+\left[\begin{array}{cc}
\omega_{h}^{2} & 0 \\
0 & \omega_{\theta}^{2} r_{\theta}^{2}
\end{array}\right]\left[\begin{array}{c}
h / b \\
\theta
\end{array}\right] \\
=\frac{\omega^{2}}{\mu}\left[\begin{array}{cc}
L_{h} & L_{\theta}-\frac{1}{2} L_{h} \\
M_{h}-\frac{1}{2} L_{h} & M_{\theta}-\frac{1}{2}\left(L_{\theta}+M_{h}\right)+\left(\frac{1}{2}\right)^{2} L_{h}
\end{array}\right]\left[\begin{array}{c}
h / b \\
\theta
\end{array}\right]
\end{aligned}
$$

Definindo $\Omega^{2}=\frac{\omega^{2}}{\omega_{\theta}^{2}}$ e $R^{2}=\frac{\omega_{h}^{2}}{\omega_{\theta}^{2}}$, pode-se escrever:

$$
\begin{aligned}
-\Omega^{2}\left[\begin{array}{cc}
1 & e \\
e & r_{\theta}^{2}
\end{array}\right]\left[\begin{array}{c}
h / b \\
\theta
\end{array}\right]+\left[\begin{array}{cc}
R^{2} & 0 \\
0 & r_{\theta}^{2}
\end{array}\right]\left[\begin{array}{c}
h / b \\
\theta
\end{array}\right] \\
=\frac{\Omega^{2}}{\mu}\left[\begin{array}{cc}
L_{h} & L_{\theta}-\frac{1}{2} L_{h} \\
M_{h}-\frac{1}{2} L_{h} & M_{\theta}-\frac{1}{2}\left(L_{\theta}+M_{h}\right)+\left(\frac{1}{2}\right)^{2} L_{h}
\end{array}\right]\left[\begin{array}{c}
h / b \\
\theta
\end{array}\right]
\end{aligned}
$$

Dessa forma é possível expressar:

$$
\begin{aligned}
& \boldsymbol{M}=\left[\begin{array}{ll}
1 & \frac{e}{r_{\theta}^{2}}
\end{array}\right] \\
& \boldsymbol{K}=\left[\begin{array}{cc}
R^{2} & 0 \\
0 & r_{\theta}^{2}
\end{array}\right] \\
& \boldsymbol{A}=\frac{1}{\mu}\left[\begin{array}{cc}
L_{h} & L_{\theta}-\frac{1}{2} L_{h} \\
M_{h}-\frac{1}{2} L_{h} & M_{\theta}-\frac{1}{2}\left(L_{\theta}+M_{h}\right)+\left(\frac{1}{2}\right)^{2} L_{h}
\end{array}\right]
\end{aligned}
$$

Assim a equação (2.43) pode ser escrita como:

$$
\boldsymbol{K}\left[\begin{array}{c}
h / b \\
\theta
\end{array}\right]=\Omega^{2}(\boldsymbol{A}+\boldsymbol{M})\left[\begin{array}{c}
h / b \\
\theta
\end{array}\right]
$$

O método V-g assume inicialmente um amortecimento artificial $g$, tal que: 


$$
\boldsymbol{K}=(1+i g) \boldsymbol{K}
$$

Este fator indica o amortecimento existente no movimento harmônico. Os autovalores da equação representam um ponto na fronteira da ocorrência de flutter se o valor calculado de $g$ for igual ao valor assumido.

Das equações (2.44) e (2.45) pode-se escrever:

$$
\frac{(1+i g)}{\Omega^{2}} \boldsymbol{K}\left[\begin{array}{c}
h / b \\
\theta
\end{array}\right]=(\boldsymbol{A}+\boldsymbol{M})\left[\begin{array}{c}
h / b \\
\theta
\end{array}\right]
$$

que é um problema complexo de autovalor, cuja solução vale:

$$
\lambda=\frac{(1+i g)}{\Omega^{2}}
$$

E para esse caso tem-se

$$
\begin{gathered}
\frac{1}{\operatorname{Re}(\lambda)}=\frac{\omega^{2}}{\omega_{\theta}^{2}} \\
g=\frac{\operatorname{Im}(\lambda)}{\operatorname{Re}(\lambda)}
\end{gathered}
$$

Este problema pode ser implementado computacionalmente resolvendo-se com valores mais altos de $k$ e diminuindo, até que a velocidade de flutter seja encontrada, considerando-a na situação em que o amortecimento atingir zero.

\subsection{Imageamento infavermelho}

Com o avanço da tecnologia, novos processos de produção, projetos mais avançados e novos materiais vão sendo criados. Por esse motivo, os produtos têm se tornado mais leves, e feitos de materiais com melhor desempenho, que atendem aos requisitos de projeto sem coeficientes de segurança muito elevados.

Um típico exemplo disso é a indústria aeronáutica, que tem desenvolvido novos materiais compósitos e novas ligas metálicas de forma a tornar as estruturas mais leves e, portanto, com melhor desempenho. 
Essa tendência, porém, deve ser aplicada com cautela, pois novos materiais podem possuir características indesejadas e imprevistas, ou mesmo o uso de menores coeficientes de segurança, que podem facilitar o aparecimento de problemas estruturais, afetando a segurança e causando prejuízos aos operadores.

Assim sendo, faz-se necessário o uso de técnicas de inspeção eficientes para evitar esses problemas. É fortemente desejável que essa inspeção seja simples, rápida e não intrusiva à estrutura, para que o aproveitamento seja máximo e não cause prejuízos.

Segundo ITC (2008), câmeras infravermelho são uma opção para inspeções mecânicas, já que não interferem fisicamente na peça e, como em grande parte dos fenômenos pode haver aumento de temperatura, fornece em tempo real e com boa precisão a temperatura do objeto, permitindo uma visão holística da distribuição de temperaturas em todo o sistema.

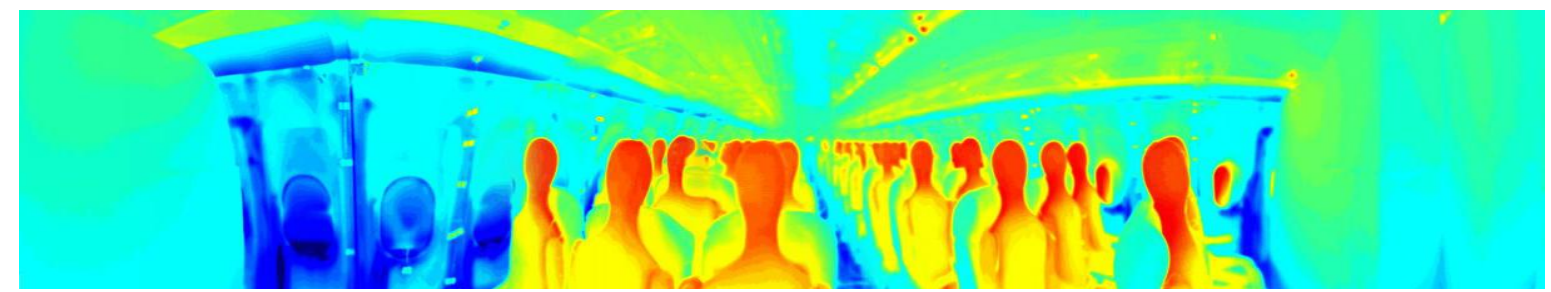

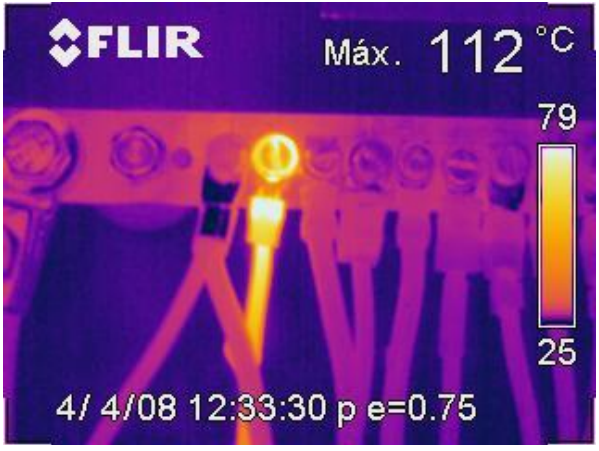

(b) (a)

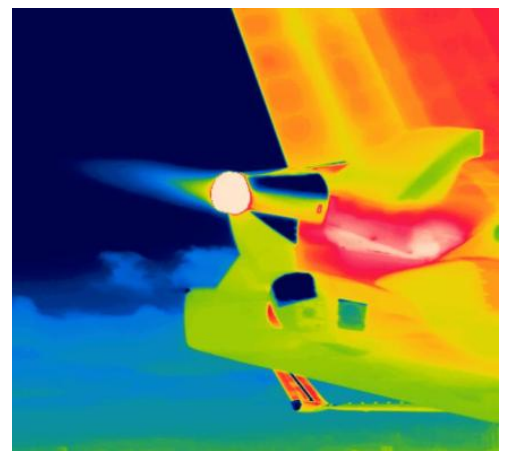

(c)

Figura 2.6 - Aplicações distintas para imageamento infravermelho

A Figura 2.6 mostra três aplicações distintas para imagens infravermelho: (a) distribuição de temperatura no ambiente de uma cabine de aeronave de passageiros, (b) detecção de um ponto de sobrecarga em um barramento elétrico e (c) distribuição de temperatura na saída de ar do APU de uma aeronave de médio porte.

A seguir é apresentada uma breve teoria sobre tecnologia infravermelho, mostrando seus fundamentos, equacionamento e uma breve explicação sobre o funcionamento das cameras utilizadas nessa tecnologia. 


\subsubsection{Tecnologia infravermelho}

Imagens infravermelho são geradas pelo processamento eletro-óptico da radiação emitida por qualquer objeto com o uso de equipamentos adequados chamados câmeras infravermelho.

Como radiação infravermelho entende-se a parte do espectro de radiações eletromagnéticas (Figura 2.7) com comprimento de onda entre 0,8 e $1000 \mu \mathrm{m}$, e se dividem em três categorias: radiação infravermelha curta $(0,8-1,5 \mu \mathrm{m})$, média $(1,5-5,6 \mu \mathrm{m})$ e longa (5,6-1.000 $\mu \mathrm{m})$, conforme descrito por Holst (2003).

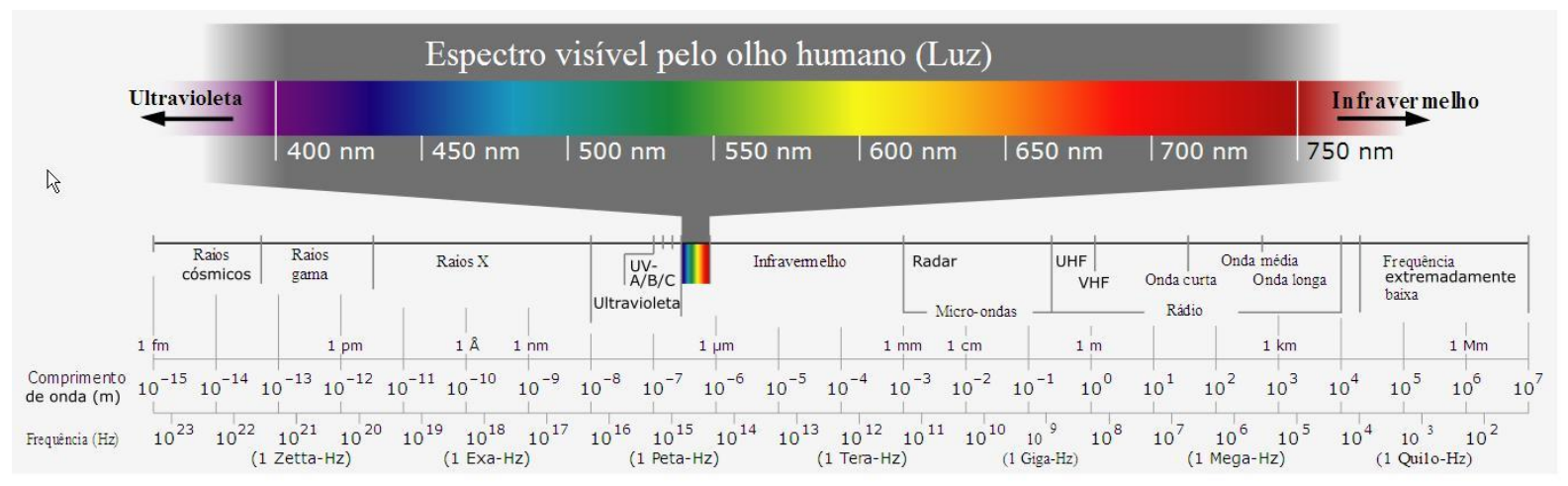

Figura 2.7 - Espectro eletromagnético. Fonte: Pion (2012)

A radiação térmica normalmente ocorre na região da radiação infravermelha média (para altas temperaturas) ou longa (para baixas temperaturas) e essa diferença de comprimento de onda (e consequentemente de frequências) é processada pela câmera infravermelho de forma a gerar as imagens baseadas em radiação. Algumas características importantes da radiação térmica são:

- Todos os objetos emitem radiação térmica;

- Ela não necessita de meio material para ocorrer;

- Atravessa facilmente a maioria dos gases;

- Dificilmente atravessa líquidos ou sólidos.

Além de emitir radiação, um objeto também absorve e reflete parte da radiação incidente do meio ambiente, ou permitindo que uma pequena parte desta radiação a atravesse (como através de uma lente). A lei de radiação total $(W)$ é derivada deste princípio físico, e pode ser estabelecida pela seguinte fórmula:

$$
W=\alpha W+\tau W+\rho W
$$


onde

$$
\alpha+\rho+\tau=1
$$

Os coeficientes $\alpha, \rho$, e $\tau$ descrevem a absorção de energia incidente do objeto $(\alpha)$, reflexão $(\rho)$ e transmissão $(\tau)$. O valor de cada coeficiente pode ser entre zero e um, dependendo da forma como o objeto absorve, reflete ou transmite a radiação incidente. Por exemplo, se $\rho=0, \tau=0$ e $\alpha=1$, então não há energia refletida ou transmitida e $100 \%$ da radiação incidente é absorvida. Isso é o que se chama de um corpo negro perfeito (Hudson Jr., 1969).

A lei de Kirchhoff da radiação térmica descreve matematicamente o comportamento dos corpos com respeito ao calor irradiado. As propriedades ligadas à irradiação da energia são denotadas pelo símbolo $\varepsilon$, chamado emissividade do corpo. Essa lei prevê que $\alpha=\varepsilon$, ou, como ambas dependem do comprimento de onda, $\alpha(\lambda)=\varepsilon(\lambda)$. A equação (2.50), para o caso de corpos opacos $(\tau=0)$, pode ser simplificada por:

$$
\rho+\varepsilon=1
$$

No caso do corpo negro tem-se $\rho=0$ e portanto, $\varepsilon=1$.

Wyatt (1987) afirma que a lei de Planck (equação 2.52) descreve a quantidade de energia irradiada por um corpo negro em equilíbrio térmico e foi formulada em 1900 com constantes empiricamente determinadas. Planck descreveu com precisão a radiação do corpo negro, propondo que a radiação eletromagnética era emitida em quanta. A Figura 2.8 mostra a emissão de radiação de um corpo negro em função do comprimento de onda, para diferentes temperaturas.

$$
u(v, T)=\frac{4 \pi}{c} I(v, T)=\frac{8 \pi h v^{3}}{c^{3}} \frac{1}{e^{\frac{h v}{k T}}-1}
$$

onde:

$$
\begin{aligned}
& I \text { é a radiância espectral }\left[\mathrm{Js}^{-1} \mathrm{~m}^{-2} \mathrm{sr}^{-1} \mathrm{~Hz}^{-1}\right] \\
& v \text { é a frequência de radiação }[\mathrm{Hz}] \\
& T \text { é a temperatura do corpo negro }[\mathrm{K}] \\
& h \text { é a constante de Planck }\left(6,62 \times 10^{-34} \mathrm{~J} / \mathrm{Hz}\right)
\end{aligned}
$$


$c$ é a velocidade da luz $\left(3,0 \times 10^{8} \mathrm{~m} / \mathrm{s}\right)$

$e$ é o número de Euler

$k$ é a constante de Boltzmann $\left(1,38 \times 10^{-23} \mathrm{~J} / \mathrm{K}\right)$

Na figura observa-se que, para temperaturas abaixo de $5000 \mathrm{~K}$, as maiores potências de radiação emitidas pelos corpos negros em equilíbrio térmico estão na zona classificada como infravermelho, o que mostra que o imageamento infravermelho é uma boa opção para visualização nessa faixa de temperaturas.

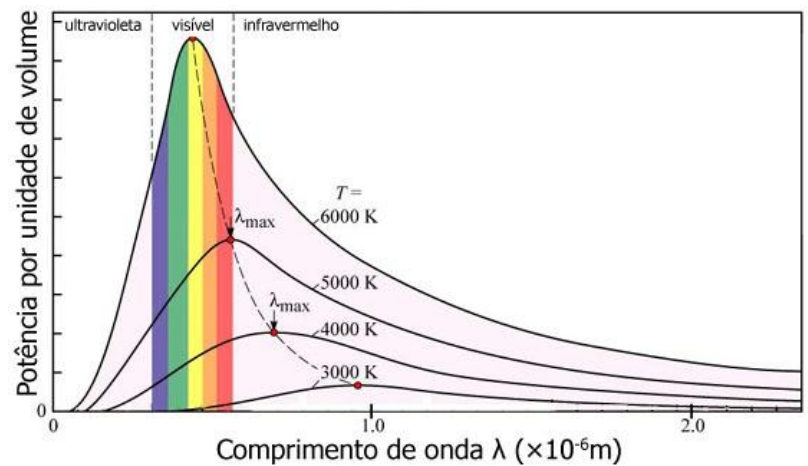

Figura 2.8 - Potência de radiação em função do comprimento de onda. Fonte: Centro de Ciências da Educação (2008)

Além disso, Planck resolveu uma imprecisão na teoria clássica conhecida como “catástrofe do ultravioleta". Segundo a teoriaclássica, para baixos comprimentos de onda, a emissão de radiação tenderia ao infinito, conforme mostrado na Figura 2.9.

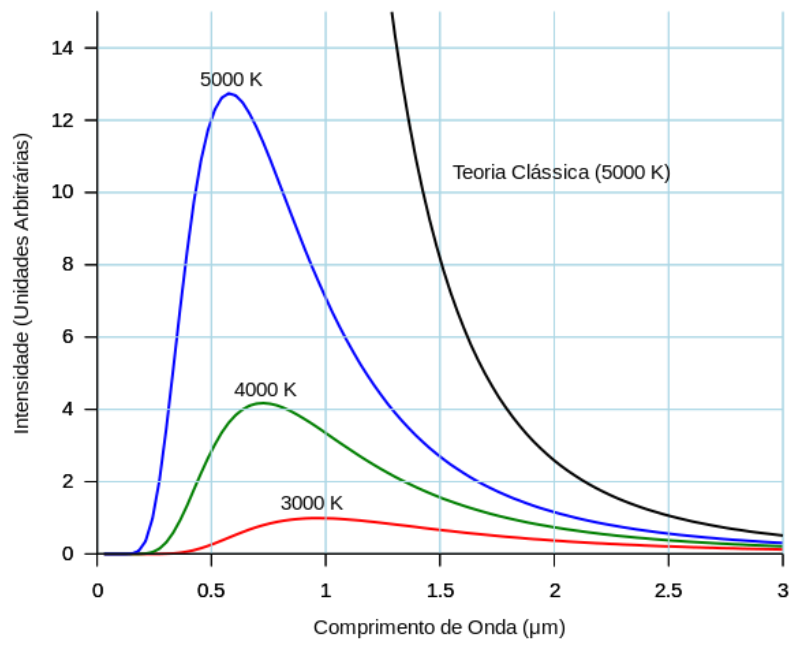

Figura 2.9 - Comparação entre a teoria clássica de radiação e a catástrofe do ultravioleta. Fonte: Ponto Ciência (2013) 
Para solução, ele sugeriu que a emissão de energia eletromagnética era emitida em pacotes discretos de energia proporcionais à sua frequência. Esses pacotes depois foram conhecidos como fótons e tiveram papel fundamental na origem da mecânica quântica. Ainda a partir dessa formulação foi possível se determinar a constante de Planck $(h)$ usada na equação (2.52).

Comprovando que a teoria dos "pacotes" era correta, Planck provou que a energia destas oscilações é limitada a múltiplos inteiros da energia fundamental $E$, e proporcional à frequência de oscilação $v$, conforme mostra a equação (2.53).

$$
E=h v
$$

Ele assumiu essa quantização, cinco anos depois de Albert Einstein ter sugerido a existência de fótons para explicar o fenômeno do efeito fotoelétrico.

A partir da Lei de Planck, descobriu-se que a energia total irradiada por um corpo negro poderia ser calculada, e pela lei de Stefan-Boltzmann descobriu-se que ela é proporcional à quarta potência da sua temperatura em Kelvin.

$$
W=\sigma T^{4}
$$

onde $\sigma$ é a constante de Stefan-Boltzmann $\left(5,67 \times 10^{-8} \mathrm{Wm}^{2} \mathrm{~K}^{4}\right)$.

As propriedades de objetos radioativos são geralmente descritas em relação a um corpo negro perfeito. Se a energia emitida a partir de um corpo negro é denotada como $W_{b b}$ e a de um objeto normal à mesma temperatura como $W_{o b j}$, a relação entre estes dois valores descreve a emissividade $(\varepsilon)$ do objeto,

$$
\varepsilon=W_{o b j} / W_{b b}
$$

Por conseguinte, a emissividade é um número entre 0 e 1 . Quanto melhor as propriedades radioativas do objeto, mais elevada será sua emissividade. Um objeto que tem a mesma emissividade para todos os comprimentos de onda é chamado um corpo cinza.

As câmeras infravermelho atuais conseguem transformar a radiação emitida por um objeto em uma imagem. A radiação infravermelho é emitida por todos os objetos com temperaturas acima do zero absoluto e possui características semelhantes às da radiação 
visual como reflexão, refração e transmissão. Quanto maior a temperatura do corpo, maior será a energia irradiada.

Por esse motivo, o princípio de funcionamento de uma câmera infravermelho é semelhante ao de uma câmera para luz no comprimento de onda visível. Elas possuem uma lente que foca a radiação sobre o detector, e um conjunto de hardware eletrônico e software para processamento e amostra dos sinais e imagens gerados (Figura 2.10).

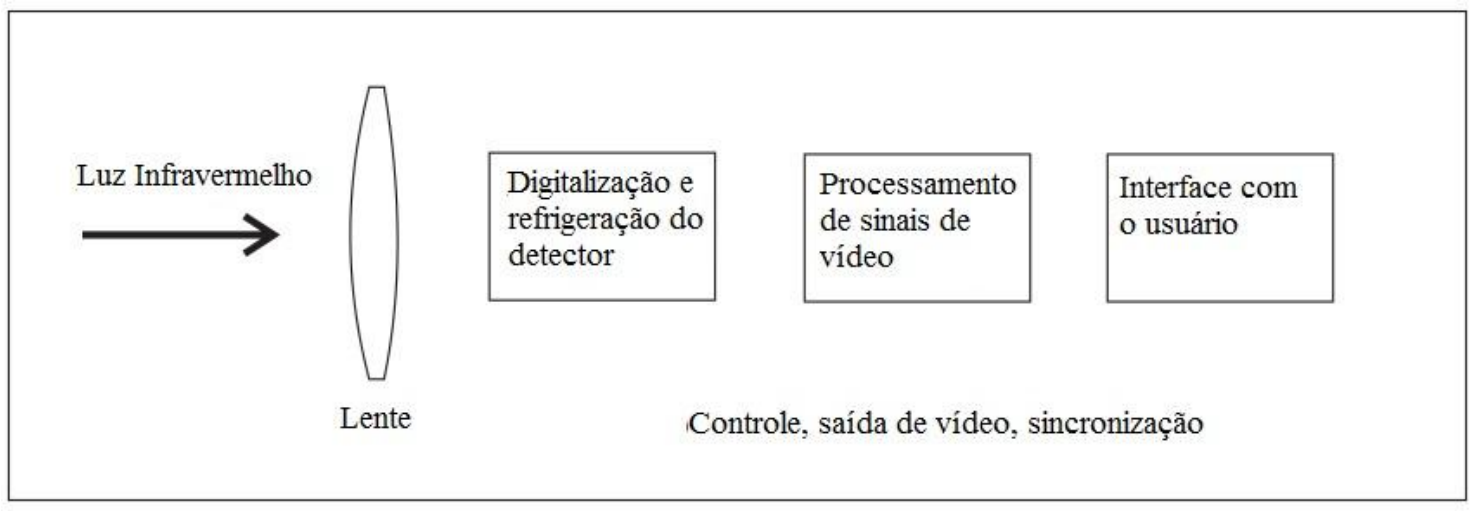

Figura 2.10 - Diagrama simplificado de uma câmera infravermelho

Portanto, a termografia permite que se faça medições de temperatura de um objeto sem contato físico. Os detectores infravermelho de câmeras modernas são compostos de uma matriz de plano focal ou Focal Plan Array (FPA) de vários materiais sensíveis a um comprimento de onda específico. A resolução da matriz de sensores pode variar de cerca de $160 \times 120$ pixels até $1024 \times 1024$ pixels. Dependendo do tamanho e resolução da uma matriz de detectores ela pode conter de 60.000 a mais de 1 milhão de detectores individuais.

Além disso, muitos fabricantes de câmeras fornecem softwares que permitem que as câmeras se concentrem em áreas específicas do plano focal para medir a temperatura. As câmeras infravermelho possuem curvas de calibração que transformam a energia irradiada em temperatura na superfície do objeto.

A tecnologia dos detectores infravermelho pode ser dividida em dois principais tipos: detectores termais e detectores quânticos. Um tipo bastante utilizado de detector termal utiliza um microbolômetro (sensor infravermelho não-refrigerado) feito de metal ou material semicondutor. Este tipo de detector apresenta custo mais baixo e uma resposta espectral mais ampla quando comparado aos detectores quânticos. Microbolômetros têm resposta mais lenta (cerca de $12 \mu \mathrm{s}$ ), e são menos sensíveis do que os detectores quânticos (cerca de $1 \mu \mathrm{s}$ ). 
Os detectores quânticos são tipicamente feitos de InSb, InGaAs, PtSiu, HgCdTe (MCT) ou camadas de GaAs/AlGaAs nos detectores QWIP (Quantum Well Infrared Photon). Os detectores quânticos funcionam baseados na mudança de estado dos elétrons da camada de condução ao receberem radiação infravermelha. Estes detectores são em geral mais rápidos e mais sensíveis que os detectores termais, entretanto eles requerem resfriamento. Para aplicações de maior demanda os detectores quânticos são normalmente preferidos e operam tomando proveito do princípio fotoelétrico. Estes materiais, ao absorverem fótons elevam seus elétrons a um nível maior de energia causando uma mudança na condutividade, voltagem ou corrente. Reduzindo a temperatura destes detectores a níveis criogênicos, eles podem ser muito sensíveis à radiação infravermelho que é focada neles, ao mesmo tempo em que o tempo de reação a mudanças de energia se torna muito pequeno. Câmeras que utilizam este tipo de sensores são úteis para gravar eventos de transientes de temperatura. Entretanto, detectores quânticos têm respostas que variam fortemente com o comprimento de onda (Figura 2.11).

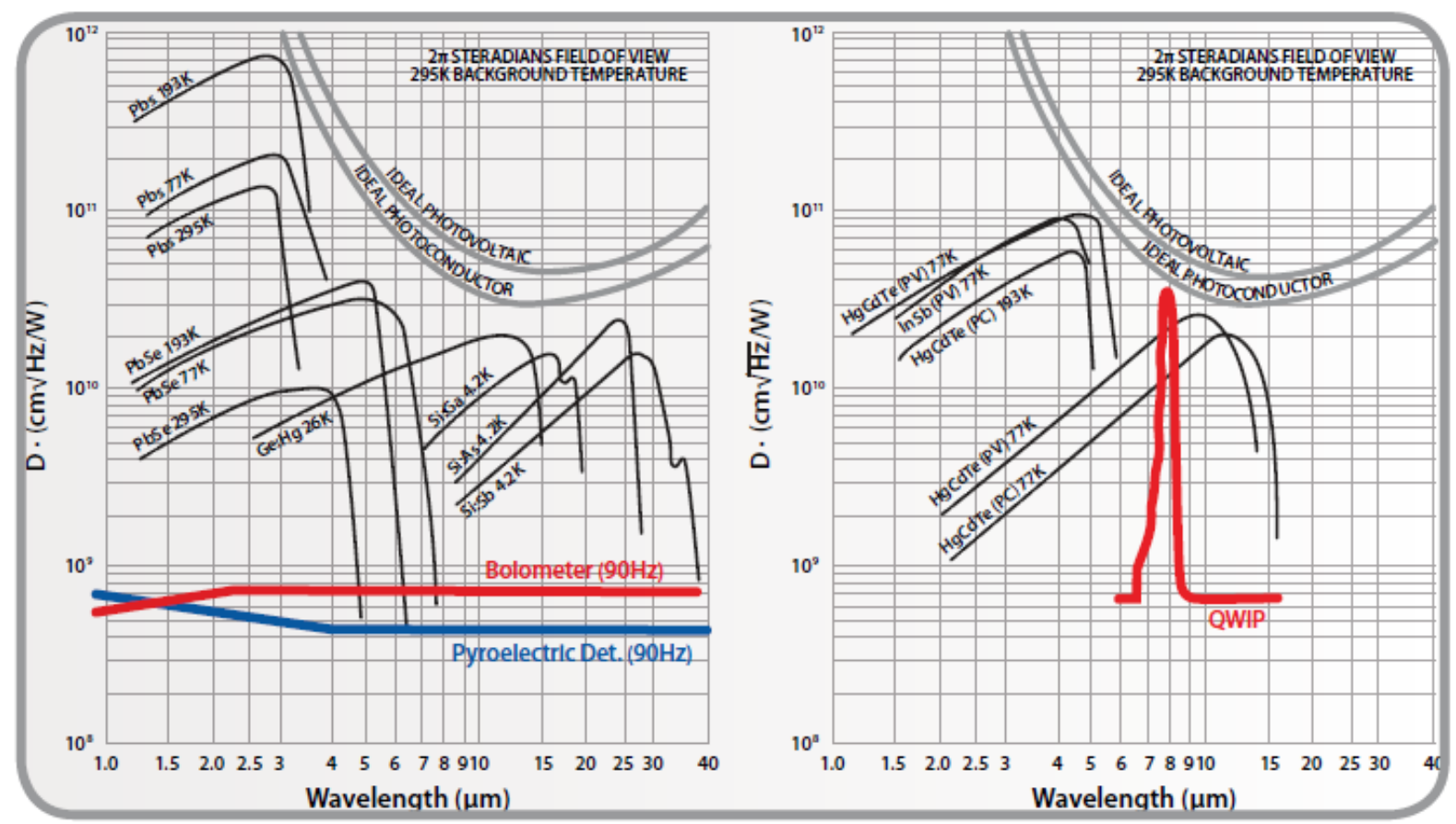

Figura 2.11 - Curvas de detectividade para diferentes tipos de detectores. Fonte: FLIR (2012b)

Dos exemplos de câmeras apresentados no Anexo A deste texto, os modelos E40 e P620 possuem detectores termais, enquanto o modelo SC5000 apresenta detectores quânticos. A Tabela 2.2 mostra alguns dos detectores mais comuns utilizados hoje. 
Tabela 2.2 - Tipos de detectores tipicamente usados em câmeras infravermelho

\begin{tabular}{ccc}
\hline Tipo de detector & Operação & Temperatura de operação \\
\hline Microbolômetro & Ampla faixa & Não refrigerado $\left(\sim 30^{\circ} \mathrm{C}\right)$ \\
\hline $\mathrm{HgCdTe}$ & $\begin{array}{c}\text { Detector quântico de ondas } \\
\text { IR curtas }\end{array}$ & $200 \mathrm{~K}$ \\
\hline $\mathrm{HgCdTe}$ & $\begin{array}{c}\text { Detector quântico de ondas } \\
\text { IR longas }\end{array}$ & $77 \mathrm{~K}$ \\
\hline $\mathrm{InSb}$ & $\begin{array}{c}\text { Detector quântico de ondas } \\
\text { IR médias }\end{array}$ & $77 \mathrm{~K}$ \\
\hline $\mathrm{PtSi}$ & $\begin{array}{c}\text { Detector quântico de ondas } \\
\text { IR médias }\end{array}$ & $70 \mathrm{~K}$ \\
\hline $\mathrm{QWIP}$ & $\begin{array}{c}\text { Detector quântico de ondas } \\
\text { IR longas }\end{array}$ \\
\hline
\end{tabular}

Lentes infravermelho tipicamente utilizam materiais à base de Silício ( $\mathrm{Si}$ ) e Germânio (Ge). Normalmente o Si é usado para sistemas de câmeras na faixa do infravermelho de médio comprimento de onda (3 a $5 \mu \mathrm{m}$ ), enquanto o Germânio é utilizando em câmeras de longo comprimento de onda. Ambos possuem boas propriedades mecânicas, isto é, não quebram facilmente, não são higroscópicos e podem ser conformados em lentes por meio das técnicas atuais. As lentes infravermelho também possuem coberturas antirreflexo e podem transmitir perto de $100 \%$ da radiação incidente com o desenho apropriado.

\subsection{Modelamento termomecânico}

Guy (1976) explica que deformações em materiais apresentam dispersão de energia em forma de calor. Van Vlack (1992) vai ao encontro dessa explicação e acrescenta que, quando uma tensão é aplicada a um material, causando deformação elástica, e em seguida removida, a energia envolvida nessa deformação é dispersada em sua maior parte na forma de calor, gerando um aumento local da temperatura, e em pouco tempo é liberado para o ambiente.

De forma a tentar quantificar esse aumento de temperatura, um estudo foi realizado para se criar um modelo numérico de previsão do aumento de temperatura em uma determinada parte da estrutura quando aplicada uma carga específica. 
Conforme já explicado anteriormente, esse modelo tem caráter multidisciplinar, e serão abordados a seguir os conceitos teóricos utilizados, que envolvem Resistência dos Materiais, Ciência dos Materiais e Termodinâmica.

\subsubsection{Método de energia aplicado a vigas}

Beer et al. (2010) descreve o modelamento de vários tipos de estruturas pelo método de energia com a aplicação de diferentes tipos de carga.

No caso abordado neste trabalho, a parte da estrutura a ser analisada pode ser modelada como uma viga em engastada-engastada deslizante sujeita a momentos em dois planos de aplicação diferentes, além de uma carga cortante, conforme mostrado na Figura 2.12.
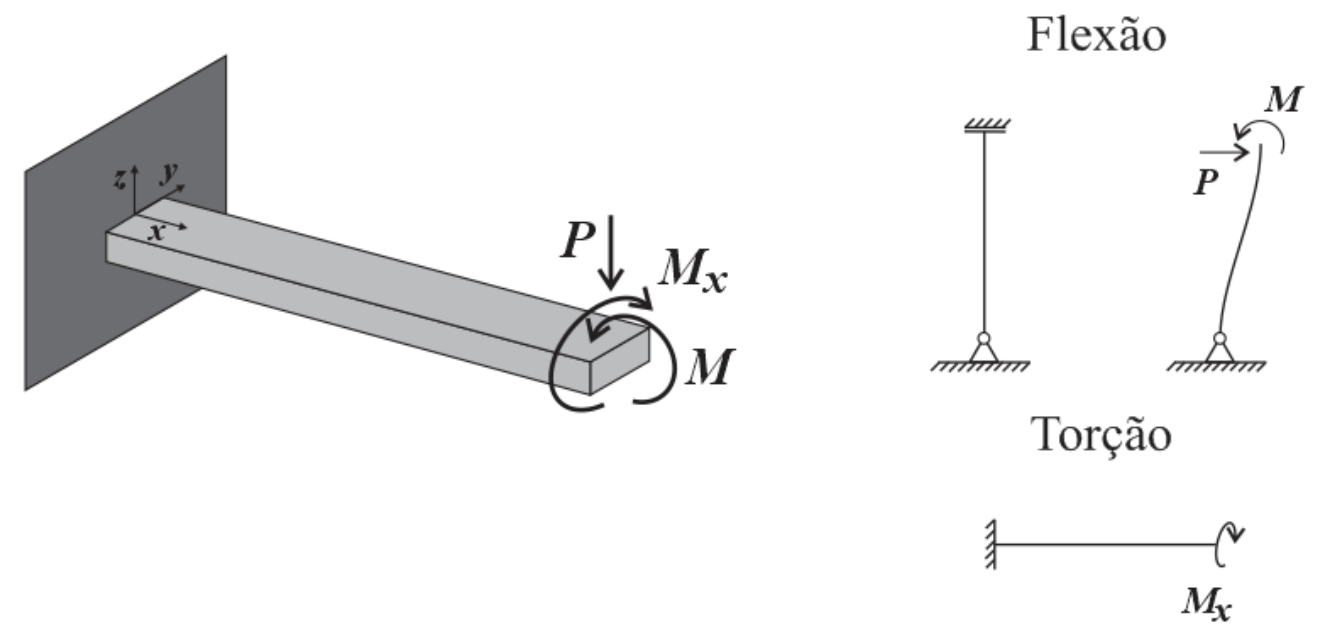

Figura 2.12 - Modelo simplificado da estrutura a ser estudada

Dessa forma, o efeito aplicado pela força que causa flexão $(P)$ e momento fletor $(M)$ serão estudados separadamente do momento de torção $\left(M_{x}\right)$.

\subsubsection{Flexão}

Para o equacionamento da viga em flexão, foi utilizado o método de energia de deformação, que dá o trabalho total de uma carga para a deformação da estrutura, representado pela Figura 2.13. 


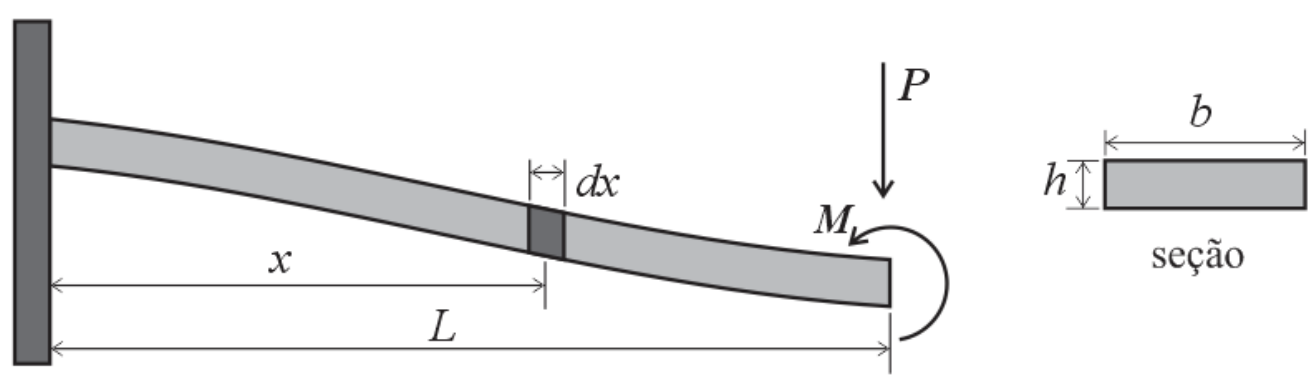

Figura 2.13 - Modelo de viga em flexão sob influência da força cortante

Segundo esse método, a energia obtida na deformação é uma soma de duas parcelas: a energia de deformação por tensão normal $\left(U_{\sigma}\right)$ e a energia de tensão de cisalhamento $\left(U_{\tau}\right)$, sendo a primeira função do momento fletor e a segunda da força cortante.

Por esse motivo, a Figura 2.14 apresenta os diagramas citados.

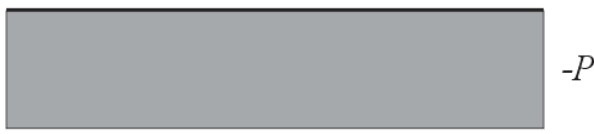

(a)

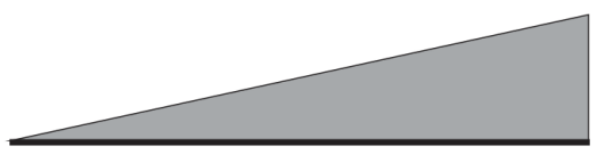

(b)

Figura 2.14 - Diagramas de força cortante (a) e momento fletor (b) aplicados na estrutura

Pelo gráfico, sabe-se que a força cortante é constante de módulo P, e o momento fletor é dado pela equação (2.56).

$$
M=P x
$$

Para tensão normal tem-se que a energia de deformação é dada por (Beer et al. 2010):

$$
U_{\sigma}=\int_{0}^{L} \frac{M^{2}}{2 E I} d x
$$

onde:

$E$ é o Módulo de Young do material da estrutura

I é o momento de inércia da seção da estrutura 
Substituindo (2.56) em (2.57),

$$
U_{\sigma}=\frac{1}{2 E I} \int_{0}^{L / 2}(P x)^{2} d x
$$

Logo, para ambas as parcelas, o resultado da integral será

$$
U_{\sigma}=\frac{P^{2} L^{3}}{6 E I}
$$

Ainda segundo Beer et al. (2010),

$$
\sigma=\frac{|M|}{W}=\frac{P x}{W}
$$

onde $W$ é o módulo de resistência à flexão, que para a seção mostrada na Figura 2.13, é dado por

$$
W=\frac{1}{6} b h^{2}
$$

Assim, substituindo (2.60) e (2.61) em (2.59),

$$
U_{\sigma}=\sigma^{2} \frac{b^{2} h^{4} L^{3}}{216 x^{2} E I}
$$

Para tensão de cisalhamento, pode-se afirmar que

$$
U_{\tau}=\int_{0}^{L} \frac{\tau^{2} b h}{2 G} d x
$$

onde:

$G$ é o módulo de elasticidade transversal do material da estrutura

Sabe-se ainda que, para esse caso,

$$
\tau=\frac{3}{2} \frac{P}{b h}\left(1-\frac{z^{2}}{c^{2}}\right)
$$

Onde $c / z$ é o ponto da coordenada vertical em que se quer encontrar a tensão de cisalhamento. 
Logo, substituindo (2.64) em (2.63),

$$
U_{\tau}=\frac{1}{2 G}\left(\frac{3}{2} \frac{P}{b h}\right)^{2} \int\left(1-\frac{z^{2}}{c^{2}}\right) b d x d z
$$

Fazendo as integrações, considerando que $c$ varia de $-h / 2 \mathrm{a}+h / 2$,

$$
U_{\tau}=\frac{9 P^{2} L}{8 G b h^{2}}\left[z-\frac{2}{3} \frac{z^{3}}{c^{2}}+\frac{1}{5} \frac{z^{5}}{c^{4}}\right]_{-h / 2}^{+h / 2}=\frac{3 P^{2} L}{5 G b h}
$$

Considerando a tensão como uma grandeza scalar e sabendo que para esse caso,

$$
\sigma=\frac{|M|}{W}=\frac{P L}{W}
$$

Pode-se substituir (2.67) e (2.61) em (2.66), chegando-se a

$$
U_{\tau}=\sigma^{2} \frac{1}{60} \frac{b h^{3}}{G L}
$$

Assim, somando-se as parcelas da equação (2.62) e da (2.68), pode-se obter a energia total de deformação em flexão.

$$
U_{h}=U_{\sigma}+U_{\tau}=\sigma^{2} \frac{b h^{3}}{12}\left[\frac{b h L^{3}}{18 x^{2} E I}+\frac{1}{5 G L}\right]
$$

\subsubsection{Torção}

Utilizando o mesmo método, foi feito o equacionamento da viga sujeita ao esforço de torção, esquematizado na Figura 2.15 e modelado pela equação (2.70).
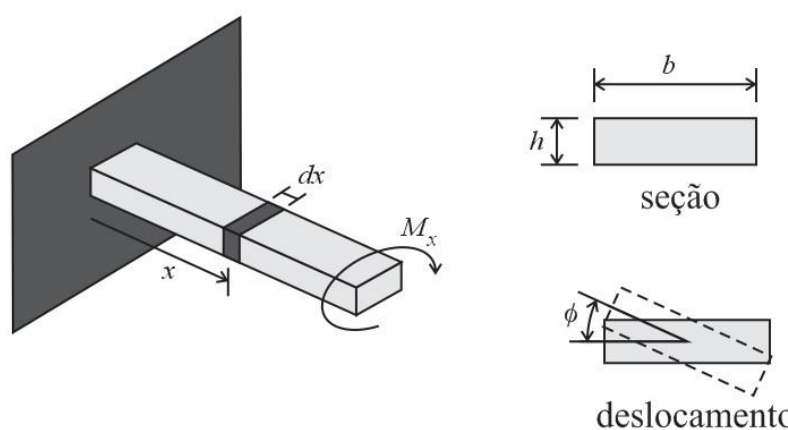

Figura 2.15 - Modelo da viga em torção 


$$
U_{\theta}=\int_{0}^{L} M_{x} d \phi
$$

Analogamente ao caso anterior, pode-se afirmar que

$$
\phi=-\frac{M_{x} x}{c_{2} b h^{3} G}
$$

Substituindo (2.71) em (2.70),

$$
U_{\theta}=\int_{0}^{\phi} \frac{M_{x}^{2}}{c_{2} b h^{3} G} d x
$$

onde:

$c_{2}$ é um coeficiente para barras de seção retangular sujeitas a torção que segundo Beer et al. (2010), para o caso de paredes finas $(h<10 b)$, vale 0,333 .

Analisando o trecho $d x$, pode-se avaliar a presença de uma tensão de cisalhamento $\tau$ conforme mostrado na Figura 2.16.

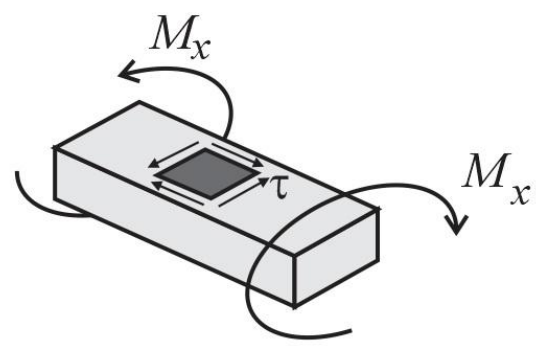

Figura 2.16 - Tensão de cisalhamento aplicada ao trecho $d x$

E para esse caso, a tensão de cisalhamento aplicada pode ser representada por

$$
\tau=\frac{M_{x}}{c_{1} b h^{2}}
$$

Onde $b$ e $h$ são as dimensões da seção da estrutura (Figura 2.15) e $c_{1}$ é um coeficiente para barras retangulares em torção, que segundo Beer et al. (2010), para o caso de paredes finas, vale 0,333 . 
Substituindo (2.73) em (2.72), chega-se a

$$
U_{\theta}=\int_{0}^{\phi} \frac{\tau^{2} c_{1}^{2} b^{2} h^{4}}{c_{2} b h^{3} G} d x
$$

Logo,

$$
U_{\theta}=\frac{c_{1}^{2} b h}{c_{2} G} \int_{0}^{L} \tau^{2} d x=\frac{c_{1}^{2} b h L}{c_{2} G} \tau^{2}
$$

\subsubsection{Primeira lei da termodinâmica}

Van Wylen \& Sonntag (1970) definem a Primeira Lei da Termodinâmica afirmando que, para um sistema, a integral cíclica do calor é igual à integral cíclica do trabalho.

$$
\oint \delta Q=\oint \delta W
$$

Sendo que, quando aplicado a sistemas com mudança de características, muitas vezes parte do calor se converte em uma variação de energia, chegando a:

$$
\oint \delta Q-\oint \delta W=\oint d E
$$

A energia é a soma da energia cinética, energia potencial e energia interna do sistema, levando a equação à forma:

$$
\oint \delta Q-\oint \delta W=\oint\left[\frac{1}{2} V^{2}+g z+u\right] \rho d V o l
$$

Onde:

$\delta Q$ é a variação da quantidade de calor

$\delta W$ é a variação da quantidade de trabalho

$V$ é a velocidade do volume considerado

$g$ é a aceleração da gravidade

$z$ é a posição vertical do volume considerado 
$u$ é a energia interna

$\rho$ é a densidade do material do volume considerado

Schulz (2003) afirma ainda que a variação da energia térmica pode ser expressa pela equação (2.77).

$$
\partial Q=m c \partial T=\rho(d x d y d z) c \partial T
$$

onde:

$c$ é o calor específico do material considerado

$\partial T$ é a variação de temperatura

Para o caso da viga a ser analisada, pode-se afirmar que o sistema é fechado e as energias envolvidas na equação (2.78) não apresentam variação considerável.

Inicialmente será analisado o caso de uma deflexão estática da estrutura, portanto sem velocidade envolvida. Dessa forma a energia cinética é zero. Também não há variação na posição de nenhuma parte da estrutura, podendo-se ignorar a variação na energia potencial. E finalmente, como se trata da análise de uma estrutura (portanto um sólido), a energia interna também pode ser omitida dos cálculos.

Da mesma forma pode ser adaptada a equação (2.79) para o caso em questão, de tal forma que, para a viga representada nas Figuras 2.13 e 2.15, pode-se escrever que, para a região analisada, tem-se:

$$
\partial Q=\rho(h b d x) c \partial T
$$

Logo, substituindo a equação (2.80) na (2.78), e omitindo os termos do lado direito, conforme explicado anteriormente, tem-se a equação de energia aplicada à viga em questão.

$$
\oint \delta W=\int \rho(h b d x) c \partial T
$$

Analisando as equações (2.69) e (2.75), pode-se afirmar que, pela Lei da Conservação da Energia (Schulz, 2003), desprezando as perdas, toda a energia envolvida nas tensões de flexão e torção $(U)$ são convertidas em trabalho $(W)$, portanto, substituindo as equações supracitadas em (2.81), tem-se, para flexão e torção, respectivamente: 


$$
\begin{gathered}
\sigma^{2} \frac{b h^{3}}{12}\left[\frac{b h L^{3}}{18 x^{2} E I}+\frac{1}{5 G L}\right]=\int_{0}^{L} \rho(h b d x) c \partial T \\
\frac{c_{1}^{2} b h L}{c_{2} G} \tau^{2}=\int_{0}^{L} \rho(h b d x) c \partial T
\end{gathered}
$$

Calculando a integral ao longo da viga para cada caso, tem-se a equação de variação de temperatura (em graus celsius) para flexão (2.84) e torção (2.85).

$$
\begin{gathered}
\Delta T_{h}=\sigma^{2} \frac{h^{2}}{12 \rho c}\left[\frac{b h L^{2}}{18 x^{2} E I}+\frac{1}{5 G L^{2}}\right] \\
\Delta T_{\theta}=\tau^{2} \frac{c_{1}^{2}}{c_{2} G \rho c}
\end{gathered}
$$

Tais equações serão posteriormente aplicadas no caso da estrutura a ser estudada. 
Intencionalmente em branco 


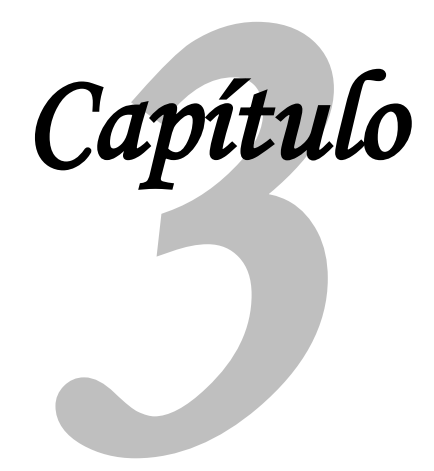

\section{Materiais e métodos}

Para a realização desse trabalho, foi utilizada uma estrutura na qual foram feitas várias simulações e testes, de forma a se conhecer suas propriedades, para enfim realizar os testes em túnel de vento, visando à validação do método já citado.

A estrutura utilizada é uma asa ligada a um suporte flexível, já utilizado em trabalhos anteriores do Departamento de Engenharia Aeronáutica da Escola da Engenharia de São Carlos (EESC - USP). Foi realizado um intenso trabalho de engenharia reversa, de forma a conhecer e validar as características dessa estrutura. Suas metodologias detalhadas, resultados e características são apresentados no Capítulo 4 deste trabalho.

Os materiais utilizados no trabalho são citados com sua respectiva fonte a seguir, e quando for o caso, são detalhados no capítulo que demonstra sua utilização.

\subsection{Aeroelasticidade}

\subsubsection{Estrutura utilizada}

Conforme já descrito, a estrutura utilizada foi aproveitada de outros trabalhos já realizados no Departamento, portanto já estava construída, necessitando de poucos ajustes de montagem e manutenção.

Em suas medições diretas foram utilizados instrumentos comuns de medição já disponíveis no laboratório, como paquímetro, réguas graduadas, balanças, etc. 


\section{Simulações}

Foram realizadas várias simulações ao longo do trabalho, como simulações estruturais, pelo método dos elementos finitos. Para tal foi utilizando o software Nastran 2010 para processamento, e o pacote Patran 2010 para pré- e pós-processamento, cujas licenças eram de propriedade do Departamento.

Para simulações utilizando CFD foram utilizados os softwares ICEM para criação da malha e CFX para processamento e análise dos dados. Ambos os programas pertencem ao pacote ANSYS 13.0, também de propriedade do Departamento.

Algumas subrotinas também foram feitas utilizando o software Matlab 2010a, cuja licença é livre no campus da Universidade.

\section{Ensaios}

Os ensaios de rigidez foram realizados utilizando infraestrutura do Departamento, que dispõe de mesa rígida para fixação da estrutura, polias e massas de peso conhecido, além dos instrumentos de medição necessários.

O ensaio para análise modal também foi realizado na mesma infraestrutura, que contava com acelerômetro, amplificadores de sinal, martelo de impacto, cartão de interface e laptop com entrada PCMCIA. Para análise e armazenamento dos dados foi utilizado o software SignalCalc 4.0. Todos os itens de propriedade do Laboratório de Aeroelasticidade, Dinâmica de Voo e Controle (LADinC).

Para o ensaio modal utilizando imageamento infravermelho, foi utilizada a infraestrutura do Laboratório de Dinâmica, no Departamento de Engenharia Mecânica da mesma instituição, que contava com fixação apropriada para a estrutura, shaker, acelerômetro, amplificadores de sinal, cartão de interface e laptop com o software SignalCalc 240 Dynamic Signal Analyzer. Para este ensaio foi utilizada uma câmera de imageamento infravermelho modelo FLIR E40 cedida por uma clínica veterinária de equinos, que dispõe deste dispositivo para detecção de inflamações em tecidos vivos.

Para o ensaio de detecção de flutter, foi utilizado um soprador de circuito aberto do Laboratório de Aerodinâmica do Departamento de Engenharia Aeronáutica da Universidade, 
foi utilizada ainda uma câmera de imageamento infravermelho modelo FLIR P620, adquirida por empréstimo de uma empresa privada.

\section{Recursos computacionais, material de consumo e de consulta}

Os materiais de consumo utilizados, tais como papel, tinta de impressora, etc., foram cedidos pelo próprio Departamento ou pelo Departamento de Engenharia Mecânica da Universidade Federal de São Carlos (UFSCar), onde o doutorando é docente. Os recursos computacionais utilizados foram do Departamento onde o doutorando realiza o trabalho ou na instituição onde é docente, além dos recursos próprios do doutorando.

Para a análise dos dados do trabalho e confecção de relatórios e textos técnicos, foi utilizado o pacote Microsoft Office 2007, de propriedade do doutorando.

Materiais de consulta, como livros ou pesquisas em internet foram utilizados os recursos próprios do doutorando e os das bibliotecas da EESC e da UFSCar, bem como recursos do Departamento.

\subsection{Metodologia}

Com a estrutura já existente, foi realizada uma análise teórico-experimental na mesma, cujo resultado foi o levantamento de todas as características relevantes da estrutura, seu modelamento e a validação de todos os dados, para posterior ensaio em túnel de vento. Foi previsto que todos os modelos teóricos fossem verificados experimentalmente e que os dados obtidos tivessem consistência adequada.

Com a estrutura devidamente caracterizada, foi realizado um ensaio modal utilizando imageamento infravermelho, comparando-se com os dados obtidos até então via modelamento e via ensaio modal com aquisição de dados por acelerômetro. Essa análise valida a metodologia para aplicações mais simples (sem componente aerodinâmica).

Finalmente foi realizado um ensaio em túnel de vento nas condições de flutter do conjunto, verificando a detecção da ocorrência do fenômeno através de imageamento infravermelho, validando o método. 
A metodologia seguida no trabalho é esquematizada na Figura 3.1.

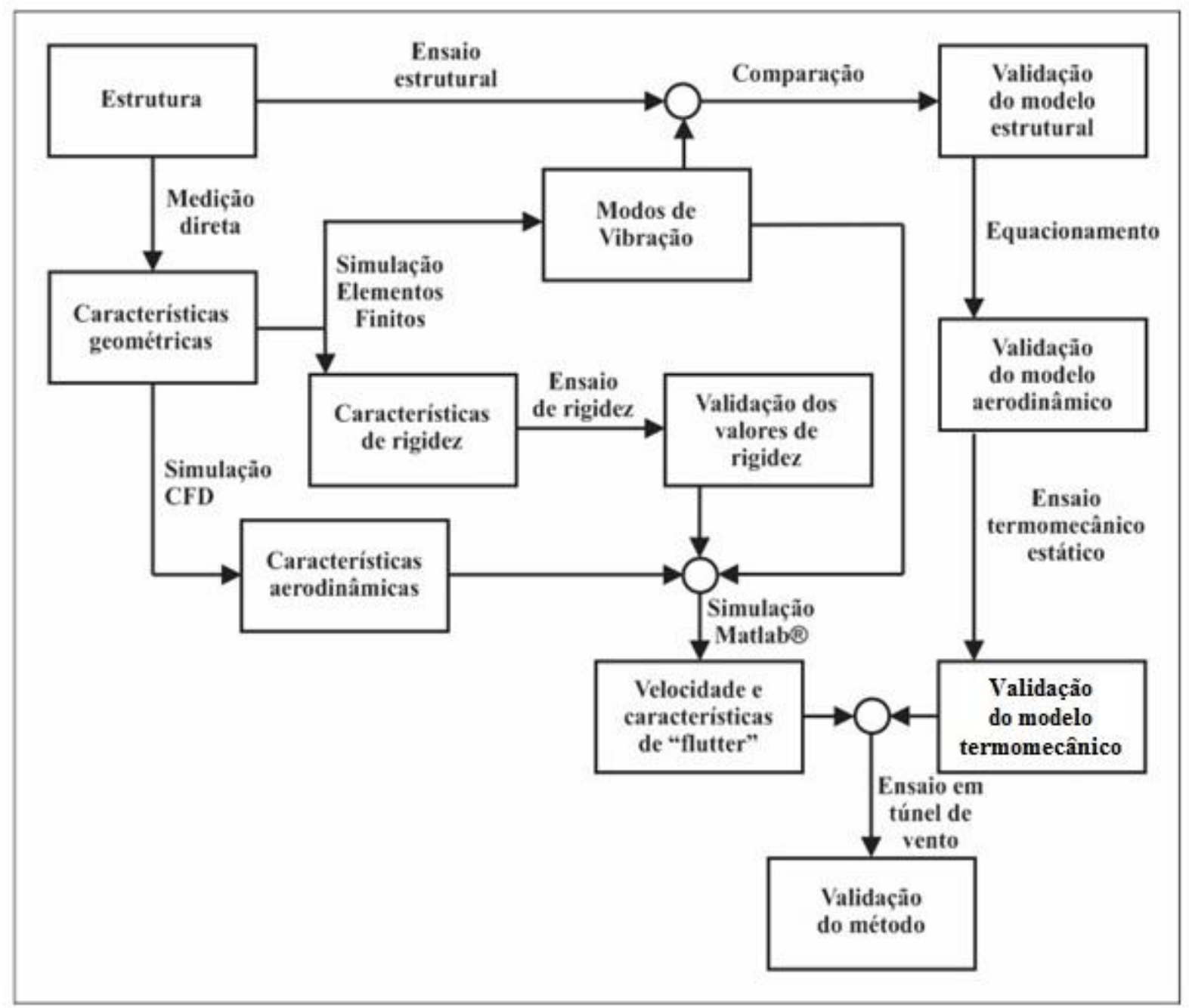

Figura 3.1 - Fluxograma de atividades para dimensionamento e validação dos modelos utilizados 


\section{Determinação das características da estrutura}

\subsection{Estrutura a ser utilizada}

Neste capítulo será apresentada a estrutura utilizada no trabalho, bem como todas as simulações e ensaios nela realizados durante o trabalho de engenharia reversa com a finalidade de se obter as características da mesma. Serão mostradas todas as etapas realizadas, seus resultados e verificação dos mesmos através de ensaios.

A estrutura utilizada neste trabalho foi concebida para a realização dos projetos de Rocha (2003) e de De Marqui Jr. (2004). Ela consiste em uma asa acoplada a uma base flexível onde, nos ensaios em túnel de vento, apenas a asa é exposta ao escoamento. A Figura 4.1 mostra um esquema da estrutura citada, de sua montagem e fotos da mesma.

A asa é feita de alumínio 2024T e possui perfil NACA 0012, com envergadura de $800 \mathrm{~mm}$ e corda de $450 \mathrm{~mm}$. Tais dimensões foram limitadas pelo tamanho da câmara de ensaios do túnel de vento utilizado nos trabalhos para a qual foi concebida.

A base flexível é um modelo proposto por Dansberry et al (1993), cujo dimensionamento afeta diretamente as frequências naturais e os modos de vibrar são suficientemente desacoplados, de forma a ser possível trabalhar em cada um deles afetando minimamente os outros.

Com a estrutura já existente, foi realizada uma análise teórico-experimental na mesma, cujo resultado foi o levantamento de todas as características relevantes da estrutura, seu modelamento e a verificação de todos os dados, para posteriores ensaios utilizando tecnologia infravermelho. 

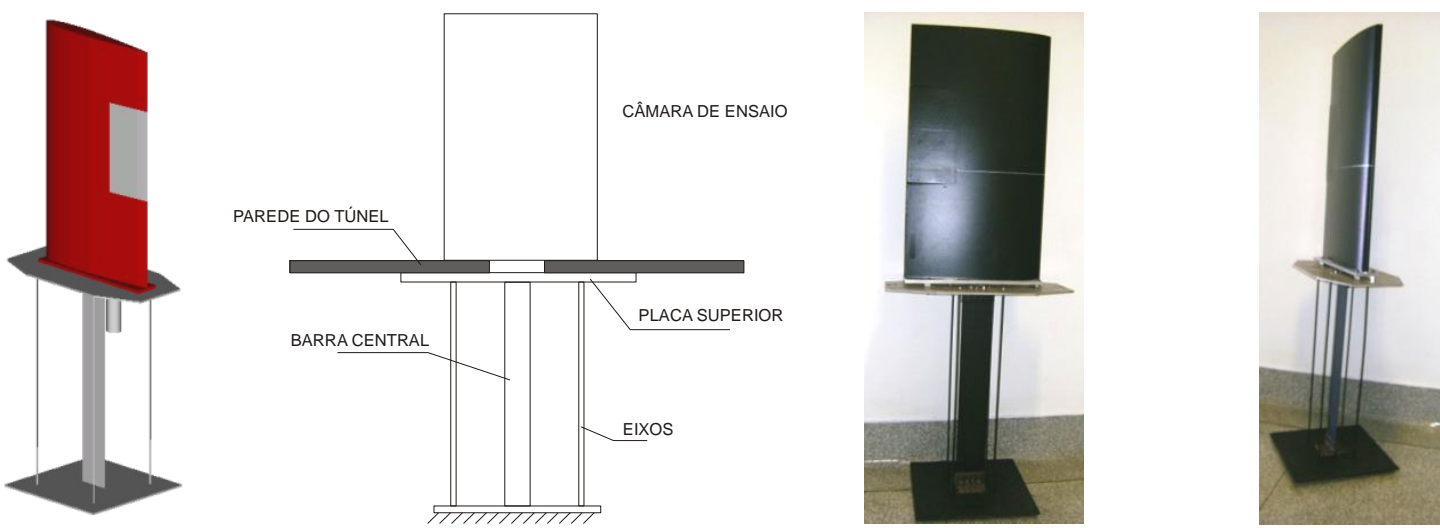

Figura 4.1 - Desenho em CAD da estrutura acoplada à asa, esquema de sua montagem no túnel de vento e fotos do conjunto montado

Durante a utilização da estrutura nos trabalhos para o qual ela foi construída, todas essas características foram mapeadas. Por ser a estrutura muito sensível a desvios na montagem, e por estar sendo usada em condições diferentes da utilizada anteriormente (sem atuadores dentro da asa), faz-se necessária essa verificação e levantamento das características.

\subsection{Características geométricas da estrutura}

As primeiras características obtidas da estrutura foram por medição direta utilizando régua graduada ou paquímetro. A Tabela 4.1 mostra os dados obtidos.

Tabela 4.1 - Dados medidos na estrutura

\begin{tabular}{|c|c|c|c|}
\hline Elemento & Material & \multicolumn{2}{|c|}{ Dimensões [mm] } \\
\hline \multirow[t]{3}{*}{ Barra central } & Aço 1020 & Comprimento & 700 \\
\hline & & Largura & 100 \\
\hline & & Espessura & 2 \\
\hline Eixos & Aço 1020 & Diâmetro & 5,5 \\
\hline \multirow[t]{3}{*}{ Placa superior } & Alumínio 2024T & Espessura & 5,8 \\
\hline & & Largura & 300 \\
\hline & & Comprimento & 600 \\
\hline \multirow[t]{2}{*}{ Asa } & Alumínio 2024T & Envergadura & 800 \\
\hline & & Corda & 450 \\
\hline
\end{tabular}


Tais dimensões serão utilizadas na construção de modelos para simulação em CFD e pelo método dos elementos finitos.

\subsubsection{Cálculo da massa e posição do CG}

Para o cálculo de algumas características aerodinâmicas, será necessária a massa e posição do centro de gravidade do aerofólio ao longo de sua corda. Para isso, considerando que o aerofólio é homogêneo e possui corda constante, foi desenvolvido um método numérico em excel dividindo-se a corda do aerofólio em pequenos trechos e calculando a área de cada trecho, conforme mostrado na Figura 4.2.

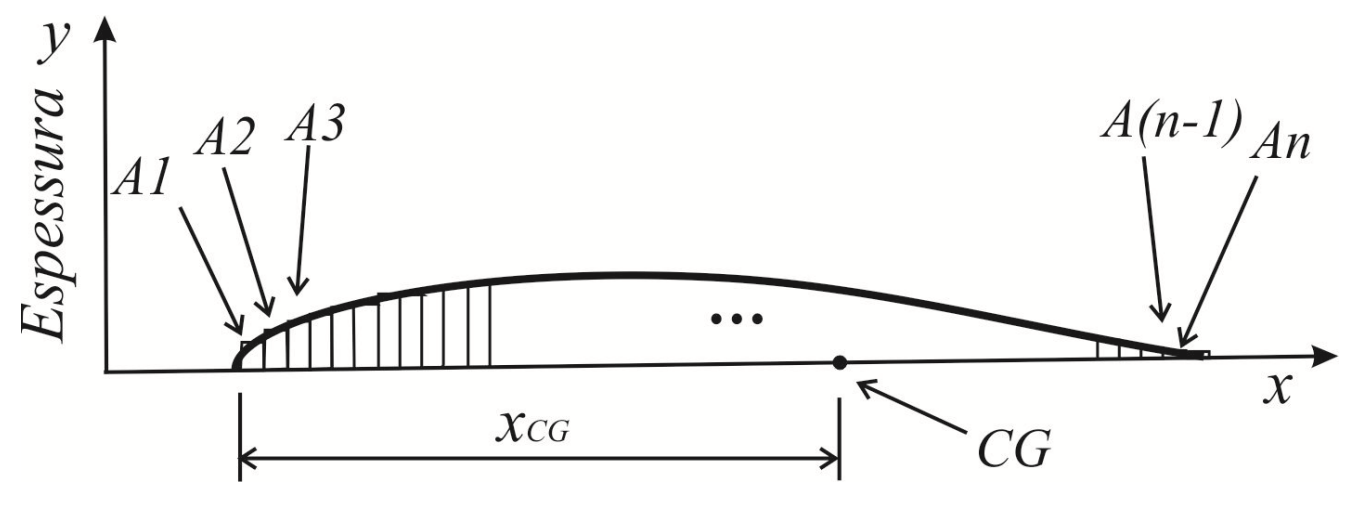

Figura 4.2 - Determinação da posição do CG

Foi localizado o ponto médio dessas áreas, ou seja, o ponto em que a soma dessas áreas era metade da área total, e ali foi considerado o centro de gravidade do aerofólio, que fica a $41 \%$ da corda do mesmo.

A massa da asa e do suporte foram medidas separadamente, sendo a primeira 11,970 kg, e a segunda $13,310 \mathrm{~kg}$.

\subsection{Características aerodinâmicas do aerofólio}

Foi realizada uma simulação em CFD do aerofólio para o levantamento de alguns dados que possibilitarão o cálculo de características aerodinâmicas importantes, utilizadas no modelo matemático. Tais propriedades e seus cálculos são apresentados a seguir. 


\subsubsection{Centro aerodinâmico e centro de pressão}

Houghton \& Carpenter (2004) fornecem a definição destes pontos conforme descrito abaixo.

Centro aerodinâmico $(C A)$ é um ponto específico do aerofólio em que o valor do momento de arfagem em torno do mesmo é constante, independente do seu coeficiente de sustentação, $C_{L}$. Para um aerofólio simétrico, ele se localiza sobre a corda média aerodinâmica, a $25 \%$ do valor da corda, a partir do bordo de ataque.

Centro de pressão $(C P)$ é um ponto onde as cargas atuantes na seção do aerofólio (sustentação, arrasto e momento de arfagem) podem ser resumidas em apenas duas: sustentação e arrasto. Ou seja, o momento de arfagem é nulo. A localização deste ponto não necessariamente se localiza dentro da geometria do aerofólio. A Figura 4.3 mostra um esquema com o $\mathrm{CA}$, o $\mathrm{CP}$ e as cargas atuantes.
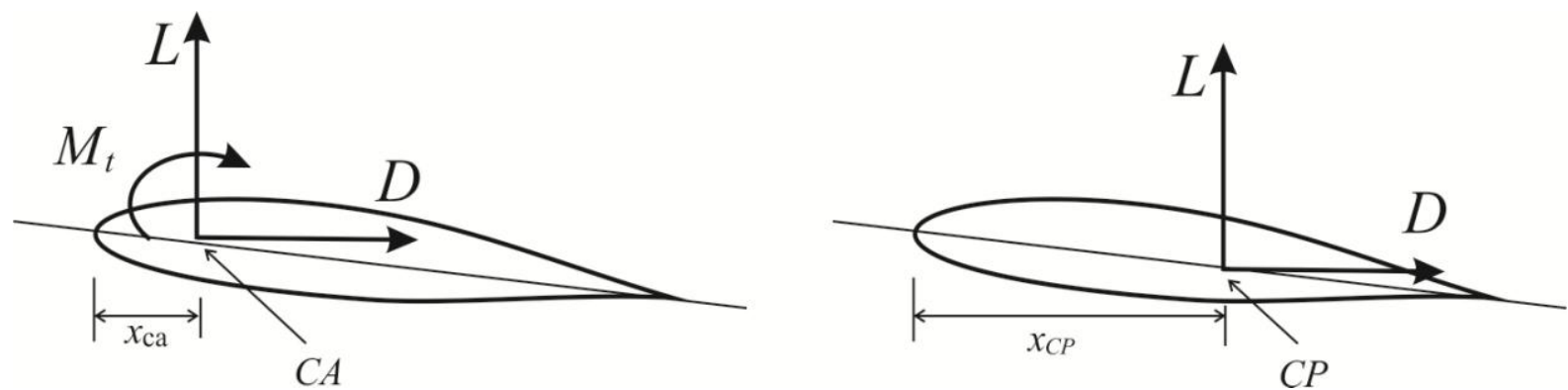

Figura 4.3 - Ilustração das definições de centro aerodinâmico e centro de pressão

Anderson (1991) afirma que, para um aerofólio simétrico, a posição desse ponto não varia com o ângulo de ataque, e para a localização do mesmo, foi realizada uma simulação em CFD com 5 graus de ângulo de ataque, de onde se obtiveram as informações buscadas. A Figura 4.4 mostra a malha utilizada na simulação, detalhando seu grau de discretização. Para isso foi utilizada uma malha estruturada, em formato tetraédrico na região do fluido e formato triangular na superfície da asa.

Pode-se observar pela figura que o bordo de ataque e o bordo de fuga tiveram um refinamento diferente da malha, devido à geometria dessas regiões, a fim de se obter os resultados mais precisos possíveis. 

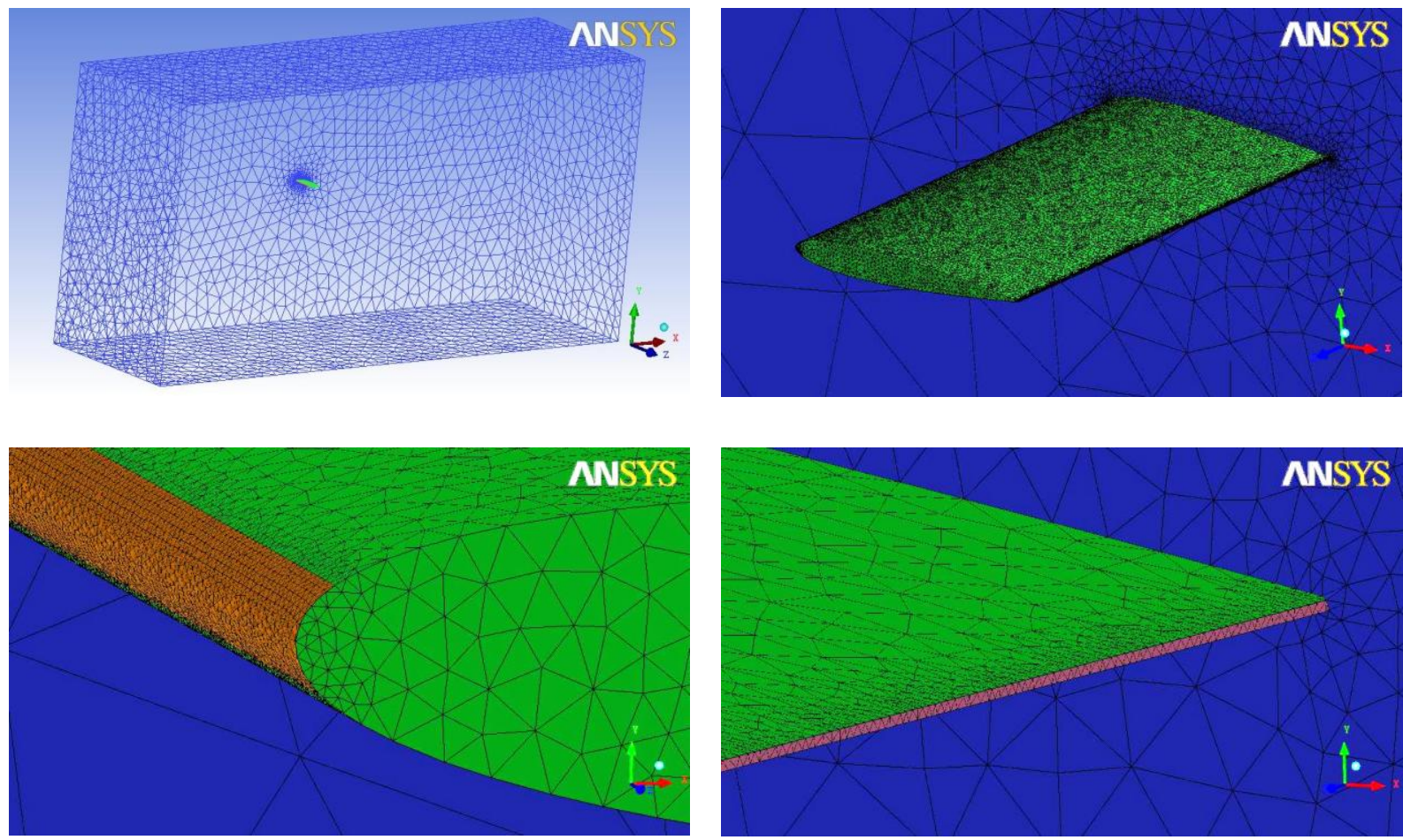

Figura 4.4 - Malha utilizada na simulação em CFD

A Figura 4.5 mostra o resultado da simulação, detalhando a distribuição de pressão em volta do aerofólio.

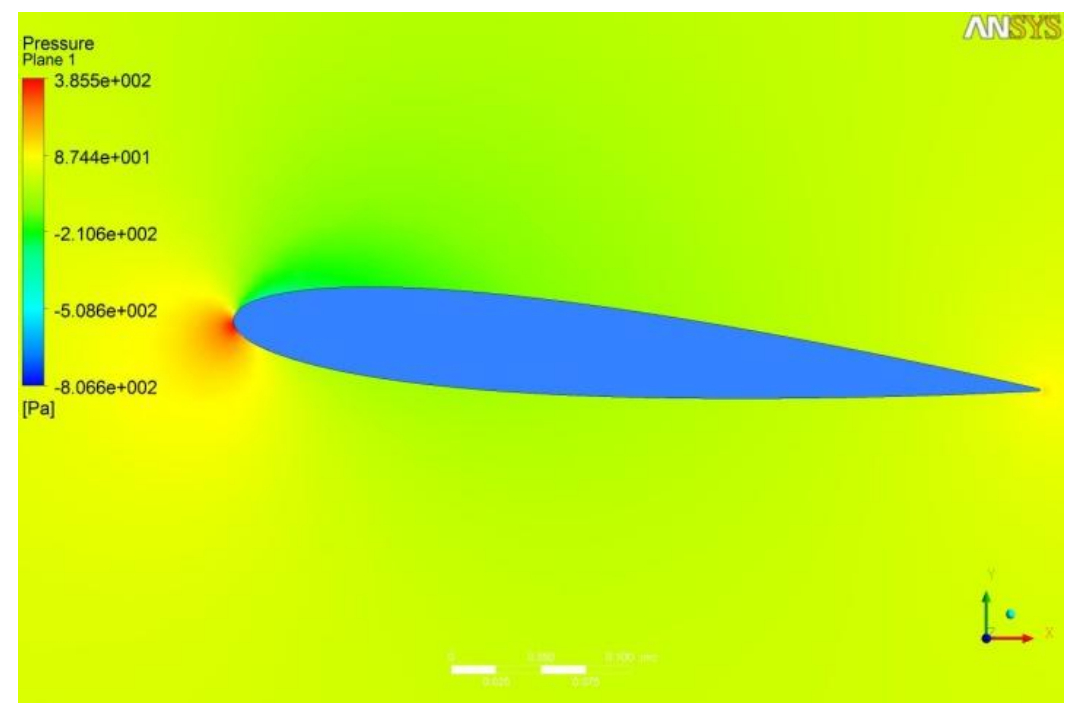

Figura 4.5 - Resultado da simulação em CFD da asa

Como resultados da simulação, foi possível se obter, entre outras informações, a sustentação gerada pelo aerofólio e seu momento em torno do centro aerodinâmico, mostrados a seguir. 


$$
\begin{aligned}
& L=23,099 N \\
& M=1,882 N . m
\end{aligned}
$$

Pela definição de centro de pressão e centro aerodinâmico, foi possível se calcular a distância entre eles $(\ell)$.

$$
\ell=\frac{M}{L}=\frac{1,882}{23,099}=0,0815 \mathrm{~m}=81,5 \mathrm{~mm}
$$

como mostrado na Figura 4.6.

Considerando o centro aerodinâmico a $25 \%$ da corda (Houghton \& Carpenter, 2004) e o valor da corda de 450 milímetros, pode-se obter a posição de ambos os pontos a partir do bordo de ataque.

$$
\begin{aligned}
& x_{c a}=0,25 \times 450=112,5 \mathrm{~mm} \\
& x_{c p}=x_{c a}-\ell=112,5-81,5=31 \mathrm{~mm}
\end{aligned}
$$

A Figura 4.6 mostra as posições do $C A$ e do $C P$ representadas a partir do bordo de ataque do aerofólio

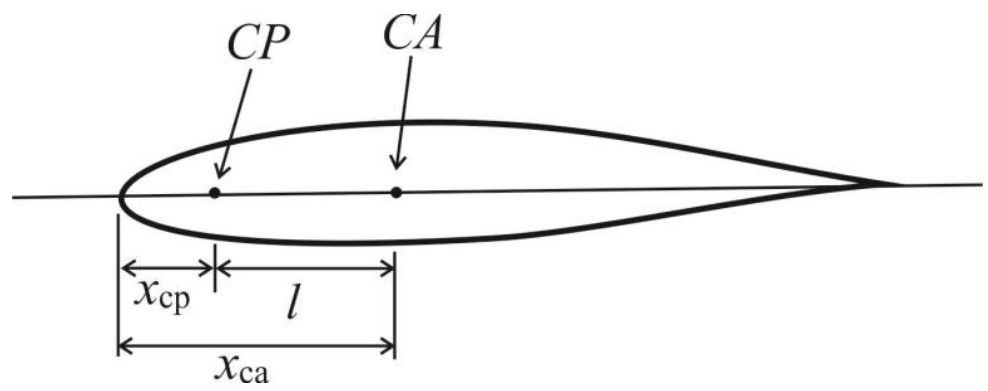

Figura 4.6 - Posições do centro aerodinâmico e centro de pressão

A partir destes resultados da mesma simulação, outras características aerodinâmicas puderam ser obtidas, conforme mostrado adiante.

\subsubsection{Coeficientes de sustentação e momento de arfagem}

Da mesma forma o aerofólio foi simulado utilizando CFD em vários ângulos de ataque, obtendo-se sua sustentação e seu momento de arfagem, conforme mostrado na Figura 4.7. 

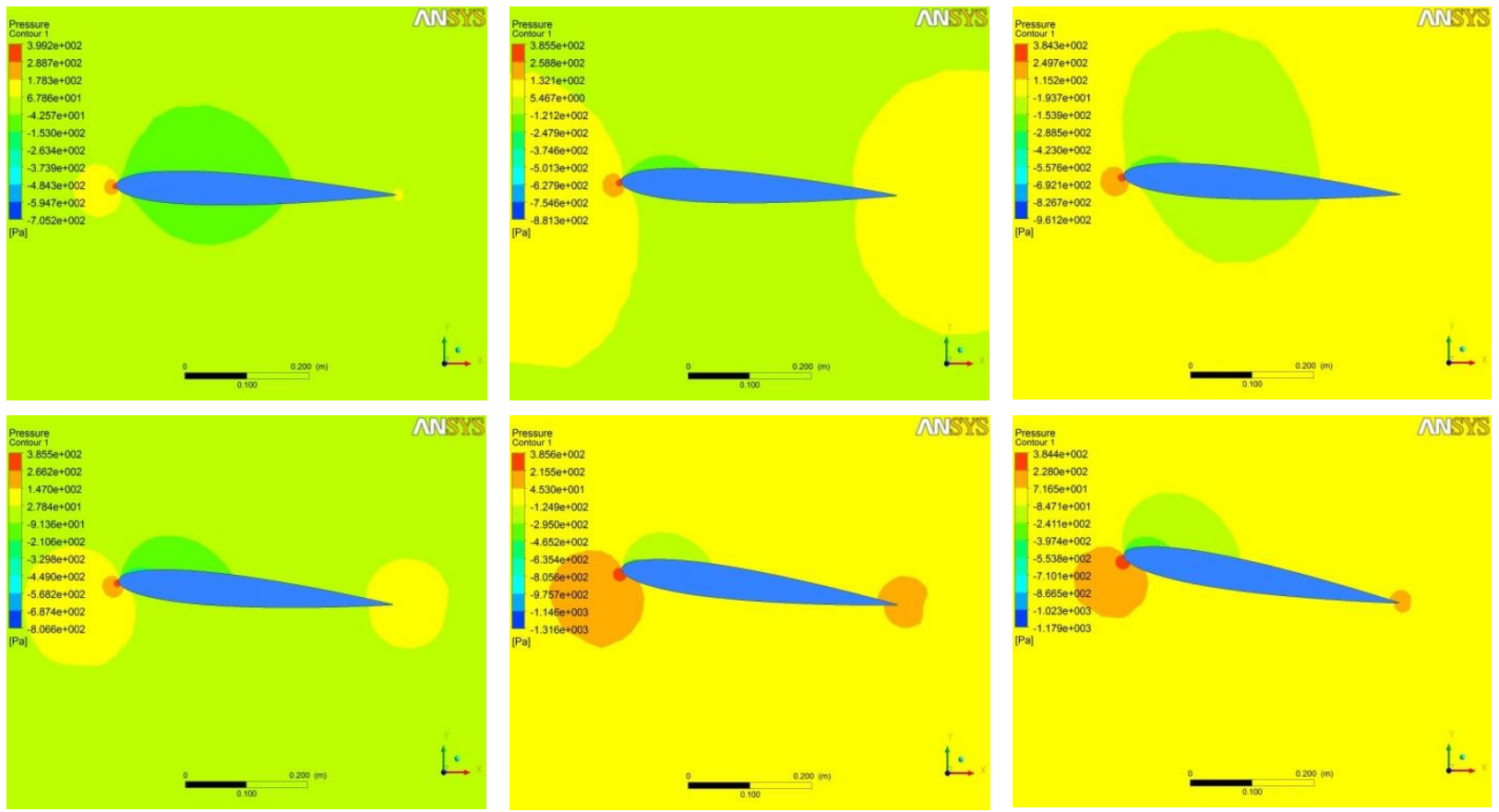

Figura 4.7 - Resultado da simulação em CFD com vários ângulos de ataque

Com as informações obtidas nas simulações, em conjunto com as equações do coeficiente de sustentação e do coeficiente de momento (equações 4.4), fornecidas por Anderson (1991), foi possível obter-se os gráficos das Figuras 4.8 e 4.9.

$$
\begin{gathered}
C_{L}=\frac{L}{1 / 2 \rho V^{2} c b} \\
C_{M}=\frac{M}{1 / 2 \rho V^{2} c^{2} b}
\end{gathered}
$$

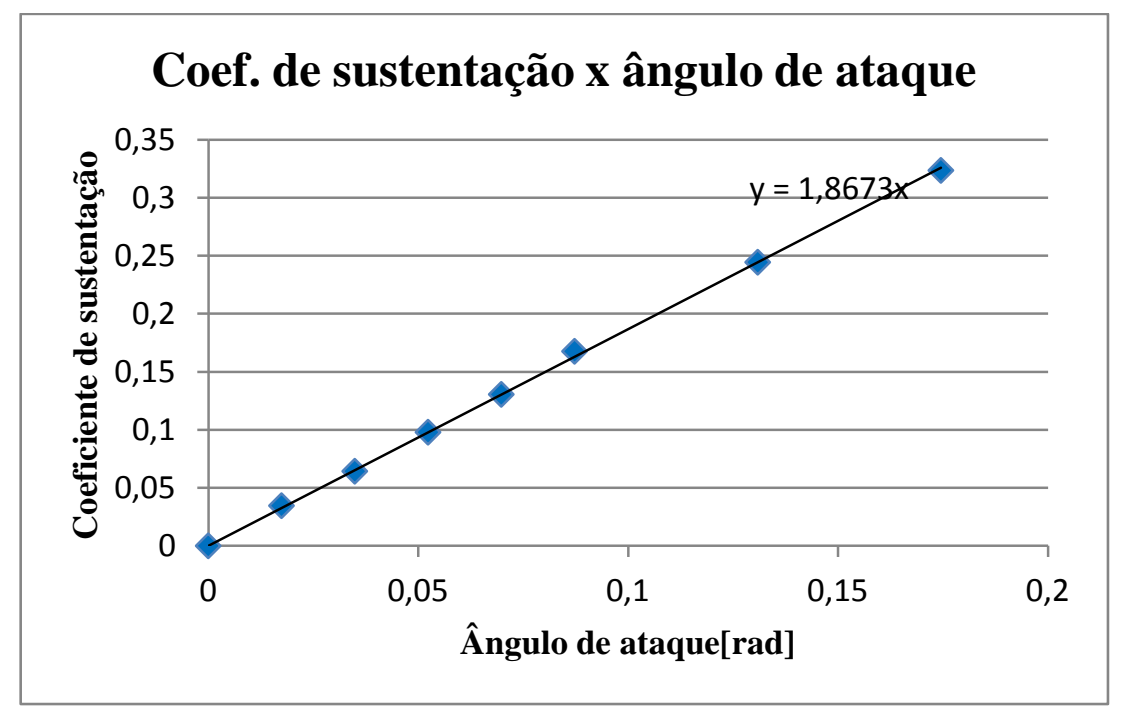

Figura 4.8 - Curva $\mathrm{C}_{\mathrm{L}} \mathrm{x} \alpha$ obtida por simulações de CFD 


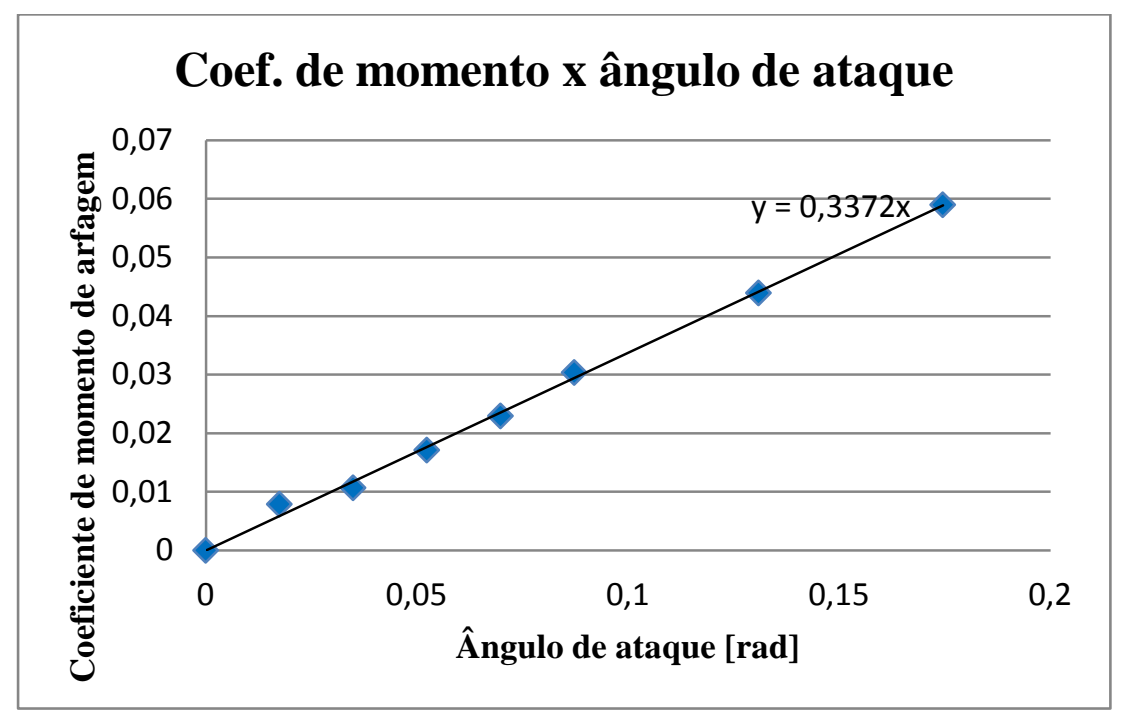

Figura 4.9 - Curva $\mathrm{C}_{\mathrm{M}} \mathrm{x} \alpha$ obtida por simulações de CFD

Pela inclinação das linhas de tendência, pode-se obter

$$
\begin{gathered}
C_{L \alpha}=1,8673 \mathrm{rad}^{-1} \\
C_{M \alpha}=0,3372 \mathrm{~m}^{-1} \mathrm{rad}^{-1}
\end{gathered}
$$

\subsubsection{Derivadas de estabilidade}

O Hoak \& Ellison (1965) apresentam métodos para a obtenção das derivadas de estabilidade utilizadas no modelo matemático que fornecerá as características de flutter da estrutura. Tais derivadas são $C_{L \dot{\alpha}}, C_{M \dot{\alpha}}, C_{L q}$ e $C_{M q}$.

O método fornece, para o cálculo de $C_{L \dot{\alpha}}$, a equação (4.6).

$$
C_{L \dot{\alpha}}=1,5\left(\frac{x_{c a}}{c}\right) C_{L \alpha}+3 C_{L}(g)
$$

onde $C_{L}(g)$ é a correção do coeficiente de sustentação devido ao Mach.

Tal equação vale para a condição subsônica e para valores tais que $0<\beta A<4$. Sendo que $\beta$ é dado por

$$
\beta=\sqrt{1-M^{2}}
$$


onde

$M$ é o número de Mach, que para a condição considerada (em torno de $25 \mathrm{~m} / \mathrm{s}$ ao nível do mar) equivale a 0,0754 ;

$A$ é a area da asa. Neste caso o produto entre a corda e a envergadura.

Dessa forma

$$
\beta=\sqrt{1-0,0754^{2}}=0,9971
$$

Logo,

$$
\beta A=\beta c b=0,9971 \times 0,45 \times 0,8=0,3590
$$

Que satisfaz a condição.

Assim pode-se calcular $C_{L}(g)$, que segundo a mesma referência é obtido pelo gráfico mostrado na Figura 4.10.

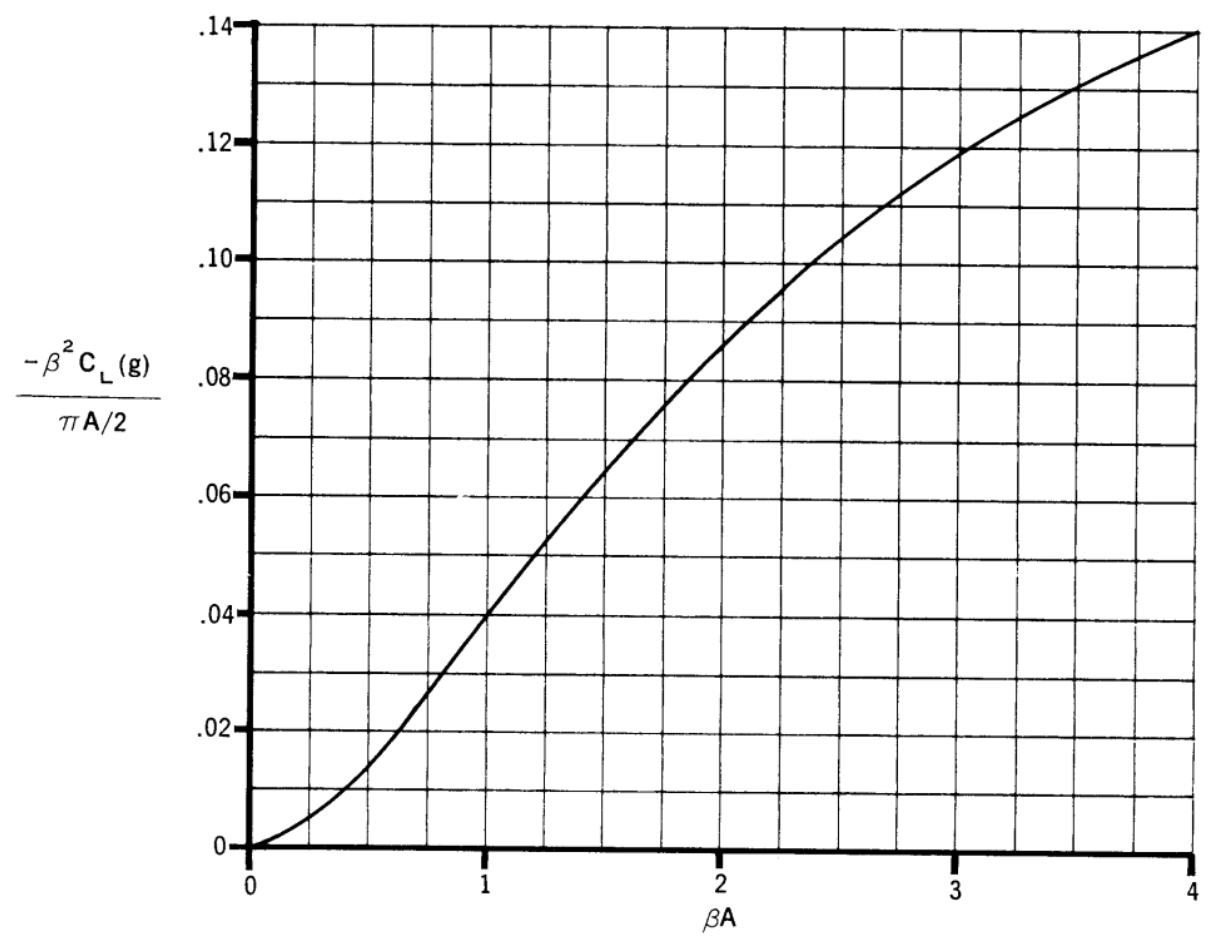

Figura 4.10 - obtenção de $C_{L}(g)$. Fonte: Hoak \& Ellison (1965) 
Do gráfico se obtém que

$-\frac{\beta^{2} C_{L}(g)}{\pi A / 2}=0,01 \Rightarrow-\frac{0,9971^{2} C_{L}(g)}{\pi \times 0,45 \times 0,8 / 2}=0,01 \Rightarrow C_{L}(g)=-0,00569 \mathrm{rad}^{-1}$

Logo, da equação (4.6)

$$
C_{L \dot{\alpha}}=1,5 \times 0,25 \times 1,925+3 \times(-0,00569) \Rightarrow C_{L \dot{\alpha}}=0,705 \mathrm{rad}^{-1}
$$

A mesma referência cita que, para o cálculo de $C_{M \dot{\alpha}}$, nas mesmas condições de Mach e área da asa, utiliza-se a equação (4.12).

$$
C_{M \dot{\alpha}}=C_{M \dot{\alpha}}^{\prime \prime}+\left(\frac{x_{C G}}{C}\right) C_{L \dot{\alpha}}
$$

onde

$$
C_{M \dot{\alpha}}^{\prime \prime}=-\frac{27}{16}\left(\frac{x_{a c}}{c}\right)^{2} C_{L \alpha}+3 C_{M o}(g)
$$

Sendo que $C_{M o}(g)$ é o fator de correção do coeficiente do momento de arfagem devido ao Mach e é obtido do gráfico da Figura 4.11.

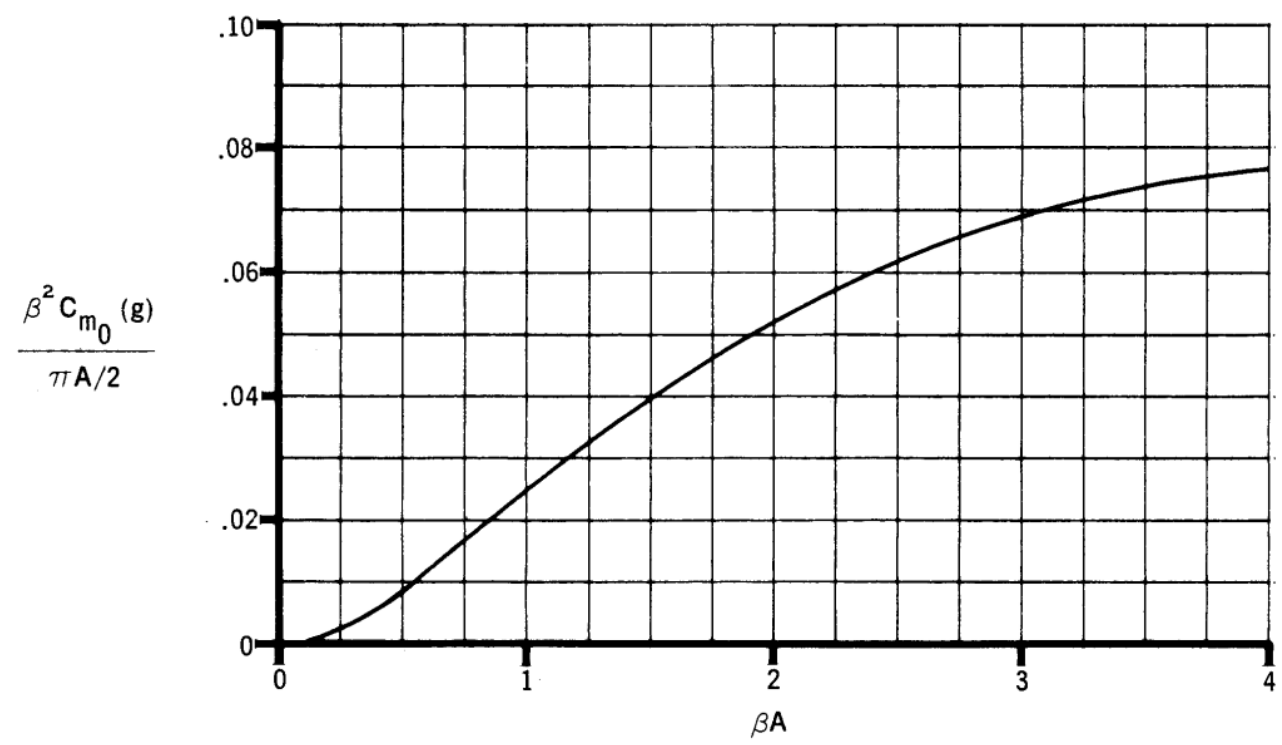

Figura 4.11 - obtenção de $C_{M_{0}}(g)$. Fonte: Hoak \& Ellison (1965) 
Analogamente ao caso anterior, pode-se calcular que

$$
C_{M o}(g)=0,00284 \mathrm{rad}^{-1}
$$

Logo, da equação (4.13)

$$
C_{M \dot{\alpha}}^{\prime \prime}=-\frac{27}{16} \times 0,25^{2} \times 1,925+3 \times 0,00284 \Rightarrow C_{M \dot{\alpha}}^{\prime \prime}=-0,195 \mathrm{rad}^{-1}
$$

E finalmente da equação (4.12)

$$
C_{M \dot{\alpha}}=-0,195+0,41 \times 0,705 \Rightarrow C_{M \dot{\alpha}}=0,0945 \mathrm{rad}^{-1}
$$

Para o cálculo de $C_{L q}$, a equação dada é

$$
C_{L q}=\left[\frac{1}{2}+2 \frac{\bar{x}}{c}\right] C_{L \alpha}
$$

onde $\bar{x}=x_{a c}-x_{C G}$

Logo

$$
C_{L q}=\left[\frac{1}{2}+2 \times(0,25-0,41)\right] 1,925 \Rightarrow C_{L q}=0,3465 \mathrm{rad}^{-1}
$$

Para o cálculo de $C_{M q}$ é fornecida a equação a seguir

$$
C_{M q}=-0,7 c_{\ell} \cos \Lambda c / 4\left\{\frac{A\left[\frac{1}{2} \frac{\bar{x}}{c}+2\left(\frac{\bar{x}}{c}\right)^{2}\right]}{A+2 \cos \Lambda c / 4}+\frac{1}{24}\left(\frac{A^{3} \tan ^{2} \Lambda c / 4}{A+6 \cos \Lambda c / 4}\right)+\frac{1}{8}\right\}
$$

Nesse caso, o enflechamento ( $\Lambda$ ) do aerofólio é zero e, segundo Abbot \& Von Doenhoff (1956), o perfil NACA 0012 possui $c_{\ell}=5,730 \mathrm{rad}^{-1}$. Logo

$$
C_{M q}=-0,4838 \mathrm{rad}^{-1}
$$

Assim sendo, pode-se criar a Tabela 4.2 com os valores encontrados para cada uma das variáveis anteriormente citadas 
Tabela 4.2 - Valores obtidos para as derivadas de estabilidade

\begin{tabular}{cc}
\hline Derivada & Valor $\left[\mathrm{rad}^{-1}\right]$ \\
\hline$C_{L \dot{\alpha}}$ & 0,705 \\
\hline$C_{M \dot{\alpha}}$ & 0,0945 \\
\hline$C_{L q}$ & 0,3165 \\
\hline$C_{M q}$ & $-0,4838$
\end{tabular}

\subsection{Simulação pelo método dos elementos finitos}

A estrutura foi simulada utilizando-se o método dos elementos finitos de forma a se obter as características de rigidez e os modos de vibrar.

Foi utilizado o pacote Patran x64 2010 e MD Nastran 2010 para a construção e processamento de um modelo estrutural. Para isso a estrutura foi dividida em elementos tipo Beam4 nos eixos, por permitir flexão ao longo do elemento, dando maior precisão aos resultados e Quad4 no restante da estrutura, pois são elementos elásticos em três dimensões que permitem o emprego de espessuras ao longo da estrutura. Ambos os elementos são considerados de boa precisão e custo computacional relativamente baixo (MSC.Software Corporation, 2000).

A região da asa foi modelada como sendo uma placa com variação de espessura ao longo da corda do aerofólio. Seu material é o alumínio e, devido às nervuras e espaços internos da asa, a densidade do material utilizada foi de $900 \mathrm{~kg} / \mathrm{m}^{3}$. Esse valor veio da medição da massa da asa e o cálculo do seu volume através de um software de CAD.

A condição de contorno imposta ao modelo foi a fixação em todos os graus de liberdade da extremidade inferior dos quarto eixos, dispostos de forma simétrica, e da barra central. A Figura 4.12 ilustra o modelo utilizado, detalhes da disposição dos elementos da estrutura e sua condição de contorno. 

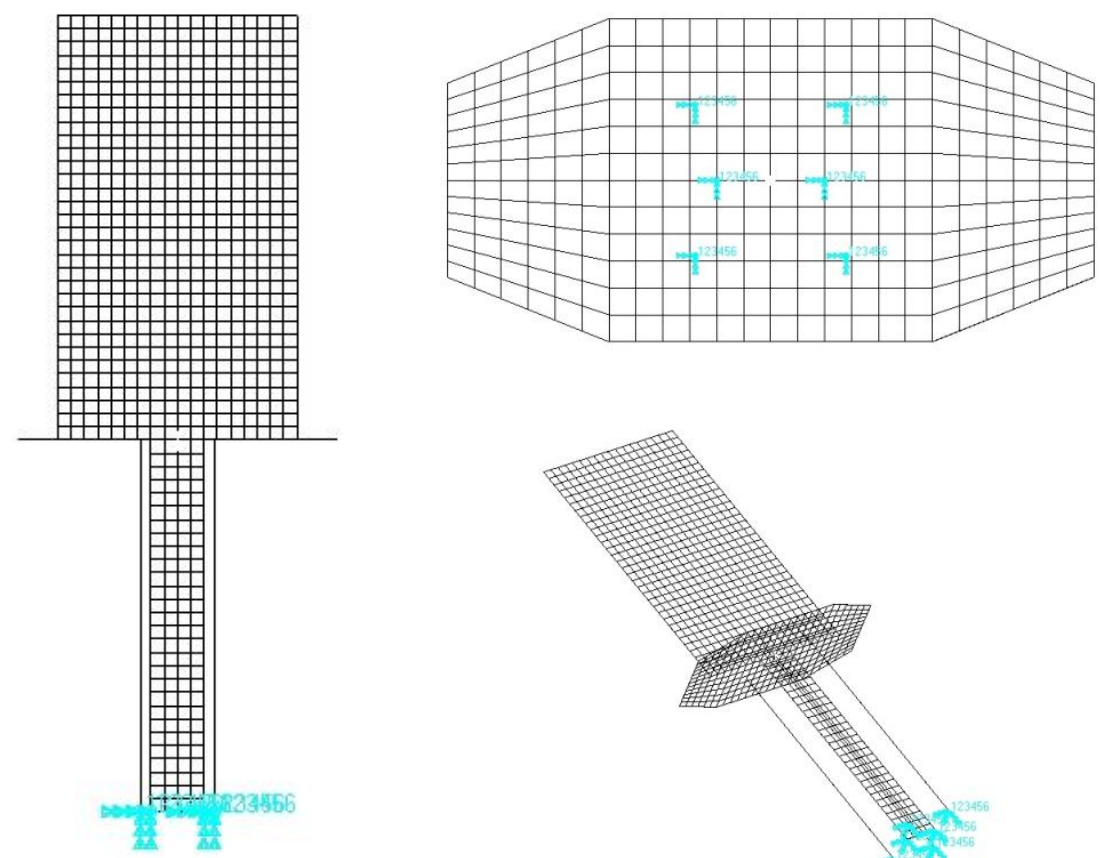

Figura 4.12 - Modelo estrutural simulado pelo método dos elementos finitos

Inicialmente foi realizada uma análise modal no modelo construído de forma a se obter os primeiros modos de vibrar da estrutura. Os 5 primeiros modos obtidos e suas respectivas frequências naturais são apresentados na Tabela 4.3 .

Tabela 4.3 - Modos de vibrar e suas respectivas frequências naturais

\begin{tabular}{ccc}
\hline Modo & Descrição & Frequência $[\mathbf{H z}]$ \\
\hline 1 & Primeiro modo de flexão & 1,56 \\
\hline 2 & Primeiro modo de torção & 2,60 \\
\hline 3 & Primeiro modo de flexão lateral & 15,17 \\
\hline 4 & Segundo modo de flexão \\
\hline 5 & Terceiro modo de flexão & 21,80 \\
& & 27,81 \\
\hline
\end{tabular}

E o formato de cada modo é apresentado nas Figuras 4.13 a 4.17. 
Patran 2010 64-Bit (MD Enabled) 21-May-14 11:11:05

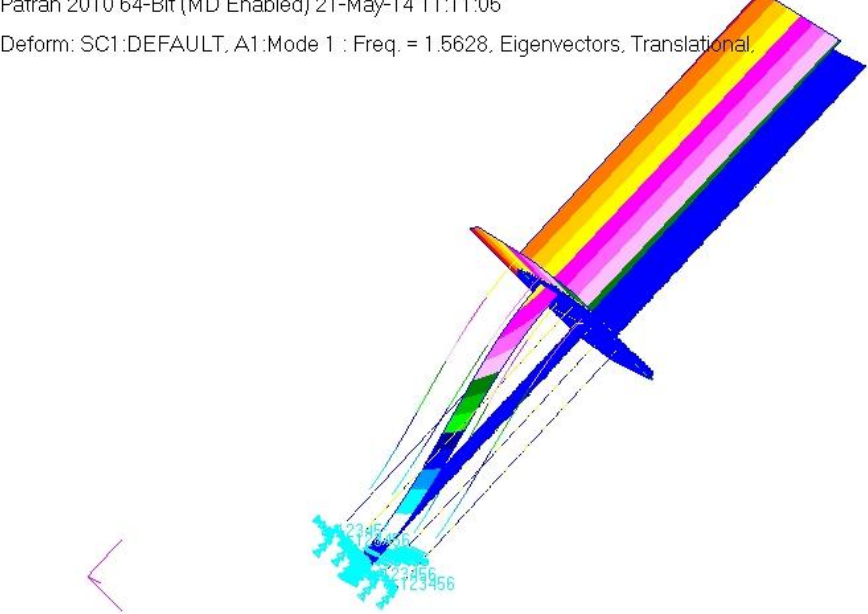

Figura 4.13 - Primeiro modo de vibrar a $1,56 \mathrm{~Hz}$

Patran 2010 64-Bit (MD Enabled) 21-May-14 11:10:42

Deform: SC1:DEFAULT, A1: Mode $2:$ Freq. $=2.5972$, Eigenvectors, Translational,

$$
\begin{aligned}
& 6.31-001 \\
& 5.89-001 \\
& 5.47-001 \\
& 5.05-001 \\
& 4.63-001 \\
& 4.21-001 \\
& 3.79-001 \\
& 3.37-001 \\
& 2.95-001 \\
& 2.53-001 \\
& 2.10-001 \\
& 1.68-001 \\
& 1.26-001 \\
& 8.42-002 \\
& 4.21-002 \\
& 0 .
\end{aligned}
$$

Figura 4.14 - Segundo modo de vibrar a 2,60 Hz

Patran 2010 64-Bit (MD Enabled) 21-May-14 11:10:24 


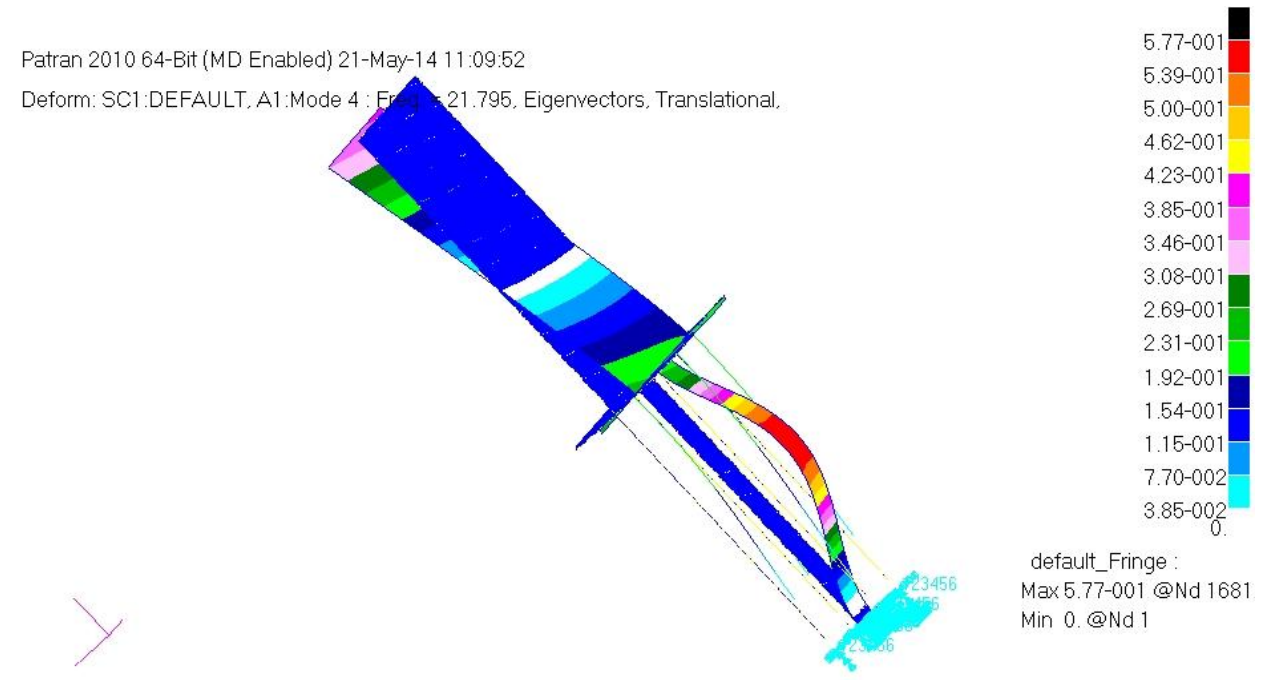

Figura 4.16 - Quarto modo de vibrar a $21,80 \mathrm{~Hz}$

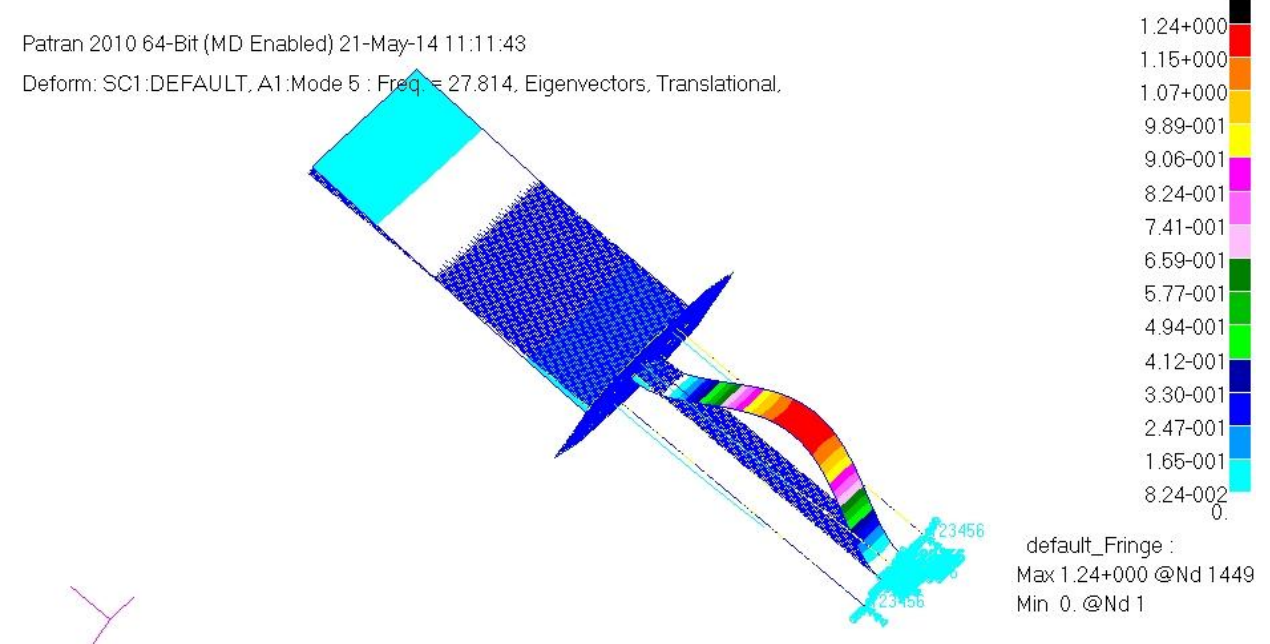

Figura 4.17 - Quinto modo de vibrar a $27,81 \mathrm{~Hz}$

Pode-se observar pelos resultados da simulação que os dois primeiros modos de vibrar possuem frequências naturais próximas entre si e distantes dos modos seguintes, caracterizando uma estrutura que pode ter uma tendência à ocorrência de flutter flexotorsional.

Em seguida foram realizadas duas simulações estáticas, inicialmente aplicando-se uma força conhecida na extremidade da estrutura e posteriormente aplicando-se um momento conhecido no mesmo ponto. Com isso foi medida a deformação da mesma e, considerando que em ambos os casos o material estava no regime elástico, foi calculada a rigidez torsional e flexional. As Figuras 4.18 e 4.19 mostram o resultado das simulações estáticas. 


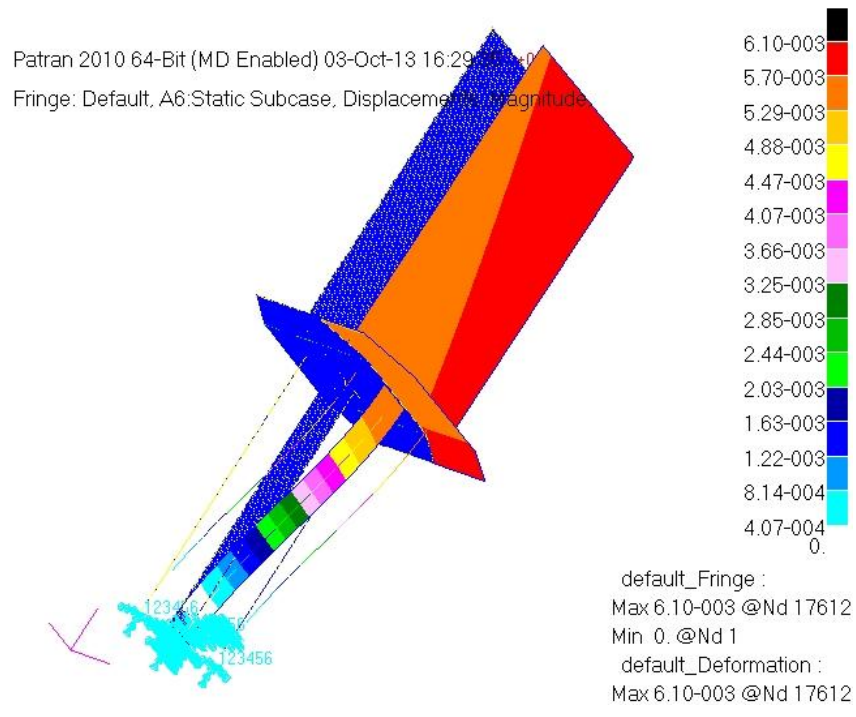

Figura 4.18 - Resultado da simulação estática flexional

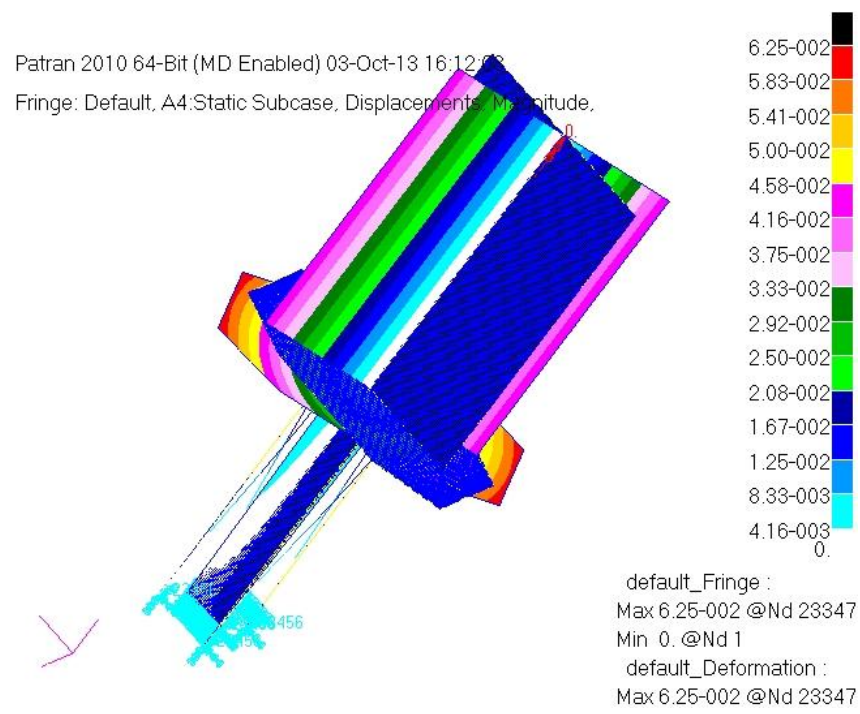

Figura 4.19 - Resultado da simulação estática torsional

A simulação confirmou que o centro de cisalhamento da estrutura completa (asa mais suporte flexível) encontra-se no centro da corda do aerofólio, posicionado por sua vez no centro da barra central, pois quando aplicada uma força flexional nesse ponto, a asa não apresentava torção. Isso se dá pelo fato de o suporte ser simétrico e a deformação da asa ser desprezível com relação à deformação do suporte.

Baseado nos dados obtidos na simulação foi possível o cálculo da rigidez flexional e torsional da estrutura. Para o primeiro caso, foi utilizada a equação a seguir. 


$$
P=k_{h} x
$$

onde:

$P$ é a força aplicada na estrutura (nesse caso, $5 \mathrm{~N}$ )

$k_{h}$ é a rigidez flexional

$x$ é o deslocamento da extremidade da estrutura (conforme observado no resultado da simulação, $6,1 \times 10^{-3} \mathrm{~m}$ )

Dessa forma o cálculo da rigidez é obtido por:

$$
k_{h}=\frac{5}{6,1 \times 10^{-3}}=820 \mathrm{~N} / \mathrm{m}
$$

Da mesma forma foi obtida a rigidez torsional

$$
M=k_{\theta} \theta
$$

onde:

$M$ é o momento aplicado na estrutura (nesse caso $10 \mathrm{~N} . \mathrm{m}$ )

$k_{\theta}$ é a rigidez torsional

$\theta$ é o ângulo deslocado na estrutura (dependente do deslocamento linear, $x$, e do tamanho da estrutura, $\ell$ )

Logo,

$$
k_{\theta}=\frac{M}{\theta}=\frac{M}{x / \ell}=\frac{10}{6,25 \times 10^{-2} / 0,3}=48 N . m
$$

\subsection{Ensaio de rigidez da estrutura}

De forma a verificar os dados de rigidez obtidos na simulação, foi realizado um ensaio que consistia em pendurar pesos de massa conhecida à estrutura e medir sua deformação, conforme o esquema da Figura 4.20. 

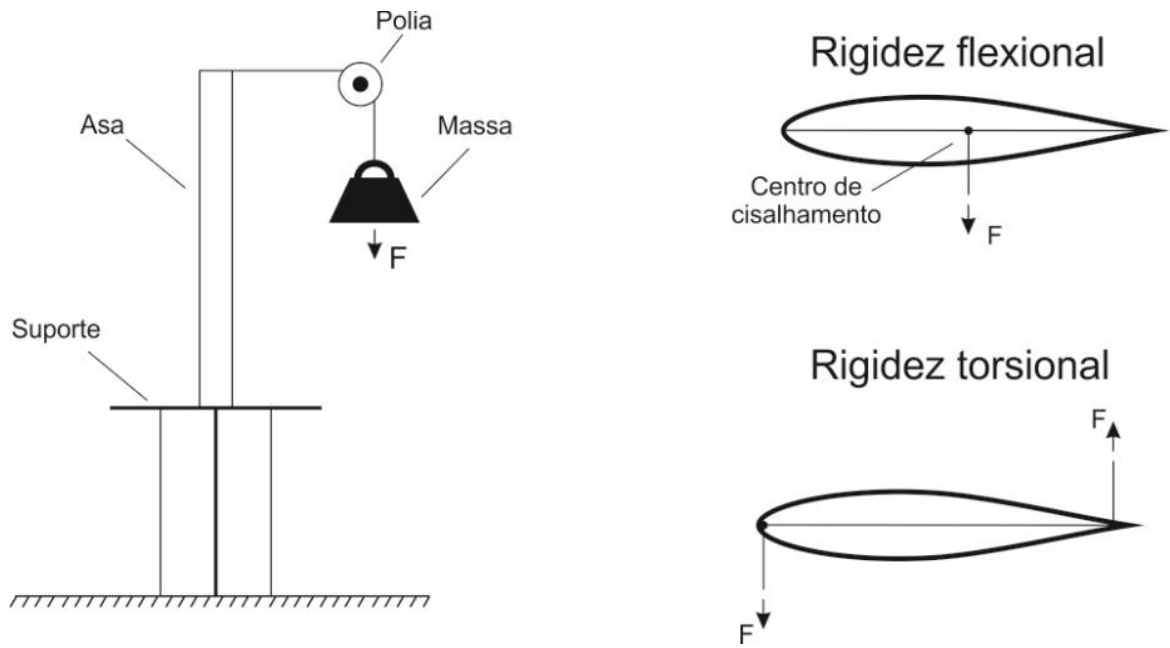

Figura 4.20 - Esquema do ensaio de rigidez

A estrutura ensaiada foi fixada em uma mesa rígida e foi montado um aparato experimental onde era possível se pendurar massas conhecidas em um sistema de polias e medir a deformação nos dois bordos da asa através de uma régua graduada.

Desses ensaios foram obtidos os seguintes dados para flexão (Tabela 4.4):

Tabela 4.4 - Resultados obtidos no ensaio de rigidez flexional

\begin{tabular}{cc}
\hline Carga $[\mathbf{k g}]$ & Deflexão $[\mathbf{m m}]$ \\
\hline 0 & 0 \\
\hline 0,557 & 7 \\
\hline 1,630 & 26,5 \\
\hline 0,195 & 34 \\
\hline 3,268 & 41,5 \\
\hline 4,412 & 45,5 \\
\hline
\end{tabular}

E analisando os dados foi possível traçar o gráfico abaixo, cuja linha de tendência fornece o valor da rigidez obtida experimentalmente. 


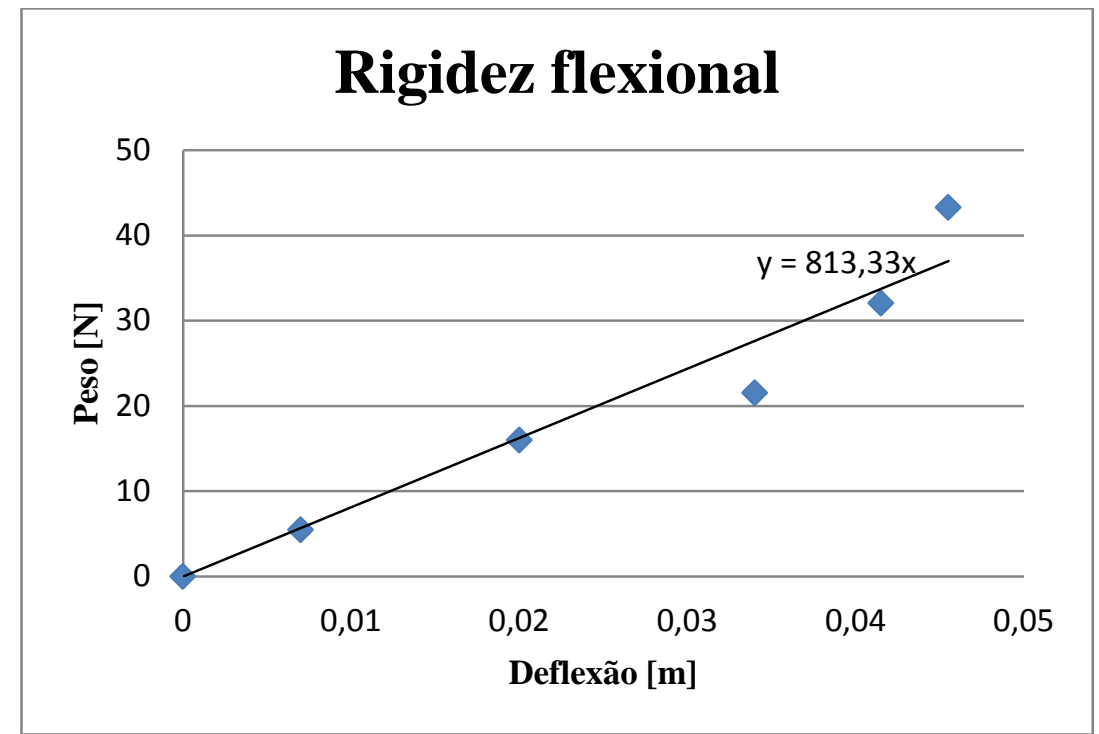

Figura 4.21 - Gráfico obtido no ensaio de rigidez flexional

Do ensaio de rigidez torsional, foi possível se obter os dados apresentados na Tabela 4.5 .

Tabela 4.5 - Resultados obtidos no ensaio de rigidez torsional

\begin{tabular}{cccc}
\hline \multicolumn{2}{c}{ Carga $[\mathrm{kg}]$} & \multicolumn{2}{c}{ Deflexão [mm] } \\
\hline Bordo de Ataque & Bordo de Fuga & Bordo de Ataque & Bordo de Fuga \\
\hline 0 & 0 & 0 & 0 \\
\hline 0,665 & 0,665 & 14 & 15 \\
\hline 1,264 & 1,255 & 29 & 36 \\
\hline 1,768 & 1,765 & 39 & 40 \\
\hline 2,367 & 1,765 & 53 & 40 \\
\hline
\end{tabular}

E a partir desses dados foi possível se traçar o gráfico abaixo, cuja linha de tendência fornece a rigidez torsional da estrutura (Figura 4.22). 


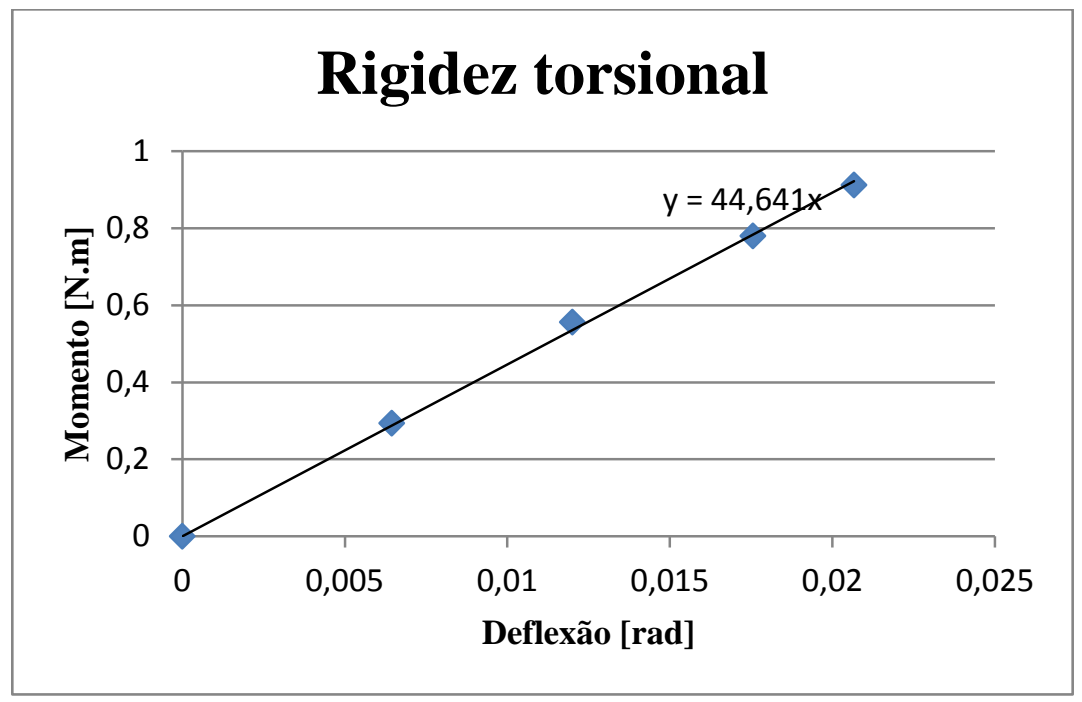

Figura 4.22 - Gráfico obtido no ensaio de rigidez torsional

Dessa forma se obteve os dados de rigidez flexional e torsional, apresentados na Tabela 4.6.

Tabela 4.6 - Valores de rigidez obtidos experimentalmente

\begin{tabular}{ccc}
\hline Rigidez & Valor & Unidade \\
\hline Flexão & 813 & $N / m$ \\
\hline Torção & 45 & $N . m$ \\
& & \\
\hline
\end{tabular}

Pode-se observar que os valores obtidos experimentalmente e por simulação são bastante semelhantes, o que permite validar o modelo quanto à rigidez.

\subsection{Análise modal experimental}

Para o levantamento dos modos de vibrar da estrutura suporte/asa, foi realizado um ensaio visando principalmente o formato do modo da barra central do suporte, que é basicamente o único elemento que deve se deformar em uma solicitação.

Dessa forma, devido a limitações da estrutura e ao tipo de informações que se deseja, optou-se por um ensaio utilizando martelo de impacto com os pontos de medição discretizados na barra central, sendo que seria medido um ponto por vez, mudando o 
acelerômetro de posição, de modo a adicionar o mínimo de massa possível ao sistema, afetando minimamente seu comportamento inercial.

Segundo McConnel \& Varoto (2008) e Rao (1990), ensaios desse tipo são indicados quando a força aplicada na estrutura deve ser baixa e tem a vantagem de não influenciar no carregamento de massa da estrutura, além de ser mais rápido, simples e barato, portanto se mostra ideal para esse caso.

Assim sendo, montou-se o arranjo experimental esquematizado na Figura 4.23.

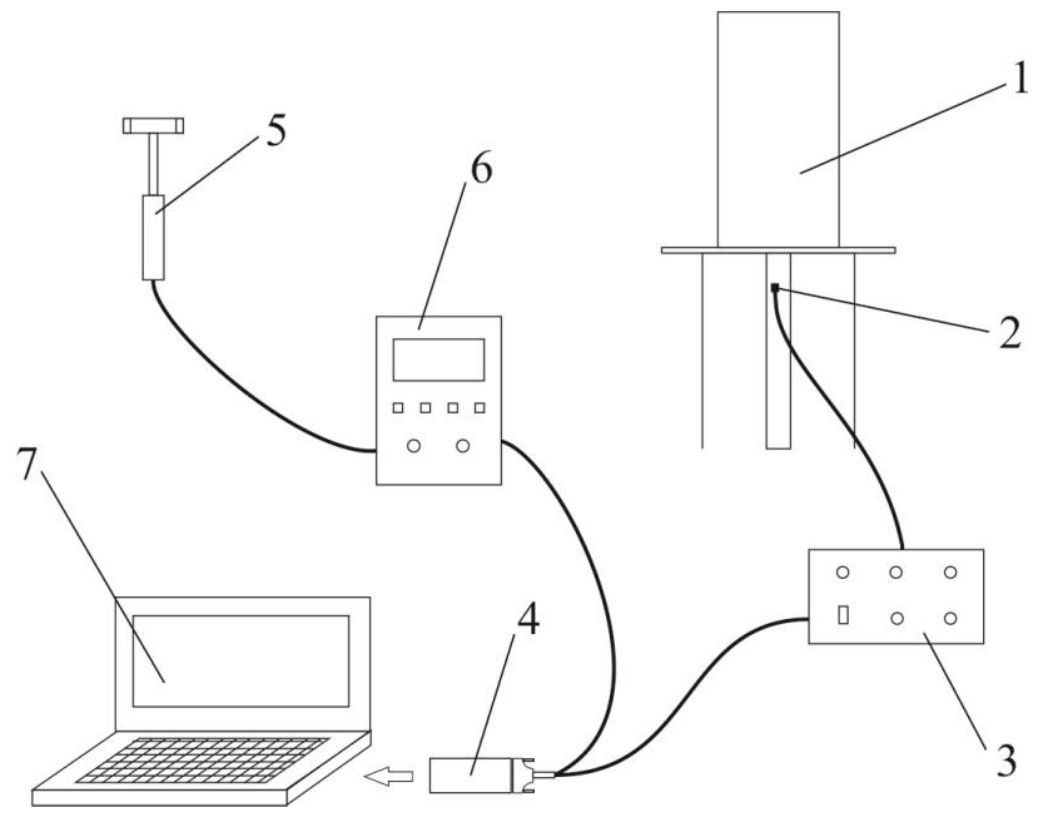

Figura 4.23 - Esquema do aparato experimental

onde cada um dos elementos é descrito abaixo:

1. Estrutura Asa/suporte engastado no desempeno do laboratório

2. Acelerômetro Kistler K-Beam

Tipo: 8303A10M4

Fixação: cera de abelha

Serial: C121082

Faixa de trabalho: $\pm 10 \mathrm{~g}$

Sensibilidade: 99,2 mV/g

Frequência de ressonância: 4,0 kHz

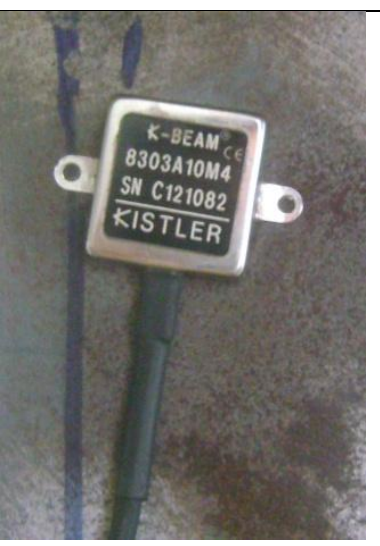


3. Amplificador de sinal Kistler

Tipo: 5210

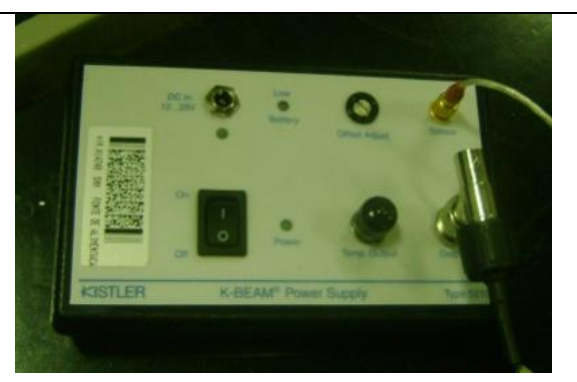

4. Cartão Signal Calc

Tipo: PCMCIA

Interface entre os sinais de entrada e saída no laptop.

Sinal de entrada (martelo): canal 1

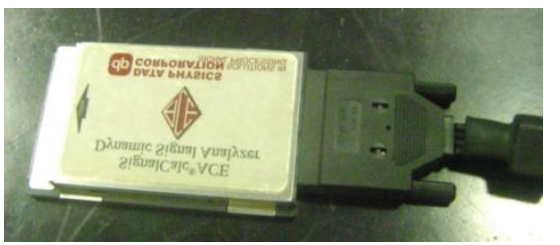

Sinal de saída (acelerômetro): canal 2

5. Martelo de impacto Kistler

Tipo: 9724A2000

Serial: C139057

Faixa de trabalho: 0 a $2000 \mathrm{~N}$

Sensibilidade: $2,41 \mathrm{mV} / \mathrm{N}$

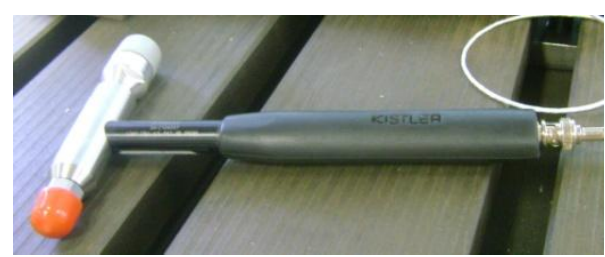

Ponta: 9912 (plástico mole com extensor)

6. Amplificador de sinal Kistler

Tipo: 5134

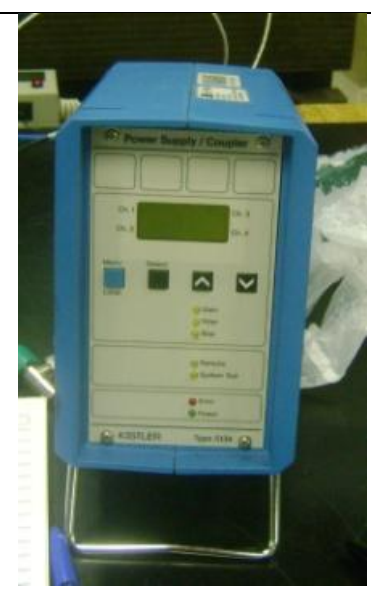

7. Laptop com entrada PCMCIA.

Software: SignalCalc 4.0.000 
O sinal foi configurado da seguinte forma:

Número de amostras por medição: 10

Tipo de média: exponencial

Faixa de frequências: 0 a 19,53125 Hz

Linhas: 200

Intervalo de frequências: $97,656 \mathrm{mHz}$

Faixa de tempo: 10,24 s

Intervalo de tempo: $20 \mathrm{~ms}$

Dessa forma, a estrutura foi excitada na região do centro aerodinâmico da asa, no centro da envergadura da mesma, conforme mostrado na Figura 4.24, e o sinal foi medido nos pontos em que foi discretizada a barra central do suporte, de acordo com o esquema mostrado.

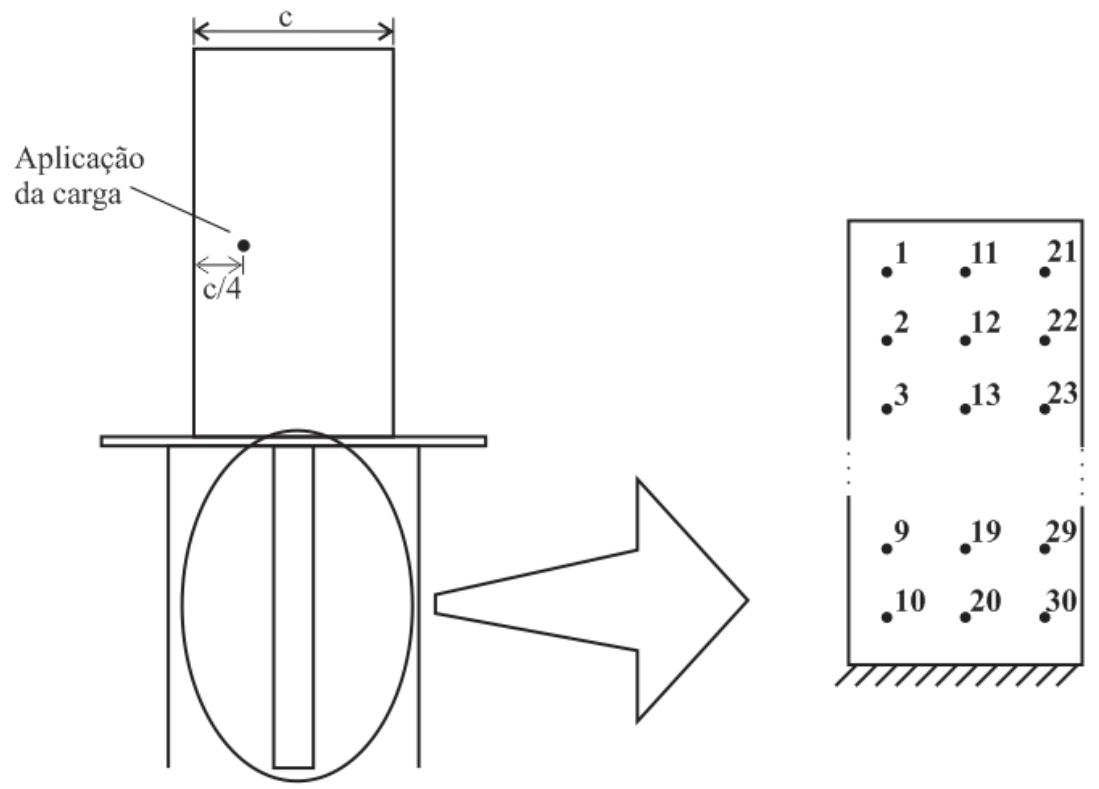

Figura 4.24 - Discretização da barra central

Para cada medição, o acelerômetro era mudado de posição e uma nova excitação era realizada. 
Foi extraída a Função de Resposta em Frequência entre a saída, que consistia na aceleração medida pelo acelerômetro (em g) e a entrada, que era a força de impacto medida pela ponta do martelo de impacto (em newtons). Plotando os sinais de todos os pontos no mesmo gráfico foi possível se obter a Figura 4.25, onde no detalhe é mostrada uma imagem ampliada dos picos dos dois primeiros modos de vibrar.

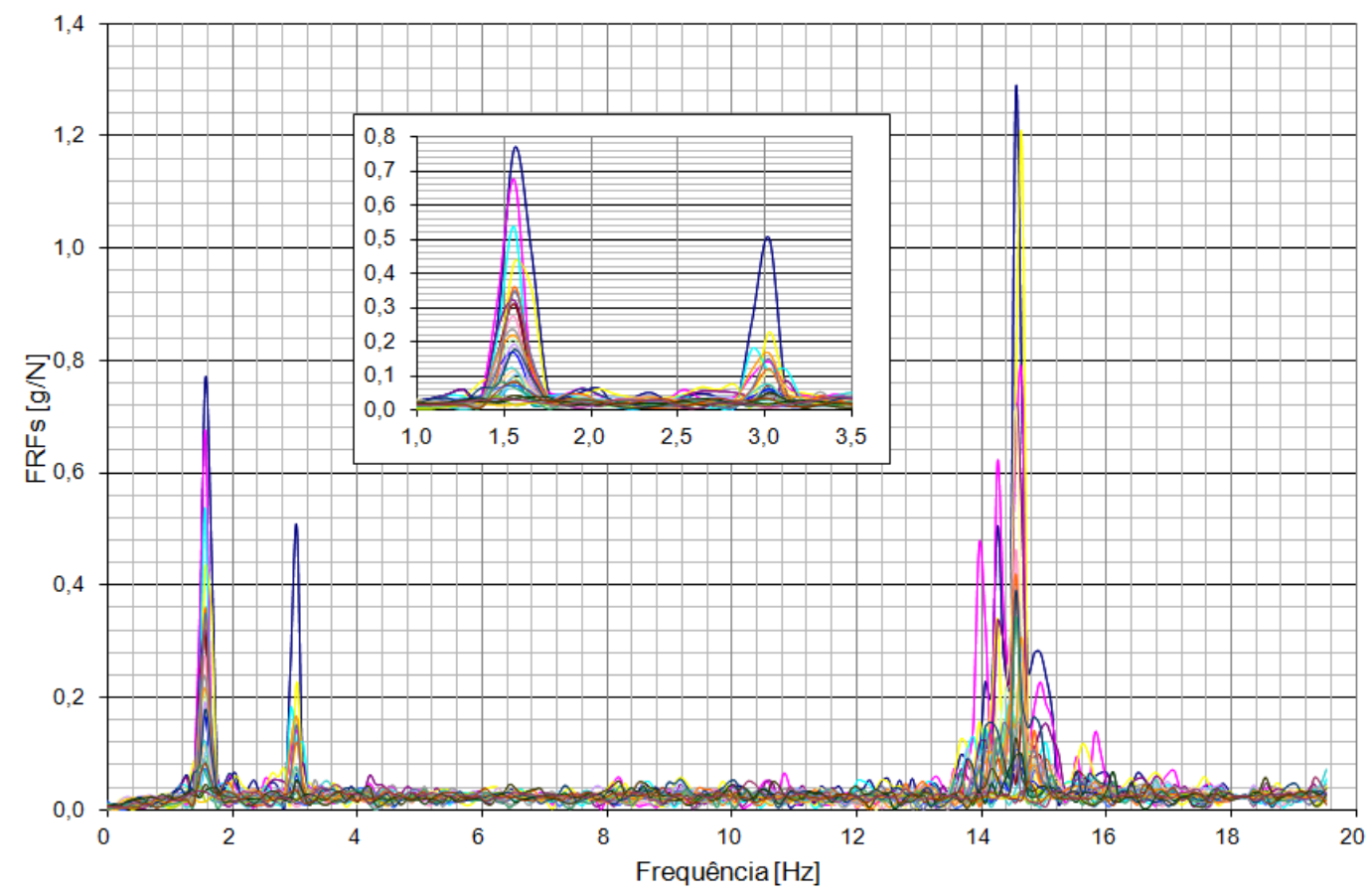

Figura 4.25 - FRFs de todos os pontos medidos

No gráfico se observa claramente 3 modos de vibrar atuando dentro dessa faixa de frequências na direção medida pelo acelerômetro, conforme ilustrado na Tabela 4.7.

Tabela 4.7 - Frequências naturais obtidas experimentalmente

\begin{tabular}{ccc}
\hline Modo & Frequência $[\mathbf{H z}]$ & Tipo \\
\hline 1 & 1,5625 & Primeiro de flexão \\
\hline 2 & 3,0273 & Primeiro de torção \\
\hline 3 & 14,551 & Segundo de flexão
\end{tabular}

Para cada um desses modos foi plotado o vetor modal, que fornece o formato dos mesmos, utilizando os valores da FRF de cada ponto da estrutura, na frequência especificada. O resultado pode ser visualizado nas Figuras 4.26 a 4.28 . 


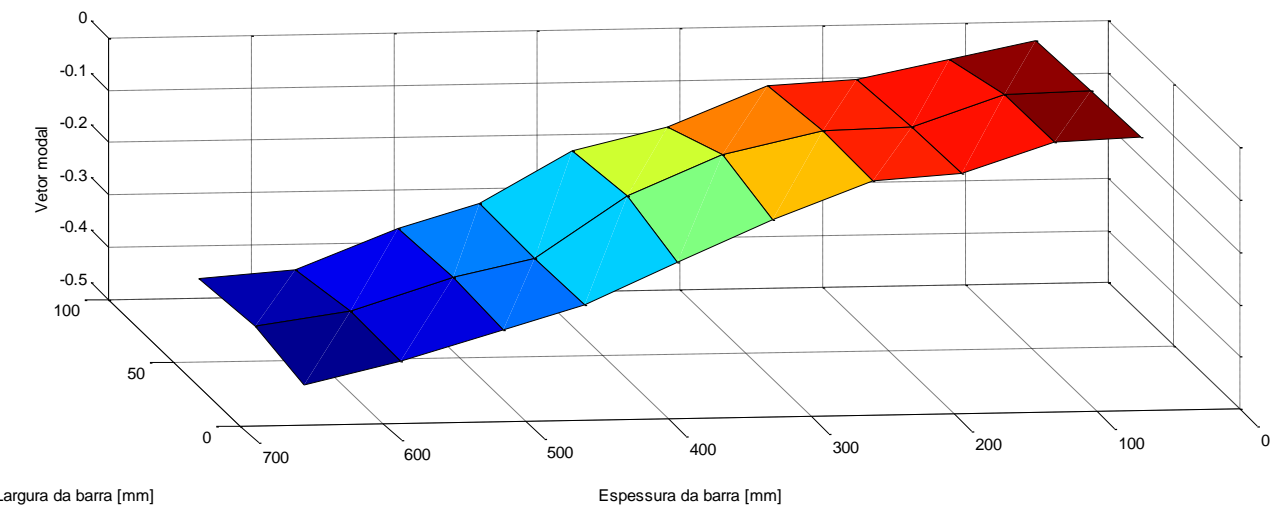

Figura 4.26 - primeiro modo de vibrar determinado experimentalmente

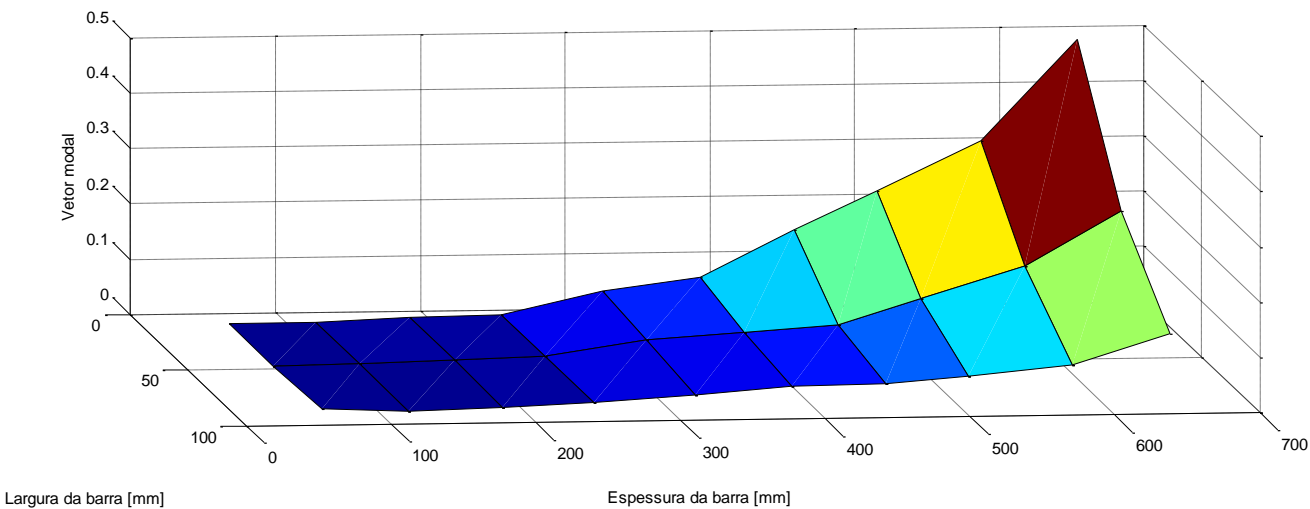

Figura 4.27 - segundo modo de vibrar determinado experimentalmente

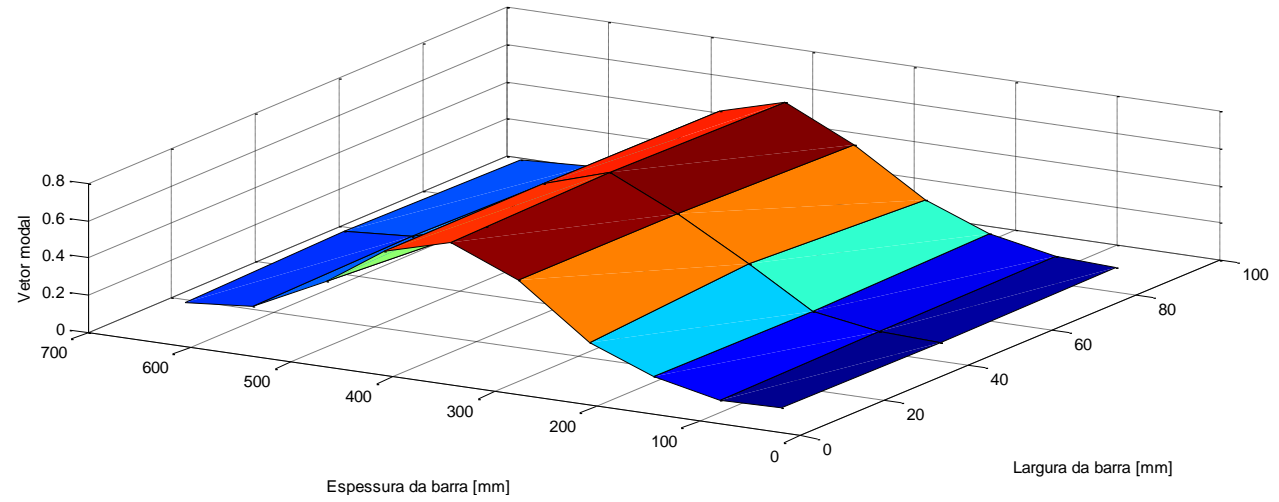

Figura 4.28 - terceiro modo de vibrar determinado experimentalmente

Com os dados obtidos experimentalmente pode-se concluir que o modelo obtido para simulação pelo método dos elementos finitos é satisfatório, pois tem valores de frequências 
naturais próximos dos obtidos experimentalmente e os formatos dos modos de vibrar são os mesmos da simulação.

Além disso, confirma-se que a estrutura analisada é satisfatória para o experimento, pois possui dois modos de vibrar em frequências próximas, e distantes do terceiro modo, propriedades características de estruturas susceptíveis à ocorrência de flutter.

\subsection{Cálculo da velocidade e frequência de flutter}

Utilizando os dados obtidos nas simulações de CFD e pelo método dos Elementos Finitos, bem como os coeficientes calculados, foram feitas subrotinas em Matlab utilizando dois métodos diferentes de análise para obtenção das características de flutter. Os resultados são mostrados a seguir.

\section{Método 1: quase-estático}

Utilizando as equações de Lagrange e espaço de estados, para se obter a velocidade de flutter do sistema asa/suporte, e a sua resposta no domínio da frequência, conforme os métodos explicados no item 2.1 deste trabalho. Nas Figuras 4.29 a 4.33 é possível se verificar a resposta no tempo em flexão e torção obtidas na simulação para algumas das velocidades simuladas até a velocidade considerada a de ocorrência de flutter, que foi de $25,0 \mathrm{~m} / \mathrm{s}$.

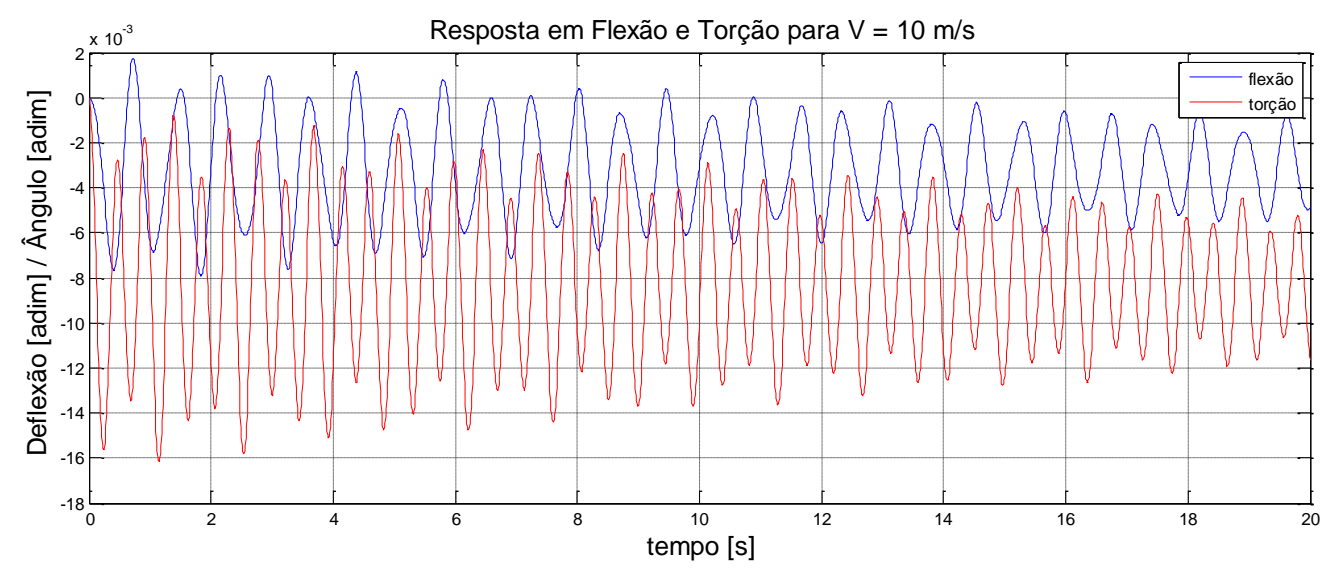

Figura 4.29 - Resposta do sistema a $10 \mathrm{~m} / \mathrm{s}$ 


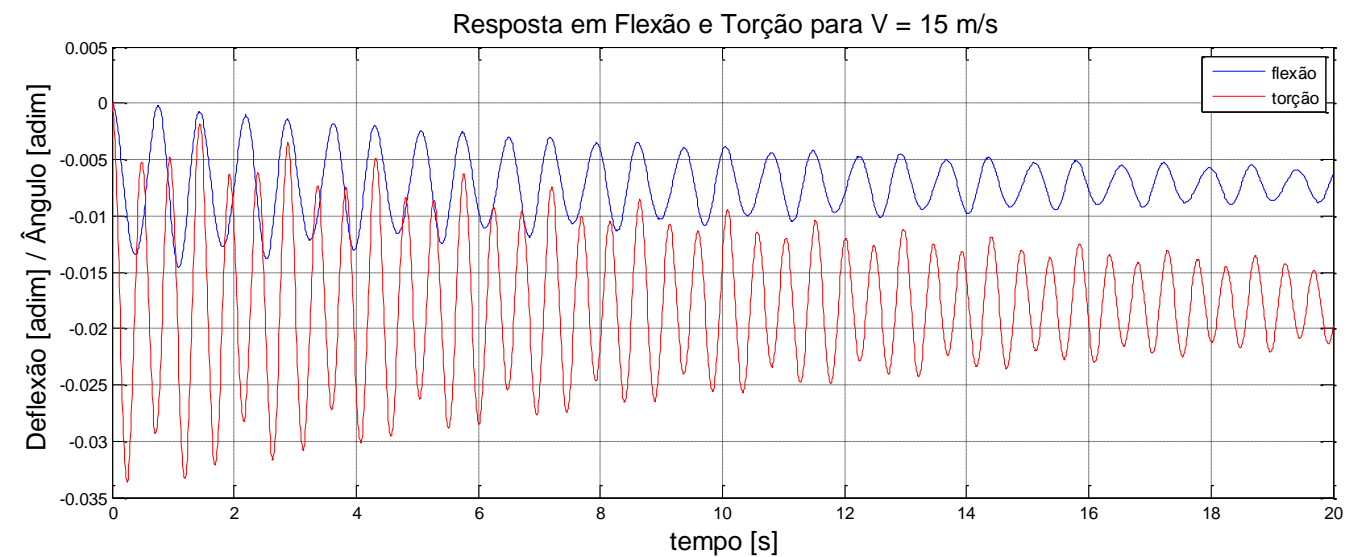

Figura 4.30 - Resposta do sistema a 15 m/s

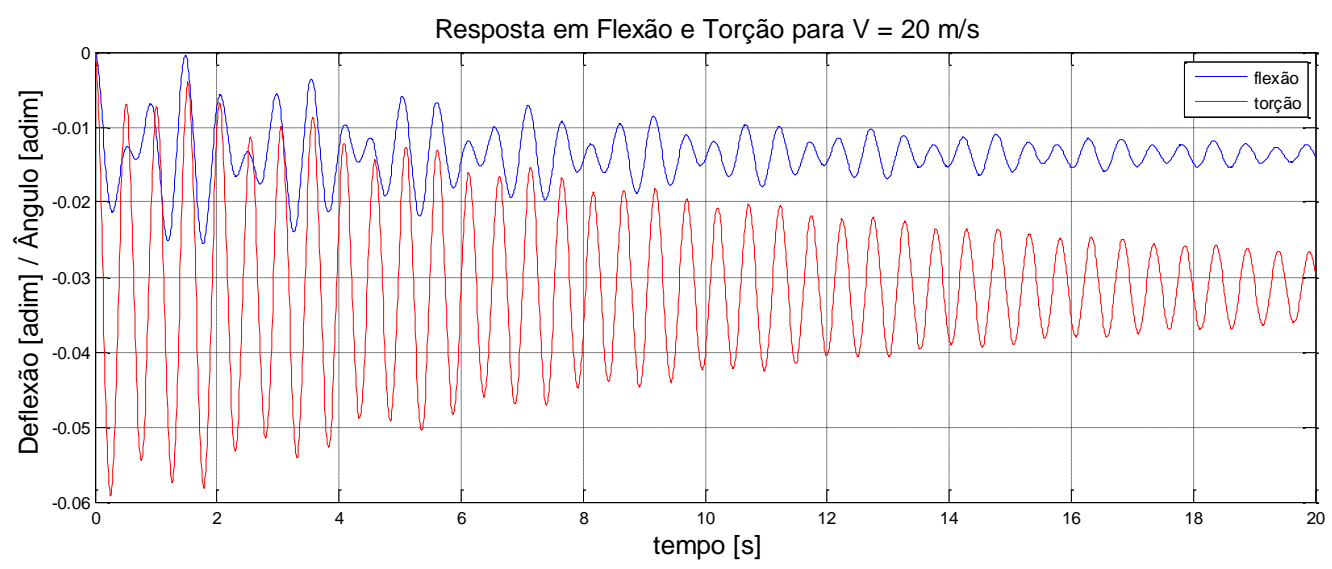

Figura 4.31 - Resposta do sistema a $20 \mathrm{~m} / \mathrm{s}$

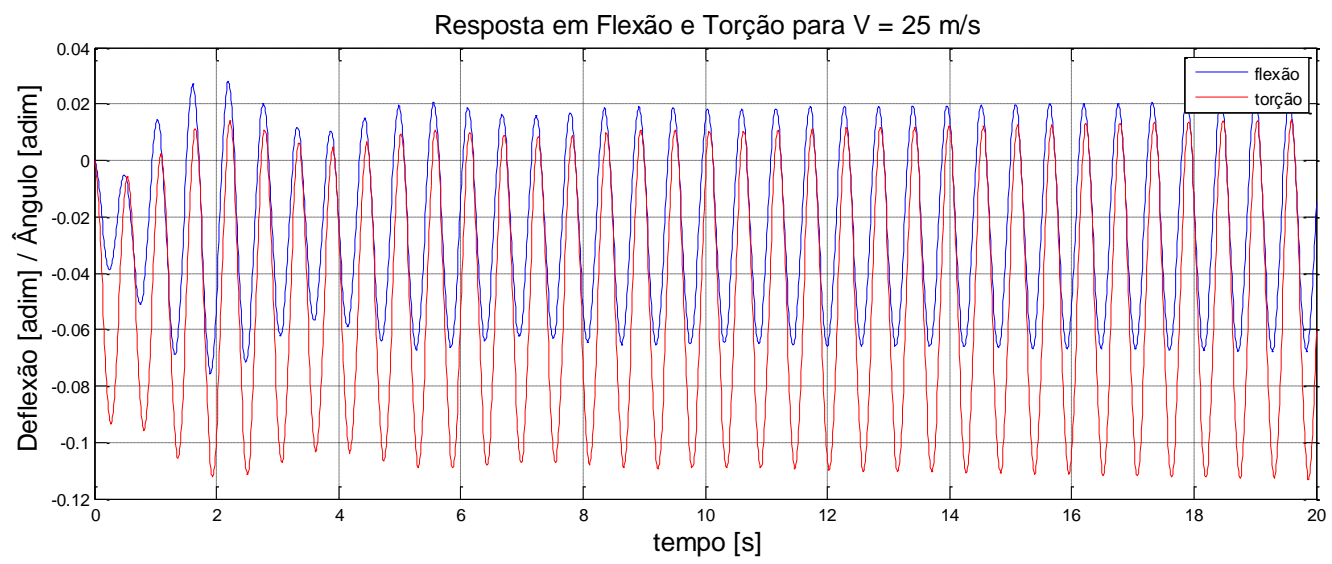

Figura 4.32 - Resposta do sistema a $25 \mathrm{~m} / \mathrm{s}$ 


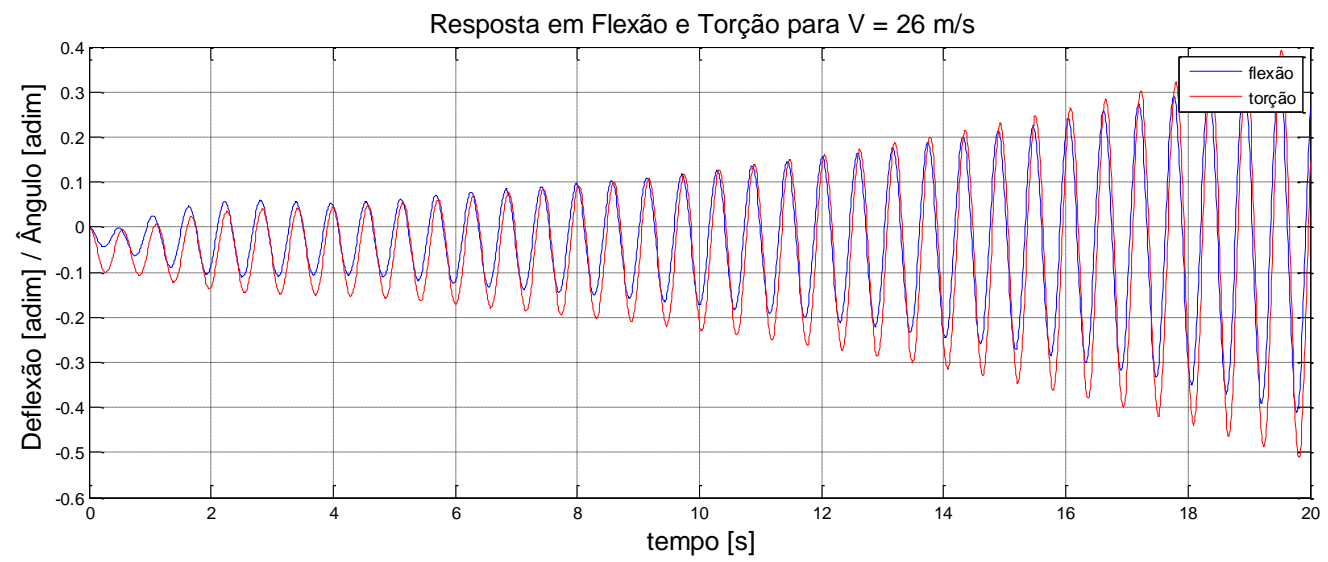

Figura 4.33 - Resposta do sistema a $26 \mathrm{~m} / \mathrm{s}$

Nas velocidades mais altas, nota-se claramente que as respostas no tempo dos dois modos de vibrar estão em fase, o que indica acoplamento dos modos de vibrar.

Em seguida é apresentada a resposta em frequência para várias velocidades (Figura 4.34), onde pode-se verificar claramente o acoplamento dos modos de vibrar na velocidade indicada como a de ocorrência de flutter. A partir dessa velocidade observa-se que os dois picos da curva, representando as frequências naturais dos dois modos de vibrar, tornam-se um só, sugerindo que os modos de vibrar se acoplam e se realimentam, causando uma instabilidade estrutural.

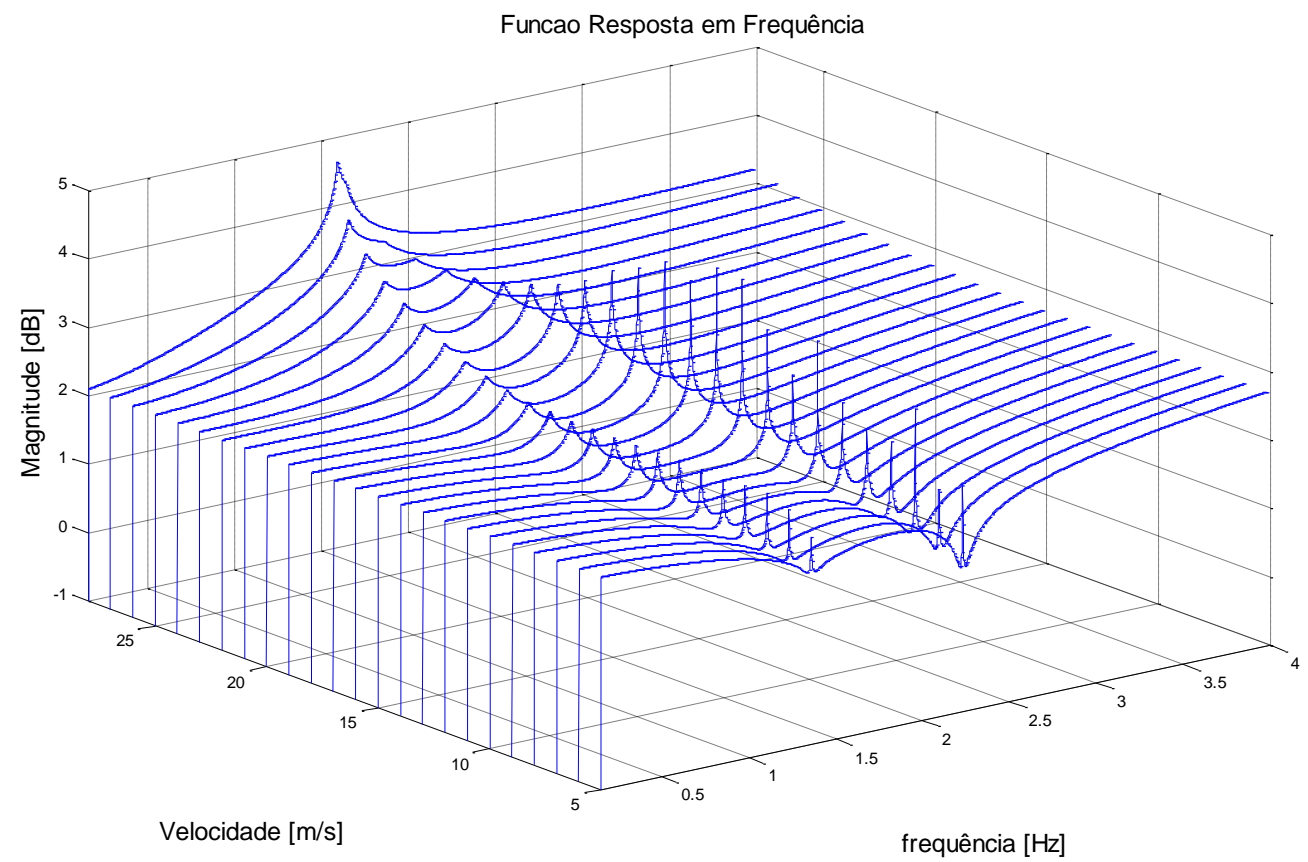

Figura 4.34 - Função resposta em frequência do sistema em várias velocidades, de 5 a 27 m/s 
Desta simulação também foi possível se estimar numericamente a frequência de ocorrência do flutter, que é de 1,590 Hz.

\section{Método 2: diagrama V-g}

Por esse método foram traçados os gráficos mostrados na Figura 4.35, de onde é possível se obter as características desejadas, descritas em seguida.
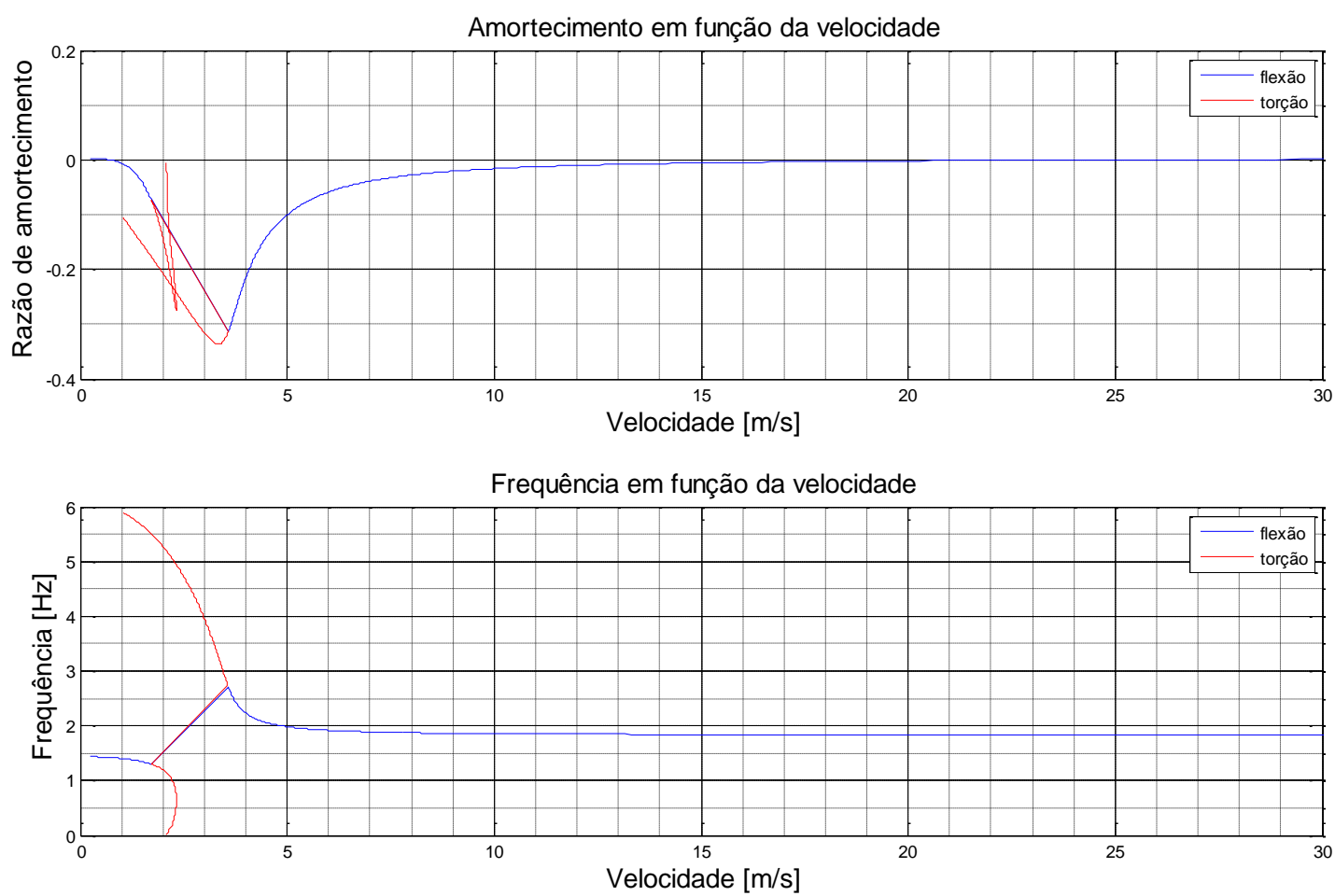

Figura 4.35 - Diagramas V-g para determinação das condições de flutter

Pelos resultados obtidos é possível se determinar que a ocorrência de flutter acontece a $25,4 \mathrm{~m} / \mathrm{s}$, que é a velocidade onde o amortecimento atinge valores positivos. Nessa mesma velocidade pode-se determinar que a frequência do sistema é de 1,83 Hz, considerada a frequência de flutter da estrutura.

Esses resultados permitem uma previsão da resposta da estrutura quando exposta a um escoamento aerodinâmico no túnel de vento, cujo ensaio será abordado adiante neste trabalho. Vale observar também que os dados obtidos por ambos os métodos são bastante semelhantes 
quanto a velocidade de flutter e relativamente próximos quanto à sua frequência, o que comprova a consistência dos dados e a robustez dos modelos teóricos construídos

\subsection{Determinação experimental das características de flutter}

Com o objetivo de se checar os dados obtidos pelo modelo matemático do item anterior, foi realizado um ensaio onde a estrutura asa/suporte foi posicionada na saída de um soprador aerodinâmico, instrumentada com um acelerômetro no ponto 1 mostrado na Figura 4.24, de forma a se detectar cargas em flexão e em torção.

O experimento foi montado conforme esquematizado na Figura 4.36.

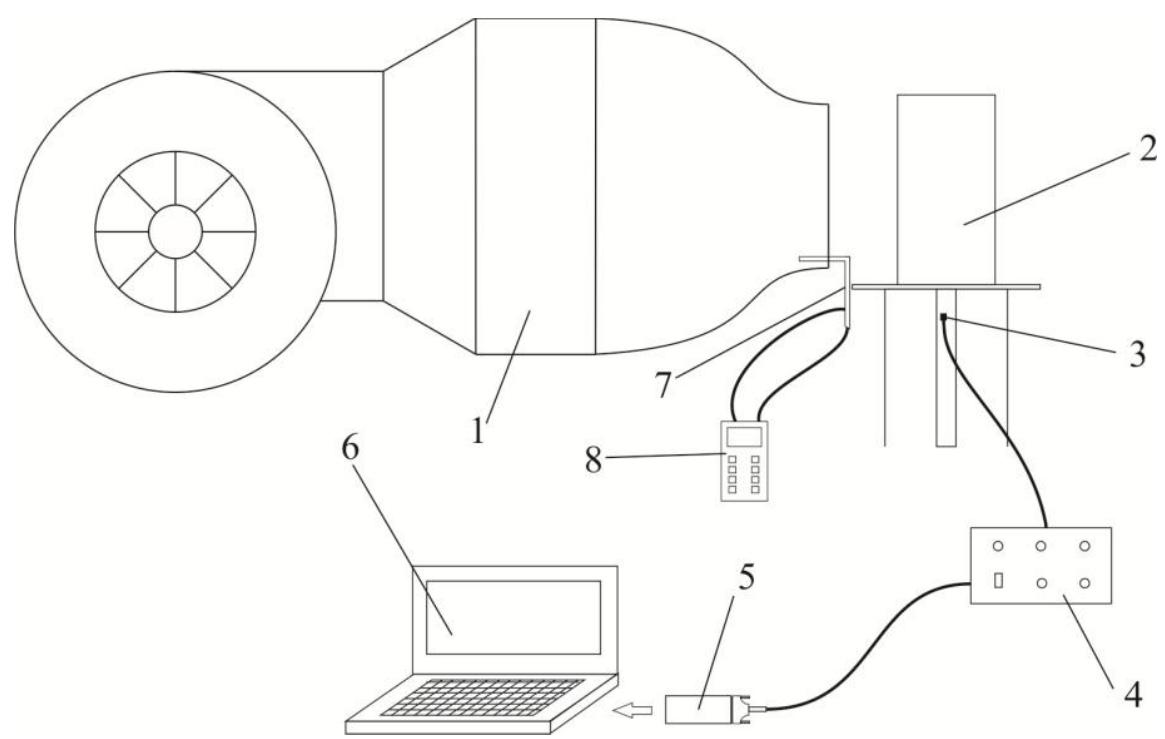

Figura 4.36 - Esquema do experimento para obtenção das características de flutter

onde cada um dos elementos é descrito a seguir:

1. Soprador aerodinâmico

Velocidade maxima: $32 \mathrm{~m} / \mathrm{s}$

Rotação maxima do motor: 1175 rpm

Potência maxima do motor: $40 \mathrm{Hp}$

Dimensões da seção de escoamento:

$780 \times 1050 \mathrm{~mm}$

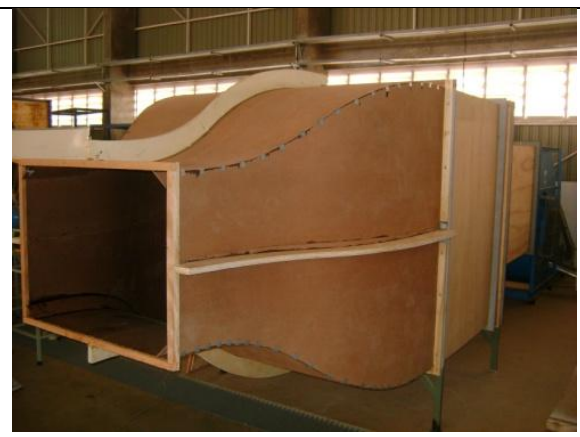


2. Estrutura asa/suporte flexível

3. Acelerômetro Kistler K-Beam

Tipo: 8303A10M4

Fixação: cera de abelha

Serial: C121082

Faixa de trabalho: $\pm 10 \mathrm{~g}$

Sensibilidade: $99,2 \mathrm{mV} / \mathrm{g}$

Frequência de ressonância: 4,0kHz

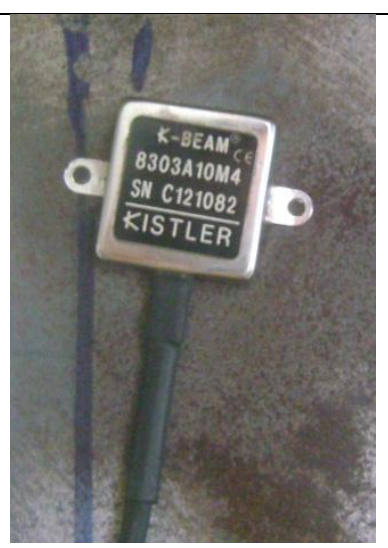

4. Amplificador de sinal Kistler

Tipo: 5210

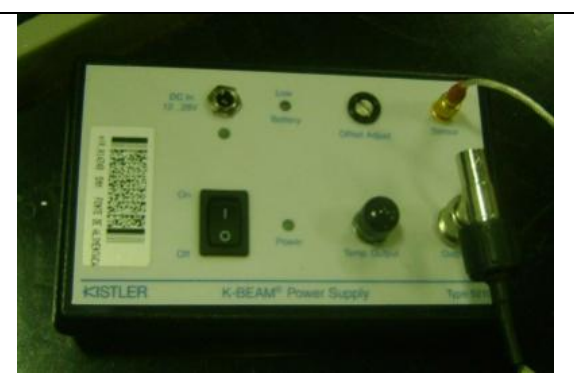

5. Cartão Signal Calc

Tipo: PCMCIA

Interface entre os sinais de entrada e saída no laptop.

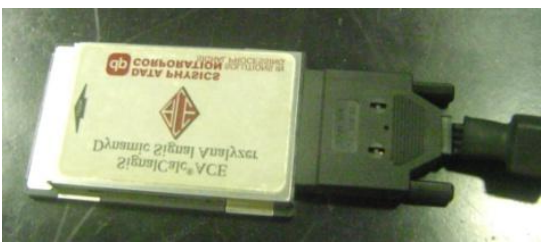

Sinal de saída (acelerômetro): canal 1

6. Laptop com entrada PCMCIA.

Software: SignalCalc 4.0.000

7. Tubo de pitot

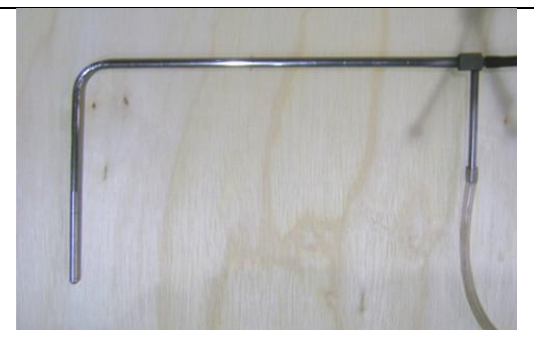

8. MicromanômetroDigital TSI

Modelo: DPCalc 8705-M-GB

Serial: 54120589

Regulado para fornecer sinal de

velocidade em $\mathrm{m} / \mathrm{s}$

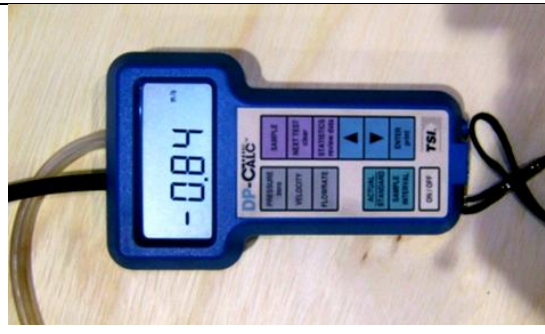


O sinal foi configurado da seguinte forma:

Número de amostras por medição: 10

Tipo de média: exponencial

Faixa de frequências: 0 a 19,53125 Hz

Linhas: 200

Intervalo de frequências: 97,656 mHz

Faixa de tempo: 10,24 s

Intervalo de tempo: $20 \mathrm{~ms}$

A Figura 4.37 mostra uma foto do experimento montado.

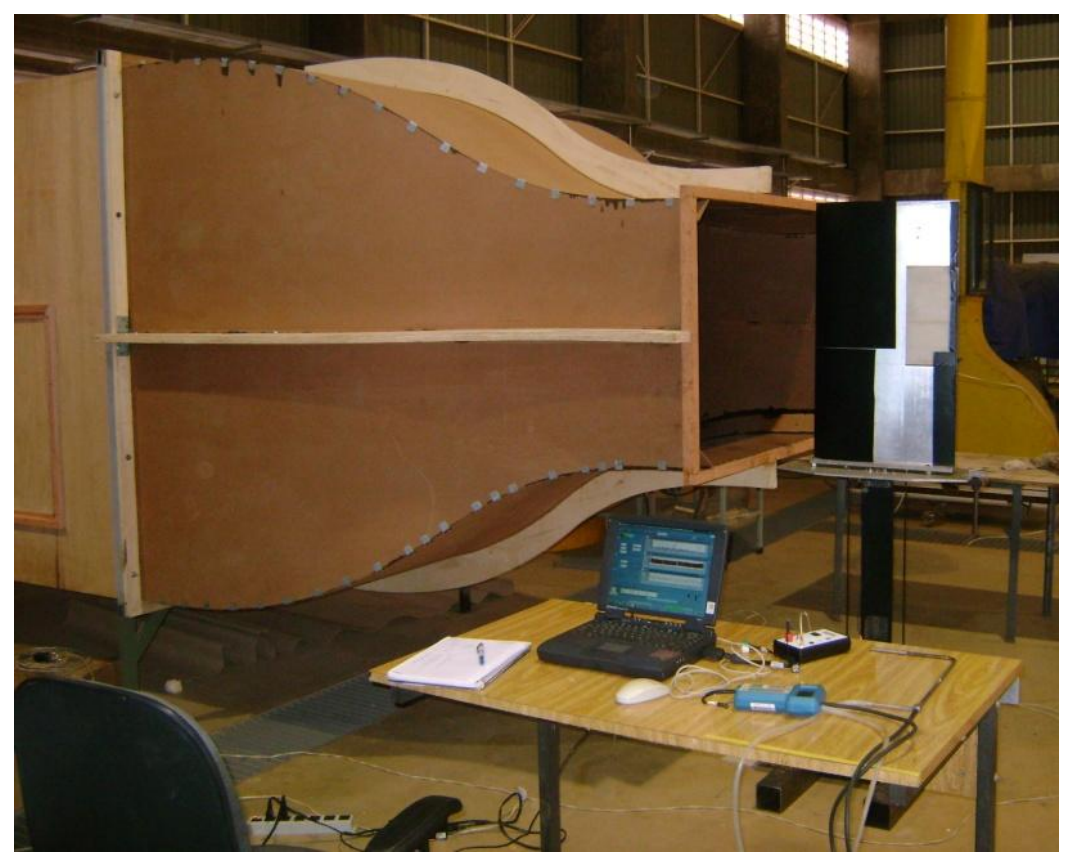

Figura 4.37 - Experimento para cálculo das características de flutter

Com esse aparato, a velocidade do ar era variada e medida pelo pitot, com leitura pelo micromanômetro, e a cada velocidade diferente, um pequeno deslocamento era provocado na asa, medindo-se sua resposta livre com o acelerômetro.

Nas Figuras 4.38 a 4.42 é possível verificar a resposta no tempo de algumas das velocidades medidas. 


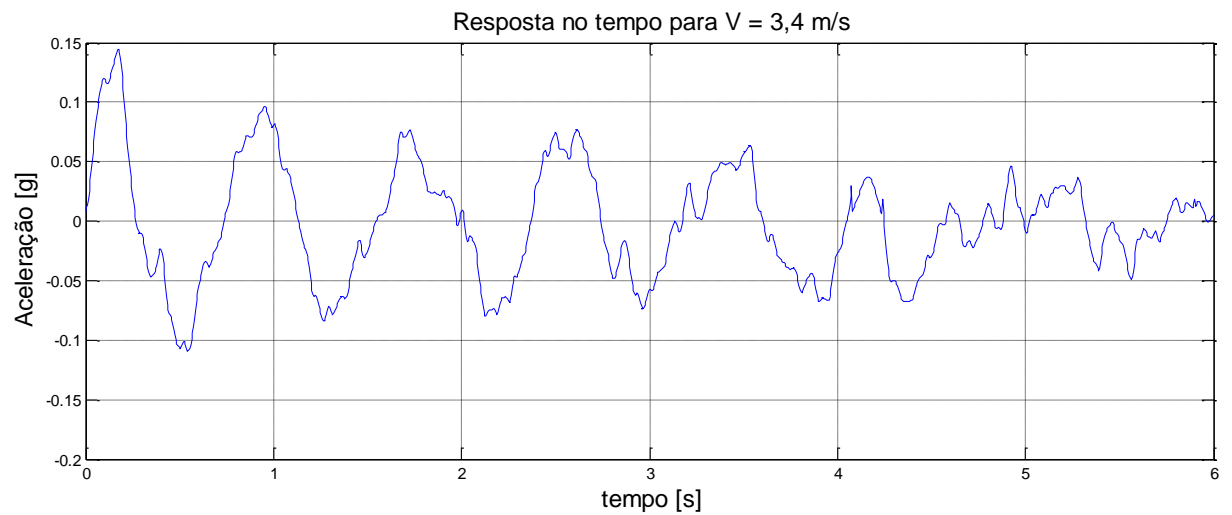

Figura 4.38 - Resposta no tempo para $3,4 \mathrm{~m} / \mathrm{s}$

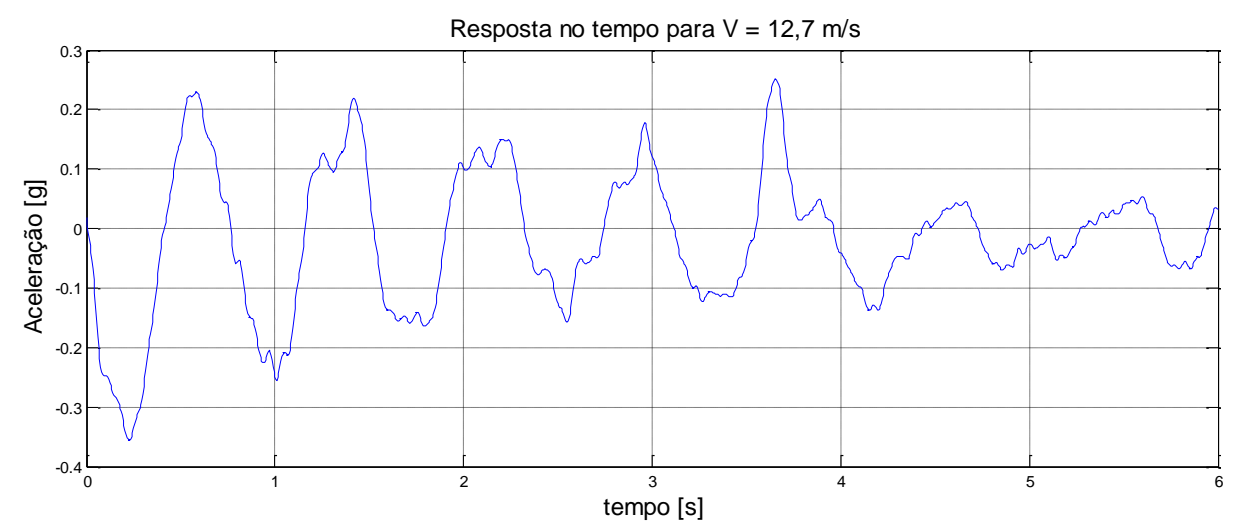

Figura 4.39 - Resposta no tempo para $12,7 \mathrm{~m} / \mathrm{s}$

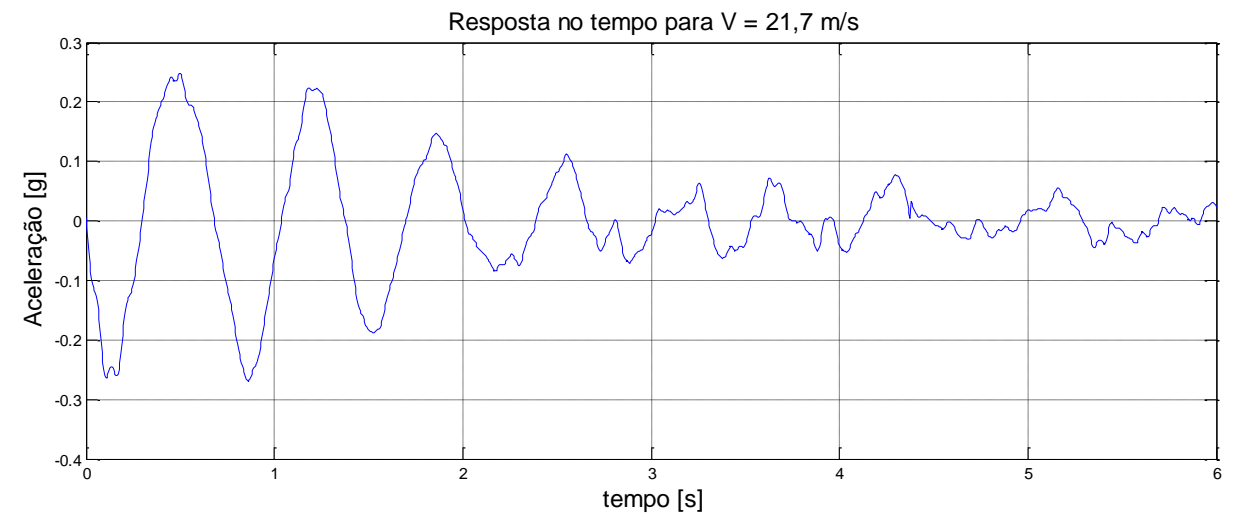

Figura 4.40 - Resposta no tempo para $21,7 \mathrm{~m} / \mathrm{s}$ 


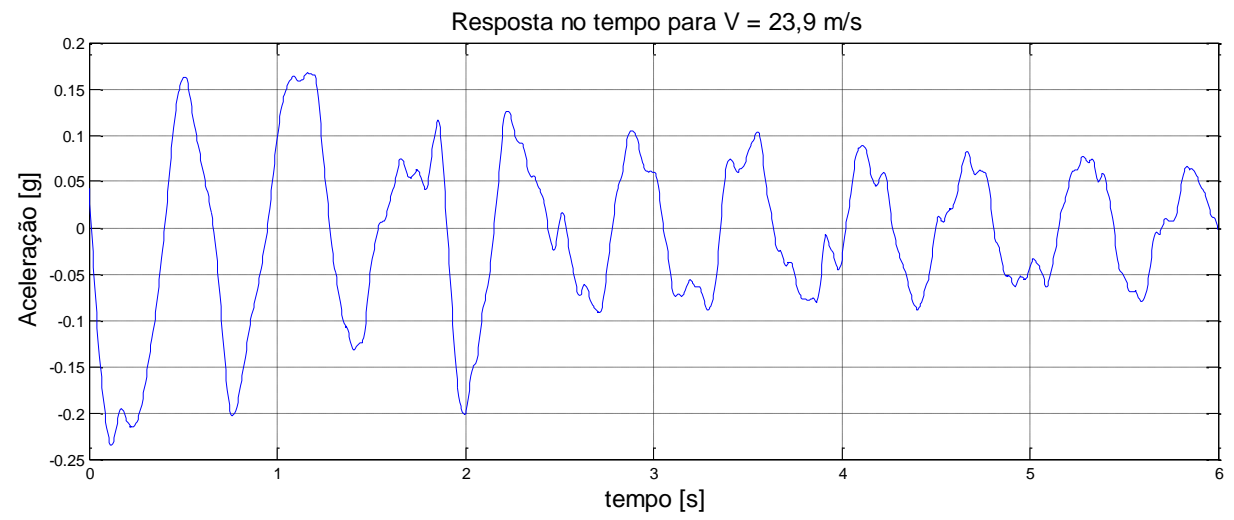

Figura 4.41 - Resposta no tempo para 23,9 m/s

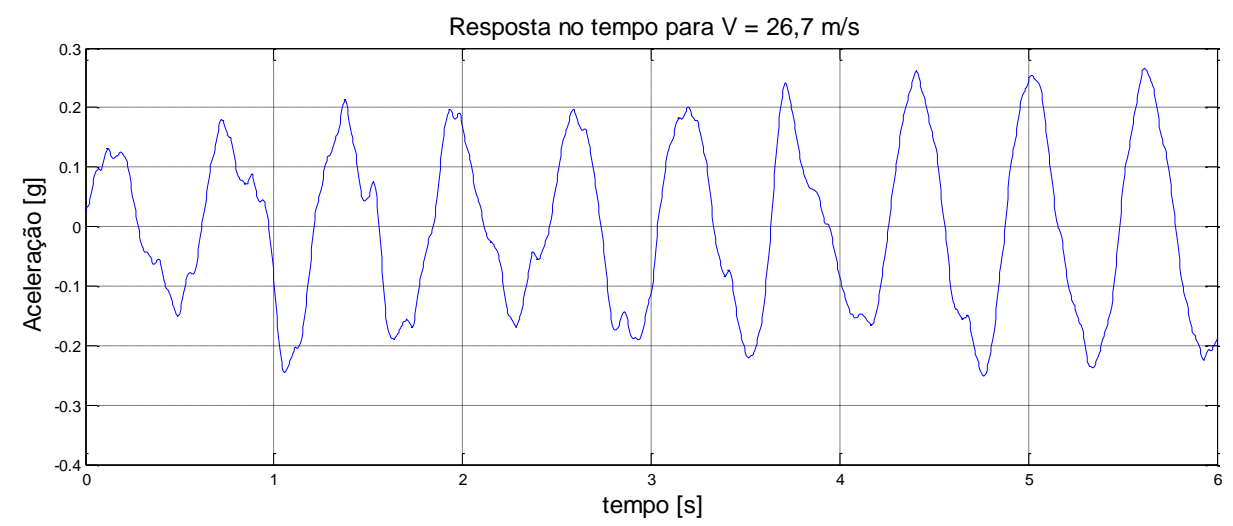

Figura 4.42 - Resposta no tempo para $26,7 \mathrm{~m} / \mathrm{s}$

Das medições realizadas, foi possível se calcular o amortecimento para as várias velocidades, com base no decremento logarítmico dos gráficos. A Tabela 4.8 apresenta os dados.

Em seguida, foi possível se traçar um gráfico do amortecimento em função da velocidade, apresentado na Figura 4.43. Adicionando-se uma linha de tendência aos pontos traçados, obteve-se sua equação e, igualando-a a zero (amortecimento neutro), foi possível se calcular a velocidade de flutter do sistema, cujo valor é $25,9 \mathrm{~m} / \mathrm{s}$.

Observando-se os dados pode-se notar que os resultados experimentais são bem próximos aos obtidos analiticamente, o que permite afirmar que o modelo numérico é adequado para essa aplicação. 
Tabela 4.8 - Amortecimento calculado para cada velocidade obtida no ensaio

\begin{tabular}{cc}
\hline Velocidade $[\mathrm{m} / \mathrm{s}]$ & Amortecimento [adim] \\
\hline 3,8 & 0,057 \\
\hline 8,3 & 0,052 \\
\hline 12,7 & 0,05 \\
\hline 17,3 & 0,046 \\
\hline 19,5 & 0,04 \\
\hline 21,7 & 0,033 \\
\hline 23,9 & 0,015 \\
\hline 26,3 & $-0,007$ \\
\hline
\end{tabular}

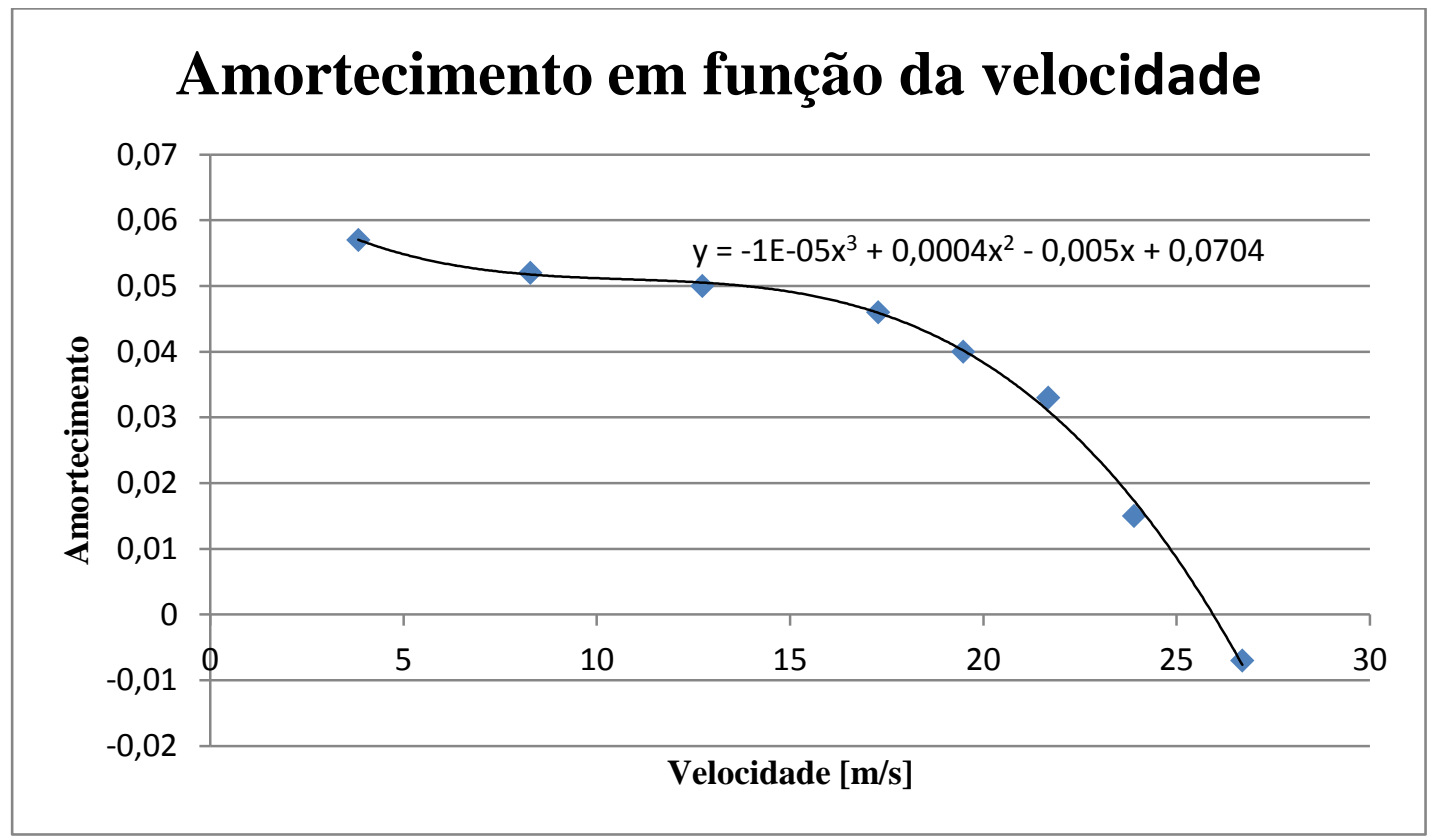

Figura 4.43 - Gráfico de amortecimento em função da velocidade 


\subsection{Sumário com todas as características encontradas}

Após este trabalho de engenharia reversa e investigação das propriedades da estrutura, foi possível criar a Tabela 4.9, que apresenta todas as características encontradas nos procedimentos descritos neste capítulo.

Tabela 4.9 - Propriedades obtidas para a estrutura

\begin{tabular}{|c|c|c|}
\hline \multicolumn{3}{|c|}{ Propriedades inerciais } \\
\hline Massa da asa & \multicolumn{2}{|c|}{$11,970 \mathrm{~kg}$} \\
\hline Massa do suporte & \multicolumn{2}{|c|}{$13,310 \mathrm{~kg}$} \\
\hline Posição do CG & \multicolumn{2}{|c|}{$41 \%$ CMA } \\
\hline \multicolumn{3}{|c|}{ Frequências naturais } \\
\hline Modo de vibrar & experimental & modelo \\
\hline 1.o modo (flexão) & $1,56 \mathrm{~Hz}$ & $1,56 \mathrm{~Hz}$ \\
\hline 2.0 modo (torção) & $3,02 \mathrm{~Hz}$ & $2,60 \mathrm{~Hz}$ \\
\hline 3.0 modo (flexão) & $14,56 \mathrm{~Hz}$ & $15,17 \mathrm{~Hz}$ \\
\hline \multicolumn{3}{|c|}{ Propriedades aerodinâmicas } \\
\hline Posição do CA & \multicolumn{2}{|c|}{$112,5 \mathrm{~mm}$} \\
\hline Posição do CP & \multicolumn{2}{|c|}{$31 \mathrm{~mm}$} \\
\hline$C_{L \alpha}$ & \multicolumn{2}{|c|}{$1,8673 \mathrm{rad}^{-1}$} \\
\hline$C_{M \alpha}$ & \multicolumn{2}{|c|}{$0,3372 \mathrm{~m}^{-1} \mathrm{rad}^{-1}$} \\
\hline$C_{L \dot{\alpha}}$ & \multicolumn{2}{|c|}{$0,705 \mathrm{rad}^{-1}$} \\
\hline$C_{M \dot{\alpha}}$ & \multicolumn{2}{|c|}{$0,0945 \mathrm{rad}^{-1}$} \\
\hline$C_{L q}$ & \multicolumn{2}{|c|}{$0,3161 \mathrm{rad}^{-1}$} \\
\hline$C_{M q}$ & \multicolumn{2}{|c|}{$-0,4838 \mathrm{rad}^{-1}$} \\
\hline
\end{tabular}


continuação

\begin{tabular}{|c|c|c|}
\hline \multicolumn{3}{|c|}{ Propriedades de rigidez } \\
\hline Rigidez & experimental & modelo \\
\hline Flexional & $813 \mathrm{~N} / \mathrm{m}$ & $820 \mathrm{~N} / \mathrm{m}$ \\
\hline Torsional & 45 N.m & 43 N.m \\
\hline \multicolumn{3}{|c|}{ Propriedades de flutter } \\
\hline Propriedade & experimental & modelo 1 modelo 2 \\
\hline Velocidade de flutter & $25,9 \mathrm{~m} / \mathrm{s}$ & $25,0 \mathrm{~m} / \mathrm{s}$ \\
\hline Frequência de flutter & $1,63 \mathrm{~Hz}$ & $1,59 \mathrm{~Hz}$ \\
\hline
\end{tabular}




\section{Capítulo}

\section{Testes com imageamento infravermelho}

Seguindo a metodologia proposta neste trabalho, serão apresentados neste capítulo os ensaios realizados com imageamento infravermelho, sendo o primeiro deles uma análise modal e o segundo um ensaio em túnel de vento para detecção de flutter. Antes dos ensaios foi realizada uma modelagem teórica para posterior comparação com os dados experimentais. Tais análises também são apresentadas neste capítulo.

\subsection{Modelamento termomecânico da estrutura}

As equações (2.84) e (2.85) fornecem o cálculo do aumento local de temperatura para uma estrutura sujeita a uma deformação elástica, sujeita respectivamente a flexão e torção. Tais equações são válidas para uma viga com as carga aplicadas conforme detalhado nas seções 2.3 e 2.4 deste texto. As mesmas equações são representadas abaixo.

$$
\begin{gathered}
\Delta T_{h}=\sigma^{2} \frac{h^{2}}{12 \rho c}\left[\frac{b h L^{2}}{18 x^{2} E I}+\frac{1}{5 G L^{2}}\right] \\
\Delta T_{\theta}=\tau^{2} \frac{c_{1}^{2}}{\rho c_{2} G c}
\end{gathered}
$$

Aplicando para o caso específico desta estrutura, serão utilizados os dados dimensionais fornecidos pela Tabela 4.1 e os dados referentes ao aço 1020 (Tabela 5.1), material do qual é feita a barra central da estrutura. 
Tabela 5.1 - Propriedades do aço 1020

\begin{tabular}{ccc}
\hline Símbolo & Propriedade & Valor \\
\hline$E$ & Módulo de elasticidade longitudinal & $200 \times 10^{9} \mathrm{~Pa}$ \\
\hline$G$ & Módulo de elasticidade transversal & $77,2 \times 10^{9} \mathrm{~Pa}$ \\
\hline$c$ & Calor específico & $486 \mathrm{~J} / \mathrm{kg} \cdot \mathrm{K}$ \\
\hline$\rho$ & Densidade & $7860 \mathrm{~kg} / \mathrm{m}^{3}$ \\
\hline$I$ & Momento de inércia & $\frac{b \times h^{3}}{12}$ \\
& &
\end{tabular}

Tais dados numéricos aplicados às equações fornecerão a variação de temperatura em função da tensão para cada caso.

Para flexão:

$$
\Delta T_{h}=\sigma^{2}\left[3,563 \times 10^{-17} x^{-2}+3,242 \times 10^{-21}\right]
$$

Para torção:

$$
\Delta T_{\theta}=1,129 \times 10^{-15} \tau^{2}
$$

Para aplicação deste modelo na estrutura, foi utilizado o modelo mostrado anteriormente para simulação pelo método dos elementos finitos (Figura 4.12), aplicando-se como entrada um deslocamento na placa superior para deformar a estrutura em flexão e torção, na mesma posição e mesma magnitude da aplicada pelo shaker durante o ensaio modal com imageamento infravermelho (item 5.2 deste texto). Em ambos os casos foi obtido o espectro de tensões na placa central da estrutura, utilizando o critério de von Misses.

A Figura 5.1 mostra a posição do deslocamento aplicado na estrutura para cada caso, sendo que em flexão seu valor foi de $35 \mathrm{~mm}$ e no caso de torção foi de $15 \mathrm{~mm}$. 


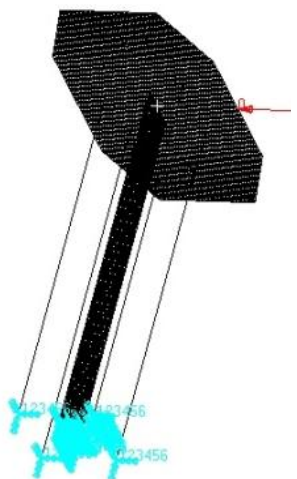

(a)

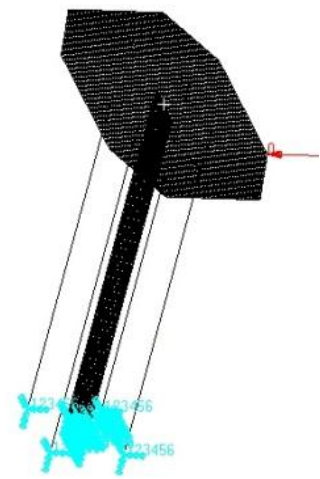

(b)

Figura 5.1 - Modelo utilizado para deformação da estrutura em flexão (a) e torção (b)

Em flexão, o resultado obtido é mostrado na Figura 5.2.

\section{Patran 2010 64-Bit 29-May-14 21:22:06}

Fringe: Load Case 1. Stress Tensor, von Mises, At Z2

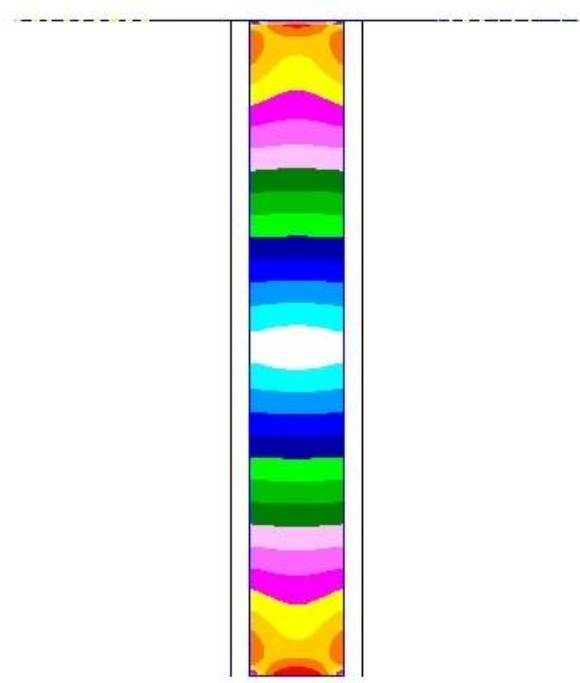

Figura 5.2 - Estado de tensões na estrutura sujeita à flexão

Utilizando nesse resultado a equação (5.3), pode-se obter uma nova escala, dessa vez aplicada à variação de temperatura, em graus celsius, em cada região do espectro, conforme mostrado na Figura 5.3. 
Patran 2010 64-Bit 29-May-14 21:29:34

Fringe: Load Case 1. Stress Tensor. Temperature Analysis

Figura 5.3 - Espectro de variação de temperatura na estrutura sujeita à flexão

Da mesma forma, o resultado da simulação em torção, fornecendo o estado de tensão da estrutura, pode ser visualizado na Figura 5.4.

Patran 2010 64-Bit 29-May-14 21:43:07

Fringe: Load Case 2. Stress Tensor, von Misses, At Z2

Figura 5.4 - Estado de tensões na estrutura sujeita à torção 
E utilizando a equação (5.4), foi possível se traçar o espectro de variação de temperatura em torção, conforme apresentado na Figura 5.5.

Patran 2010 64-Bit 29-May-14 21:50:00

Fringe: Load Case 2, Stress Tensor. Temperature Analysis

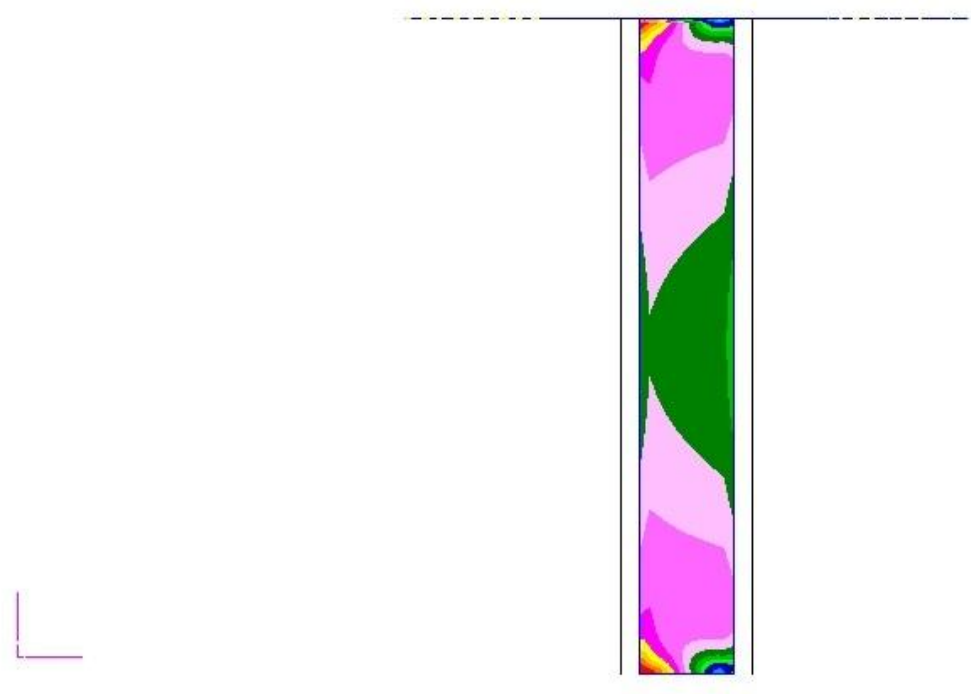

Figura 5.5 - Espectro de variação de temperatura na estrutura sujeita à torção

\subsection{Validação do modelo termomecânico}

Para validação do modelo termomecânico, foi realizado um ensaio modal considerando os dois primeiros modos de vibrar, de tal forma a compará-los com os obtidos experimentalmente conforme já descrito no item 4.6 e com o obtido no modelo do item 5.1 deste trabalho.

Nesse caso, foi necessária a excitação da estrutura nas frequências naturais, para que o modo ficasse bem caracterizado e pudesse ser captado pela câmera infravermelho. Por esse motivo, optou-se pela excitação via shaker, com a estrutura fixada no chão, nos mesmos pontos de excitação utilizados no modelo, obtendo-se sua frequência através de um acelerômetro fixado na própria haste do excitador. Dessa forma, a estrutura sofria deformações a cada ciclo da vibração e a câmera infravermelho captava as pequenas mudanças de temperatura ao longo da barra central conforme ocorria a movimentação.

Assim, o ensaio foi realizado com o aparato experimental mostrado na Figura 5.6, cujos componentes são detalhados em seguida. 


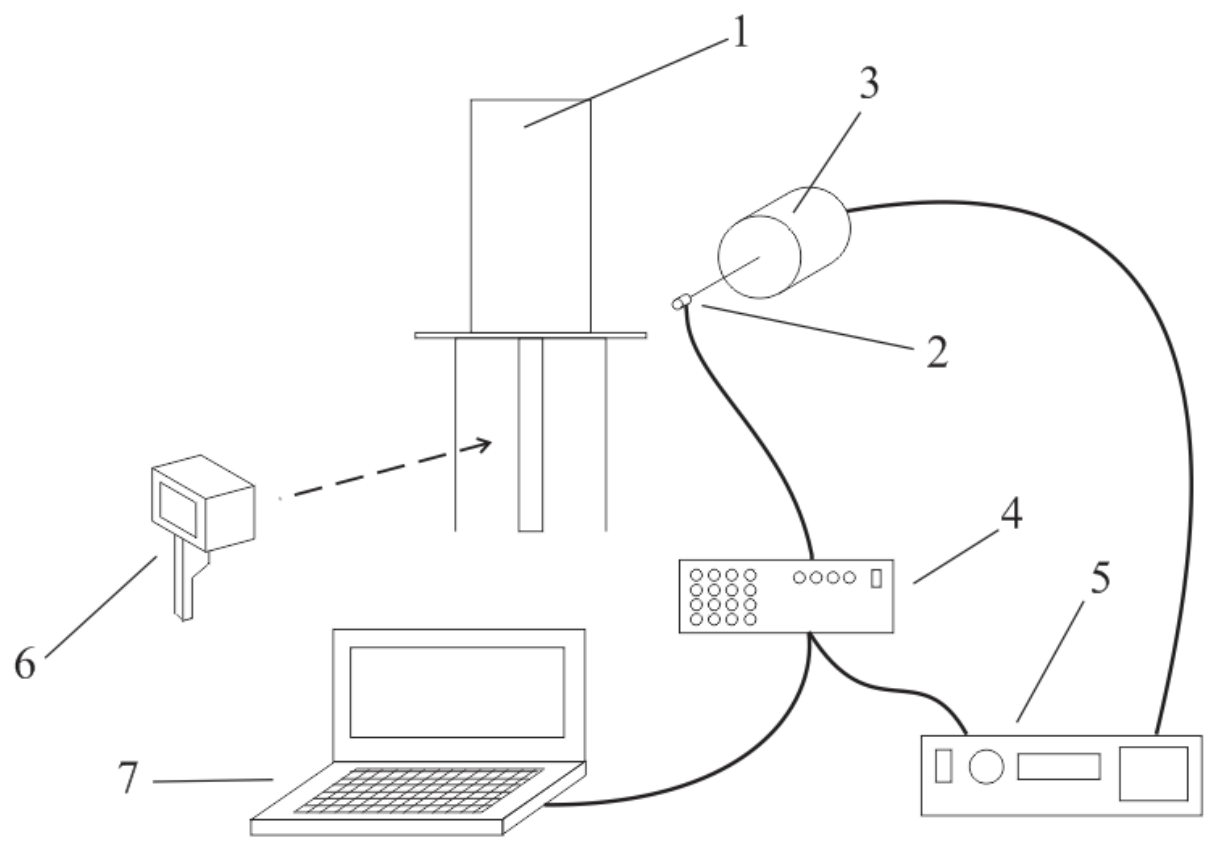

Figura 5.6 - Aparato experimental utilizado na validação do modelo termomecânico

1. Estrutura Asa/suporte engastado no desempeno do laboratório

2. Acelerômetro PCB Piezotronics

Tipo: 288D01

Fixação: Adesivo instantâneo Loctite

Serial: 2850

Faixa de trabalho: $\pm 50 \mathrm{~g}$

Sensibilidade: $100 \mathrm{mV} / \mathrm{g}$

Frequência de ressonância: > 20 kHz

3. Shaker MB Dynamics

Tipo: Modal 50

Serial: 00736

Faixa de trabalho: 1 a $4000 \mathrm{~Hz}$

Força máxima aplicada: $220 \mathrm{~N}$
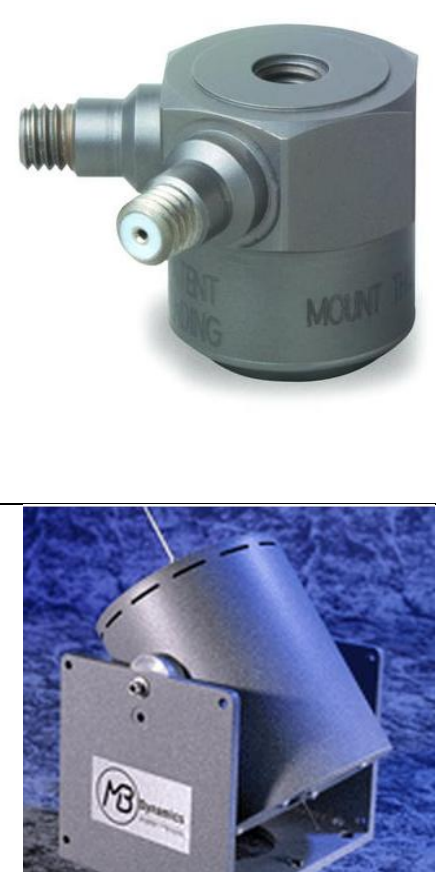

4. Analisador de sinal LMS

Tipo: SCADAS - SCM 01

Capacidade: 24 canais

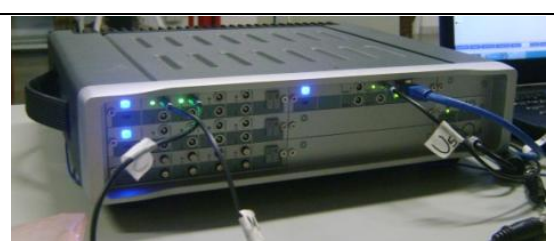


5. Amplificador de sinal MB Dynamics Tipo: SL500VCF

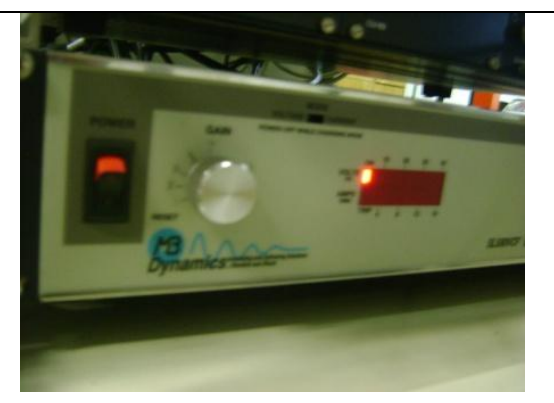

6. Câmera infravermelho FLIR

Modelo: FLIR E40

Resolução da imagem: 160x120 pixels

Intervalo de trabalho: -20 a $650{ }^{\circ} \mathrm{C}$

Sensibilidade térmica: $<0,07^{\circ} \mathrm{C}$

7. Laptop com cabo de rede ligado ao sistema.

Software: SignalCalc 240 Dynamic Signal Analyzer

Para esse ensaio foram tomadas três importantes precauções:

- Pintou-se a barra central com tinta spray resina acrílica preto fosco, para se minimizar os efeitos de reflexão, conforme sugerido por ITC (2008);

- Resfriou-se o ambiente para que o contraste de temperaturas fosse captado com mais facilidade pela câmera infravermelho. Dessa forma, o ambiente era resfriado com ar condicionado até atingir cerca de 15 graus celsius, e em seguida o mesmo era desligado para que ocorresse o ensaio. Esse procedimento foi repetido em cada etapa do ensaio;

- Posicionou-se, atrás da barra central, uma placa de madeira, que ficava armazenada em um ambiente a aproximadamente 25 graus enquanto o recinto do ensaio era resfriado. Dessa forma o contraste da barra central com o fundo era muito melhor visualizado nas imagens termográficas.

Assim sendo, a Figura 5.7 mostra imagens do aparato experimental utilizado. 

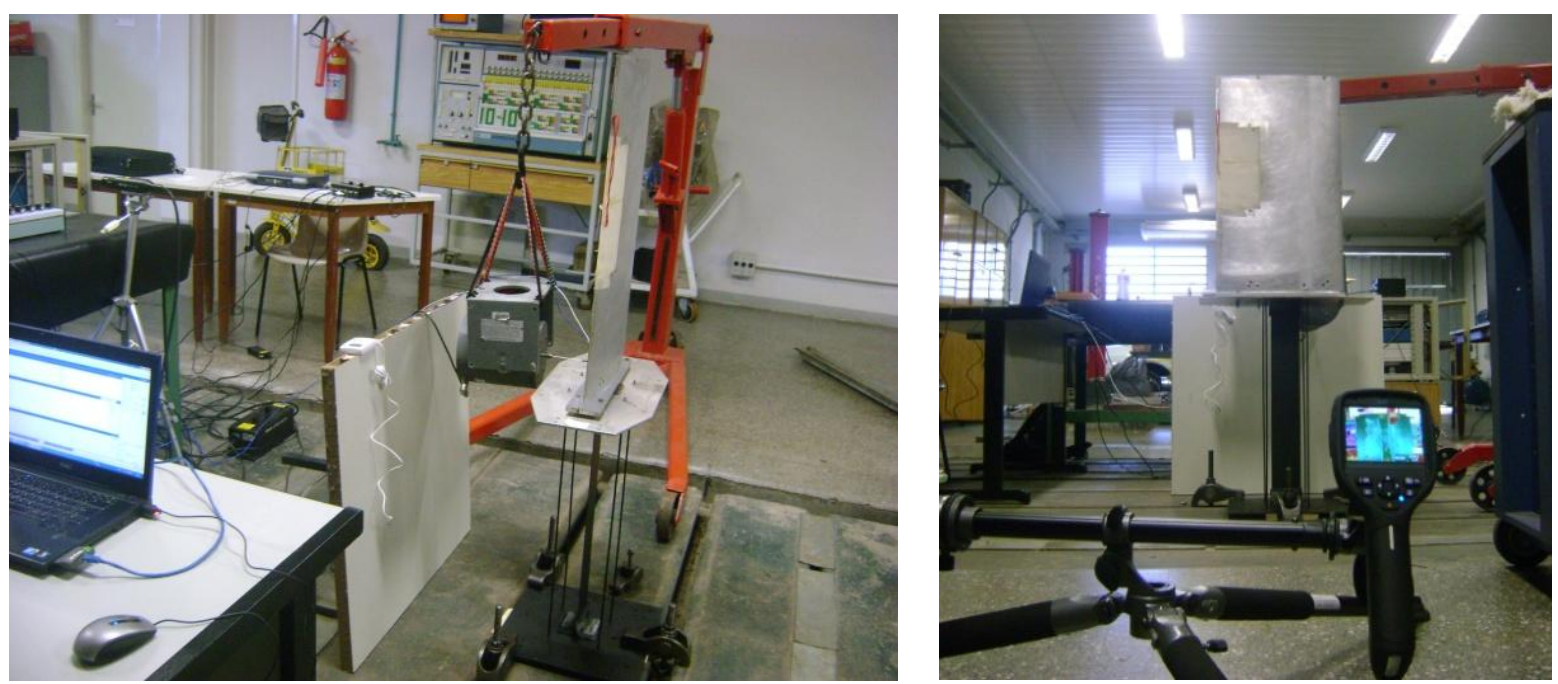

Figura 5.7 - Fotos do experimento realizado para validação do modelo termomecânico

Neste experimento foram realizadas duas baterias de testes. Em cada uma delas a estrutura foi excitada na frequência natural dos dois primeiros modos. Dessa forma, os resultados de cada bateria serão analisados separadamente a seguir.

\subsubsection{Flexão}

Para o ensaio em flexão, a estrutura foi excitada e as condições de ensaio são as citadas abaixo:

Frequência de excitação: $1,5 \mathrm{~Hz}$

Temperatura ambiente: $18^{\circ} \mathrm{C}$

Os resultados foram obtidos com a câmera, na forma de filmagens e fotos em infravermelho. Tais imagens foram manipuladas utilizando-se o software FLIR QuickReport 1.2 SP2, fornecido pela fabricante do equipamento.

Assim sendo, os resultados obtidos são mostrados na Figura 5.8, onde a figura da esquerda mostra a estrutura no seu ponto neutro (não deformada) e a figura da direita mostra a estrutura no seu ponto de máxima deformação, ou seja: quando o shaker atingiu sua deflexão máxima. 


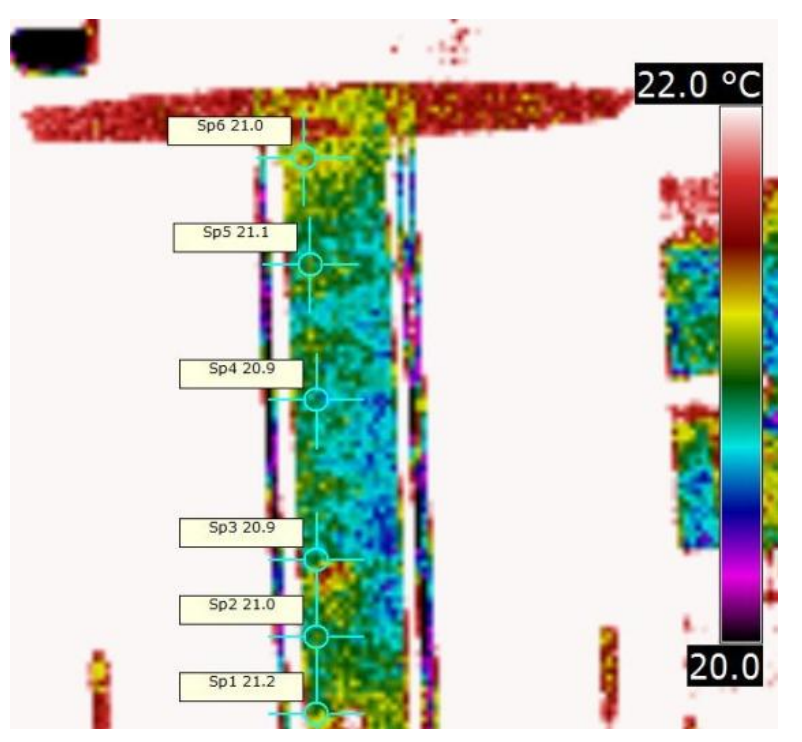

(a)

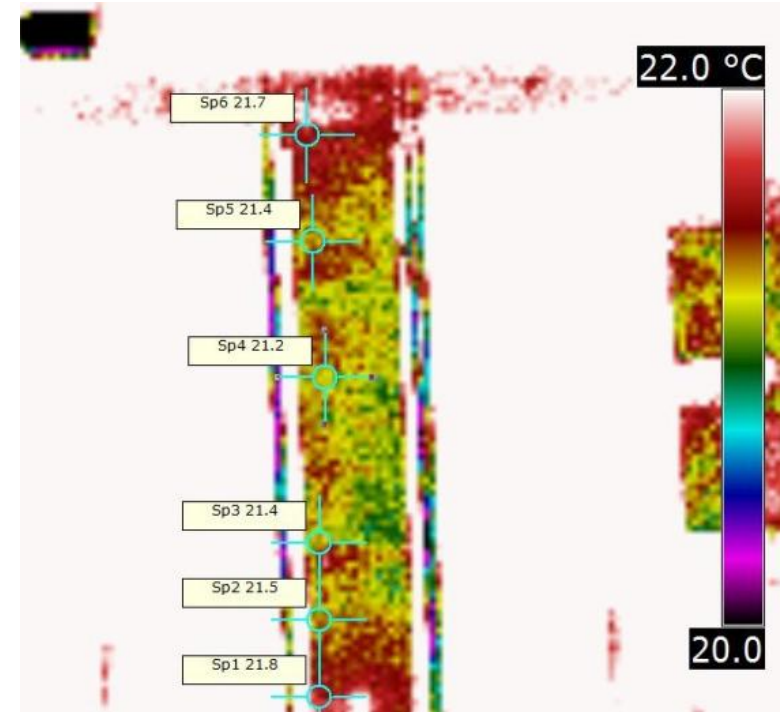

(b)

Figura 5.8 - Imagens infravermelho da estrutura excitada em flexão, em seu ponto neutro (a) e no ponto de máxima deflexão (b)

$\mathrm{Na}$ imagem foram marcados cinco pontos onde o software fornece numericamente a temperatura. Em ambas as figuras foram marcados os mesmos pontos, e pode-se observar que, entre a imagem da barra sem deflexão e a da barra defletida, houve uma mudança considerável na temperatura. Pode-se observar, ainda, que na região central da barra o aumento de temperatura foi consideravelmente menor do que nas extremidades $\left(0,3{ }^{\circ} \mathrm{C}\right.$ contra $\left.0,7^{\circ} \mathrm{C}\right)$, confirmando a previsão do modelo numérico.

Para manipulação da imagem, porém, o software possui um limitante bastante considerável: seu gradiente de temperaturas para análise de vídeos é de no mínimo $4^{\circ} \mathrm{C}$, e para a análise de imagens, é de no mínimo $2^{\circ} \mathrm{C}$, sendo que nesse último caso o gradiente pode ser modificado no pós-processamento da imagem, o que não é possível no processamento de vídeos.

Por esse motivo, foi utilizado um outro recurso do software: o mesmo fornece uma tabela em Excel, onde cada pixel da imagem gera uma célula no arquivo, com o valor da temperatura naquele pixel. Com essa ferramenta, foram isolados os pixels correspondentes à barra central da estrutura e, utilizando uma rotina em Matlab, os dados foram filtrados e plotados em um gráfico de cores, que pode ser visualizado na Figura 5.9.

Neste gráfico é possível se observar que o gradiente de temperaturas fica mais adequado às condições do ensaio, já que passa a ser de aproximadamente $1{ }^{\circ} \mathrm{C}$, o que possibilita uma 
distinção melhor das regiões da imagem, sendo possível se caracterizar mais facilmente o modo de flexão, conforme foi previsto pelo modelo.

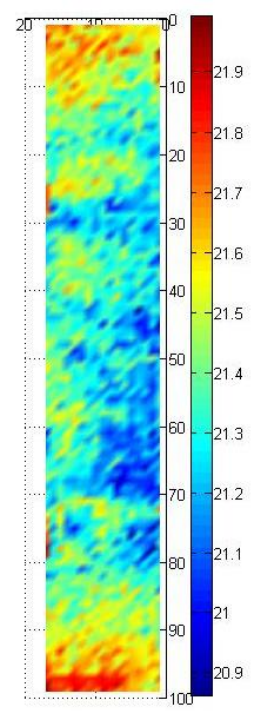

Figura 5.9 - Temperatura de cada pixel da barra central plotado pelo Matlab

Para melhor visualização do resultado previsto pelo modelo, o resultado experimental bruto e o resultado experimental após tratamento dos dados, foi gerada a Figura 5.10, que apresenta os três resultados lado a lado para comparação direta.

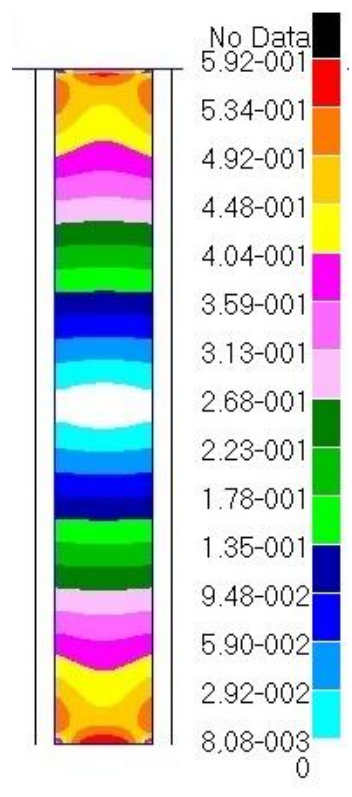

(a)

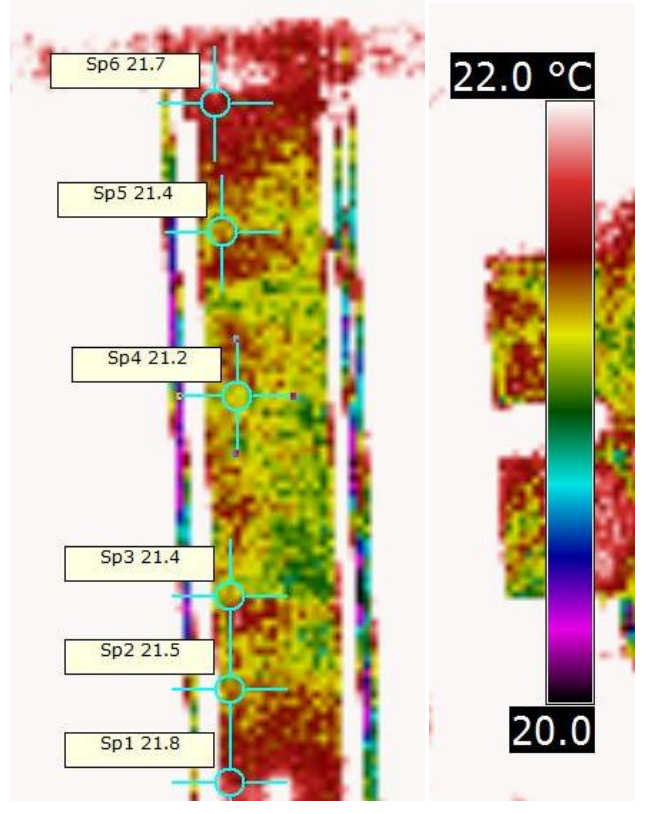

(b)

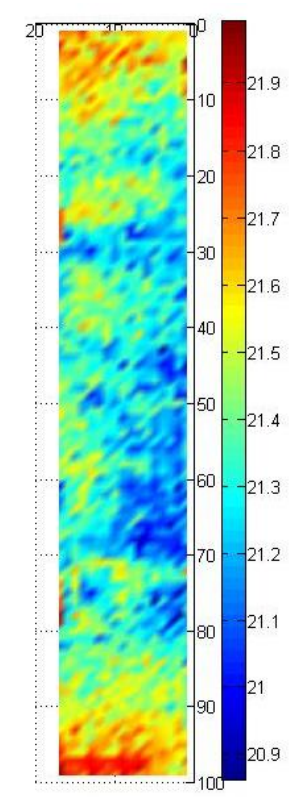

(c)

Figura 5.10 - Comparativo entre os resultados obtidos pelo modelo termomecânico (a), dados experimentais (b) e dados experimentais com tratamento (c) 
Comparando-se os dados observa-se que o comportamento dos resultados experimentais são bastante semelhantes ao modelo, com variação de temperatura de aproximadamente $0,5^{\circ} \mathrm{C}$ entre o meio da barra e suas extremidades. Qualitativamente pode-se observar um padrão de temperaturas muito parecido com o do modelo, permitindo afirmar que os dados são consistentes e o modelo apresenta resultados satisfatórios.

\subsubsection{Torção}

Para o ensaio em torção, foi realizado o mesmo procedimento nas condições de ensaio descritas abaixo:

Frequência de excitação: $3,0 \mathrm{~Hz}$

Temperatura ambiente: $16^{\circ} \mathrm{C}$

Analogamente ao caso anterior, são mostrados na Figura 5.11, a estrutura no seu ponto neutro (não deformada) à esquerda e a figura da direita mostra a estrutura no seu ponto de máxima deformação.

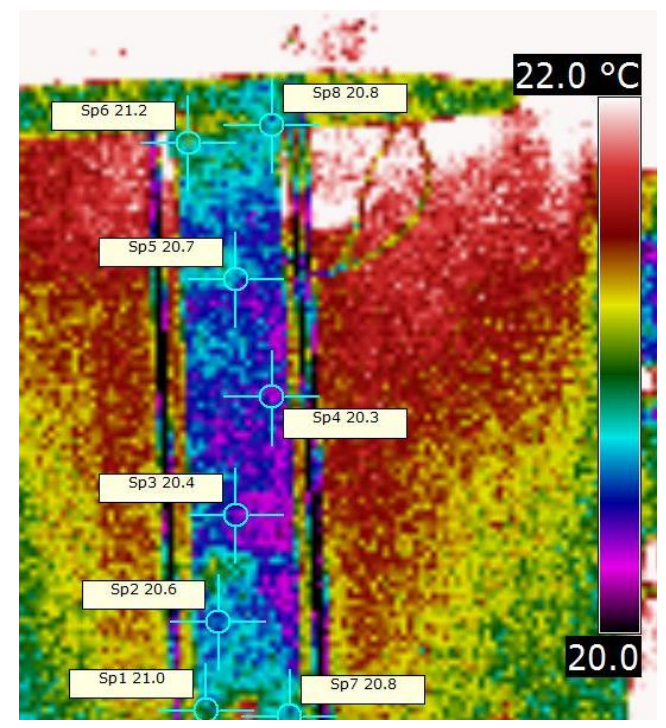

(a)

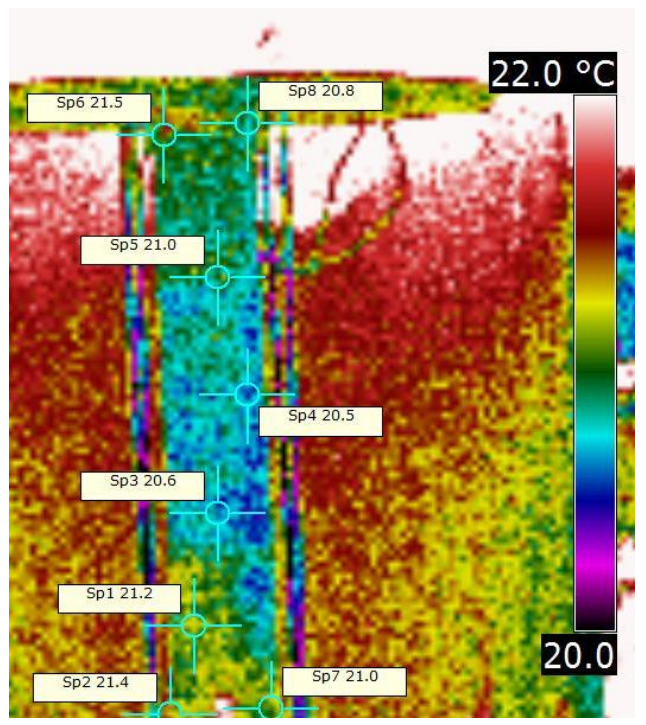

(b)

Figura 5.11 - Imagens infravermelho da estrutura excitada em torção, em seu ponto neutro (a) e no ponto de máxima deflexão (b)

Assim como feito anteriormente, foram marcados pontos para a medição da temperatura, sendo marcados os mesmos pontos em ambas as figuras. O que se observa novamente é um comportamento semelhante ao previsto pelo modelo. 
Novamente os dados de temperatura de cada pixel foram manipulados utilizando-se o software Matlab para traçar um gráfico de cores indicando a temperatura de cada região. $\mathrm{O}$ resultado pode ser visualizado na Figura 5.12.

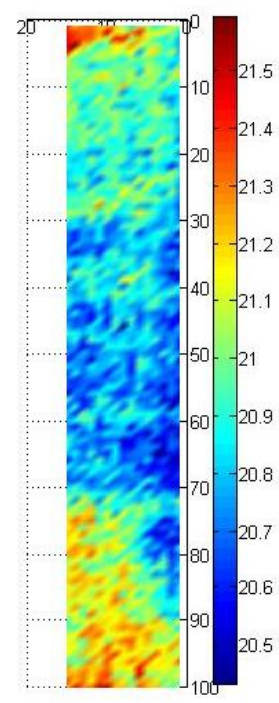

Figura 5.12 - Temperatura de cada pixel da barra central plotado pelo Matlab

Assim como no caso anterior, pode-se observar mais claramente o comportamento do espectro de temperaturas nesse caso, se comparado à imagem infravermelho pura, $\operatorname{com} 2^{\circ} \mathrm{C}$ de intervalo para visualização.

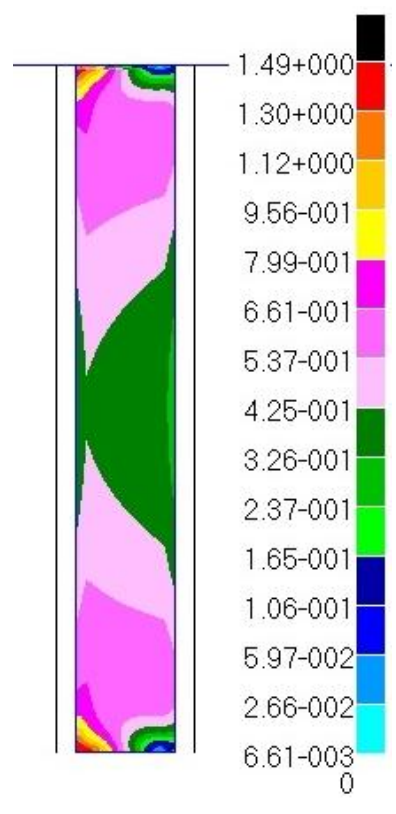

(a)

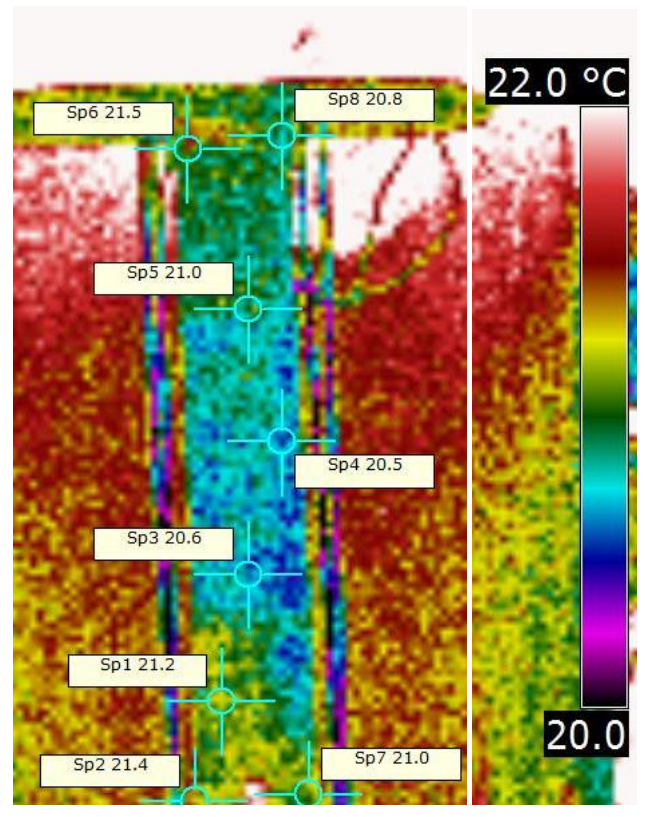

(b)

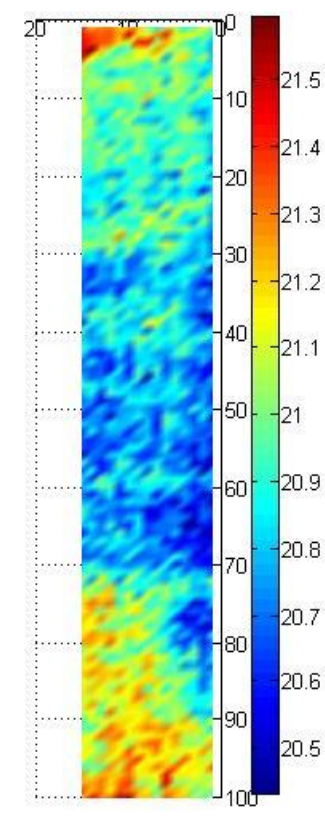

(c)

Figura 5.13 - Comparativo entre os resultados obtidos pelo modelo termomecânico (a), dados experimentais (b) e dados experimentais com tratamento (c) 
Da mesma forma que o caso anterior, foram plotados para fins de comparação, na Figura 5.13, os três casos obtidos: a previsão do modelo (a), a imagem infravermelho sem tratamento (b) e a imagem com os dados tratados, plotados em Matlab (c).

Mais uma vez pode-se observar um comportamento bastante semelhante entre a previsão do modelo e os dados obtidos experimentalmente, com uma diferença de aproximadamente $1{ }^{\circ} \mathrm{C}$ entre a região mais quente e a região central da estrutura, com um padrão de distribuição de temperaturas bastante semelhante entre os dados experimentais e o modelo, permitindo mais uma vez afirmar que os dados são consistentes e o modelo apresenta resultados satisfatórios.

\subsection{Detecção de flutter com imageamento infravermelho}

A fim de se verificar a possibilidade de detecção de flutter utilizando imageamento infravermelho, um experimento foi montado com a estrutura estudada até aqui nesse trabalho.

Para tal, a asa foi posicionada num soprador aerodinâmico e a barra central do suporte flexível foi filmada com uma câmera infravermelho. A velocidade do ar foi variada e cada velocidade diferente era medida com um pitot. As condições atmosféricas também foram monitoradas constantemente.

A Figura 5.14 mostra um esquema do aparato experimental e apresenta cada elemento presente no mesmo.

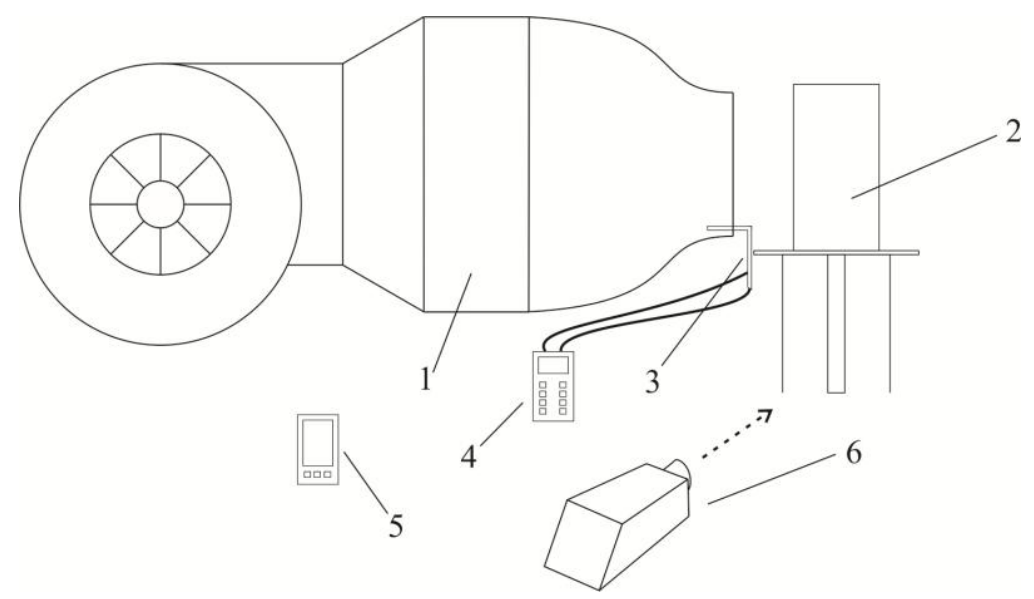

Figura 5.14 - Aparato experimental para detecção de flutter com imageamento infravermelho 
1. Soprador aerodinâmico

Velocidade maxima: $32 \mathrm{~m} / \mathrm{s}$

Rotação maxima do motor: 1175 rpm

Potência maxima do motor: $40 \mathrm{Hp}$

Dimensões da seção de escoamento:

$780 \times 1050 \mathrm{~mm}$

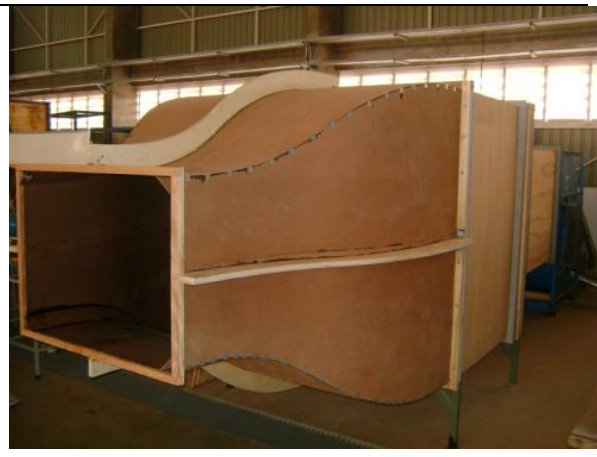

2. Estrutura asa/suporte flexível

3. Tubo de pitot

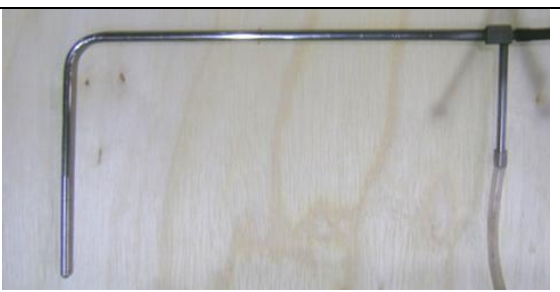

4. MicromanômetroDigital TSI

Modelo: DPCalc 8705-M-GB

Serial: 54120589

Regulado para fornecer sinal de

velocidade $\mathrm{em} \mathrm{m} / \mathrm{s}$

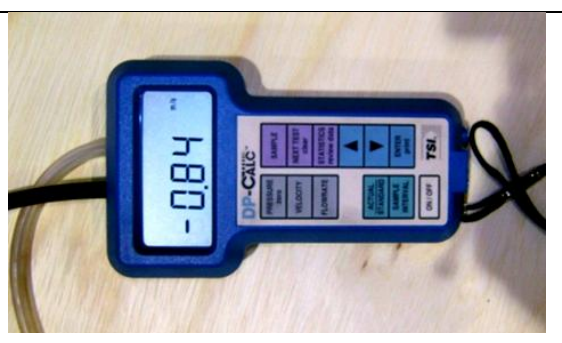

5. Estação meteorológica portátil digital Instrutemp ITWH 1170

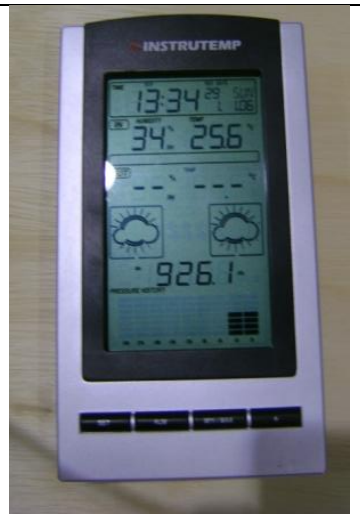

6. Câmera infravermelho FLIR Modelo: FLIR P620

Resolução da imagem: 640x480 pixels

Intervalo de trabalho: -40 a $500{ }^{\circ} \mathrm{C}$

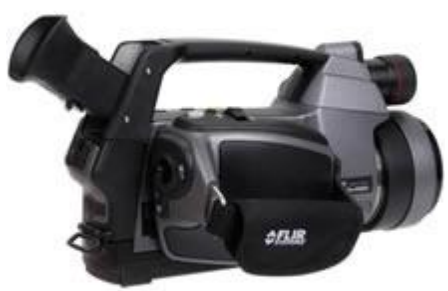

Sensibilidade térmica: $<0,04{ }^{\circ} \mathrm{C}$ 
Conforme já justificado anteriormente, o contraste de temperaturas é intensificado nesse caso se a estrutura sofrer um resfriamento. Para isso, a cada medição o suporte flexível era resfriado utilizando-se um extintor de incêndio de gás carbônico.

Outro fator positivo deste caso estudado é que a barra a ser filmada não está imersa no escoamento aerodinâmico, o que poderia dificultar a visualização de um contraste de temperaturas, já que a sensação térmica causada pelo vento também deveria ser embutida na análise dos dados obtidos.

A Figura 5.15 mostra uma foto da execução do experimento.

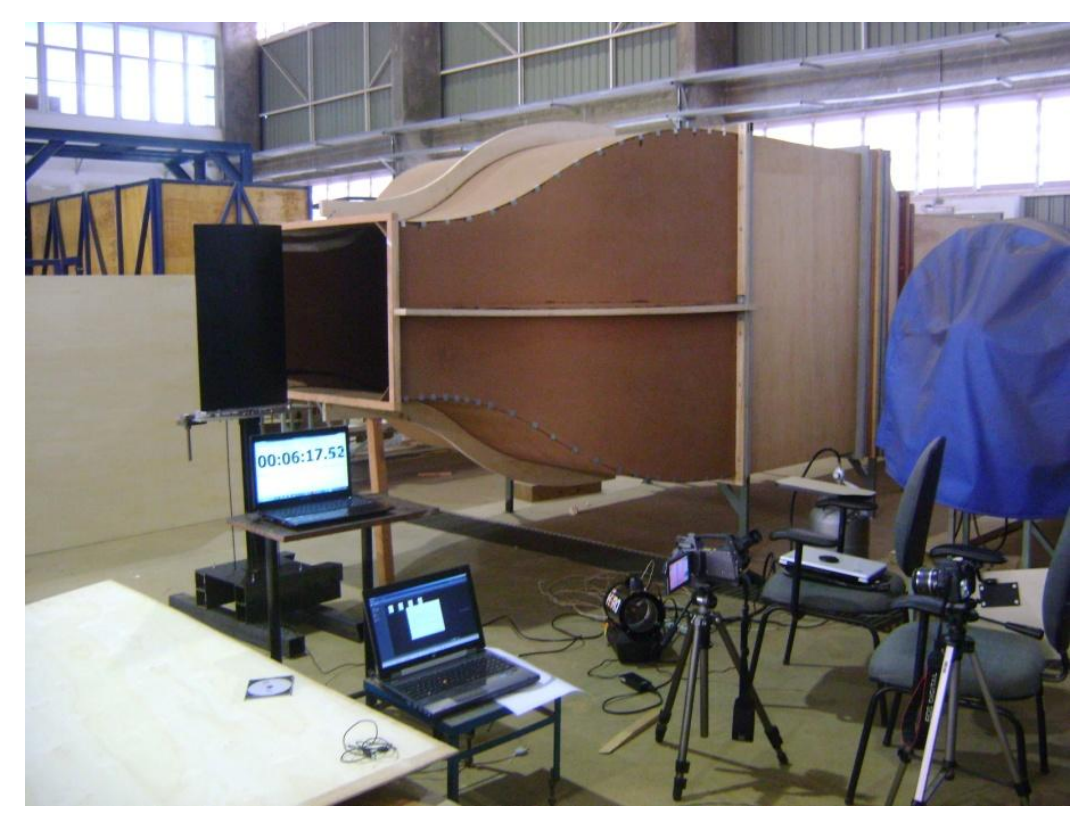

Figura 5.15 - Experimento para detecção de flutter com imageamento infravermelho

Para a análise destes resultados, verificou-se que não foi necessário o tratamento da imagem com a rotina em Matlab, já que o resfriamento neste ensaio foi mais hostil, o que tornou o contraste mais forte. Além disso, a resolução maior da câmera modelo P620 permitiu imagens com melhor qualidade e mais fáceis de serem analisadas.

A Figura 5.16 mostra uma série de fotos da estrutura em imageamento infravermelho, em diversas velocidades abaixo da de condição de flutter: (a) $6,0 \mathrm{~m} / \mathrm{s}$; (b) 10,5 m/s; (c) $18,4 \mathrm{~m} / \mathrm{s} \mathrm{e}$ (d) $20,6 \mathrm{~m} / \mathrm{s}$. Pode-se observar padrões de distribuição e valores de temperaturas bastante semelhantes. Todas as imagens apresentadas nesta figura estão na mesma escala de cores e temperaturas. 


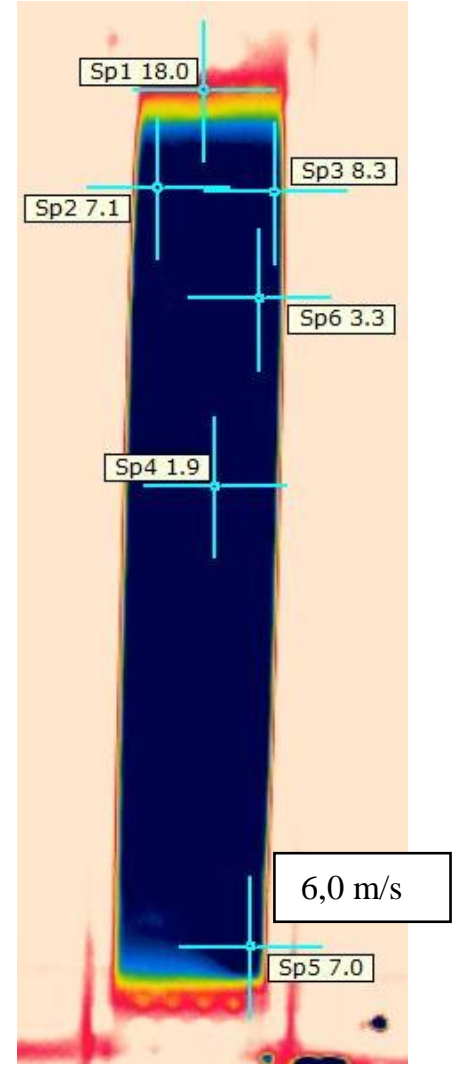

(a)

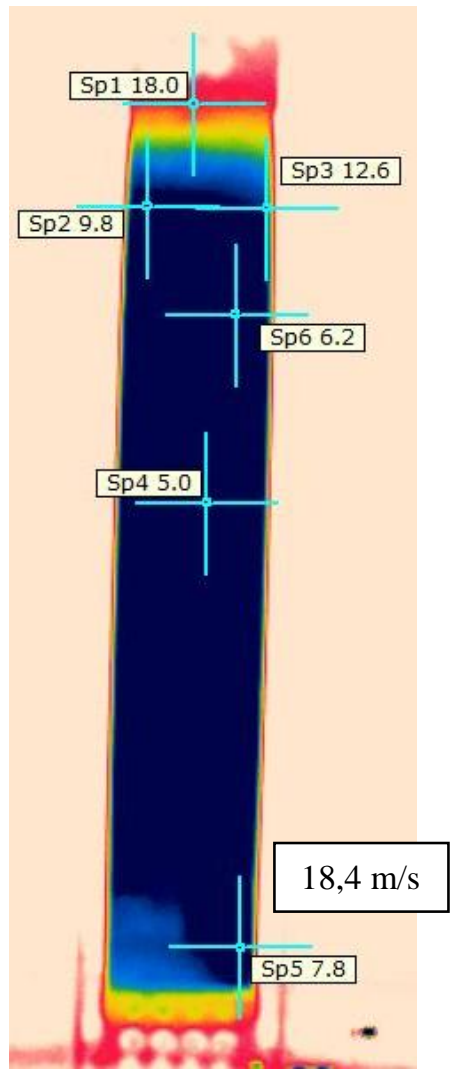

(c)
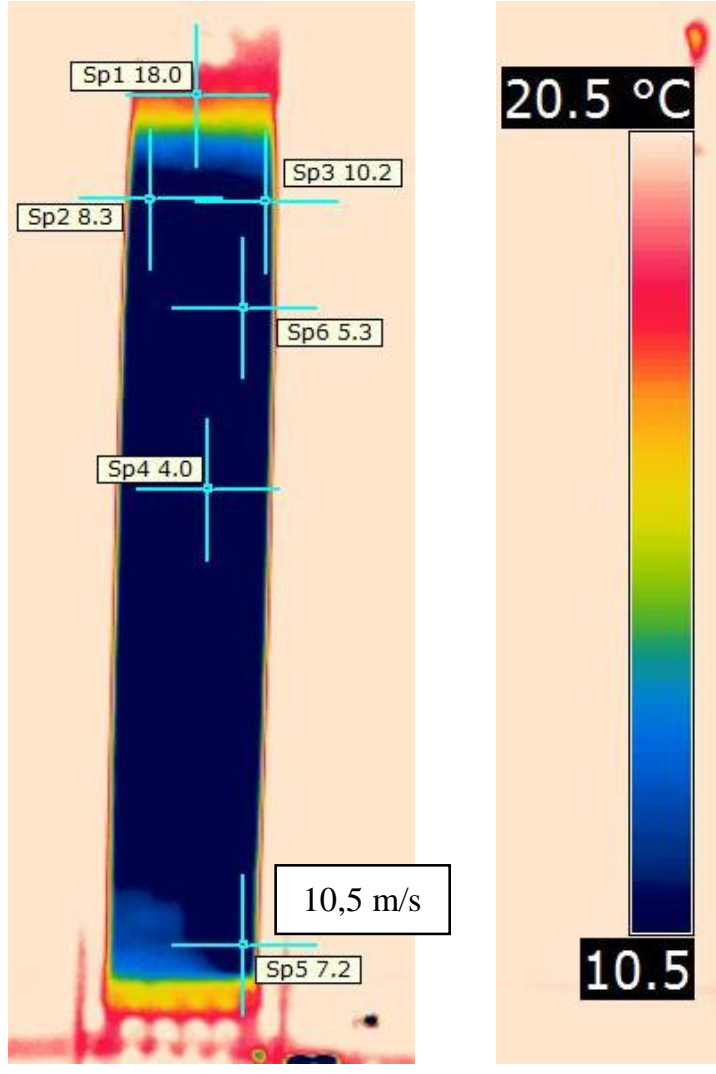

(b)
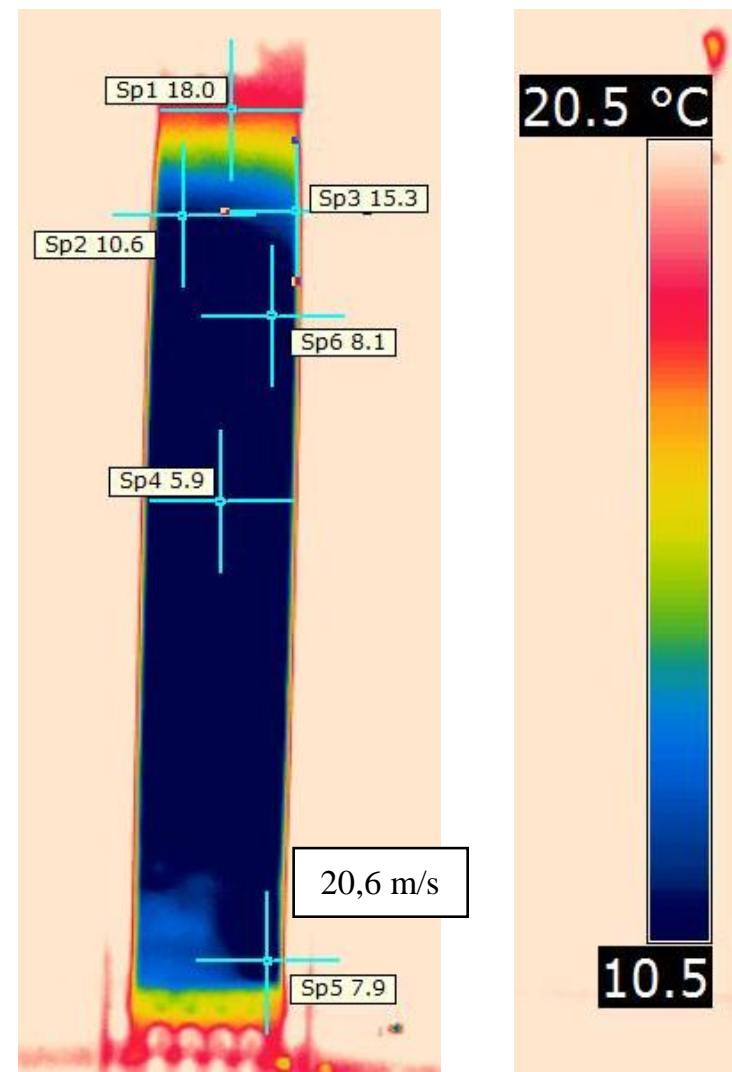

(d)

Figura 5.16 - Imagens infravermelho da estrutura a velocidades inferiores à de flutter 
Analisando-se os resultados, as seguintes observações podem ser consideradas:

- Os pontos mais quentes da estrutura não sofrem mudança de temperatura. Por já estarem quase em equilíbrio térmico com o ambiente, essa variação é nula, conforme observado nos pontos assinalados como Sp1;

- Nos pontos frios onde não é prevista uma concentração grande de tensões, há um pequeno aumento na temperatura, devido à troca de calor com o ambiente em função do tempo, como mostram os pontos $\mathrm{Sp} 4$ e Sp5;

- Nos pontos onde uma maior concentração de tensões é esperada, a variação de temperatura é mais pronunciada com o aumento da velocidade do escoamento, como se vê nos pontos Sp2, Sp3 e Sp6;

- Essa variação de temperatura mostra um padrão de flexão, que pode ser observado comparando-se os pontos Sp3 e Sp6;

- Pode ser observado também um padrão em torção, se comparados os pontos Sp2 e Sp3, além do padrão de cores na extremidade superior da estrutura, conforme ocorre o aumento da velocidade.

A Figura 5.17 apresenta imagens da estrutura em flutter. Para se obter essa condição, a asa ficou exposta a um escoamento aerodinâmico de $26,4 \mathrm{~m} / \mathrm{s}$. Nessa condição, diversas fotos com imageamento infravermelho foram obtidas, sendo algumas delas ilustradas nesta figura.

É importante salientar que antes do ensaio em condição de flutter, a estrutura foi novamente resfriada, ficando com a temperatura homogênea ao longo da sua superfície. Por esse motivo a Figura 5.17 apresenta uma nova escala de cores e o padrão de distribuição de temperaturas foi novamente formado a partir de uma condição homogênea.

Pode-se observar que em condição de flutter, o padrão de temperaturas segue a mesma tendência das figuras anteriores, porém com diferenças de temperaturas mais pronunciadas, tornando a visualização mais fácil.

Observa-se também as mesmas tendências de deformação em flexão e em torção, comparando os pontos em que a temperatura é medida numericamente, analogamente ao caso anterior. 

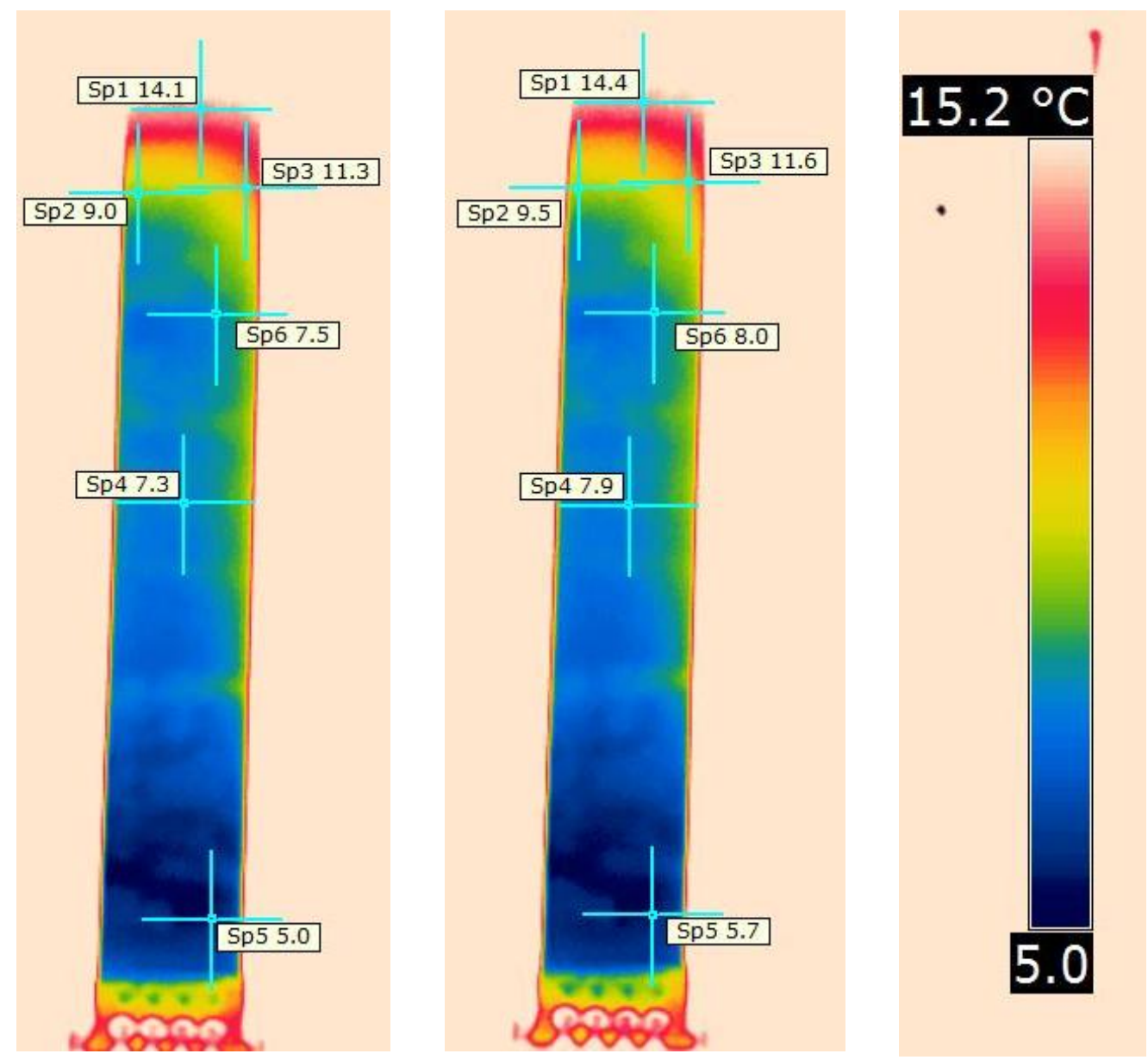

Figura 5.17 - Imagens infravermelho da estrutura em condição de flutter

Uma diferença, porém, pode ser observada nos padrões de temperaturas antes e depois de atingida a condição de flutter: nota-se que a parte inferior da estrutura (lado engastado) fica mais fria que a parte superior, apesar de ser uma região onde é prevista uma alta concentração de tensões.

Esta diferença pode-se atribuir ao fato de que, quando sujeita a flutter, a estrutura está em movimento oscilatório, o que produz uma troca de calor por convexão forçada na região superior da estrutura, fazendo com que ela aqueça mais rapidamente, de forma a entrar em equilíbrio com a temperatura ambiente. Apesar disso, ainda assim a diferença de temperaturas ao longo da superfície da estrutura permite identificar a concentração de tensões causada pela deformação e consequentemente identificar o acúmulo de energia envolvido devido à ocorrência de flutter. Portanto considera-se que o método é adequado para identificação do fenômeno e com alguns novos desenvolvimentos pode ser utilizado em aplicações reais em aeronaves. 


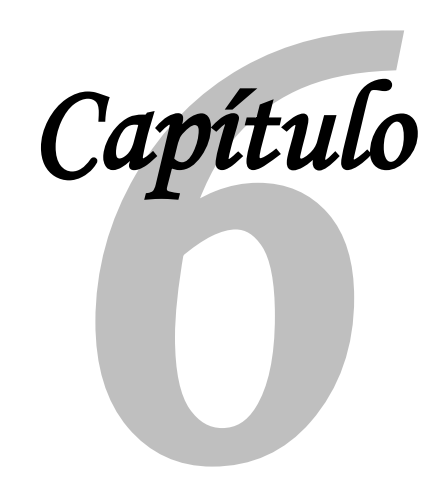

\section{Considerações finais}

Após a exposição deste trabalho, algumas considerações finais são feitas, dividindo-as em três tópicos: um relativo às conclusões obtidas, o segundo apresentando as dificuldades e limitações encontradas durante este trabalho e o último com apresentação de propostas para trabalhos futuros.

\subsection{Conclusões}

Diante do exposto, algumas conclusões puderam ser obtidas:

- Imageamento infravermelho é uma ferramenta eficiente para detecção de processos que envolvem variações de temperatura, já que a emissão de ondas em frequência infravermelho é maior do que a de onda visível em objetos a temperatura abaixo de $5000 \mathrm{~K}$;

- A detecção de flutter pode ser realizada com imageamento infravermelho, visto que, de acordo com os modelos teóricos apresentados e testados nesse trabalho, regiões com acúmulo de tensão apresentam aumento significativo de temperatura, detectáveis por esse tipo de visualização;

- Tecnologia infravermelho também pode ser utilizada para medição da forma de modos de vibrar, pelos mesmos motivos e com o uso dos mesmos modelos citados no item anterior, com resultados bastante consistentes; 
- Os modelos teóricos construídos com a finalidade de se obter o aumento local de temperaturas apresentou resultados consistentes e que puderam ser validados experimentalmente;

- O uso dessa tecnologia para os fins supracitados é importante, já que com a tendência de se fazer estruturas cada vez mais leves, a massa dos sensores utilizados em análises modais ou ensaios de flutter passam a ter influência significativa;

- A metodologia aqui apresentada mostrou-se confiável e segura, conforme era a intenção descrita no início deste trabalho;

- Acredita-se que com algumas adaptações é possível se utilizar essa metodologia em ensaios em voo, seja para flutter ou para outras aplicações aeronáuticas, reduzindo-se o tempo e custo e aumentando a segurança neste tipo de ensaio;

- A detecção de flutter através de imageamento infravermelho é uma técnica inovadora e que não foi encontrada na bibliografia técnica atual, mostrando-se uma metodologia inédita.

\subsection{Limitações}

Durante o desenvolvimento desse trabalho, a maior limitação que pode ser citada foi relativa à obtenção de câmeras de imageamento infravermelho. As duas câmeras obtidas foram por empréstimo da iniciativa privada e os modelos não correspondiam ao ideal para essa aplicação. Além disso, sempre que as câmeras foram obtidas, era para uso em tempo restrito, o que impossibilitou a obtenção de dados com melhor qualidade. As duas câmeras utilizadas, modelos FLIR E40 e FLIR P620 têm os dados técnicos descritos no Anexo A deste texto.

Para trabalhos futuros se almeja a obtenção de câmeras mais adequadas para essas aplicações, possibilitando novos métodos e obtendo qualidade mais elevada nas medições. A intenção é se obter uma câmera modelo SC5000, cujo descritivo técnico se encontra no mesmo anexo. Em comparação com as utilizadas, nota-se um considerável aumento de qualidade nas imagens por ter maior sensibilidade térmica, melhor precisão, melhor resolução da imagem e maior frequência na obtenção das imagens. 


\subsection{Proposta para trabalhos futuros}

Como continuação deste trabalho, algumas propostas podem ser feitas, como por exemplo:

- Realização desses ensaios com modelos de câmera mais adequados;

- Utilização dessa técnica em estruturas mais complexas, com aplicação do modelo teórico e posterior ensaio para verificação dos resultados;

- Detecção de flutter (modelo e ensaios) em estruturas que estejam imersas no escoamento aerodinâmico;

- Tentativa de realização desses testes em estruturas de materiais mais complexos, como fibras ou compósitos;

- Utilização desta técnica para detecção de outros fenômenos aeronáuticos, como buffeting onset, transição de camada limite, entre outros 
Intencionalmente em branco 


\section{Capítulo}

\section{Referências $^{1}$}

ABBOT, I. H. ; VON DOENHOFF, A. E. Theory of wing sections, Dover Publications, Inc. New York, 1959.

ANDERSON, J.D. Fundamentals of aerodynamics. 2nd ed. McGraw-Hill, New York, 1991

BANKS, D. W. Visualization of In-Flight Flow Phenomena Using Infrared Thermography. NASA TM-2000-209027, 2000.

BEER, F. P. ; JOHNSTON JR, E. R. ; DEWOLF, J. T. Resistência dos Materiais: Mecânica dos Materiais. Tradução de Mario Moro Fecchio. 4. ed. AMHG, Porto Alegre, 2010.

BENINI, G. R. Modelo Numérico para Simulação da Resposta Aeroelástica de Asas Fixas. Dissertação (Mestrado) - Escola de Engenharia de São Carlos, Universidade de São Paulo, 2002.

BOWERS, P. M. Aeronaves não-convencionais. Editora Lutécia, Brasil, 1984.

BREWER, G. The Collapse of Monoplane Wings, Flight, v. V, n. 211, p. 33, Jan. 1913.

BRINSON, L. C. One-Dimensional Constitutive Behavior of Shape Memory Alloys: Thermomechanical Derivations with Non-Constant Material Functions and Redefined Martensite Internal Variable. Journal of Intelligent Material Systems and Structures, v. 4, p. 229-242, 1993.

BFU - BUNDESSTELLE FÜR FLUGUNFALLUNTERSUCHUNG (GERMAN FEDERAL BUREAU OF AIRCRAFT ACCIDENT INVESTIGATION). Investigation Report 3X1810/06, Braunschweig, 2010.

\footnotetext{
${ }^{1}$ De acordo com a Associação Brasileira de Normas Técnicas. NBR 6023.
} 
BISPlingHOFF, R. L. ; ASHLEY, H. ; HALFMAN, R. L. Aeroelasticity. Addison-Wesley Publishing Company, USA, 1955.

BRENNER, M. J. ; LIND, R. C. ; VORACEK, D. F. Overview of recent flight flutter testing research at NASA Dryden. NASA TM-4792, 1997.

CENTRO DE CIÊNCIAS DA EDUCAÇÃO. Lâmpadas Incandescentes, 2008. Disponível em <http://www.ced.ufsc.br/men5185/trabalhos/63_lampadas/incand/funciona04.htm>. Acesso em 22 jan. 2014.

CLIFTON, J. M. Introduction to Avionics Flight Test. AGARDograph, London, v. 15, 1996.

COLLAR, A.R. The Expanding Domain of Aeroelasticity. The Journal of the Royal Aeronautical Society, v. 50, p. 613-636, 1946.

Aeroelasticity - Retrospect and Prospect, The Journal of the Royal Aeronautical Society, v. 63, n. 577, p. 1-15, 1959.

COSTA, T. G. F. Estudo Numérico de uma Asa com Controle Ativo de 'flutter' por Realimentação da Pressão Medida Num Ponto. Dissertação (Mestrado) - Escola de Engenharia de São Carlos, Universidade de São Paulo, 2007.

DANSBERRY, B.E.; DURHAM, M.H.; BENNETT, R.M.; TURNOCK, D.L.; SILVA, E.A.; RIVERA Jr., J.A. Physical properties of the benchmark models program supercritical wing. NASA TM-4457, 1993

DE MARQUI Jr., C. Estudo teórico e experimental de um controlador para supressão de 'flutter'. Tese (Doutorado) - Escola de Engenharia de São Carlos, Universidade de São Paulo, 2004.

DE MARQUI Jr., C. ; BENINI, G. R. ; BELO, E. M. Uma revisão histórica do fenômeno 'flutter'. In: XVI Congresso Brasileiro de Engenharia Mecânica, 2001, Uberlândia. Proceedings of COBEM 2001 - Aerospace Engineering. v. 6. p. 136-144, 2001.

DE MARQUI Jr., C. ; REBOLHO, D. ; BELO, E. M. ; MARQUES, F. D. ; TSUNAKI, R. H. Design of an Experimental Flutter Mount System, Journal of the Brazilian Society of Mechanical Sciences and Engineering, v. XXIX, n. 3, p. 246-252, 2007.

DEHNE, T. ; BOSBACH, J. ; HEIDER, A. Dynamics of Arcraft Cabin Ventilation by Inflight Infrared Thermography. In: $11^{\text {th }}$ International Conference on Quantitative InfraRed Thermography, QIRT, Naples, Italy, 2012. 
DOWELL, E.H. Modern Course in Aeroelasticity. Kluwer Academic Publishers, Netherland, 1995.

DOWELL, E.H. ; CLARK, R. ; COX, D. ; CURTISS JR., H. C. ; ESWARDS, J. W. ; HALL, K. C. ; PETERS, D. A. ; SCANLAN, R. ; SIMIU, E. ; SISTO, F. ; STRGANAC, T. W. A Modern Course in Aeroelasticity. Kluwer Academic Publishers, $4^{\text {th }}$ revised and enlarged edition, Netherland, 2004.

FEDERAL AVIATION ADMINISTRATION - U.S. DEPARTMENT OF TRANSPORTATION. Flight Guide for Certification of Transport Category Airplanes AC25-7A. March, 1998.

. Code of Federal Regulations, U.S. Government Printing Office, Washington, 2000.

FISHER, D. ; HORSTMANN, K. H. ; RIEDEL, H. Flight Test MeasurementTechniques for Laminar Flow. AGARDograph, London, v. 23, 2003.

FLIR SYSTEMS. Application Story - DLR Dornier 228. FLIR Systems Co. Ltd. Hong Kong, 2011. Catálogo.

Application Story - Dassault Falcon 7X. FLIR Advanced Thermal Solutions. France, 2012a.

The Ultimate Infrared Handbook for R\&D Professionals. FLIR Systems AB. Sweden, 2012b.

Thermography Product Catalog. FLIR Systems AB. Sweden, 2012c.

FUJINO, M. ; YOSHIZAKI, Y. ; KAWAMURA, Y. Natural-Laminar-Flow Airfoil Development for a Lightweight Business Jet. Journal of Aircraft, v. 40, n. 4, p. 609-615, 2003.

FUNG, Y. C. The Theory of Aeroelasticity. John Wiley \& Sons Inc., Estados Unidos, 1955.

GARRICK, I. E. Aeroelasticity - Frontiers and Beyond, Journal of Aircraft, v. 36, n. 9, p. 105-121, 1976.

GARRICK, I. E.; REED, W. H. Historical Development of Aircraft Flutter, Journal of Aircraft, v.18, n. 11, p. 897-912, 1981. 
GUY, A. G. Essentials of Materials Science. McGraw-Hill, Inc., 1976.

HOAK, D. E. ; ELLISON, D. E. USAF Stability and Control DATCOM. Revised. Airforce Flight Dynamics Laboratory. Wright-Patterson Air Force Base, Ohio, 1965.

HODGES, D. H. ; PIERCE, G. A. Introduction to Structural Dynamics and Aeroelasticity. Cambridge University Press, 2002.

HOLST, G. C. Electro-optical Imaging System Performance. JCD Publishing, $3^{\text {rd }}$ ed., 2003.

HOUGHTON, E. L. ; CARPENTER, P. W. Aerodynamics for engineering students. 5th ed. Elsevier Butterworth-Heinemann, 2004.

HUDSON JR., R. D. Infrared System Engineering. John Wiley \& Sons, New York, USA, 1969.

ITC - INFRARED TRAINING CENTER. Termografia Nível 1 - Apostila, 2008.

KEHOE, M. W. A historical overview of flight flutter testing. NASA TM-4720, 1995.

LEE, H. T. ; CHEN, J. C. ; WANG, J. M. Thermomechanical behaviour of metals in cycling loading. Journal of Materials Science, v. 28, p. 5500-5507, 1993.

LIND, R. A Presentation on Robust Flutter Margin Analysis and a Flutterometer. NASA TM-97-206220, 1997

Flight-Test Evaluation of Flutter Prediction Methods. Journal of Aircraft, v. 40, n. 5, p. 964-970, 2003.

LIND, R. ; FREUDINGERL. C. ; VORACEK, D. F. Comparison of Aeroelastic Excitation Mechanisms. Journal of Aircraft, v. 35, n. 5, p. 830-832, 1998.

MAlERBA, M. ; ARGENTO, M. ; SAlViUOlO, A. ; ROSSI, G. L. A Boundary Layer Inspection on a Wing Profile Through High Resolution Thermography and Numerical Methods. WSEAS Transactions on Fluid Mechanics, v. 3, n. 1, p. 18-28, 2008.

McCONnELL, K.G.; VAROTO, P.S. Vibration Testing: Theory and Practice. $2^{\text {nd }}$ ed., Hoboken: John Wiley \& Sons, 2008. 
McSHEA, R. E. Test and Evaluation of Aircraft Avionics and Weapon Systems. SciTech Publishing, Inc., Raleigh, USA, 2010.

MEIROVITCH, L. Dynamics and Control of Structures. John Wiley \& Sons, United States, 1990.

MSC.SOFTWARE CORPORATION. Introduction to MSC.Patran. Course Notes, United States, 2000

NATIONAL TEST PILOTS SCHOOL. Introduction to Performance and Flying Qualities Flight Testing, $2^{\text {nd }}$ ed., Mojave, CA, United States, 1995.

NAVAL TEST PILOTS SCHOOL. Flight test manual - Fixed Wing Performance, Theory and Flight Test Techniques, Naval Test Pilot School, Patuxent River, MD, 1992.

NITZSCHE, F. Introductory Aeroelasticity. Material de curso ministrado no LAE, ago. 2001.

OLSON, W. M. Aircraft Performance Flight Testing, Air Force Flight Test Center, United States, 2000.

PION - LIGADO NA FÍSICA. Espectro Eletromagnético, 2012. Disponível em <www.sbfisica.org.br/v1/novopion/index.php/publicacoes/imagens/130-espectroeletromagnetico>. Acesso em 22 jan. 2014.

PONTO CIÊNCIA. Emissão de um Corpo Negro, 2013. Disponível em $<$ http://pontociencia.org.br/galeria/?content\%2FFisica\%2FFisica+Moderna\%2Fcorponegro.jpg>. Acesso em 22 jan. 2014.

RAO, S. Mechanical Vibrations. Addison-Wesley, Inc., 1990

RAZO, L. M. ; SOLIS, S. ; ASOMOZA, M. ; HERNANDEZ, A. Establishment of Thermodynamic Properties of Pure Solid Substancies by Thermomechanical Analysis. Journal of Thermal Analysis, v. 45, p. 1323-1330, 1995.

ROCHA, J. C. Um controlador de Flutter Baseado em Lógica Difusa. Tese (Doutorado) Escola de Engenharia de São Carlos, Universidade de São Paulo, 2003.

SCHULZ, H. E. O Essencial em Fenômenos de Transporte. EESC-USP, São Carlos, 2003. 
SULEMAN, A. ; CRAWFORD, C. ; COSTA, A. P. Experimental Response of Piezoelectric and Aileron Controlled 3D Wing. Journal of Intelligent Material Systems and Structures, v. 13, p. 75-83, 2002.

SUTHERLAND, A. N. A Small Scale Pitch-plunge Flutter Model for Active Flutter Control Research. In: $26^{\text {th }}$ International Congress of the Aeronautical Sciences, ICAS 2008, Anchorage - USA, 2008.

VAN NUNEN, J. W. G.; PIAZZOLI, G. Aeroelastic Flight Test Techniques and Instrumentation. AGARDograph, London, v. 9 n. 160, 1979.

VAN VLACK, L. H. Princípios de Ciência dos Materiais. Edgard Blücher, São Paulo, 1992.

VAN WYlen, G. J. ; SONNTAG, R. E. Fundamentos da Termodinâmica Clássica. Edgard Blücher, São Paulo, 1970.

WARD, D. T. ; STRGANAC, T. W. ; NIEWOEHNER, R. Introduction to Flight Test Engineering, $3^{\text {rd }}$ edition, Kendall/hunt Publishing Company, United States, 2006. 2 v.

WEDEKIND, M. ; BOTH, J. ; BAIER, H. Thermo Mechanical Behaviour of Metal Matrix Composite Structure. International Journal of Material Forming, v. 3, Issue 1, p. 857-860, 2010 .

WRIGHT, J. R. ; WONG, J. ; COOPER, J. E. ; DIMITRIADIS, G. On the Use of Control Surface Excitation in Flutter Testing. Journal of Aerospace Engineering, v. 217, p. 317332, 2003.

WYATT, C. L. Radiometric System Design. Macmillan Publishing Co., New York, USA, 1987.

YANG, H. ; WANG, L. Y. Thermomecanical Analysis of Shape-Memory Composite Tape Spring. Applied Composite Materials, v. 20, Issue 3, pp.287-301, 2013.

ZUCCHER, S. ; SARIC, W. S. ; REED, H. L. ; MCNEIL, L. R. The Role of Infrared Thermogaphy in the Study of Crossflow Instability at $M=2.4$. In: $7^{\text {th }}$ International Symposium on Fluid Control, Measurement and Visualization, FLUCOME, Sorrento, Italy, 2003 


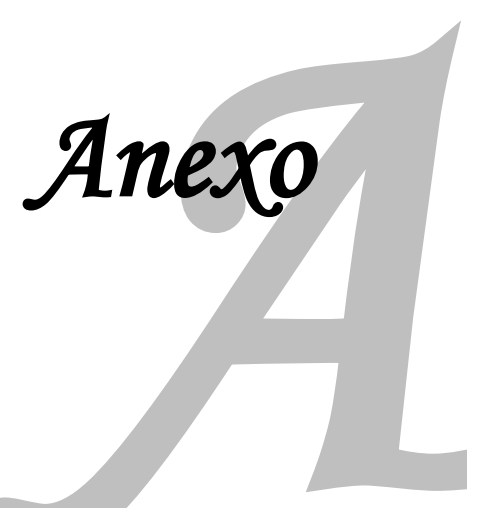

\section{Catálogos de câmeras infravermeIno}

Este anexo apresenta as especificações técnicas de três modelos de câmera de imageamento infravermelho, com diferentes capacidades, precisões, frequências e resoluções.

Os três modelos de câmera apresentados foram citados ao longo do texto. O primeiro deles (modelo FLIR E40) foi utilizado no ensaio para levantamento dos modos de vibrar da estrutura. O segundo (modelo FLIR P620) foi utilizado no ensaio em túnel de vento, para detecção de flutter. Por último, é apresentado o modelo FLIR SC5000, apontado como uma boa solução para minimizar as limitações encontradas nos ensaios realizados. Este modelo é citado nas considerações finais deste texto e sua obtenção será um passo futuro para que as pesquisas relacionadas a esse trabalho tenham continuidade e apresentem resultados ainda melhores do que os obtidos até aqui.

Todas as especificações técnicas aqui apresentadas foram obtidas do catálogo da empresa FLIR Systems, citado como referência bibliográfica deste texto (FLIR, 2012c). 


\section{$\hat{*}$ FLIR}

\section{E-Series InfraRed Camera (160 x 120 IR Resolution)} With on board Visual Camera, Wi-Fi, Picture-in-Picture, and Bright LED Light

-0.07ㄷ3 @ $30^{\circ} \mathrm{C}$ Thermal Sensitivity

- Bright LED Light

- Annotate Images with Voice

- Picture-in-Picture (Fixed)

- 3.5" Touch-Screen LCD Display
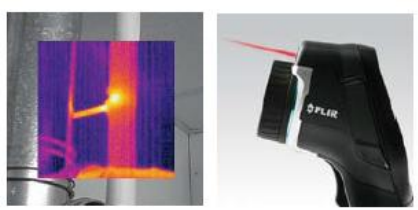

Picture-in-Picture (PIP) Fusion Built-in Laser Pointer

\section{FLIR E40 Features}

- High Resolution IR Images - 19,200 pixels $(160 \times 120)$ Infrared resolution

- Visible Light Digital Camera - 3.1MP resolution with LED lamp provides sharp images regardless of lighting conditions

- Picture in Picture (PIP) - Displays thermal image super-imposed over a digital image

- Bright LED Light - Allows the visual camera and fusion to be used in poorly lit environments

- Wide Temperature Range - From -4 to $1202^{\circ} \mathrm{F}\left(-20\right.$ to $\left.650^{\circ} \mathrm{C}\right)$ targeting electrical and industrial applications

- $\pm 2 \%$ Accuracy - reliable temperature measurement

- Thumbnail Image Gallery - Allows quick search of stored images

- Li-lon Rechargable Battery - lasts $>4 \mathrm{hrs}$ continuous use; replaceable

- Laser LocatIR ${ }^{\mathrm{TM}}$ Pointer - Pinpoints a reference spot with a lase

- Laser Marker - Marks the point on the IR displayed image as to where the Laser pointer is targeting

- Wi-Fi Connectivity - Sends images and data to mobile devices (ie iPhone ${ }^{\varpi}$ or $\left.\mathrm{iPad}^{\circledR}\right)$ to share reports and critical information quickly
- 2X Continuous Zoom

- Area Min/Max/Average with Auto Hot/Cold Spot Marker

- Delta T-Differential Temperature

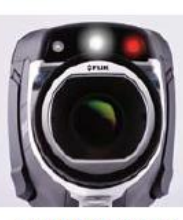

Built-in llluminator Light

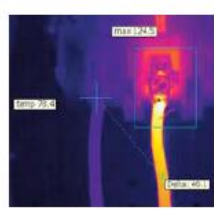

Differential Temperature
- IR Window Correction - Software settings allow you to account for transmission loss through IR windows

- Area (Min/Max/Average) Mode - Shows the Minimum, Maximum or Average

Temperature reading within the selected area

- Auto Hot/Cold Spot Marker - Marks the area that automatically finds the hottest or coldest spot within the box

- Voice Comment Recording and Text Annotation - on images \& can be integrated onto report

- Wireless Communication - Bluetooth Transmitter with METERLiNK ${ }^{\mathrm{M}}$

- Includes - Memory Card with adapter (stores > 1000 Radiometric JPEG images), Li-lon rechargeable battery, power supply, USB cable, hand strap, camera lens cap. and hard case, and FLIR Tools software CD-ROM

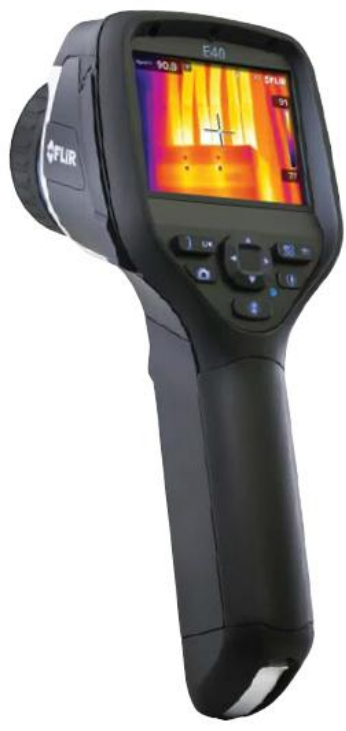

\section{Applications}

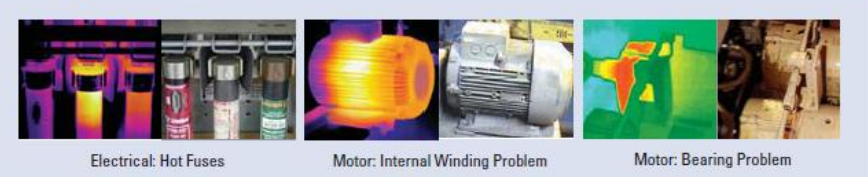




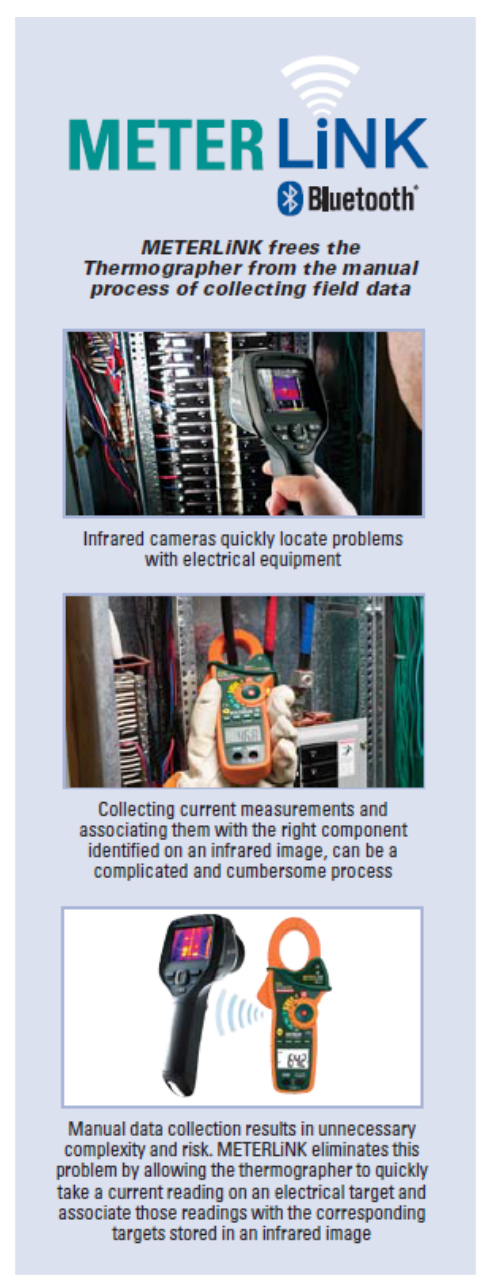

\section{Software Packages}

FUR Reporter is a powerful software for creating compelling and professional, fully customized, easy-to-interpret reports in a standard MS Word Document. You can create a report by simply Dragging and Dropping your images on a desktop icon or using the Wizards to guide you step-by-step through the process. The saved document is a 'ive' report with full access to the analysis tools and temperature measurement data. The reports can be multi-page and include all of your IR inspection data -infrared and visual images, temperature measurements, voice comments and text notes.

FUR BuildIR Software package specifically designed to carry out advanced analysis of building structures. It is used to analyze images taken with an infrared camera, and create inspection reports based on these images.

Panorama Function allows you to conveniently piece together normal sized images to create one large image for a wide angle view of the area being measured by using FLIR BuildIR or Reporter Software package

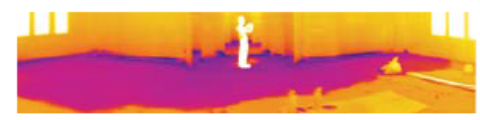

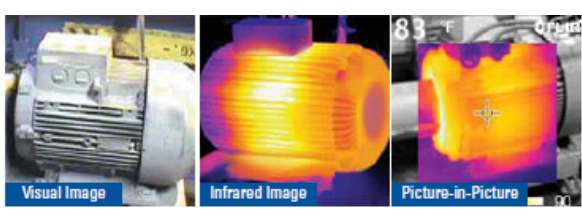

Picture-in-Picture Fusion

Allows for easier identification and interpretation of infrared images. This advanced technology enhances the value of an infrared image by allowing you to overlay it directly over the corresponding visible image. This functionality combines the benefits of both the infrared image and visual picture at the push of a button.

\section{FLIR E4O Specifications}

\begin{tabular}{|c|c|}
\hline Features & \\
\hline Temperature range & $-4^{\circ} \mathrm{F}$ to $1202^{\circ} \mathrm{F}\left(-20^{\circ} \mathrm{C}\right.$ to $\left.650^{\circ} \mathrm{C}\right)$ \\
\hline Image Storage & $>1000$ radiometric JPEG images (SD card memory) \\
\hline Imaging Performance/Image Prese & tion \\
\hline Frame Rate & $60 \mathrm{~Hz}$ \\
\hline Field of view/min focus distance & $25^{\circ} \times 19^{\circ} / 1.31 \mathrm{ft}(0.4 \mathrm{~m})$ \\
\hline Focus & Manual (Minimum focus distance $1.3 \mathrm{ft} / 0.4 \mathrm{~m}$ ) \\
\hline Thermal sensitivity (N.E.T.D) & $<0.07^{\circ} \mathrm{C}$ at $30^{\circ} \mathrm{C}$ \\
\hline $\begin{array}{l}\text { Detector Type - Focal plane array } \\
\text { (FPA) uncooled microbolometer }\end{array}$ & $160 \times 120$ pixels \\
\hline Spectral range & 7.5 to $13 \mu \mathrm{m}$ \\
\hline Display & Built-in $3.5^{*}$ color LCD \\
\hline Image modes & Thermal/Visual/Picture-in-Picture (Fixed) \\
\hline Image annotation & Voice $(60 \mathrm{sec})$; Text comments \\
\hline Video Lamp & Bright LED lamp \\
\hline Laser Classification/Type & Class 2/Semiconductor AlGalnP Diode Laser: 1mW/635nm (red) \\
\hline Set-up controls & $\begin{array}{l}\text { Mode selector, color palettes, configure info to be shown in image, local } \\
\text { adaptation of units, language, date and time formats, and image gallery }\end{array}$ \\
\hline Measurement modes & $\begin{array}{l}3 \text { Spotmeters (movable), } 3 \text { Area Boxes (full image with min/max/average), } \\
\text { Auto hot/cold spot, Isotherm (above/below/interval), Delta-T }\end{array}$ \\
\hline MPEG 4 Video Recording & Yes \\
\hline MPEG Streaming Video Wi-Fi & Yes \\
\hline Measurement correction & Reflected ambient temperature \& emissivity correction \\
\hline Battery Type/operating time & Li-lon/ >4 hours, Display shows battery status \\
\hline Charging system & In camera $\mathrm{AC}$ adapter/2 bay charging system \\
\hline Shock & 25G, IEC $68-2-29$ \\
\hline Vibration & $2 G$, IEC 68-2-6 \\
\hline Dimensions/Weight & $9.7 \times 3.8 \times 7.2^{\prime \prime}(246 \times 97 \times 184 \mathrm{~mm}) /<1.82 \mathrm{lbs}(825 \mathrm{~g})$, including battery \\
\hline Warranty & 2 years (Warranty extended to 2 years when the camera is registered) \\
\hline Ordering Infor & ation \\
\hline Part Number & \\
\hline 49001-0301 .............. & Thermal Imaging InfraRed Camera (160x120) \\
\hline $\begin{array}{l}\text { ACCESSORIES } \\
\text { T197752 }\end{array}$ & chargeable Battery \\
\hline T910814 & er Charger (110-240V, U.S. Plug) \\
\hline 1196497 & Lighter Adapter Kit, 12VDC (1.2m cable) \\
\hline T197910 …........................ & ttery Charger including Power Supply (multi plugs) \\
\hline T197717 ........ & orter Professional Analysis Software \\
\hline T197778 ......... & oftware package \\
\hline T197965 & s Software package \\
\hline $1196961 \ldots \ldots \ldots-15^{\circ} \mathrm{Tel}$ & hoto Lens \\
\hline 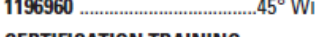 & Angle Lens \\
\hline $\begin{array}{l}\text { CERTIFICATION TRAINING } \\
\text { ITC LEVEL I ............... Le Le }\end{array}$ & I Certification Tra \\
\hline
\end{tabular}

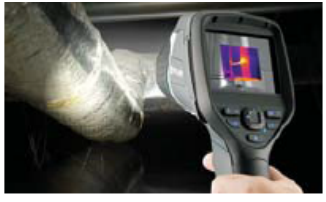

Bright LED Light

Exclusive, built-in illuminator lamp sheds light on poorly lit sites. Low light areas like electrical cabinets, storage facilities, or night-time spots will create dark visual images that can hamper your ability to illustrate ensure quality visual images regardless of job site lighting levels. problems effectively. FUIR cameras

ITC LEVEL I 


\section{FLIR P Series}

\section{FLIR P620}

The High Performance infrared inspection system

FLIR P620 is the highest performing infrared inspection system available. With its state of the art technology, including $640 \times 480$ detector resolution and unique ergonomic design it is the natural choice for professional thermographers that want the most efficient instrument producing professional results. The camera is equipped with the standard $24^{\circ}$ lens.

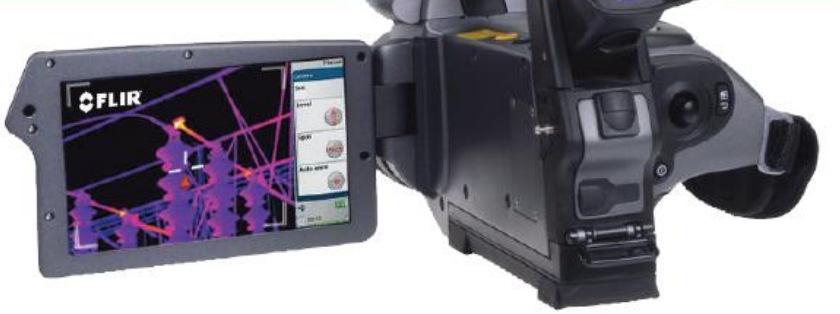

- Image resolution $640 \times 480$

- Sensitivity $40 \mathrm{mK}$

- Large high resolution 5.6" flip-out LCD

- Tiltable high resolution viewfinder

- High performance lenses with USM technology

- 1-2 times continuous zoom with pan

- Picture in Picture

- Thermal fusion: above, below interval
- Rotatable handle for convenient operation

- Built-in 3.2 Mpixel digital camera with target illuminator

- Standard temperature range $-40{ }^{\circ} \mathrm{C}$ to $500{ }^{\circ} \mathrm{C}$

- Periodic storage

- Panorama

- Voice and text annotation

- MPEG-4 streaming to PC using USB

- Programmable buttons

FLIR Systems FLIR P620 is an affordable easy-to-operate highperformance infrared camera that delivers accurate temperature measurements at productive and safe distances. This makes the P620 camera an ideal solution for cost-effective and efficient predictive maintenance programs.

The P620 includes an integrated 3.2 megapixel camera to aid in reporting. Infrared and visual images taken with the P620 can be stored in standard JPEG formats. The P620 visual camera includes matching Field Of View lenses, so IR and visual images are shown at similar long distances using the same Field Of View. 


\section{FLIR P620 Technical Specifications}

\begin{tabular}{|c|c|}
\hline \multicolumn{2}{|l|}{ Imaging and optical data } \\
\hline $\begin{array}{l}\text { Field of view (FOV) / Minimum focus } \\
\text { distance }\end{array}$ & $24^{\circ} \times 18^{\circ} / 0.3 \mathrm{~m}$ \\
\hline Spatial resolution (IFOV) & $0.65 \mathrm{mrad}$ \\
\hline Thermal sensitivity / NETD & $40 \mathrm{mK} @+30^{\circ} \mathrm{C}$ \\
\hline Image frequency & $30 \mathrm{~Hz}$ \\
\hline Focus & Automatic or manual (electric or on the lens) \\
\hline Zoom & $1-2 \times$ continuous, digital $z 00 m$, including panning \\
\hline Focal Plane Array (FPA) / Spectral range & Uncooled microbolometer / 7.5-13 $\mu \mathrm{m}$ \\
\hline IR resolution & $640 \times 480$ pixels \\
\hline \multicolumn{2}{|l|}{ Image presentation } \\
\hline Display & Built-in widescreen, 5.6 in. LCD, $1024 \times 600$ pixels \\
\hline Viewfinder & Built-in, tiltable LCD, $800 \times 600$ pixels \\
\hline Automatic image adjustment & Continuous / manual; linear or histogram based \\
\hline Manual image adjustment & Level/span/max/min \\
\hline Image modes & $\begin{array}{l}\text { IR-image, visual image, thermal fusion, picture in picture, thumbnail } \\
\text { gallery }\end{array}$ \\
\hline Thermal fusion & IR image shown above, below or within temp interval on visual image \\
\hline Picture in Picture & Resizable and movable IR area on visual image \\
\hline Reference image & Shown together with live IR image \\
\hline \multicolumn{2}{|l|}{ Measurement } \\
\hline Temperature range & $-40^{\circ} \mathrm{C}$ to $+500^{\circ} \mathrm{C}$ \\
\hline Accuracy & $\pm 2^{\circ} \mathrm{C}$ or $\pm 2 \%$ of reading \\
\hline \multicolumn{2}{|l|}{ Measurement analysis } \\
\hline Spotmeter & 3 \\
\hline Area & 3 boxes or circles with max. / min. / average \\
\hline Automatic hot / cold detection & Max / Min temp. value and position shown within box, circle or on a line \\
\hline Isotherm & 2 with above / below / interval \\
\hline Difference temperature & $\begin{array}{l}\text { Delta temperature between measurement functions or reference } \\
\text { temperature }\end{array}$ \\
\hline Reference temperature & Manually set or captured from any measurement function \\
\hline Emissivity correction & Variable from 0.01 to 1.0 or selected from editable materials list \\
\hline Measurement corrections & $\begin{array}{l}\text { Reflected temperature, optics transmission, atmospheric transmission } \\
\text { and external optics }\end{array}$ \\
\hline \multicolumn{2}{|l|}{ Set-up } \\
\hline Set-up commands & $\begin{array}{l}\text { Configurable measurement tools menu; configure information to } \\
\text { be shown in image; } 2 \text { Programmable buttons; user profiles; local } \\
\text { adaptation of units, language, date and time formats }\end{array}$ \\
\hline \multicolumn{2}{|l|}{ Storage of images } \\
\hline Image storage & Standard JPEG, including measurement data, on memory card \\
\hline Image storage mode & $\begin{array}{l}\text { IR / visual images; simultaneous storage of IR and visual images } \\
\text { Visual image is automatically associated with corresponding IR image }\end{array}$ \\
\hline Periodic image storage & Every 10 seconds up to 24 hours \\
\hline Panorama & For creating panorama images in FLIR Reporter Building software \\
\hline \multicolumn{2}{|l|}{ Image annotations } \\
\hline Voice & 60 seconds stored with the image \\
\hline Text & Predefined text or free text from PDA (via IrDA) stored with the image \\
\hline Image marker & 4 on IR or visual image \\
\hline \multicolumn{2}{|l|}{ Video recording and streaming } \\
\hline Non-radiometric IR-video streaming & MPEG-4 to PC using USB or WLAN (optional) \\
\hline \multicolumn{2}{|l|}{ Digital camera } \\
\hline Built-in digital camera & 3.2 Mpixel, auto focus, and video lamp \\
\hline \multicolumn{2}{|l|}{ Laser pointer } \\
\hline Laser & Activated by dedicated button \\
\hline \multicolumn{2}{|l|}{ Data communication interfaces } \\
\hline Interfaces & USB-mini, USB-A, IrDA, composite video, headset connection \\
\hline \multicolumn{2}{|l|}{ Power system } \\
\hline Battery & Li lon, 3 hours operating time \\
\hline Charging system & In camera ( $\mathrm{AC}$ adapter or $12 \mathrm{~V}$ from a vehicle) or 2-bay charger \\
\hline Power management & Automatic shutdown and sleep mode (user selectable) \\
\hline \multicolumn{2}{|l|}{ Environmental data } \\
\hline Operating temperature range & $-15^{\circ} \mathrm{C}$ to $+50^{\circ} \mathrm{C}$ \\
\hline Storage temperature range & $-40^{\circ} \mathrm{C}$ to $+70^{\circ} \mathrm{C}$ \\
\hline Humidity (operating and storage) & IEC $68-2-30 / 24 \mathrm{~h} 95 \%$ relative humidity $+25^{\circ} \mathrm{C}$ to $+40^{\circ} \mathrm{C}$ \\
\hline Encapsulation & IP 54 (IEC 60529) \\
\hline Bump & $25 \mathrm{~g}$ (IEC 60068-2-29) \\
\hline Vibration & $2 \mathrm{~g}$ (IEC 60068-2-6) \\
\hline \multicolumn{2}{|l|}{ Physical data } \\
\hline Camera weight, incl. lens and battery & $1.8 \mathrm{~kg}$ \\
\hline Cameras size, incl. lens $(\mathrm{L} \times \mathrm{W} \times \mathrm{H})$ & $324 \times 144 \times 147 \mathrm{~mm}$ \\
\hline Tripod mounting & UNC $y_{4}^{\prime \prime}-20$ \\
\hline
\end{tabular}

Camera includes:

Infrared camera with

Battery (2 ea.., one inserted in camera, one outside camera

Battery charger

Calibration certificate

FLIR QuickReport ${ }^{\text {TM }}$ PC software CD-ROM

Headset

Lens cap (mounted on lens)

Lens cap (2 ea.)

Lens cap (2 ea)

Memory card-to-USB adapter

Memory card with adapter

Power supply

Printed Getting Started Guide

Shoulder strap

USB cable

User documentation CD-ROM

Video cable

Warranty extension card or Registration card

\section{Supplies \& Accessories}

Close-up IR lens $0.5 \mathrm{X}, \mathrm{f}=75 \mathrm{~mm}$ (fits $24^{\circ} \mathrm{R}$ lens) for ThermaCAM and LLR 600 series

\begin{tabular}{l} 
FL lens $f=76 \mathrm{~mm}, 12^{\circ}$, incl. case for FLIR 600 series \\
\hline
\end{tabular}

Rlens, $f=131 \mathrm{~mm}, 7^{\circ}$, incl. case for FLLR 600 series

R lens $f=38 \mathrm{~mm}, 45^{\circ}$, incl. case for FLLR 600 series

Macro lens $1 \mathrm{x}$ (25 um) with case

Protective window (fits $24^{\circ}$ ) with case

High temperature option $+2000^{\circ} \mathrm{C}$

High temperature option $+1500^{\circ} \mathrm{C}$

Battery

Battery charger, incl. power supply and cable

Battery charger, incl. power supply and cab

Battery charger, incl. power supply and cable

Battery charger, incl. power supply with multi plugs

Power supply, incl. multi plugs

SD memory card, $1 \mathrm{~GB}$

Adapter, SD memory card to USB

Memory card micro-SD with adapters

USB cable Std A $\leftrightarrow$ Mini-B, $2 \mathrm{~m}$

Video cable, RCA $\leftrightarrow$ RCA, $2.0 \mathrm{~m}$

Cigarette lighter adapter kit, 12 VDC, 1.2

Hard transport case for FLIR B/P/SC640

Headset, $3.5 \mathrm{~mm}$ plug

Remote Control Unit

FLIR Reporter Ver. 8.3 Professional (Sec. device)

FLIR Reporter Ver. 8.3 Professional

FUR Reporter Ver. 8.3 Standard (Sec. device)

FUR Reporter Ver. 8.3 Standard

FLIR BuildIR

FLIR Reporter Ver. 8.5 Standar

FLIR Reporter Ver. 8.5 Professional

Cover Visual Camera mkII

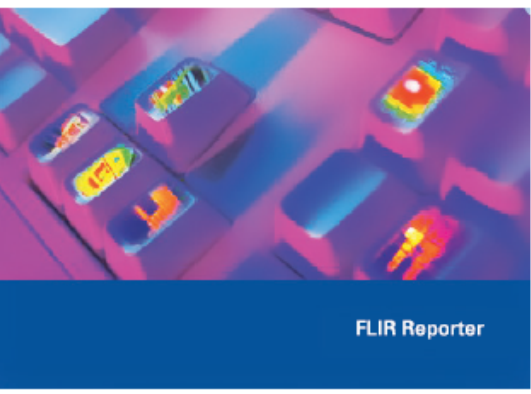

FLIR Reporter sotware FLLR Reporter sothware-
powertul yet easy-to-use tool to generate comprehensive and professional infrared
inspection reports.

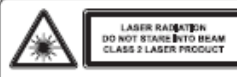

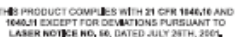

Asia Pacific Headquarter

Hong Kong

FLIR Systems Co Ltd.

Room $1613-16$, Tower 2 Grand Central Plaza

138 Shatin Rural Committee Road, N.T, Hong Kon

Tel: $+85227928955 \quad$ Fax: +85227928952

Email: flir@flir.com.hk Web: www.flir.com/thg

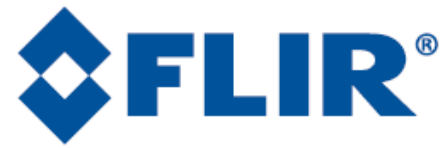




\section{FFIR}

\section{FLIR SC-SERIES}

\section{FLIR SC5000-Series}

High Performance Cameras For Industrial, Educational \& Thermography Applications

- High sensitivity InSb focal plane array

- HypercalTM for Full Thermographic Measurement

- Ultra high sensitivity (20 mK typical)

- $320 \times 256$ or $640 \times 512$ format

- 2.5 - $5.1 \mu \mathrm{m}$ spectral range

- $380 \mathrm{~Hz}$ maximum frame rate in full format

- Smart trigger and advanced capabilities

- Motorized filter wheel and focus control

- Plug \& Play interface with GigE / CAMLINK

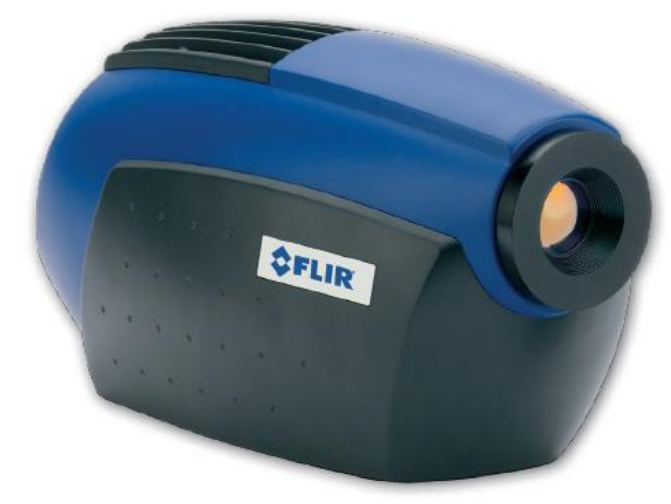

\section{FLIR SC5000-Series Features}

The SC5000-Series is specifically designed for the most demanding users of IR technology, who want to perform thermal imagery at high spatial resolution with the highest sensitivity and accuracy at an affordable cost.

\section{Ultra high frame rate obtained from the latest ROIC technology}

Our $320 \times 256$ or $640 \times 512$ pixels format InSb focal plane array delivers an outstanding 100 or $380 \mathrm{~Hz}$ frame rate while keeping extraordinary linearity and sensitivity figures. The use of our latest read out integrated circuit technology provides low noise and high pixel rate without compromising sensitivity. Integration time is adjustable in $1 \mu$ s increments. The smart external triggering feature allows synchronization of the image capture to the most fleeting events.

\section{Accurate Temperature Measurement with FLIR Hypercal ${ }^{\mathrm{TM}}$}

Factory set temperature ranges are a thing of the past with the FLIR exclusive Hypercal ${ }^{\mathrm{TM}}$. The end user simply defines the lower and upper limits of the desired temperatures to measure. The camera adjusts to the appropriate integration (exposure) time automatically to ensure accurate full range temperature measurement.

\section{Temperature Range Extension}

Temperature Range Extension (TRE) allows SC5000 cameras to acquire thermal data from up to 4 user defined temperature ranges simultaneously. The data can then be merged into a single data stream in real-time that spans all 4 temperature ranges and be displayed or recorded. TRE effectively extends the dynamic range from 14-bit to a 16-bit image.

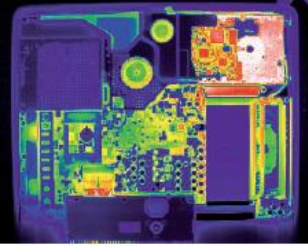

SC5000 cameras are well suited for electronic board, wafer and colls inspection thanks to their wide variety of lenses and accessories.

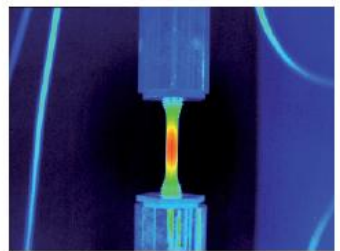

In addition with Thesa infrared Look-in system, ful teld stess imaging and second.

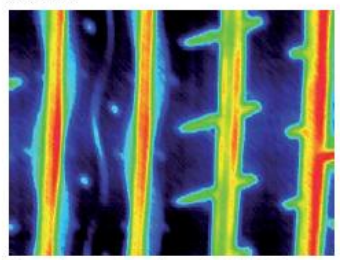




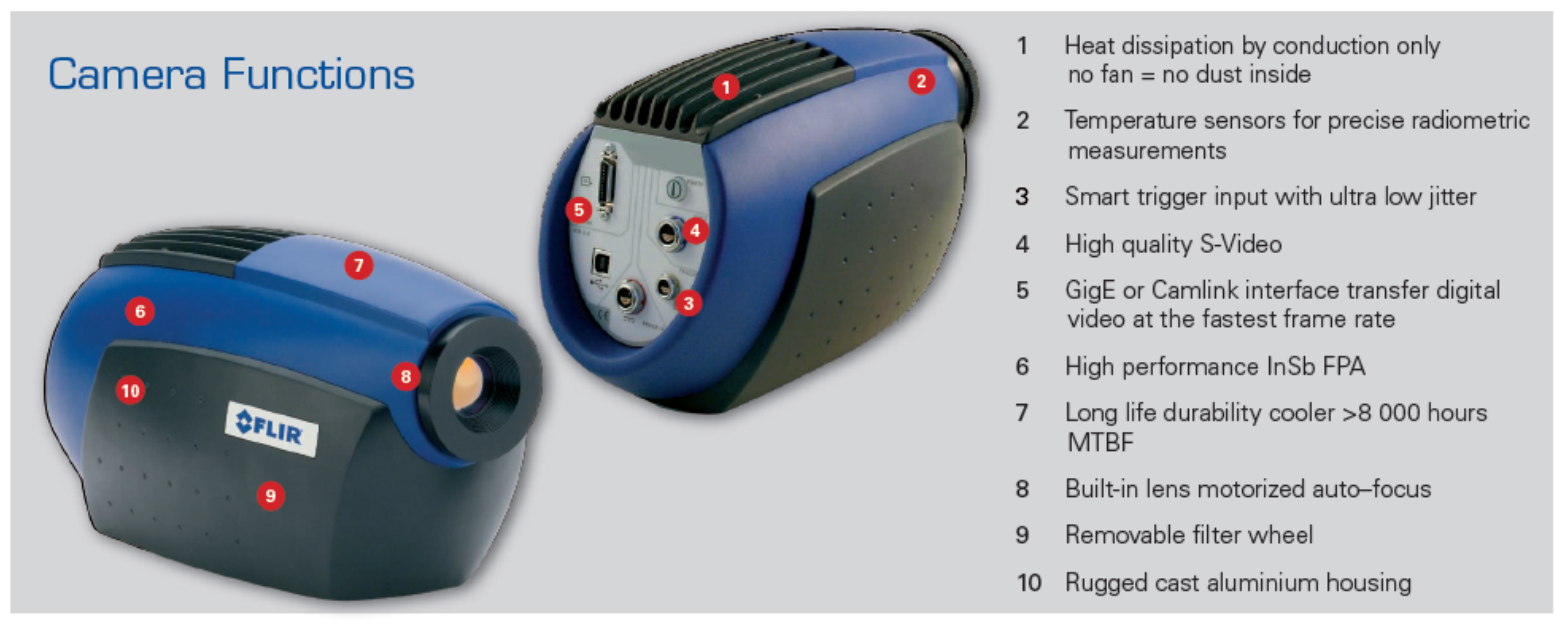

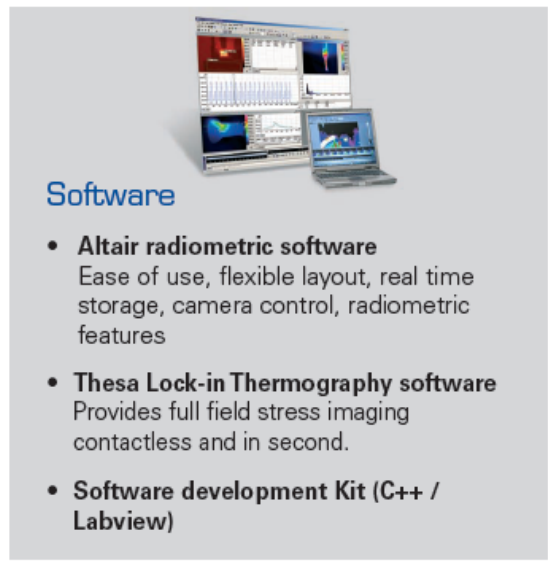

Accessories

- Spectral filters

- Battery pack for up to 4 hours autonomy

- USB advanced acquisition trigger module

\section{INFRARED CENTER}

Training

FLIR cooperates with Infrared Training Centre, an independent, ISO certified worldwide training facility. ITC offers infrared training, certifications accepted by many standardization organizations, and specialized instruction in various application areas. For more info visit www.infraredtraining.com

\section{FLIR SC5000-Series Specifications}

\begin{tabular}{|c|c|}
\hline \multicolumn{2}{|l|}{ Features* } \\
\hline Sensor type & $\ln \mathrm{Sb}$ \\
\hline Waveband & $2.5-5.1 \mu \mathrm{m}$ \\
\hline Pixel resolution & $320 \times 256$ or $640 \times 512$ available / 14 bits \\
\hline Pitch & $30 \mu \mathrm{m} / 15 \mu \mathrm{m}$ \\
\hline NETD & $<20 \mathrm{mK}$ \\
\hline Cooler & Integrated stirling cooler \\
\hline Max Full Frame rate & Up to $380 \mathrm{~Hz}$ \\
\hline Integration time & $1 \mu \mathrm{s}$ to $20 \mathrm{~ms}$ variable by $1 \mu \mathrm{s}$ step \\
\hline Optical interface & Built-in $27 \mathrm{~mm}$ lens with bayonet mount \\
\hline Field of view & $\begin{array}{l}\text { From } 42^{\circ} \times 34^{\circ}(12 \mathrm{~mm}) \text { to } 5.5^{\circ} \times 4.4^{\circ} \\
(100 \mathrm{~mm})-\text { Up to } \times 5 \text { microscope lens }\end{array}$ \\
\hline Filter wheel & Wheel 4 slots motorized removable \\
\hline Digital output & CAMLINK / GigE \\
\hline Trigger input / output & Smart trigger capabilities \\
\hline Temperature calibration range & Available from $-20^{\circ} \mathrm{C}$ to up to $3000^{\circ} \mathrm{C}$ \\
\hline Temperature measurement accuracy & $\pm 1^{\circ} \mathrm{C}$ or $\pm 1 \%$ \\
\hline Extended dynamic range & $\begin{array}{l}\text { Multi ITTM / Temperature Range } \\
\text { Extension (TRE) }\end{array}$ \\
\hline \multicolumn{2}{|l|}{${ }^{*}$ Best specifications } \\
\hline \multicolumn{2}{|l|}{ Integrated Features } \\
\hline \multicolumn{2}{|c|}{3 external analogues signals, Lockin processing, Hypercal ${ }^{\top \mathrm{M}}, \mathrm{CNUC}^{\mathrm{TM}}$} \\
\hline \multicolumn{2}{|l|}{ Physical Specifications } \\
\hline Size (w/o lens) (LxWxH) & $320 \times 141 \times 159 \mathrm{~mm}$ \\
\hline Weight (w/o lens) & $3.8 \mathrm{Kgs}$ \\
\hline Operational temperature & $-20^{\circ} \mathrm{C} /+55^{\circ} \mathrm{C}$ \\
\hline Shock & Operational 25G, IEC 68-2-29 \\
\hline Vibration & Operational 2G, IEC 68-2-26 \\
\hline Input voltage & 12 VDC \\
\hline Power consumption (cooldown/stab) & $30 \mathrm{~W} / 25 \mathrm{~W}$ \\
\hline \multicolumn{2}{|l|}{ Optional Lenses - Bayonet Mount } \\
\hline W/o additional lens & $20^{\circ} \times 16^{\circ}$ \\
\hline $12 \mathrm{~mm}$ & $42^{\circ} \times 34^{\circ}$ \\
\hline $54 \mathrm{~mm}$ & $10^{\circ} \times 8^{\circ}$ \\
\hline $100 \mathrm{~mm}$ & $5.5^{\circ} \times 4.4^{\circ}$ \\
\hline Microscope lens X0.5 & $19.2 \times 14.4 \mathrm{~mm}$ \\
\hline Microscope lens X1 & $9.6 \times 7.2 \mathrm{~mm}$ \\
\hline Microscope lens X3 & $3.2 \times 2.4 \mathrm{~mm}$ \\
\hline Microscope lens X5 & $1.9 \times 1.4 \mathrm{~mm}$ \\
\hline
\end{tabular}

FLIR SC5000-Series comes in a wide range of configurations.

Please contact your local FLIR office to define the best configuration for your application. 
Intencionalmente em branco 